\title{
The implications of health insurance for the labour market and patient satisfaction with medical care in Vietnam
}

\author{
Citation for published version (APA):
}

Le, T. Q. N. (2019). The implications of health insurance for the labour market and patient satisfaction with medical care in Vietnam. [Doctoral Thesis, Maastricht University]. ProefschriftMaken Maastricht. https://doi.org/10.26481/dis.20190925nl

Document status and date:

Published: 01/01/2019

DOI:

10.26481/dis.20190925nl

Document Version:

Publisher's PDF, also known as Version of record

\section{Please check the document version of this publication:}

- A submitted manuscript is the version of the article upon submission and before peer-review. There can be important differences between the submitted version and the official published version of record. People interested in the research are advised to contact the author for the final version of the publication, or visit the DOI to the publisher's website.

- The final author version and the galley proof are versions of the publication after peer review.

- The final published version features the final layout of the paper including the volume, issue and page numbers.

Link to publication

\footnotetext{
General rights rights.

- You may freely distribute the URL identifying the publication in the public portal. please follow below link for the End User Agreement:

www.umlib.nl/taverne-license

Take down policy

If you believe that this document breaches copyright please contact us at:

repository@maastrichtuniversity.nl

providing details and we will investigate your claim.
}

Copyright and moral rights for the publications made accessible in the public portal are retained by the authors and/or other copyright owners and it is a condition of accessing publications that users recognise and abide by the legal requirements associated with these

- Users may download and print one copy of any publication from the public portal for the purpose of private study or research.

- You may not further distribute the material or use it for any profit-making activity or commercial gain

If the publication is distributed under the terms of Article $25 \mathrm{fa}$ of the Dutch Copyright Act, indicated by the "Taverne" license above, 


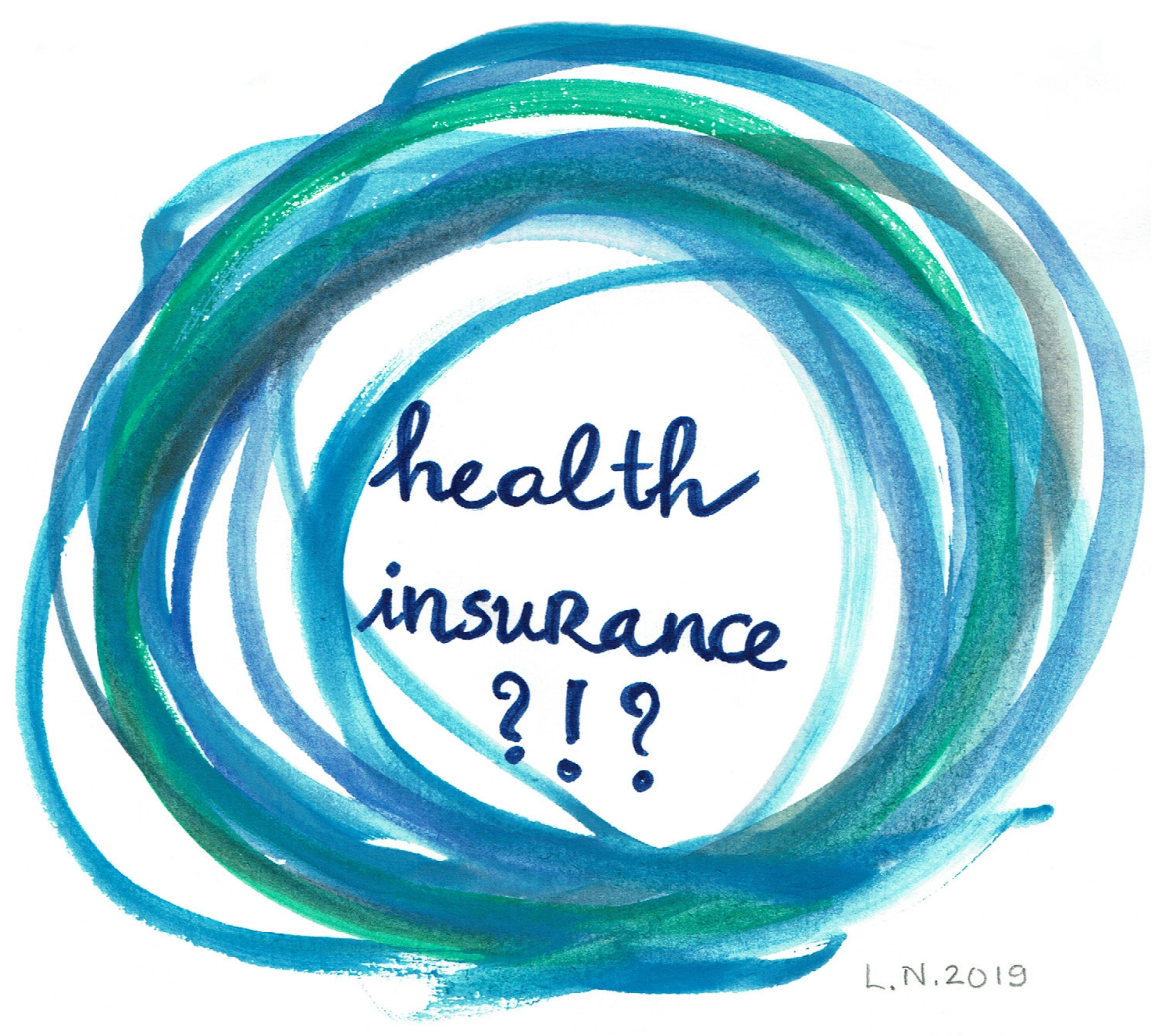

\title{
The implications of health insurance for the labour market and patient satisfaction with medical care in Vietnam
}

\author{
Lê Thị Quỳnh Nga \\ (Leopold Thi Quynh Nga)
}


The implications of health insurance for the labour market and patient satisfaction with medical care in Vietnam

\author{
Lê Thi Quynh Nga \\ (Leopold Thi Quynh Nga)
}


Copyright (C) Lê Thi Quynh Nga, 2019

Cover Design: Lê Thi Quynh Nga, water colour on paper, insprised by Kazuaki Tanahashi's paintings and Zen Master Thich Nhat Hanh's teachings.

All rights reserved. Printing by Proefschriftmaken, the Netherlands 


\section{The implications of health insurance for the labour market and patient satisfaction with medical care in Vietnam}

\section{DISSERTATION}

To obtain the degree of Doctor at Maastricht University, on the authority of the Rector Magnificus, Prof. Dr. Rianne M. Letschert, in accordance with the decision of the Board of Deans, to be defended in public on Wednesday, 25 September 2019, at 16.00

by

Lê Thi Quynh Nga

(Leopold Thi Quynh Nga) 


\section{Supervisors}

Prof. Dr. Wim Groot

Dr. Sonila M. Tomini

Dr. Florian Tomini

\section{Assessment Committee}

Prof. Dr. Franziska Gassmann (Chair)

Prof. Dr. Henriëtte Massen van den Brink

Prof. Dr. Wim Naudé

Dr. Milena Pavlova

Dr. Rodrigo Moreno-Serra 
This book is dedicated to my parents, who have always worked very hard to make sure that their kids could get the best education. It is because of them that I have tried so hard to make them proud. 


\section{Acknowledgements}

\section{The email that changed it all}

My PhD journey began with an untold story.

On 2 May 2013, Daniel Beckers, the admission officer of the Master of Public Policy programme at Maastricht University, emailed me: 'Dear Nga, I think I'm going to make you very happy'. He did not forget adding an emoticon ';-)' at the end of the sentence.

The content of that email indeed brought me to tears of happiness. That was the happiest email that I have ever received in my life: the email informed me that I was awarded a Maastricht University High Potential Scholarship for my Master's study in Maastricht.

The story would have been a normal one if I was not informed in the same email that The Scholarship Office at Maastricht University had emailed me on the 22 April 2013 but for some unknown reasons, that email had never been delivered to my mailbox.

It was Daniel who responded to my query email with the good news. That's how my life abruptly took a very big turn. That's how it all started!

Maastricht, as many of you may agree, is such a lovely and charming town. I fell in love with it the very first moment I arrived. The high-quality education that I received in the MPP programme convinced me that I should stay in Maastricht longer to learn some more cool stuff (and of course, to travel to more cool European cities!). The PhD admission then came to me naturally as if I and Maastricht, we, belonged to each other. 


\section{My PhD in Maastricht}

The $\mathrm{PhD}$ programme for me was like a marathon, very exhausting yet rewarding. I learned lots of new skills, read lots of new ideas, travelled to lots of new destinations, made some new best friends and most importantly learned a lot from everyone.

The first important person I want to thank is Prof. Wim Groot for his ample support and guidance. Despite his busy schedule, he managed to meet me every two or three weeks over the last four years and gave me lots of good advice. I was and will always be impressed by his dedication, diligence, tirelessness and meticulousness at work. I have been always in awe of his sharp mind and creative ideas. Besides technical knowledge, I have also learned a lot from his social intelligence and communication skills. Wim will always be my role model on many fronts, both in academia and in life. Secondly, I want to extend my deepest gratitude to the Tominis (Dr. Sonila M. Tomini and Dr. Florian Tomini). I sincerely thank Sonila for introducing me to Wim and willingly showing me her support from the very beginning of the proposal development. I thank her greatly for her critical reviews of my papers as well as her attention to detail, which have been shown in her comments. I thank Florian for his useful comments, which have always triggered deep reflection on my work. All in all, I could never ask for a better supervision team. The completion of my PhD is vastly attributable to their continuous support and advice.

I would like to thank the reading committee for their time in reviewing my dissertation. They include Prof. Dr. Franziska Gassmann, Prof. Dr. Henriëtte Massen van den Brink, Prof. Dr. Wim Naudé, Dr. Milena Pavlova and Dr. Rodrigo Moreno-Serra.

I also want to thank Prof. Bart Verspagen, Prof. Robin Cowan, Prof. Adam Szirmai, Prof. Franziska Gassmann, Prof. Pierre Mohnen, Prof. Theóphile T. Azomahou, Dr. Nyasha Tirivayi, Dr. Neil Foster-McGregor, Dr. Zina Nimeh and many other senior research fellows for their comments and support during my proposal development.

I sincerely thank Prof. Franziska Gassmann and Dr. Michaella Vanore for giving me the opportunity to work with them in a UNICEF-commissioned project on social assistance for Vietnamese children. I have learned a lot from them during the project.

I sincerely thank Dr. Neil Foster-McGregor, Bruhan, Tigist, Vasil, and Herman for their cooperation and support in the organisation of the first two UNU-MERIT conferences. Especially, I want to thank Neil and Vasil for their understanding and willingness to take over the workload when I fell ill before the second conference started.

I am indebted to Dr. Denis de Crombrugghe for his inspiring econometrics lectures. His enthusiasm in teaching econometrics has cultivated my love and curiosity for the subject. I am thankful to him for allowing me to sit in one of his econometrics courses at SBE and sometimes answering my ad hoc questions via email.

Many thanks to Mindel for listening to me and watching me cry after my first research pitch was highly criticized (I afterwards learned that this is a learning process for every $\mathrm{PhD}$ student, so do not take it personally!). Thanks to Eveline for her continuous willingness to support me and all other PhD students. I also want to thank Susan and other support 
staff for their assistance.

My PhD journey would have not been so exciting and rewarding without friends. First of all, I want to thank my PhD batch: Janyl, Davina, Wondi, Arip, Eli, Mario, Clotilde, Bruhan, Hugo, Choolwe, Nora, Maria, Fernando, Jemal and Francesca. Thank you for all the lovely dinners, lunches and parties together. I still remember when we danced under the moon at Vrijthof when we all were a bit high after many beers. Especially thanks to Janyl, Davina, Iulia and Elisa for all the lovely catching-up lunches and dinners. Also, I want to thank Iulia, Tamara and Davina for making me feel like home in the office (especially thanking Iulia for watering my plants when I was away). I am thankful to Elisa and Paula for the happy moments we had during the co-authorship. Thanks to the lunch gang (Mary, Alison, Elisa, Beatriz, Danilo, Michelle and more) for adopting me whenever I worked in the office. We had so much fun and lovely lunch conversations. I also want to thank many others, including Hampton, Mira, Ayla, Patima, Juan, Ibrahima, Muied, Gintare, Bart, Lika, Yanny for the beautiful conversations that we had.

I thank the Vietnamese community in Maastricht, especially Giang, for sharing her Maastricht experience with me. Thank my Dutch friends, Cyril and Garry, for their hospitality in Maastricht. Thanks to Cyril's organised activities for Asian students, I have discovered so much about Maastricht and my neighbourhood in Wolder.

I am also heavily indebted to my best friends, Mai Duong and Bui Viet Dung, for their non-stop encouragement and emotional support during my scholarship application as well as when I was living alone so far away from home.

From the bottom of my heart, I want to thank my parents for their never-ending love, care and sacrifice. This $\mathrm{PhD}$ dissertation is dedicated to my parents, because of whom I have always tried to work hard just to make them proud. I want to thank them for their continuous encouragement for whatever I do in my life. They have given me so much freedom in making important life choices.

I thank my second brother, Lê Thái Bình, for his care for me when he was doing his PhD at TU Delft. His defence in December 2018 was such an inspiration for me to finish my PhD and get another doctoral title for the Lê family. His hospitality whenever I visited Delft was also very much appreciated. Thanks to this second shelter in the Netherlands, I managed to travel a lot within the Dutch land from Delft to Rotterdam, Utrecht, Dordrecht, Leiden, Den Haag, Amsterdam, Giethoorn, Texel and so on.

No words can express my gratitude to Till Alexander Leopold, my soulmate, my best friend, my partner in crime, my better half, for his emotional support at the end of my $\mathrm{PhD}$. Also, I always feel extremely lucky to have such a critical reader for my work and a professional English language editor right at home. Meeting him during the final years of the $\mathrm{PhD}$ and getting married just several months before the defence makes my $\mathrm{PhD}$ such an unforgettable journey.

Finally, I know that it cannot read this but I still want to thank Maastricht, the city that I consider my second 'home sweet home' on earth for giving me so much peace and energy to finish my PhD. I feel grateful for the sunsets by the fields, lunch naps under 
cherry blossoms, walks on the blooming hills in Wolder in spring, silent sittings on a bench at Vrijthof, sunbaths by the Maas river, and evening walks in the old town. I am also grateful for the wind storms, snows and rains that have triggered homesickness and loneliness. I always cherish all of those weather adversities that, to my surprise, have always calmed me down inside. I am indebted to all the birds that have been chirping every morning by my window. I am grateful for all types of Maastricht's flowers whose captivating fragrances have always seduced me everywhere I have cycled to. I also want to thank huge Vermeer-style clouds which have helped me to store lots of sweet memories in the Netherlands. Evaluating the impacts of Maastricht on my life using a before-and-after approach (I know you are opposing that this method is not good enough for causal inference), I am humbled to say that since moving to Maastricht in July 2013, I have gained so many important things for a happy life: a world-class education, so many good friends, teachers and mentors, and most importantly a best friend for life (my husband). On top of that, it was in Maastricht that I have found the inner peace that I have always been looking for. It is not an exaggeration to say that my last five years in Maastricht have really completed my youth and enriched my life to the fullest.

Geneva, 8 March 2019

Nga Leopold 



\section{Abbreviations}

ASEAN Association of South East Asian Nations

ACA Affordable Care Act (often informally referred to as Obamacare)

CHIP Children's Health Insurance Programme

FHC Free Health Card

GSO General Statistics Office

HCFP Health Care Fund for the Poor

LMIC Low and Middle Income Countries

MOF Ministry of Finance

$\mathrm{MOH} \quad$ Ministry of Health

MOLISA Ministry of Labour, Invalids and Social Affairs

MPI Ministry of Planning and Investment

SHI Social Health Insurance

UHC Universal Health Coverage

VHLSS Vietnam Household Living Standards Surveys

VSS Vietnam Social Securities Agency 


\section{Contents}

Acknowledgements vii

Abbreviations vii

1 Introduction 1

1.1 The setting: rapid health insurance expansion in Vietnam . . . . . . . . . 1

1.2 Problem definition . . . . . . . . . . . . . . . . . . 4

1.3 Knowledge gaps . . . . . . . . . . . . . . . . . . 7

1.4 Research questions . . . . . . . . . . . . . . . . . . . . 8

1.5 Data and methods . . . . . . . . . . . . . . . . . . 10

1.6 Structure of the dissertation . . . . . . . . . . . . . . . . 11

2 A systematic review of health insurance effects on labour supply $\quad 15$

2.1 Introduction . . . . . . . . . . . . . . . . . . . . . . 17

2.2 Theoretical predictions . . . . . . . . . . . . . . . . . 18

2.3 Methodology . . . . . . . . . . . . . . . . . . 20

2.4 Results . . . . . . . . . . . . . . . . . . 22

2.4 Descriptive results . . . . . . . . . . . . . . 22

2.4.2 Labour supply effects of health insurance . . . . . . . . . . . . . 24

2.4.3 Health insurance and self-employment . . . . . . . . . . . . . 32

2.4.4 Health insurance and economic formalisation . . . . . . . . . . . 35

2.5 Discussion . . . . . . . . . . . . . . . . . . . . . . 37

2.6 Conclusion . . . . . . . . . . . . . . . . . . . . . . . . . . . . . . 39

3 Effects of health insurance on labour supply in Vietnam 43

3.1 Introduction . . . . . . . . . . . . . . . . . 45

3.2 Literature Review . . . . . . . . . . . . . . . . . . . . . . 46

3.3 The Health Care Fund For The Poor . . . . . . . . . . . . . . . . . . 48

3.4 Data and Methodology . . . . . . . . . . . . . . . . . 49

3.4.1 Data ........................... 49

3.4.2 Treatment definition and methods . . . . . . . . . . 50 
3.5 Results . . . . . . . . . . . . . . . . . . . . . 53

3.6 Discussion . . . . . . . . . . . . . . . . . . . . . . . 58

3.7 Conclusion . . . . . . . . . . . . . . . . . . . . . 60

4 Health insurance and self-employment transitions in Vietnam 63

4.1 Introduction . . . . . . . . . . . . . . . . . 65

4.2 The Vietnamese health insurance system . . . . . . . . . . . . . . 67

4.3 Data and Methodology . . . . . . . . . . . . . . . . . . 68

4.4 Results . . . . . . . . . . . . . . . . . . . . . . . 70

4.4 Descriptive statistics . . . . . . . . . . . . . 70

4.4 .2 Estimation results . . . . . . . . . . . . . . . . 74

4.5 Robustness checks . . . . . . . . . . . . . . . . . . 77

4.6 Discussion . . . . . . . . . . . . . . . . . . . . . . . . . 78

4.7 Conclusion . . . . . . . . . . . . . . . . . . . . . . 81

5 Health insurance and patient satisfaction with medical care $\quad 83$

5.1 Introduction . . . . . . . . . . . . . . . . . 85

5.2 Literature review . . . . . . . . . . . . . . . . . . . . . 87

5.3 Health insurance and healthcare delivery . . . . . . . . . . . . . . . . 89

5.4 Data and methodology . . . . . . . . . . . . . . . . . . . . . 91

5.5 Results . . . . . . . . . . . . . . . . . . . . . . . . . . . . 93

5.5.1 Descriptive statistics . . . . . . . . . . . . . . . . . . . 93

5.5.2 Multilevel results . . . . . . . . . . . . . . . . . . . . . . . . . . 98

5.6 Robustness checks . . . . . . . . . . . . . . . . . . . . . . . 104

5.7 Discussion and conclusion . . . . . . . . . . . . . . 105

6 Conclusion 111

6.1 Background . . . . . . . . . . . . . . . . . . . 111

6.2 Discussion of statements . . . . . . . . . . . . . . . . . . . . . . . . 113

6.3 Concluding remarks . . . . . . . . . . . . . . . 120

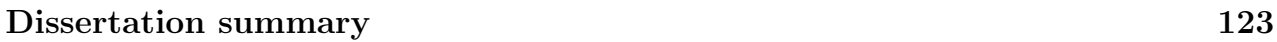

$\begin{array}{lr}\text { Valorisation Addendum } & 169\end{array}$

$\begin{array}{ll}\text { About the author } & 171\end{array}$ 



\section{Chapter 1}

\section{Introduction}

\subsection{The setting: rapid health insurance expansion in Vietnam}

This dissertation focuses on the implications of health insurance for the Vietnamese labour market and how health insurance affects patient satisfaction with medical care in the country. For Vietnam, these topics are becoming increasingly relevant due to its current path towards universal health insurance as an important step in the direction of Universal Health Coverage (UHC) ${ }^{1}$. Over the last decade, health insurance coverage in Vietnam has expanded significantly. In 2004, Social Health Insurance (SHI) - the national single payer insurance scheme - only covered 20 percent of the population (Somanathan et al., 2013). This share increased to over 60 percent in 2011 (ibid.) and reached 86.4 percent by December 2017 (Ngan, 2017).

The rapid health insurance expansion is the result of an unprecedented political commitment

${ }^{1}$ UHC is defined as enabling everyone to receive the medical care they need without any financial hardship (WHO and The World Bank, 2017, 2015). 
to achieving UHC in Vietnam (Somanathan et al., 2014), reflected not only in resolutions of the National Assembly (i.e. Vietnamese Parliament) and those of the ruling Communist Party (the only political Party in the country) but also in legal documents (e.g. Health Insurance Laws 2008 and 2014). Since the first Health Insurance Law in 2008, a roadmap towards universal health insurance has been planned out (Socialist Republic of Vietnam, 2008). Public health spending has steadily increased at an even higher rate than GDP growth, accounting for 9 percent of total public budget and 3 percent of GDP in 2010 (Barroy et al., 2014). The coverage target of more than 80 percent by 2020 was set by the government in the UHC Master Plan 2012. Universal health insurance was then made compulsory in 2014 under the amendment of Vietnam's Health Insurance Law 2008 (see Article 1, Vietnam's Health Insurance Law 2014). To accelerate the progress, in 2016, the government decided to raise the target, aiming at a 90.7 percent insurance coverage by 2020 (Socialist Republic of Vietnam, 2016a). Moving towards UHC in Vietnam has become a political imperative with a strong top-down commitment (Somanathan et al., 2014).

The first health insurance in Vietnam was launched more than three decades ago with the radical Reform in 1986 (often referred to as 'Doi Moi'). The Reform was a political, social, and economic shift from a centrally planned economy ('Thoi Bao Cap' in Vietnamese) to a more open and market-based model. Since then, Vietnam has been transformed from a poor war-ravaged land into a lower middle income country with rapid and stable economic growth (The World Bank and MPI, 2016). The country is currently among the fastest growing economies in the world with an estimated annual GDP growth of more than 6.9 percent in 2018 (OECD, 2019). Its growth rate is currently higher than ASEAN average and the average of emerging countries in Asia (ibid.). Its GDP per capita (in PPP) in 2017 was approximately 6,775 USD (The World Bank, 2018). Its poverty headcount ratio in 2016 was around two percent using the global 1.9-USD-per-day poverty line (the rate was 9.6 percent using the national poverty line) (ibid.), whereas Gini index in 2016 was estimated at 0.353 . In the wake of the Reform 1986, the universal socialist-style health system, which used to be free for all with limited resources, was replaced by a more market-based model. During the late 1980s and early 1990s, the Vietnamese health sector, which used to be centralised and heavily financed by the state, has witnessed a multitude of reforms. User-fees were introduced to compensate for a sharp reduction in public spending for healthcare (Ramesh, 2013). The participation of private actors in healthcare delivery was encouraged in the 1990s (ibid.) to mobilise resources from society for the upgrading of a poorly-resourced health system. This led to a sharp increase in outof-pocket payments (Ramesh, 2013; Somanathan et al., 2014), which reached more than 70 
percent of the total health spending in the 1990s (Somanathan et al., 2014). Consequently, to tackle the issue of high out-of-pocket payments, the Vietnamese government decided to introduce social health insurance as an instrument of financial protection. The first social health insurance was introduced as a compulsory contribution-based scheme in 1992 for the formal sector to include public servants, people working in state-owned enterprises and private companies (Palmer, 2014). It was then combined with a non-contributory scheme for public retirees, social assistance recipients and people of merit (veterans and mothers of war martyrs) (ibid.). A voluntary scheme was established in 1994 for students, informal workers (i.e. farmers and non-farm self-employed workers) and dependants of those in the compulsory scheme (ibid.). In 2003, the Health Care Fund for the Poor was introduced under Decision 139/2002/QD-TTg to provide free health insurance for poor people, selected ethnic minority groups and those living in the most disadvantaged regions (Socialist Republic of Vietnam, 2002a). From 2005, all children under six have been eligible for free health insurance subsidized by the government under Decree 36/2005/ND-CP. The first Health Insurance Law was subsequently issued in 2008 (Socialist Republic of Vietnam, 2008), in which all the schemes were consolidated into one national Social Health Insurance programme (SHI). Since then, the SHI has become the largest and most popular health insurance programme in Vietnam (in addition to other private insurance packages in the financial market).

The expansion of health insurance coverage in Vietnam has gained additional momentum from the global wave of UHC in other low and middle income countries (LMIC). Since the World Health Assembly in 2005, the World Health Organisation (WHO) has embraced the concept of UHC, urging member states to commit resources and take more action towards universal access and coverage (WHO, 2005). In the same year, all WHO member states unanimously committed to achieving UHC (WHO, 2013). Since then, UN agencies, donors, development banks and other international institutions, have been active in pushing for UHC across the globe, making it a priority in health agenda setting in many LMIC (WHO, 2013). The WHO dedicated the World Health Reports 2010 and 2013 to the topic (see WHO, 2010, 2013), whereas the World Bank discussed this matter in its study series for 24 LMIC that are moving towards UHC (see Cotlear et al., 2015). In 2014, a standardised monitoring framework for UHC was introduced to help LMIC track their progress in UHC (WHO and the World Bank, 2014; Boerma et al., 2014). UHC has also been incorporated into the Sustainable Development Goals (i.e. Goal 3.8), suggesting a global consensus in accelerating the UHC progress and strengthening health systems for LMIC (WHO and the World Bank, 2014). Up to now, despite challenges, around twenty four LMIC governments have translated the political commitment into action with encouraging progress in Asia, 
Latin America and Africa (Rodin and de Ferranti, 2012; Lagomarsino et al., 2012; Cotlear et al., 2015). At the country level, WHO constantly calls for more action towards UHC in Vietnam (WHO, 2018b). Therefore, as a country trying to provide affordable quality healthcare for all, Vietnam has quickly rallied momentum from the global UHC movement.

\subsection{Problem definition}

Despite its rapid expansion, health insurance coverage in Vietnam (the SHI particularly) is inefficient and ineffective with fragmentation in its organisation and management (Somanathan et al., 2014) as well as lots of inefficiencies in the healthcare system (Takashima et al., 2017). Even though SHI is a single payer programme, its management remains fragmented with 63 provincial funds, in which each fund includes many sub-funds for various insurance sub-schemes (Somanathan et al., 2014). These fragmented funds, combined with limited coordination and the lack of a uniform managing approach for SHI, lead to limited risk pooling (ibid.). SHI sub-schemes have different target populations and enforcement mechanisms, some of which are based on employment status. This gives rise to gaps in enrolment among different population groups (ibid.). Adverse selection remains an issue (ibid.) as many informal workers are not enrolled, negatively affecting the risk pooling goal of the programme. Additionally, the payment mechanism of the SHI fails to contain cost, and even generates incentives for supply side moral hazard (Somanathan et al., 2013). Vested interests in the healthcare delivery give healthcare suppliers the incentives to prescribe medicines that are not covered by SHI (ibid.). Consequently, balance billing ${ }^{2}$ is widespread (Somanathan et al., 2013, 2014), contributing to high out-of-pocket payments. SHI-regulated price caps can not keep pace with rises in drug prices (Somanathan et al., 2014). Therefore, despite the sharp increase in coverage rate, there remain gaps in financial protection for health, with more than 5 percent of the population incurring high out-of-pocket payments ${ }^{3}$ (WHO, 2018a). In 2015, out-of-pocket payments accounted for more than 43 percent of total health expenditure (The World Bank, 2018). Worryingly, there is discrimination against patients who use SHI in seeking care (see the media coverage by Dang, 2013; Kim and Vu, 2013; Duong, 2014), which has been discussed and questioned at many parliament testimonies. The discrimination is often manifested in the lack of friendliness and attention of medical staff towards insured

2 Balance billing is the practice of a healthcare provider billing a patient for the difference between what is covered by the patient's health insurance and what the provider wants to charge.

3 This is measured by the share of population with out-of-pocket payments higher than 25 percent of total household consumption or income. 
patients in overcrowded facilities (Duong, 2014), which is reinforced and incentivised by the profit-maximization goal of public hospitals ${ }^{4}$.

The rapid expansion of health insurance coverage does not necessarily translate into quality medical care due to the inefficiencies (Takashima et al., 2017; Somanathan et al., 2014) and corruption in healthcare delivery (Vian et al., 2012). Healthcare quality is still a concern, especially at primary care and in rural and remote areas due to the lack of finance and human resources (Lieberman and Wagstaff, 2009; Somanathan et al., 2014). Until 2013, only two-thirds of commune healthcare stations had a medical doctor (Somanathan et al., 2014). This share was only one-third in the poorest region of Vietnam (ibid.). In rural and disadvantaged regions, people face various barriers to access, including long distance to healthcare facilities, poor service quality in primary care, and unaffordability (Tran et al., 2016). Even though healthcare resources are more concentrated in big cities (Somanathan et al., 2014), healthcare quality is also a concern in urban areas with chronic overcrowding in big hospitals. The fact that two or three patients have to share one bed is rather common in large hospitals (Cheng, 2014). The excessive demand has been shown to be linked to rampant informal payments to medical staff in overcrowded facilities (Vian et al., 2012) to get faster care or more attention (cited in Matsushima and Yamada, 2016).

The ineffectiveness and inefficiency of health insurance coverage potentially weaken the desirable impact of health insurance, raising the question if health insurance can help to achieve the UHC goal: enabling everyone to get quality care that they need without any financial hardship. Therefore, improving the quality of medical care should be at the core of achieving UHC. When health insurance is used as an instrument to achieve UHC, it is important to evaluate if health insurance can improve quality of medical care. In addition to objective quality measures, the relationship between insurance coverage and patient satisfaction with medical care is pivotal to guide future patient-centred healthcare interventions. In other words, subjective patient satisfaction, which represents patients' expectations and evaluations, hence becomes a crucial source of information for quality improvement efforts. Research on patient satisfaction can significantly complement other objective quality reports in mapping the quality picture of medical care. For Vietnam, with the commitment to achieving UHC via expanding health insurance coverage, examining the relationship between health insurance and patient satisfaction has become more relevant than ever.

Meanwhile, the expansion of health insurance may have important implications for the

${ }_{4}^{4}$ See an in-depth discussion about the profit-maximization goal of public hospitals in Vietnam in Ramesh (2013) and Chapter 5. 
Vietnamese labour market. For instance, evidence on the effects of social health insurance in post-Soviet countries, which used to share a similar Socialist-style health system with Vietnam, has suggested 'reduced employment as a whole and increased unemployment' (Wagstaff and Moreno-Serra, 2009, pg.1). Moreover, despite the lack of evidence (Banerjee et al., 2017), one of the underlying arguments of those who are against redistributive policies and the universality concept is the prejudice of the 'lazy poor' (Banerjee et al., 2015, pg.178) or the undeserving poor. This school of thought argues that when provided with social benefits, the poor are more likely to become dependent on social programmes (dependency argument) and hence locked in those programmes as exiting poverty comes with the loss of the benefits (policy lock argument). Therefore, providing more universal welfare may discourage work and in the end keep the poor in a vicious poverty circle. In this logic, Gruber (2010) argues that non-contributory welfare provision is negatively correlated with labour supply as it 'raises the incentive for individuals to be poor' in order to qualify for the benefits (Gruber, 2010, p.500) ${ }^{5}$. This argument is aligned with the famous equity-efficiency trade-off (Okun, 1975) in welfare economics: more distribution and equity means less economic efficiency due to increased disincentive to work. It is also consistent with the income effect predicted by the traditional budget constraint approach in microeconomics. This argument of a negative effect of universal health insurance can receive great support especially when there is inadequate empirical evidence of better health for adults induced by health insurance ${ }^{6}$, as the available evidence is relatively thin (Sommers et al., 2012) and mixed (Boyle and Lahey, 2010; Sommers et al., 2012), and very far away from showing a causal reference (Levy and Meltzer, 2004).

The concern is that this potential disincentive to work induced by social health insurance may undermine the economic achievements that have been gained so far. This threat is very relevant for Vietnam, considering its strong ambition to maintain economic growth and accelerate the catching-up with advanced countries, which is even shown in the Vietnamese constitution (The World Bank and MPI, 2016). Therefore, despite well-intentioned social effects of health insurance, the labour supply implications of health insurance should be discussed seriously with the support of sound evidence to inform policy making.

${ }^{5}$ Gruber (2010) defines welfare broadly and also includes medical benefits, i.e. Medicaid in the US, in the definition of social welfare.

${ }^{6}$ Even though we have an abundance of evidence of improved health status for children due to health insurance, little is known about this effect for adults (Sommers et al., 2012). 


\subsection{Knowledge gaps}

The current UHC movement in Vietnam and also in other LMIC seems to overlook or even ignore important implications of health insurance for the labour market and for patient satisfaction. Very frequently, assessments of health insurance are focussed on health-related issues such as accessibility, out-of-pocket payments, utilization, health status (Escobar et al., 2011). This focus might be due to the fundamental objective of health insurance - to protect the insured against health shocks by reducing out-of-pocket payments and removing access barriers. Nevertheless, it is important to realise that health insurance potentially has broader effects beyond the spectrum of health, whereas there remain knowledge gaps within the health literature.

Despite its potential undesirable effects, little is known about the labour market effects of health insurance for LMIC because the latest literature reviews of this topic (i.e. Gruber and Madrian, 2002; Madrian, 2006) as well as book chapters (Currie and Madrian, 1999; Gruber, 2000) only focus on the American healthcare system. Insights into the US healthcare system are not necessarily relevant for LMIC in general and Vietnam in particular due to its unique institutional link between employment and health insurance. Beyond US-based literature, there are scattered studies for Uruguay (Bergolo and Cruces, 2014), Taiwan (Chou and Staiger, 2001; Kan and Lin, 2009; Liao, 2011), Thailand (Wagstaff and Manachotphong, 2012) and Eastern European countries (Wagstaff and Moreno-Serra, 2015, 2009), but this non-US literature seems very thin compared to the vast number of US-based studies. For Vietnam, to the best of the author's knowledge, no research on the labour market effects of health insurance has been done despite the unprecedented race towards UHC. This highlights a knowledge gap in this importantly relevant topic for Vietnam.

Within the health literature, even though healthcare quality is discussed greatly, little is known about the relationship between health insurance and how patients value the care delivered. This is particularly true for LMIC due to their lack of a regular monitoring mechanism of health sector performance and inadequate monitoring capacity (WHO and The World Bank, 2015). For Vietnam, no quality evidence is available on patient satisfaction in general and its relationship with health insurance in particular. This is probably because of the heavy focus on objective quality measures such as accessibility (Tran et al., 2016), out-of-pocket payments (Jowett et al., 2003; Nguyen, 2012; Nguyen and Wang, 2013; Wagstaff, 2010), affordability (Tran et al., 2016) and utilisation (Wagstaff, 2010; Nguyen, 2012; Nguyen and Wang, 2013; Guindon, 2014; Palmer et al., 2015). The 
problem is, the issue of ineffective health coverage is rather common in LMIC because these countries are frequently characterised by limited financial protection and poor healthcare access (Mills, 2014; WHO and The World Bank, 2015). This is also the case for Vietnam as discussed above (also see Somanathan et al., 2013; Takashima et al., 2017). Therefore, examining if health insurance can improve patient satisfaction with medical care is necessary to improve healthcare quality in Vietnam. More research on patient satisfaction and its relationship with health insurance is needed to fill the gap.

Realising the potential policy implications of health insurance for the labour market and for patient satisfaction with medical care, this dissertation aims to address the urgent need for more evidence on these topics for Vietnam. The objectives are to expand our knowledge on and gain more insights into policy issues that may hamper Vietnam's progress towards UHC. Additionally, because the UHC movement is witnessing the participation of many other LMIC, this dissertation on Vietnam can serve as an example for the global UHC trend. It is the author's hope that the findings of this dissertation may contribute to igniting a policy debate in countries with rapid health insurance expansion by providing evidence on these important implications of health insurance.

\subsection{Research questions}

With an eye on the aforementioned objectives, this dissertation asks two general questions:

1. What are the labour market effects of health insurance in Vietnam?

2. What are the implications of health insurance for patient satisfaction with medical care in Vietnam?

Among the labour market effects of health insurance, this dissertation focuses on potential labour market distortions (see Chapter 2 and 3 for in-depth theoretical discussion). The effects reviewed in chapters 2 and analysed in chapters 3-4 include the number of hours worked, the probability of employment, self-employment and the level of formalisation of the economy. The effects on the number of hours worked and the probability of employment are selected with the assumption that they are relevant for Vietnam in its economic catching-up with advanced economies. With the large proportion of self-employment and the informal sector in Vietnam (Cling et al., 2011) and LMIC (Gindling and Newhouse, 2014; Cho et al., 2012), it is important to examine the effects of health insurance on 
self-employment and the level of economic formalisation.

Question 1. What can we learn from the existing literature on the labour supply effects of health insurance?

Question 1 provides the background knowledge for the follow-up questions (Question 2 and 3) on the labour supply effects of health insurance. This aims to provide a systematic review, pinpointing areas for more policy queries as well as highlighting lessons learned for countries which are moving towards UHC.

As health insurance may create a disincentive to work for different population groups (Rosen, 2014; Dave et al., 2015; Boyle and Lahey, 2010; Erosa et al., 2012), it is important to investigate if this is the case for Vietnam. The second question aims to quantify the effects of health insurance on labour supply responses at the intensive and extensive margins (i.e. the number of hours worked and labour force participation).

Question 2. In Vietnam, what are the effects of health insurance on the number of hours worked and labour force participation?

Another economic concern when expanding health insurance is that health insurance in developed countries has been shown to impede self-employment (Zissimopoulos and Karoly, 2007; Fossen and König, 2017). Our third research question hence explores the relationship between health insurance and self-employment.

Question 3. In Vietnam, what are the effects of health insurance on selfemployment?

Finally, due to the aforementioned abundance of literature on health insurance effects on health-rated issues and objective quality measures, this dissertation addresses an under-researched perspective: the effect of health insurance on patient quality evaluation (i.e. subjective patient satisfaction). The final research question is:

Question 4. With the health insurance coverage expansion in Vietnam, how do patients evaluate the quality of healthcare?

This exploration helps to address the question whether the impressive expansion in health insurance coverage in Vietnam can lead to the provision of quality healthcare for Vietnamese people. Given the knowledge gaps on this topic (see Section 1.3), this would be the first investigation into subjective healthcare quality in Vietnam and the relationship 
between health insurance and patient evaluation.

\subsection{Data and methods}

This dissertation uses a mixed method approach. Chapter 2 employs a qualitative approach to conduct a systematic review, whereas a quantitative approach is used in all empirical studies of chapters 3-5. In Chapter 2, a literature review method combined with snowballing are used to collect the data (i.e. all English language studies on the labour supply effects of health insurance). After data collection, due to the huge variation in theoretical underpinnings, methods, outcomes as well as the heterogeneity of healthcare systems and health insurance programmes reviewed, a qualitative approach is used for data analysis rather than a meta-analysis with statistical methods.

Chapters 3-5 use a quantitative approach to analyse secondary data from three large scale datasets. Different econometric models and techniques are used across the chapters. Chapter 3 uses various matching techniques (i.e. Mahalanobis matching, nearest neighbour matching, Kernel matching) combined with a Difference-in-Differences model. Chapter 4 employs a probit model with selection (Van de Ven and Van Praag, 1981) while Chapter 5 uses multi-level models for ordinal responses (multi level models are also referred to as mixed models or random-effects models).

Chapters 3 and 4 use two panels from the Vietnam Household Living Standards Surveys (VHLSS) during two periods 2002-2006 and 2010-2014. VHLSS is the largest nationwide biannual household surveys in Vietnam, covering all topics ranging from education, health, labour, income and agriculture production to social assistance benefits. This survey originated from the well-known World Bank's Living Standards Measurement Surveys (LSMS) and was renamed VHLSS since 2002. Data collection is currently carried out and managed by Vietnam's General Statistical Office (GSO). All surveys during 2002-2008 use the same master sample for sampling, which is extracted from the Vietnamese Population Census 1999. Since 2010, another master sample has been used, which is based on the latest Population Census in 2009. Importantly, all surveys have two different samples, one larger sample covering all general information and income, and one smaller sample with additional details on expenditure. In each survey, the expenditure component of the household questionnaires is only used for the small sample. As this dissertation uses information on income, expenditure and poverty, small samples of all surveys are used. In 2002, the sample size was the largest, covering more than 30,000 households for the small 
sample and 45,000 households for the large sample (this makes a total sample of 75,000 households). Since 2004, more than 9,000 households have been surveyed each wave for the small sample and approximately 37,000 households for the large sample (this makes a total sample of more than 45,000 households).

Another important feature of VHLSS is its sample rotation where only half of the total sample in a previous survey is re-sampled in the next round. This is to adjust for demographic changes over time to ensure the national representativeness of each crosssection. Consequently, the sample rotating technique significantly reduces the sample size of the panels used in this dissertation. With the change in the master sample, as well as the rotating sampling, using the panel component of VHLSS will end up using short panels with a trade-off between sample size and the length of the panel. This is the biggest limitation of VHLSS as it does not enable any long-term analysis for Vietnam.

Chapter 5 employs a dataset from the end-line survey of phase two of the largest poverty reduction programme in Vietnam called the National Target Programme for Poverty Reduction, often referred to as Programme 135-II. The programme targets the poorest communes which have a high concentration of ethnic minorities living in remote and disadvantaged areas. The dataset is owned by UNDP Vietnam under a commission work by Nguyen et al. (2013) to evaluate the impacts of the Programme 135-II after its closure. The survey was conducted in 2012, covering 398 communes and 5,668 households (ibid.). The questionnaires of the surveys were developed based on that of the multi-purpose VHLSS with additional questions on healthcare utilization and the level of satisfaction with medical care. These additional questions enable the examination of the relationship between health insurance and patient satisfaction in the most disadvantaged areas of Vietnam. The largest limitation in using the P135-II dataset is its limited scope which only covers the poorest regions of Vietnam.

\subsection{Structure of the dissertation}

This dissertation consists of six chapters. After this introduction, Chapter 2 answers research question 1 by conducting a systematic review on the effects of health insurance on labour supply. As expanding health insurance and moving towards UHC is the current reality in LMIC, the focus is placed on lessons learned for these countries. In particular, this chapter reviews the effects of health insurance on LMIC-relevant outcomes: the number of hours worked, the probability of employment, self-employment and the level 
of (in)formality. It summarises what we have learned so far regarding the labour supply effects of health insurance, highlighting literature gaps and pinpointing areas for further research.

Chapter 3 answers research question 2 by examining the effects of health insurance on labour supply. The policy under investigation is the Health Care Fund for the Poor (HCFP) which was introduced in 2003 in Vietnam. This chapter uses Matching Differencein-Differences models to quantify how the poor in Vietnam have responded, both at intensive and extensive margins (i.e. the number of hours worked and the probability of employment), to the free health insurance provided under the HCFP. This chapter helps to shed some new light on the theoretical debate between the income effect literature, which predicts a reduction in labour supply of the poor due to the free health insurance coverage, and the health-fostering argument which argues that health insurance makes people healthier and hence enables them to work more.

Chapter 4 addresses research question 3 by employing a Probit model with selection to examine the association between health insurance and self-employment transitions (entry and exit) in Vietnam. In particular, it focuses on the difference between two different health insurance schemes for formal workers (often wage earners and public workers) and informal workers (mostly the self-employed) to analyse the relationship between health insurance and self-employment entry and exit. Chapter 4 contributes to find more evidence for LMIC in general and Vietnam in particular on a topic which is overly represented by US-based studies.

Chapter 5 answers research question 4 by using different random-effects models for ordinal responses to study the impact of health insurance on patient satisfaction in the poor regions of Vietnam. This is to measure how Vietnamese patients, with or without health insurance, are satisfied with the medical care they receive. Chapter 5 contributes to the under-researched literature on the relationship between health insurance and patient satisfaction while the existing literature is mainly concentrated on patient satisfaction per se and its determinants. Finally, Chapter 6 concludes the book with policy implications and suggestion for future research. 


Chapter 2

\section{A systematic review of health insurance effects on labour supply}

\section{This chapter is based on}

Lê, N., Groot, W., Tomini, S. M., \& Tomini, F. (2019). Effects of health insurance on labour supply: A systematic review. International Journal of Manpower. DOI: https://doi.org/10.1108/IJM-02-2018-0038 


\begin{abstract}
This chapter answers the first research question by conducting a systematic review of empirical evidence on the labour market effects of health insurance from the supply side. The outcomes in the 63 studies reviewed include the number of hours worked, the probability of employment, self-employment and the level of economic formalisation. We find that the current literature is vastly concentrated on the US. Spousal coverage in the US is associated with reduced labour supply of secondary earners. The effect of Medicaid in the US on labour supply of its recipients is ambiguous. However, we have initial evidence of labour supply distortion caused by Children's Health Insurance Program, Affordable Care Act and other public health insurance expansions. A tentative result is that dependent young adults in the US who can access health insurance via their parents' employer have lower labour supply through fewer hours worked while keeping the same employment probability. The link between health insurance and employment in the US is an important determinant of labour supply of people with health problems. Similarly, the relationship between health insurance and employment is a strong driver of self-employment decisions. Universal coverage may create either an incentive or a disincentive to work depending on the design of the system. Finally, evidence on the relationship between health insurance and the level of economic formalisation in low and middle income countries is fragmented, limited and inconclusive.
\end{abstract}




\subsection{Introduction}

Health insurance may have important effects on labour force participation and job mobility (Gruber and Madrian, 2002). In some cases, it has been shown to reduce aggregate employment (Wagstaff and Moreno-Serra, 2015) and increase unemployment (Wagstaff and Moreno-Serra, 2007). In this regard, the theory of static labour supply predicts that non-contributory health insurance, which is not provided by employers, may 'make working less attractive' as it helps to ease catastrophic health expenses (Chou and Staiger, 2001). Similarly, Netzer and Scheuer (2007) in their precautionary labour theory suggest that individuals may work less if they are faced with less income uncertainty. This implies that more security in health coverage potentially lowers labour supply if the share of health costs out of the total household expenses is large enough. Providing non-contributory safety nets outside employment may also undesirably encourage the informal labour market which is often associated with poor work conditions and social security avoidance (Levy and Meltzer, 2004). The rolling out of Seguro Popular programme, a non-contributory health insurance in Mexico for informal workers is found to reduce the inflow into formal employment (Aterido et al., 2011). Despite the sporadic evidence from selected countries, the international empirical evidence of the labour market effects of health insurance has not been thoroughly reviewed. Previous reviews (Gruber and Madrian, 2002; Madrian, 2006) as well as book chapters in Currie and Madrian (1999) and Gruber (2000) merely focus on the American healthcare system with its rather unique insurance-employment link, therefore the findings cannot be generalised. Besides, these syntheses may summarise potentially biased results as many of the studies reviewed fail to address the endogeneity of the health insurance - for instance in the case of spousal coverage with assortative mating - or bias arising from unobserved heterogeneity due to the use of cross-sectional data.

This chapter answers the first research question. Its aim is to synthesize empirical evidence on the labour market effects of health insurance from the labour supply side. This is to increase our knowledge and understanding of the labour market effects of health insurance. Another aim is to better inform policy makers in LMIC given the current interest in expanding health coverage under the wave of UHC (Rodin and de Ferranti, 2012; Lagomarsino et al., 2012; Cotlear et al., 2015). Because of the diversity in healthcare coverage, the concept of health insurance in this review concerns different types: employment-provided health insurance (which is dominant in the US and consists of various schemes such as dependant coverage, spousal and employee packages); public 
health insurance for social assistance recipients; social health insurance and UHC; tax and price subsidies to make health insurance cheaper and more accessible; and other less-known public schemes. The outcomes reviewed include labour force participation (i.e. labour supply at extensive margin), the number of hours worked (i.e. labour supply at intensive margin), self-employment decision, and work in the informal sector. We only focus on the outcomes that we consider most relevant for LMIC. We disregard retirement effects and only focus on labour market effects on the working age population. Our study is conducted systematically, covering the largest peer-reviewed and working paper databases for economics and health studies. We follow the PRISMA 2009 protocol for systematic reviews (Moher et al., 2009).

\subsection{Theoretical predictions}

This section summarises the theoretical predictions on the effects of health insurance on the outcomes. We discuss the debate over positive versus negative effects of health insurance on labour supply and highlight the difference between labour supply effects at the intensive and extensive margins (i.e. the number of hours worked vs. labour force participation). We also discuss the effects of health insurance on self-employment and work informality due to the important role of the informal sector and the self-employed in low and middle income economies.

\section{Non-contributory health insurance and labour supply: the debate}

Despite the varied taxonomy of health insurance, the theoretical debate over the labour supply effects is mainly focused on non-contributory schemes. The theory of static labour supply predicts that public health insurance, which is not tied to employment, may 'make working less attractive' because of a consumption smoothing effect resulting from the removal of unexpected catastrophic health expenses (Chou and Staiger, 2001). The effect, however, depends on the share of health costs in total household expenses (ibid.) and will be more pronounced in the case of low-income recipients or those with large health spending. Studies that rely on the budget constraint approach argue that government-provided health insurance can be considered as a positive income shock subsidized by tax, especially for lower income groups and those who have high health expenses (Boyle and Lahey, 2010). Therefore, universal health insurance or any non-contributory schemes potentially give these individuals a disincentive to work due to the income effect as leisure is a normal good (ibid.). These two theories, based on the income effect whether via consumption 
smoothing or income increase, consistently predict a negative labour supply as a result of non-contributory health insurance schemes. However, health insurance is necessarily different from cash transfers because it potentially affects not only the recipients' labour supply, but also health and productivity (Boyle and Lahey, 2010, 2016). Intuitively, better health access likely makes the beneficiaries healthier and more productive, enabling them to work more and earn extra income. This health fostering argument, in addition to the allegation of human right violation, is widely used by human rights activists in the global UHC movement. However, the empirical evidence for this argument is relatively thin especially for adults (Sommers et al., 2012) and sometimes mixed (Boyle and Lahey, 2010; Sommers et al., 2012). We have evidence that health insurance expansions reduce child mortality (Currie and Gruber, 1996; Howell et al., 2010) while it does not necessarily translate into better health for adults (Levy and Meltzer, 2004). Levy and Meltzer (2001) highlight that a majority of studies that look at the effects of health insurance on health status are observational studies which are hence unable to draw a causal link, while 'most, but not all' quasi experimental studies suggest that health insurance helps to improve health, even though 'the interpretation is not always straightforward' (Levy and Meltzer, 2001, p.5). Drawing a causal link between health insurance and labour productivity is even harder as productivity is difficult to measure and hence not often asked in micro labour surveys. Therefore, finding hard evidence of the positive impacts of health insurance on health and labour supply is not always trivial.

Importantly, the static labour supply theory and simplified budget constraint approach tend to mix two distinctive labour supply effects (i.e. labour force participation and hours worked) under the same umbrella of labour supply. However, while labour force participation refers to the likelihood of participating in the labour market, the number of hours worked reflects the intensity of work on the job. The labour force participation and hours worked responses of low income people to receiving public assistance may differ, as has been shown in empirical studies as well as theoretical work (Saez, 2002). The elasticity of labour force participation is significant among low income earners while that of the number of work hours conditional on working are found to be relatively small (ibid). In modelling the optimal income transfers, intensive versus extensive labour supply responses are often disentangled (Saez, 2002). Therefore, when considering the income effect of non-contributory schemes, it is important to separate the two.

\section{Health insurance and self-employment: entrepreneurship lock or push}

Self employment responses to health insurance reforms are varied. Employer-provided health insurance is believed to dampen entrepreneurial activities as it incentivises people 
to stay or move into wage and salary employment for the coverage. This phenomenon is referred to as 'entrepreneurship lock' (Fairlie et al., 2011). On the contrary, de-linking health insurance from employment is hypothesised to induce more job mobility toward self-employment and open the lock via different transition paths (Heim and Lurie, 2010). Therefore, the two phenomena in this review will be analysed in the context of the link (or detachment) between health insurance and employment.

\section{Health insurance and informal labour}

The informal sector is playing an important role in low and middle income economies. The main concern, however, is that expanding non-contributory social safety nets beyond the formal sector may encourage informality which is often linked to poor working conditions, limited labour protection and even social security avoidance (Levy, 2010). Therefore, despite the large contribution of the informal sector in LMIC, the informalisation of the economy as a result of increased social safety nets in general and non-contributory health insurance in particular may not be intentional. This review wants to test this hypothesis.

\subsection{Methodology}

The systematic literature review was conducted in agreement with the PRISMA guidelines. PRISMA stands for Preferred Reporting Items for Systematic Reviews and Meta-Analyses, developed to reduce the risk of flawed research reporting (Moher et al., 2009; Liberati et al., 2009). PRISMA includes a 27-item checklist and a diagram, both of which serve as a guideline for transparent reporting of meta-analyses and systematic reviews (ibid.). PRISMA statement has been endorsed by the Cochrane Collaboration in 2009. We use the PRISMA 2009 (Moher et al., 2009) in this chapter.

\section{Information sources}

Databases are selected to ensure that all related disciplines (health economics, labour economics, public economics, public policy, health and medical studies) are covered. They include Web of Science, Google Scholar, Pubmed and the most popular economics working paper sources such as NBER, ECONSTOR, IDEAS, IZA, SSRN, World Bank Working Paper Series. The rationale for database selection following PRISMA 2009 checklist (Moher et al., 2009) is presented in Annex 2.1. This review includes publications released after 2000 and written in English. 


\section{Search strategy}

The search was implemented using key terms listed in Annex 2.2. We combined each of the two key words representing dependent variables (labour market effects) and independent variables (health insurance) in the advanced search field, if available, with colophon 'and', and set search locations in all fields (i.e., title, abstract and content). We used a file-naming protocol to detect and remove duplicates before saving, which helps to minimize duplicates and save screening time. Therefore, our method is slightly different from the work flow illustrated in the PRISMA diagram (Moher et al., 2009) as we did initial screening before saving. Our search was carried out from October 2015 to January 2016. After the initial search, we carried out snowballing where we only added six working papers published in less known working paper series. This small number of added papers suggests a relatively high level of accuracy and reliability of the search.

\section{Study selection and exclusion criteria}

We deliberately do not set any methodology filter as an exclusion criterion. Instead, we discuss how the methodology and quality of the studies reviewed may influence the results if we find any inconsistencies in the results. We exclude papers that fail to separate health insurance from other benefits under broader terms like social insurance, social assistance, social protection, fringe benefits. Because this review targets empirical evidence, we opt to exclude i) ex-ante evaluations and simulations and ii) purely theoretical articles. Studies that compare the labour supply effects of different types of health insurance and healthcare systems are removed since they are not directly relevant. Diagram 2.1 summarises the whole search and screening process based on PRISMA 2009 Flow Diagram (Moher et al., 2009). The final selection consists of 63 papers and articles. 


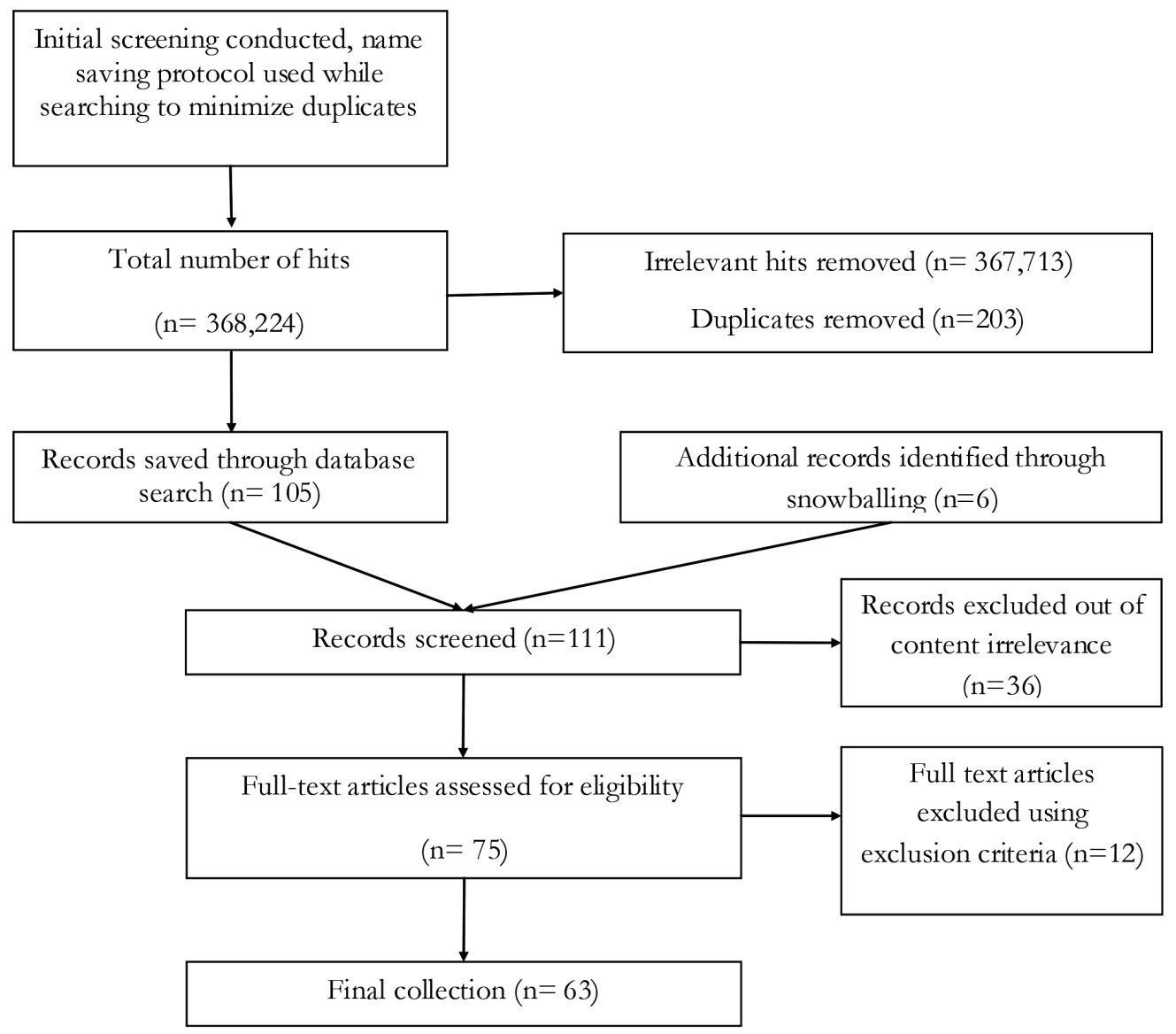

Figure 2.1: Study selection process

\subsection{Results}

\subsubsection{Descriptive results}

A majority of the studies found in our search are US-based studies, 47 out of the 63 selected papers. This may reflect the history of the literature where theoretical models on the relationship between health insurance and labour supply, or between social insurance, social assistance and labour supply are predominantly from the US. Additionally, the 
American dominance in this literature may be due to the fact that there is more discussion on the equity-efficiency trade-off in the US, while notions of equity often dominate the debate in other OECD countries. Quasi-experimental designs are the most frequently used (47 in 63 papers), out of which Difference-in-Differences (DD) and Difference-in-Differencein-Differences (DDD) are frequently adopted. The collection is relatively diverse in terms of type of health insurance and target groups. However, the aforementioned American focus, which concentrates on US-specific health insurance, limits the generalisation of these findings to the context of LMIC. Therefore, our strategy is to summarise results in the context of specific health systems.

Table 2.1: Categorisation of all studies reviewed

\begin{tabular}{lr}
\hline Topic & $66^{*}$ \\
Labour supply (labour force participation and hours worked) & 40 \\
Self-employment & 16 \\
Formality & 10 \\
\hline Methodology & 0 \\
Experimental & 47 \\
Quasi-experimental & 16 \\
Non experimental & 47 \\
\hline Location & 16 \\
US & \\
Non-US & 8 \\
\hline Type of insurance/ policy intervention & 6 \\
Spousal coverage for secondary earners (employer-provided) & 7 \\
Dependant coverage for young adults (employer-provided) & 14 \\
Employer-provided health insurance & 4 \\
Public health insurance for assistance recipients & 2 \\
Tax subsidy to make health insurance cheaper for informal & 12 \\
Rising premiums & 10 \\
\hline Universal coverage & 63 \\
\hline Other reforms for coverage expansion & \\
\hline Total &
\end{tabular}

*There are three double-counting cases. One paper looks at labour supply and self-employment, the other two examine labour supply and informality.

In sub-sections 2.4.2 to 2.4.4, we respectively discuss three outcomes: labour supply in terms of labour force participation or hours worked, self-employment decisions, and work in the informal sector. We analyse the effects by different types of health insurance and separate the discussion into inside and outside the US. When possible, we separate the labour supply effects at the extensive versus intensive margins.

Additionally, we categorise the collected studies by experimental, quasi-experimental and non-experimental. Due to the lack of consensus on what constitutes 'quasi-experimental', we follow the taxonomy by Rockers et al. (2012), who review the use of the 'quasi- 
experimental' term in reviews from various disciplines and define the term as consisting of: natural experiments, instrumental variable analysis, regression discontinuity analyses, interrupted times series, controlled before-and-after designs, difference-in-differences design and fixed effects analyses of panel data. We use the conventional definition of an experimental design: any study with the randomisation of the treatment and control groups. Non-experimental studies hence include all studies that are neither experiment nor quasi-experimental.

\subsubsection{Labour supply effects of health insurance}

\section{Spousal coverage and labour supply of secondary earners}

As shown in Table 2.2. we have identified six papers using US-based data on the effects of health care coverage on the labour supply of secondary income earners. As suggested, methodologies are mixed, with both quasi-experimental and non-experimental techniques being used. Despite the methodological variation, the prevailing evidence (five out of six articles) suggests a negative impact of spousal health coverage on labour supply of secondary earners in the US in term of decreases in employment likelihood (Murasko, 2008; Kapinos, 2009; Cebi and Wang, 2013), probability of working full-time (Royalty and Abraham, 2006; Kapinos, 2009; Wenger and Reynolds, 2009; Cebi and Wang, 2013) and work hours (Wellington and Cobb-Clark, 2000; Murasko, 2008; Cebi and Wang, 2013). However the effect size appears to become much smaller after controlling for unobserved heterogeneity (Cebi and Wang, 2013). The literature on this topic evolved significantly, with a particular focus on methodological improvement to account for the endogeneity of spousal coverage due to assortative mating. Therefore, studies since Royalty and Abraham (2006) are more methodologically reliable. This improvement however does not change the main conclusion of the negative effect of spousal coverage because earlier studies (e.g. Wellington and Cobb-Clark, 2000) yield the same results. 


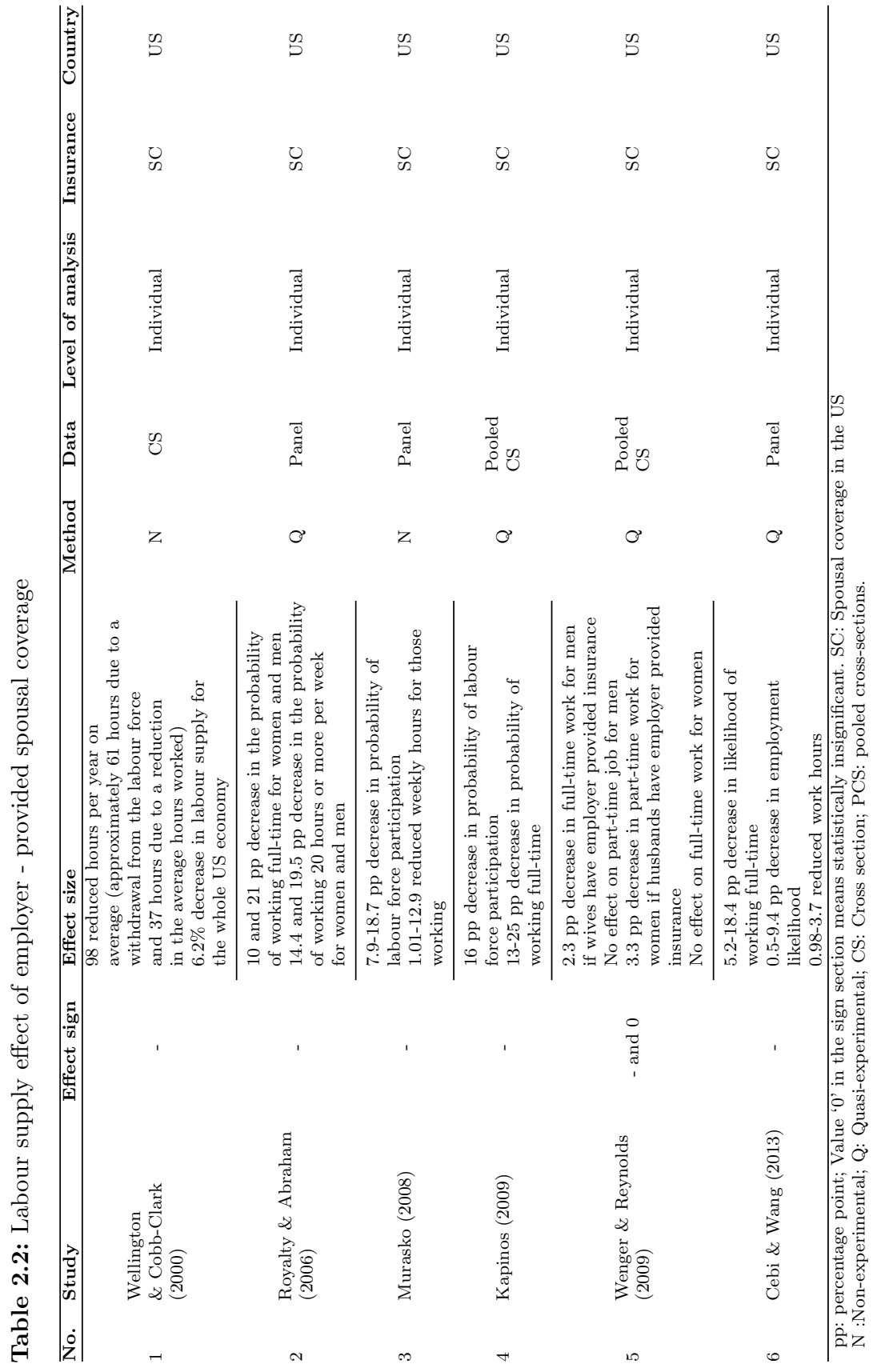




\section{Dependant coverage and labour supply of young adults}

Table 2.3 presents the findings of four studies analysing the labour supply of young adults who get access to health insurance via their parents' employers. Again, all publications found in this topic are about the US and they all use quasi-experimental methods. The effects of dependant coverage on labour supply of American young adults are mixed. The probability of labour force participation appears not to be affected (Antwi et al., 2013; Depew, 2015) but the likelihood of working full-time is reduced (Antwi et al., 2013; Hahn and Yang, 2016; Depew, 2015). From another perspective, dis-enrolment at the age cut-off of 25 seemingly urges young adults in the US to work more and become more active in the labour market (Dahlen, 2015). However, with the small number of studies, it is difficult to provide any definite conclusion on this issue.

Table 2.3: Labour supply effect of dependant coverage

\begin{tabular}{|c|c|c|c|c|c|c|c|}
\hline No. & Study & Sign & Effect size & Method & Data & $\begin{array}{l}\text { Level of } \\
\text { analysis }\end{array}$ & Country \\
\hline 1 & $\begin{array}{l}\text { Antwi } \\
\text { et al. } \\
(2012)\end{array}$ & - and 0 & $\begin{array}{l}2.0 \text { pp decrease ( } 5.8 \% \text { decrease) in } \\
\text { likelihood of full-time work } \\
3 \% \text { decrease in weekly work hours } \\
\text { No effect on employment probability }\end{array}$ & Q & Panel & Individual & US \\
\hline 2 & $\begin{array}{l}\text { Hahn \& } \\
\text { Yang } \\
(2016)\end{array}$ & - & $\begin{array}{l}3.1 \mathrm{pp} \text { decrease in the likelihood of } \\
\text { full-time work ( } 2.6 \mathrm{pp} \text { decrease for } \\
\text { women and } 3.7 \mathrm{pp} \text { decrease } \\
\text { for men) } \\
2.1 \mathrm{pp} \text { decrease in employment } \\
\text { likelihood }\end{array}$ & Q & PCS & Individual & US \\
\hline 3 & $\begin{array}{l}\text { Depew } \\
(2015)\end{array}$ & - and 0 & $\begin{array}{l}2.65 \mathrm{pp} \text { decrease in the likelihood of } \\
\text { full-time work ( } 3.7 \mathrm{pp} \text { decrease for } \\
\text { women and } 2.24 \mathrm{pp} \text { decrease for } \\
\text { men) } \\
\text { No effect on labour supply } \\
\text { participation for men } \\
1.5 \text { pp decrease in labour supply } \\
\text { participation for women }\end{array}$ & Q & Panel & Individual & US \\
\hline 4 & $\begin{array}{l}\text { Dahlen } \\
(2015)\end{array}$ & - & $\begin{array}{l}\text { Aging out (dependant coverage } \\
\text { dis-enrollment at the cut-off } 26 \text { years } \\
\text { old) is associated with } \\
7.9 \text { pp increase in employment } \\
\text { likelihood for all; } \\
9.7 \text { pp increase in the share of labour } \\
\text { market participation for men }\end{array}$ & Q & PCS & Individual & US \\
\hline
\end{tabular}

\section{Health insurance and labour supply of people with health impairments}

Table 2.4 summarises the results of three papers from the US on the labour supply effects for people with health impairments. Labour supply of people with health impairments seems sensitive to the link between health coverage and employment. Employment-linked health insurance tends to keep them staying in employment to avoid coverage loss in 
the face of future health costs. The effect is positive for cancer survivors (Tunceli et al., 2009) and people with other health impairments (Bradley et al., 2012). However, if health insurance is not tied to employment, health insurance is more likely to reduce labour force participation. This is the finding of Page (2011) who evaluated the impact of the US's Medicare expansion which increases medication coverage for newly recovered kidney transplant patients although this specific medical coverage might not reflect the effect of general health insurance. The two behaviours are straightforward as people with health problems often depend heavily on health insurance while the incentive to work is negatively affected by their health status. However, the limited number of studies on this issue prevents us from drawing an unequivocal conclusion, therefore the evidence is preliminary and merely serves as a suggestion for further research.

Table 2.4: Health insurance and labour supply of people with health impairments

\begin{tabular}{|c|c|c|c|c|c|c|c|}
\hline No. & Study & Effect sign & Effect size & Method & Data & $\begin{array}{l}\text { Level of } \\
\text { analysis }\end{array}$ & Country \\
\hline 1 & $\begin{array}{l}\text { Tunceli et al. } \\
(2009)\end{array}$ & + & $\begin{array}{l}23.6-32.1 \text { pp decrease in exit } \\
\text { likelihood for men } \\
13.9-16.9 \text { pp decrease in exit } \\
\text { likelihood for women } \\
34.7-42.2 \text { pp decrease in the } \\
\text { likelihood of job change } \\
\text { for men } \\
19.1 \text { - } 28 \text { pp decrease in the } \\
\text { likelihood of job change } \\
\text { for women }\end{array}$ & $\mathrm{Q}$ & Panel & Individual & US \\
\hline 2 & Page (2011) & - & $\begin{array}{l}10 \% \text { increase in coverage amount } \\
\text { leads to } 0.8-2.3 \text { pp decrease of } \\
\text { employment likelihood }\end{array}$ & Q & Panel & Individual & US \\
\hline 3 & $\begin{array}{l}\text { Bradley et al. } \\
(2012)\end{array}$ & + & $\begin{array}{l}30 \mathrm{pp} \text { increase in the likelihood } \\
\text { to stay in employment }\end{array}$ & $\mathrm{Q}$ & Panel & Individual & US \\
\hline
\end{tabular}

\section{Health insurance and labour supply of public assistance recipients}

Table 2.5 summarises the findings on the effects of health insurance on labour supply of assistance recipients who are mainly low income adults with dependants (i.e. single mothers). We have 14 papers in total, 13 of which are from the US and investigate health assistance schemes such as Medicaid or Children's Health Insurance Program (CHIP) ${ }^{1}$ or state-level health insurance interventions.

The US-based evidence is mixed (see Table 2.5). Interestingly, if zooming in on individual programmes, we see that the results are ambiguous even within the same programme. For instance, the labour supply effect of Medicaid introduction and expansion is negative

\footnotetext{
1 Medicaid in the US is a joint federal and state programme that provides low income earners with free health insurance. CHIP is an insurance programme that provides health coverage to eligible children though Medicaid and separate CHIP schemes.
} 
(Rosen, 2014; Dave et al., 2015), insignificant (Ham and Shore-Sheppard, 2005; Strumpf, 2011; Gooptu et al., 2016) or both (Montgomery and Navin, 2000; Yelowitz, 2003). Notably, these studies have many things in common: they use the same data source (Current Population Survey), share rather similar methods (almost all of them combine different methods such as DD or DDD or panel techniques, with one exemption being a paper by Ham and Shore-Sheppard (2005) that uses a Tobit model) and mostly adopt a similar definition of labour supply in terms of probability of employment or hours worked. One possible explanation for the mixed findings is that these studies cover different periods ranging from 1963-1975 in Strumpf (2011) to the most recent 2005-2015 period in Gooptu et al. (2016). Additionally, the studies vary slightly in the research subject: married women (Yelowitz, 2003), single women (Strumpf, 2011) or single mothers (Ham and Shore-Sheppard, 2005; Rosen, 2014), women with dependants irrespective of marital status (Montgomery and Navin, 2000), pregnant women (Dave et al., 2015) or the poor in general (Gooptu et al., 2016). What we can conclude is that different groups of low-income assistance recipients tend to react differently to Medicaid expansion. Similarly, the effect of CHIP on the labour supply of women is mixed (Tomohara and Lee, 2007; Lee and Tomohara, 2008). However, a closer look into the demographics reveals some evidence that non-white women tend to work less hours (Tomohara and Lee, 2007) or reduce labour participation (Lee and Tomohara, 2008) while the effect for white women are statistically insignificant (Tomohara and Lee, 2007; Lee and Tomohara, 2008). The authors explain that non-white married women tend to reduce labour supply just to make their children qualified for the benefits (Tomohara and Lee, 2007; Lee and Tomohara, 2008).

Affordable Care Act (ACA) ${ }^{2}$ and other state-level expansions of public health schemes tend to create a disincentive to work for less educated adults (Garthwaite et al., 2014) and low-income and childless adults (Guy et al., 2012; Dague et al., 2017). These, consistent with theoretical predictions, imply sizeable labour supply distortion of public health insurance expansions to low-income adults (Guy et al., 2012; Garthwaite et al., 2014; Dague et al., 2017). There is scarce evidence on this aspect outside the US. A paper in Uruguay (Bergolo and Cruces, 2014) that delves into the extension of health coverage to dependent children of registered private sector workers reports that people tend to increase their labour supply in the benefit-eligible employment sector to make their children eligible for health insurance. However, this is the only study on this topic outside the US.

\footnotetext{
2 Affordable Care Act, shorthand of the Patient Protection and Affordable Care Act, is a federal law introduced under the Obama Administration in 2010 to expand the eligibility of health insurance programmes in the US. The aim was to improve health insurance coverage and ensure quality, affordable healthcare for all Americans. The program is often informally referred to as Obamacare.
} 


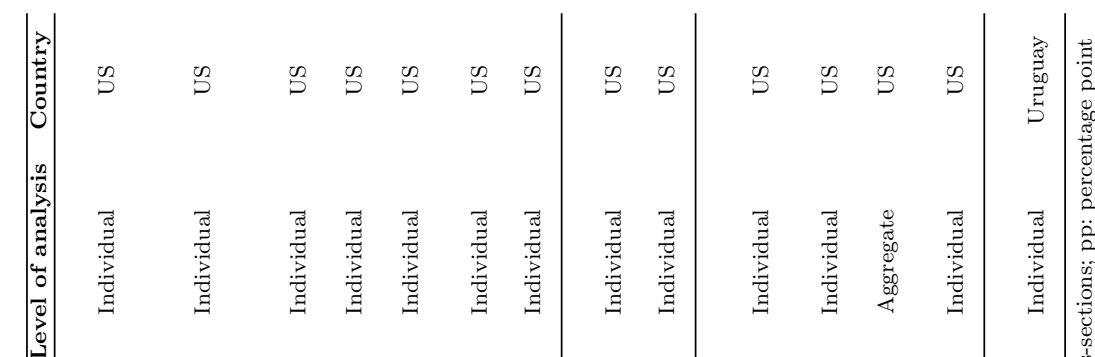

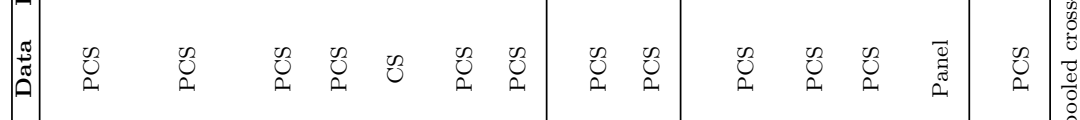

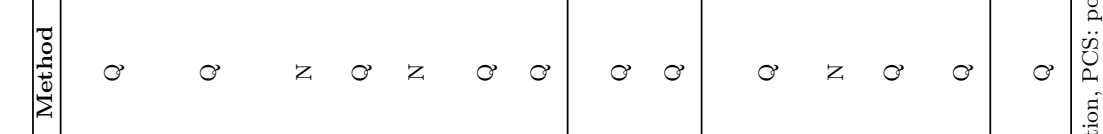

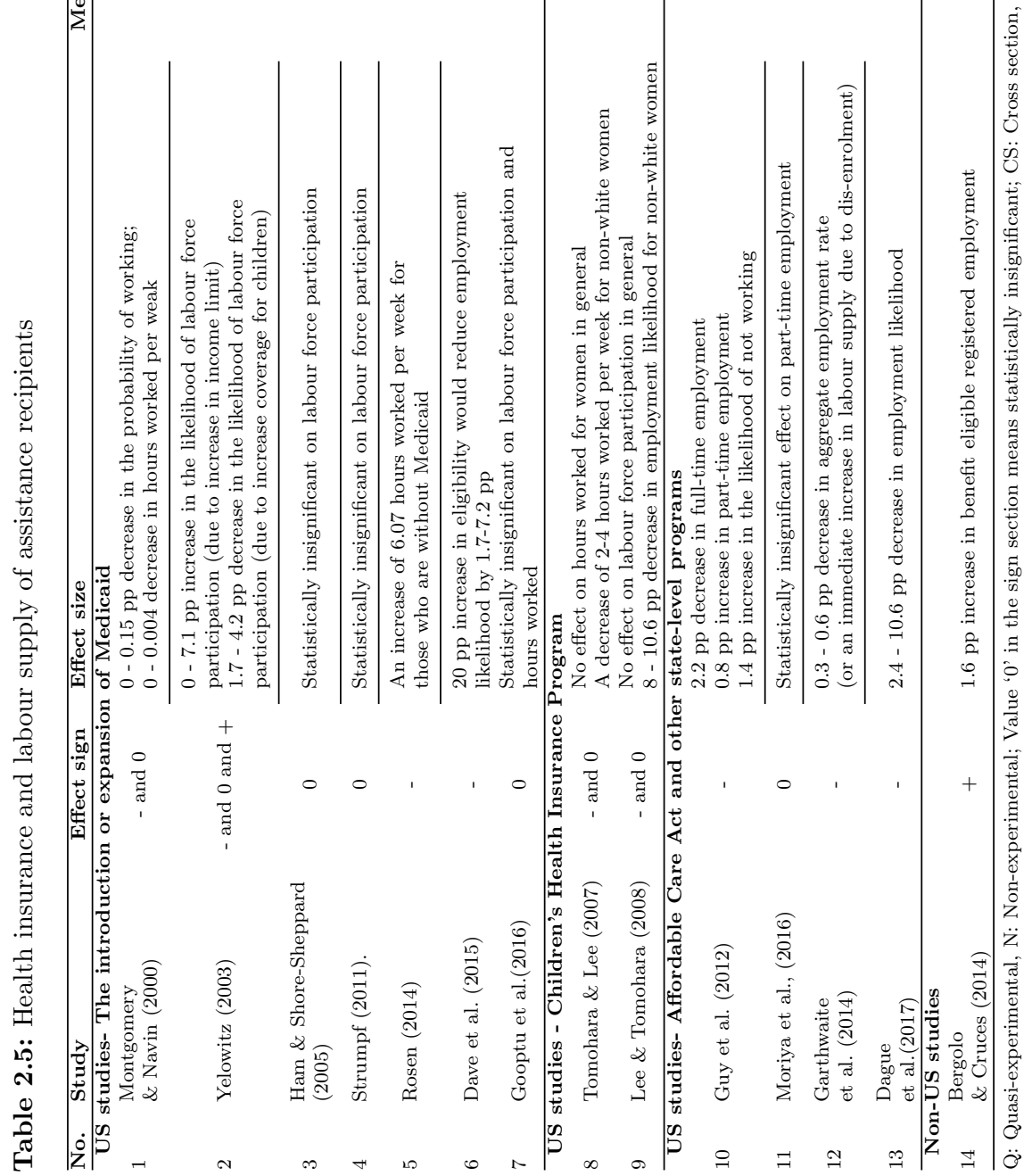




\section{Labour supply effects of universal health coverage}

Studies on the labour supply effects of moving towards UHC are summarized in Table 2.6 The results are mixed, varying between negative (Chou and Staiger, 2001; Kan and Lin, 2009), statistically insignificant (Chou et al., 2002), positive (Wagstaff and Manachotphong, 2012) or both negative and statistically insignificant (Liao, 2011). The result for Taiwan is relatively puzzling as the four studies examine the same UHC expansion in 1995 and use the same data source (three out of four Taiwan-based studies employ the Survey of Family Income and Expenditure) yet yield different results. This is probably explained by the difference in data range used and research subjects. The positive case of Thailand is rather interesting as a lesson learned on how to trigger positive labour market effects while expanding health coverage universally. In-depth examination of the Thailand case reveals that the Thai UHC reform in 2001 is not fully universal as it merely targets formal employees first. The reform can thus incentivise working-age household members to seek formal jobs and participate in the labour market (Wagstaff and Manachotphong, 2012). This is why the largest effect size is observed for Thai married women, who were more likely to work less before the reform (ibid.).

Table 2.6: Universal health insurance coverage and labour supply effects

\begin{tabular}{|c|c|c|c|c|c|c|c|}
\hline No. & Study & $\begin{array}{l}\text { Effect } \\
\text { sign }\end{array}$ & Effect size & Method & Data & $\begin{array}{l}\text { Level of } \\
\text { analysis }\end{array}$ & Country \\
\hline 1 & $\begin{array}{l}\text { Chou \& } \\
\text { Staiger } \\
(2001)\end{array}$ & - & $\begin{array}{l}4 \text { pp decrease in the employment } \\
\text { probability of married women }\end{array}$ & $\mathrm{N}$ & PCS & Individual & Taiwan \\
\hline 2 & $\begin{array}{l}\text { Chou } \\
\text { et al. } \\
(2002)\end{array}$ & 0 & $\begin{array}{l}\text { Statistically insignificant effect } \\
\text { on labour supply of married women }\end{array}$ & $\mathrm{Q}$ & PCS & Individual & Taiwan \\
\hline 3 & $\begin{array}{l}\text { Kan \& } \\
\text { Lin } \\
(2009)\end{array}$ & - & $\begin{array}{l}\text { Decrease of } 2 \text { work hours per } \\
\text { week for private sector employees }\end{array}$ & $\mathrm{Q}$ & PCS & Individual & Taiwan \\
\hline 4 & $\begin{array}{l}\text { Liao } \\
(2011)\end{array}$ & -and 0 & $\begin{array}{l}17.8-21.7 \text { pp reduction in labour } \\
\text { force participation of married women } \\
\text { in the second income quartile } \\
\text { No significant effect for other income } \\
\text { groups }\end{array}$ & $\mathrm{Q}$ & PCS & Individual & Taiwan \\
\hline 5 & $\begin{array}{l}\text { Wagstaff \& } \\
\text { Manachot } \\
\text {-phong(2012) }\end{array}$ & + & $\begin{array}{l}3.3-7 \mathrm{pp} \text { increase in employment } \\
\text { for single men; } \\
2.3-7.5 \text { pp increase in employment } \\
\text { for single women; } \\
6.1 \text { - } 11.6 \text { pp increase in employment } \\
\text { for married women }\end{array}$ & $\mathrm{Q}$ & Panel & Individual & Thailand \\
\hline
\end{tabular}

Q: Quasi-experimental, N: Non-experimental, UHC: Universal heal coverage expansion, PCS: pooled cross-sections, pp: percentage point.

The remaining studies which do not fit in any of the above categories are presented in Table 2.7. As suggested, this collection is extremely fragmented. However, we still observe several important trends. First, as a worrying trend, the expansion of social health insurance in Eastern Europe and Central Asia during 1990-2004 has been associated with an increase in unemployment (Wagstaff and Moreno-Serra, 2007) and a decline in the employment ratio (Wagstaff and Moreno-Serra, 2007, 2015). Second, in the US where health insurance is mainly tied to employment, any increase in health insurance premiums is related to an increase in unemployment (Baicker and Chandra, 2005) and a decrease in the number of hours worked (Baicker and Chandra, 2005, 2006). 


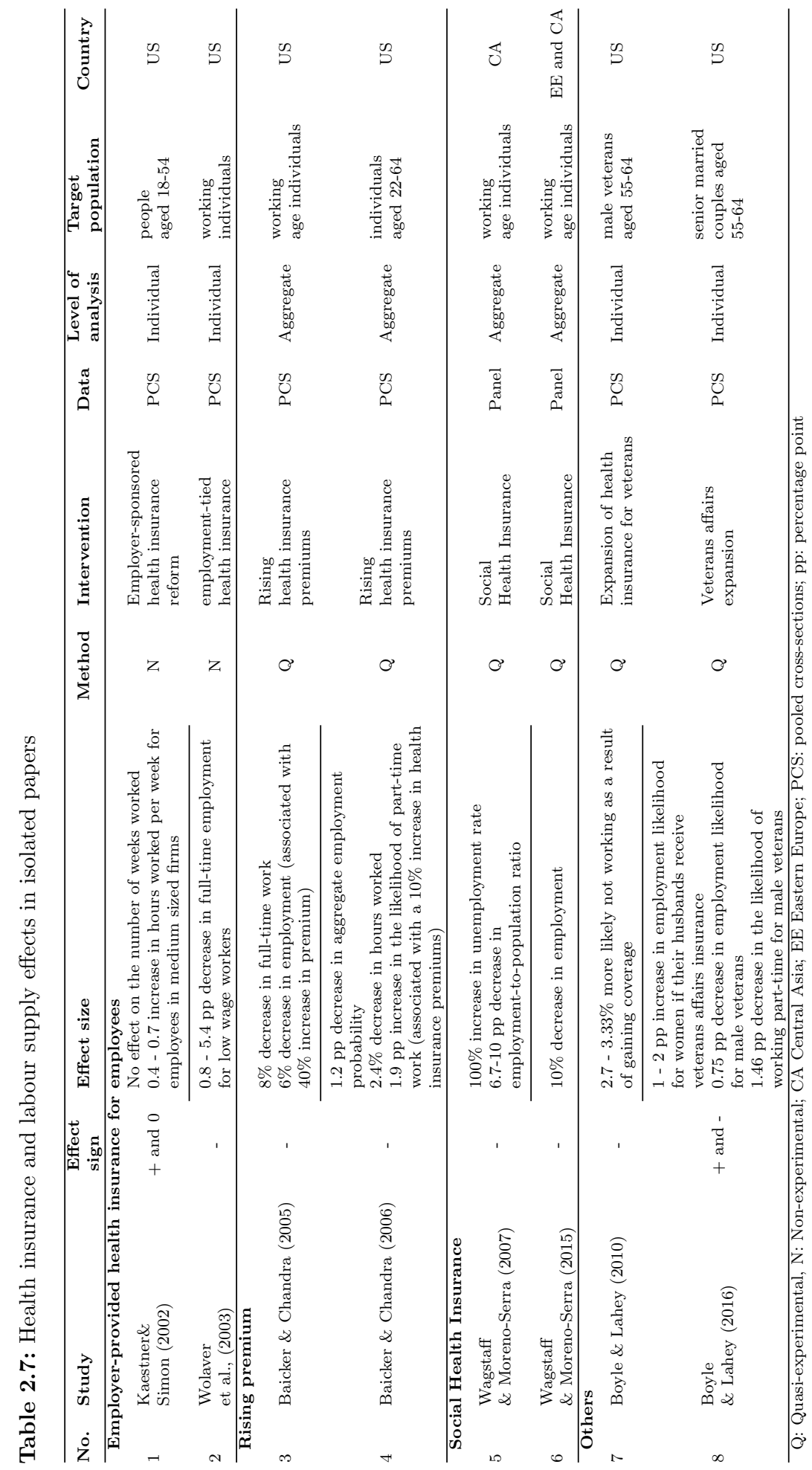




\subsubsection{Health insurance and self-employment}

Table 2.8 presents the findings of studies on the relationship between health insurance and self-employment. Unsurprisingly, a dominant number of studies are from the US (14 out of 16). Healthcare or tax reforms that increase tax deductibility or provide tax subsidies for the self-employed tend to increase the probability of self-employment in the US (Heim and Lurie, 2010; Gurley-Calvez, 2011; Velamuri, 2012; Gumus and Regan, 2015). Interestingly, the contradicting effect signs do not conflict but complement each other and provide varied insights from distinctive angles. On the one hand, general coverage expansion is positively correlated with self-employment (Niu, 2014; DeCicca, 2007; Becker and Tuzemen, 2014). On the other hand, entrepreneurship lock which implies a negative effect of employment-linked insurance on self-employment (Fairlie et al., 2011; Zissimopoulos and Karoly, 2007) is evidenced. We also find preliminary evidence of a self-employment effect of dependant coverage (Bailey, 2013; Jia, 2014) and spousal coverage (Wellington, 2001; Gai and Minniti, 2015) but the results are rather mixed and the number of existing studies on this topic is relatively thin.

We found only two publications outside the US, one for Central Asia (Wagstaff and Moreno-Serra, 2015) and the other for Germany (Fossen and König, 2017). These two papers fall into the two literature strands described above. Fossen and König (2017) find entrepreneurship lock in a public health insurance system in Germany where public health insurance is mandatory for public sector workers but not for the self-employed, whereas social health insurance expansions in Eastern Europe and Central Asia seem to increase self-employment.

In summary, the relationship between health insurance and self-employment strongly depends on whether health insurance is linked to employment. We find evidence both inside and outside the US for entrepreneurship lock and entrepreneurship push. Additionally, tax reforms that reduce insurance premiums seem to promote self-employment. 


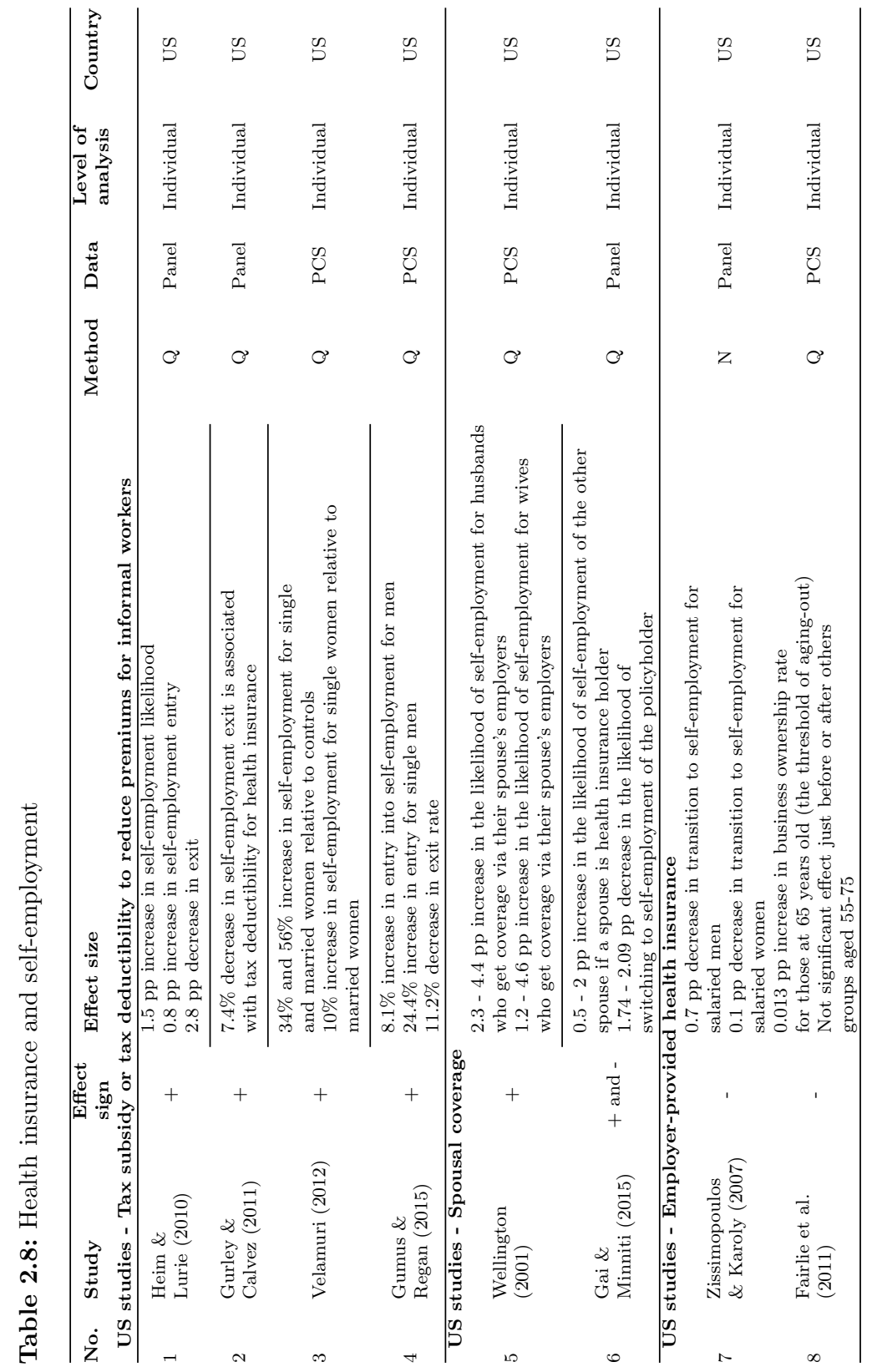




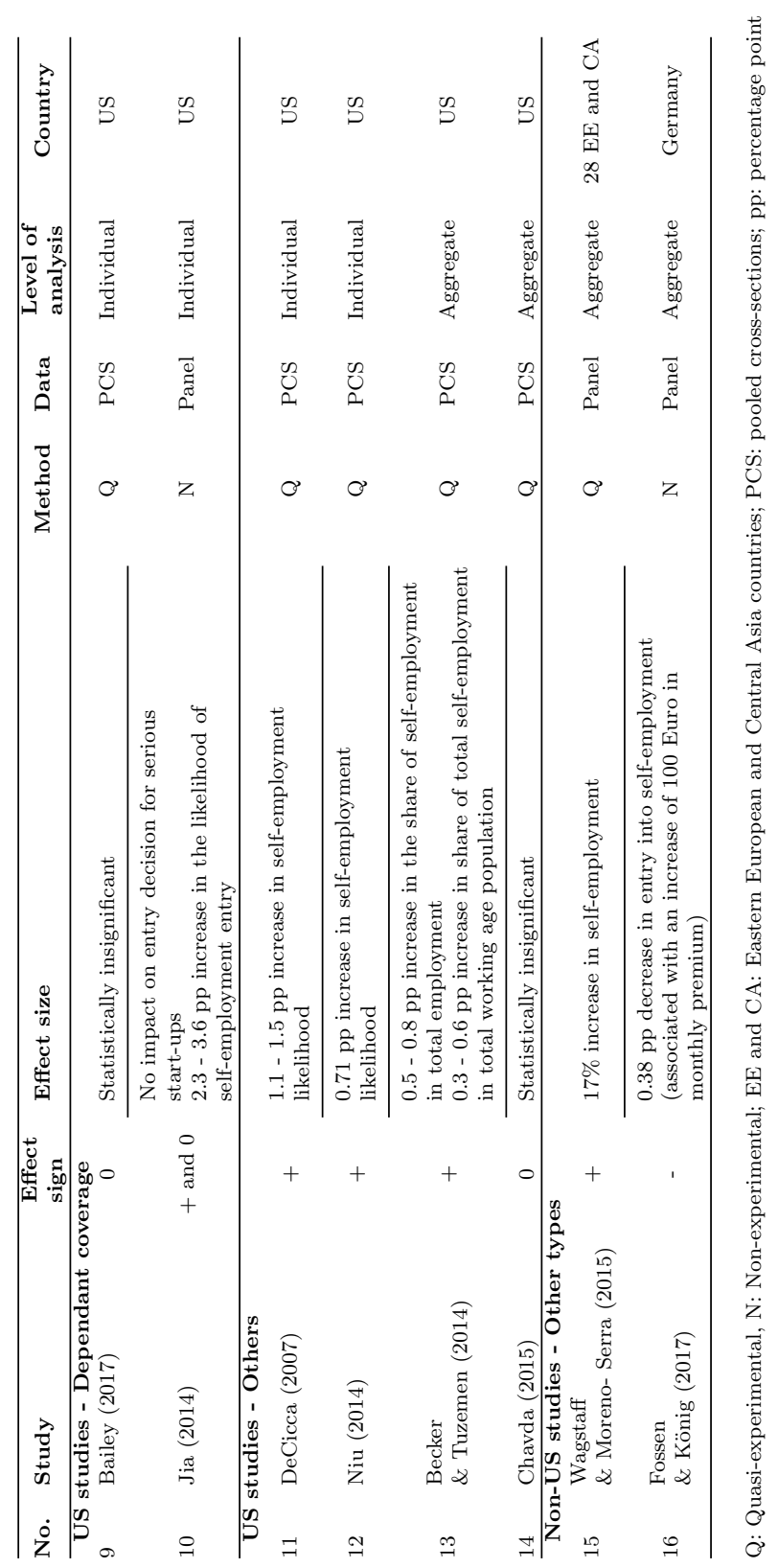




\subsubsection{Health insurance and economic formalisation}

The ten studies found on informal work are summarised in Table 2.9, which shows that the effects are not uniform. In Thailand, effects of UHC on economic formalisation differ across population groups (Wagstaff and Manachotphong, 2012). Two papers in Mexico (Aterido et al., 2011; Bosch and Campos-Vazquez, 2014) find that the Seguro Popular programme, which provides non-contributory health insurance for informal sector workers, reduces the inflow into formal employment. This result is expected and consistent with the case of Columbia (Camacho et al., 2014). The other two papers on the same programme, however, report statistically insignificant results (Campos-Vazquez and Knox, 2013; Azuara and Marinescu, 2013). This inconsistency is explained by the difference in data periods as well as the research subjects. In particular, the programme does not have any effect on the likelihood of working informally (Azuara and Marinescu, 2013) nor transition into informal sector (Campos-Vazquez and Knox, 2013) of urban individuals. In contrast, it appears to reduce the likelihood of working informally at both individual and household levels (Aterido et al., 2011) and the number of registered small and medium enterprises in Mexico (Bosch and Campos-Vazquez, 2014).

Another trend is that people move into the sector where health insurance is available. The healthcare reform in Uruguay which extended coverage to registered workers' children successfully pushed people to move into the formal sector (Bergolo and Cruces, 2014). Similarly, farm households in the US allocate more of their time to off-farm work, which is more likely in formal and bigger firms, to get employer-provided health coverage (Ahearn et al., 2013). If health insurance is not linked to employment as in the case of Taiwan's UHC reform, labour supply of farm households' wives in off-farm jobs tends to decline (Liao and Taylor, 2010). Indeed, it is difficult to draw a definite conclusion about the effect of health insurance on economic formalisation, especially in LMIC because of the fragmented and limited number of studies. 


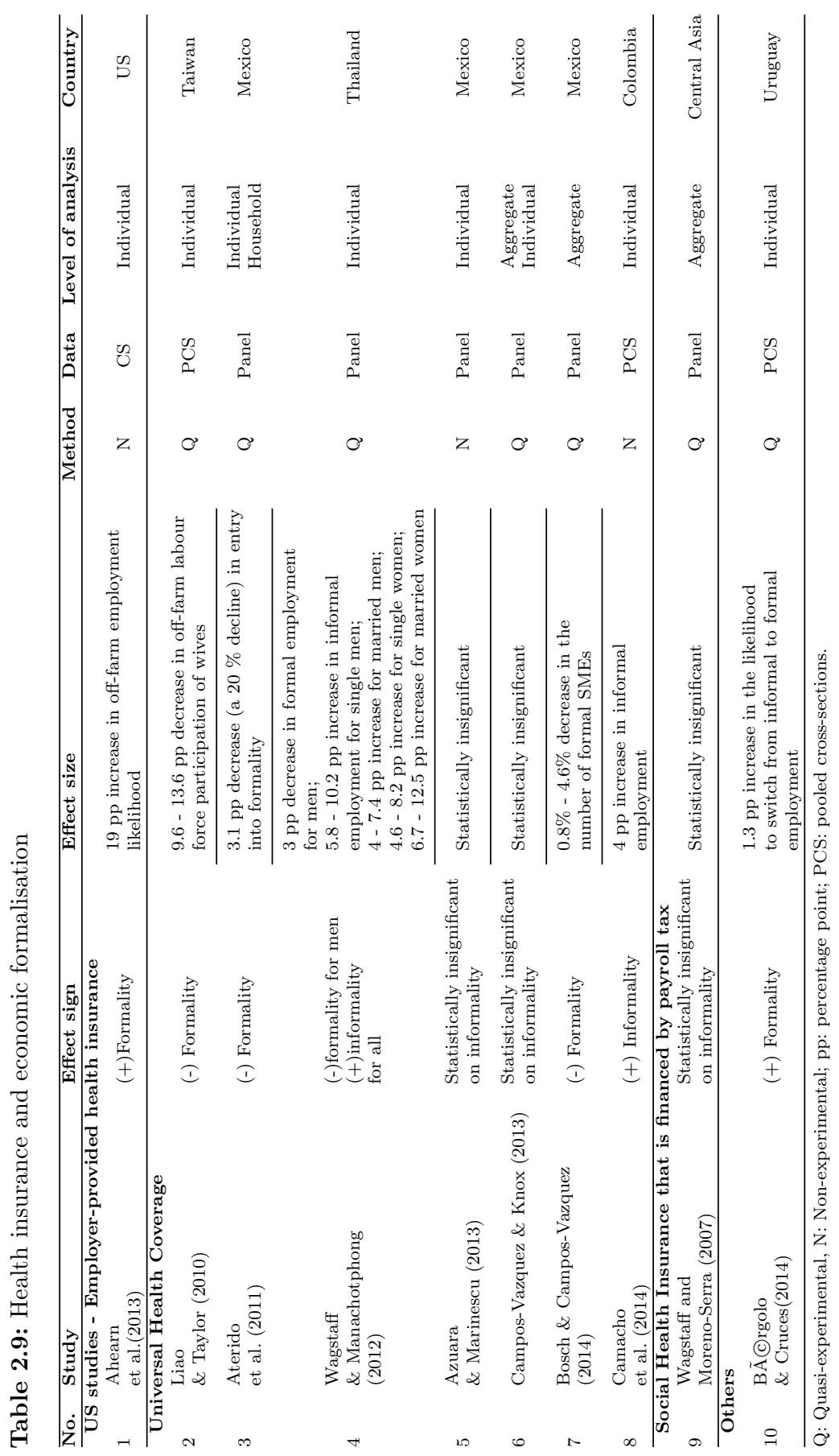




\subsection{Discussion}

This study reviews the existing literature on the labour market effects of health insurance from the supply side. We find that the studies are dominantly about the US, suggesting a large knowledge gap in other countries, especially in LMIC where health coverage is expanding. We show that the employer-provided health insurance system in the US has a strong impact on labour supply. We confirm findings by Gruber and Madrian (2002) and Madrian (2006) that: i) spousal coverage is associated with reduced labour supply of secondary earners, and ii) the labour supply effect of social assistance recipients of Medicaid is ambiguous. Importantly, at the time of these reviews, their collection mostly included papers on Medicaid. More than a decade later, we see that the literature on social assistance recipients has been expanded to also cover other programmes including CHIP, ACA and other state-level interventions. We have preliminary evidence that non-white low income women tend to reduce their labour supply to keep their children qualified for CHIP (Tomohara and Lee, 2007; Lee and Tomohara, 2008), whereas ACA and similar schemes seem to create a disincentive to work for low-income adults who are normally ineligible for normal public health insurance (Guy et al., 2012; Garthwaite et al., 2014; Dague et al., 2017).

Additionally, by focusing on more recent studies with more advanced econometric techniques, we find that the effect size of spousal health insurance is much smaller after controlling for unobserved heterogeneity (Cebi and Wang, 2013). The disincentive to work for secondary earners in the US is as expected and consistent with theoretical predictions based on the income effect. However, it might be more interesting to analyse the phenomenon in tandem with intra-household labour supply decision making to better understand the underlying mechanisms of this result. This evidence might be a suggestion for future studies on secondary earners in less developed countries where health coverage is expanding.

The institutional link between health insurance and employment, which strongly affects labour supply and self-employment decisions, provides important policy implications in view of the human rights-based movement for UHC. The mixed results of studies on Medicaid recipients combined with preliminary evidence of labour supply distortion by CHIP and Affordable Care Act seem consistent with the current theoretical debate. Notably, the results show mostly mixed results that vary between negative and insignificant effects, implying that the potential positive effect induced by improved health on productivity (if any) is not strong enough to dominate the income effect. Given the current theoretical debate and the mixed empirical results, we can conclude that more research is needed. It is also interesting to examine the mechanisms through which low income people react to health insurance availability and expansion. Previous studies have suggested that Medicaid recipients either reduce their labour supply (Rosen, 2014; Dave et al., 2015) or are not really affected by health insurance coverage (Ham and Shore-Sheppard, 2005; Strumpf, 2011) or both (Montgomery and Navin, 2000; Yelowitz, 2003). It is, however, unknown how, and under which circumstances, they would react differently as the difference in the data range and target population do not seem to explain all the variation in the effect sign. This topic is very relevant for LMIC where government-provided social protection is 
expanding for the poor and the disadvantaged in response to UHC and human rights-based movements.

The fragmentation and scarcity of studies on economic formalisation and self-employment in LMIC are notable. Additionally, the evidence of reduced employment (Wagstaff and Moreno-Serra, 2007, 2015) and increased unemployment (Wagstaff and Moreno-Serra, 2015) induced by social health insurance in Central Asia and Eastern Europe may serve as a trigger for further research to address the concern about these undesirable effects. Importantly, there seems to be an implicit assumption in the labour supply literature that working more is better while working conditions are mostly ignored. Even though increasing aggregate labour supply is good for economic growth, there is increasing concern about the rise of precarious and non-standard employment which is often associated with labour insecurity and negative health outcomes (Quinlan et al., 2015). Therefore, the working-more-is-better assumption should be carefully contextualised in policy making to avoid unintended social impacts on employees.

This study complements previous reviews in many ways. While previous reviews have mainly focused on the US, this review moves beyond that to bring new insights from elsewhere. Additionally, our study is conducted in a systematic way, providing a transparent search procedure which makes the results reproducible. By focusing on studies published after 2000, our reviewed studies address methodological issues in the pre-2000 literature and form a more varied collection. One important caveat raised by Gruber and Madrian (2002) is that almost all of the spousal coverage studies before 2000 assume that husband's employer-provided health insurance coverage is exogenous, which is not necessarily true. The exogeneity assumption is problematic as couples can make joint labour supply and employment choices (Gruber and Madrian, 2002) and because unobserved characteristics can be correlated with spousal health insurance via assortative mating (Murasko, 2008; Royalty and Abraham, 2006). Another limitation of the pre-2000 studies lies in data constraints where some of them used cross-sectional data (e.g. Olson, 1998; Buchmueller and Valletta, 1999) and hence could not adequately address the issue of unobserved heterogeneity. These issues were addressed by later studies included in our review. For instance, Royalty and Abraham (2006) addressed the endogeneity issue caused by assortative mating by allowing health insurance of both spouses to be endogenous and used 'paid sick leave' as an instrument. Kapinos (2009) followed Olson (2002) and employed husband's union status and firm size as instruments for health coverage. Alternatively, Murasko (2008) and Zimmer (2010) used panel data techniques while Cebi and Wang (2013) employed different approaches from cross-sectional data techniques, instrumental variables to panel data specifications to account for both unobserved heterogeneity and endogeneity.

Regarding the quality and robustness of the reviewed papers, we observe that a majority (47 out of 63) use quasi-experimental techniques. Additionally, there is no severe case of methodological sensitivity except the inconsistency in studies of Medicaid in the US (see Table 2.5) and Taiwan's UHC (see Table 2.6). The variations are, however, explained by the variation in the target population and data periods. Therefore, our removal of the publication filter (while many reviews normally include only studies published in peer-reviewed journals) manages to guarantee the internal validity of this synthesis. It is important to emphasise that methodologies used by the studies reviewed vary while the 
findings are compiled mainly based on the effect size and magnitude. It is unnecessary and impossible to evaluate each study separately on the risk of bias. The dominance of the US studies remains one of the main limitations of our study, especially if we aim to inform policy making in LMIC. Therefore, the evidence reviewed may not be able to provide many lessons learned for LMIC where health insurance is not usually provided by employers. However, this once again highlights the need for more research in LMIC on the topic.

\subsection{Conclusion}

This review finds that the effects of health insurance on labour supply have been mostly studied in the US, highlighting a real literature gap on this topic in other parts of the world. Therefore, the synthesis of the most recent literature can only provide a partial picture mostly applicable to the US and some other isolated cases. Given the diversity of insurance schemes in different healthcare systems, we examine the effect by type of health insurance with its specific target population. There are six conclusions we can draw from the review. First, spousal coverage in the US seems to induce a disincentive to work for secondary earners, who are, in most cases, wives. However, the effect becomes smaller after applying more advanced econometric techniques. Second, we have preliminary evidence that dependent young adults in the US who can access health insurance via their parents' employers reduce their work hour as they are less likely to participate in full-time employment. On the other hand, this group tends to increase their employment when ageing out of this benefit. Third, we find preliminary evidence that labour supply of people with health impairments is sensitive to the link between health coverage and employment, which tends to keep them staying at work to avoid coverage loss in the face of future health costs while discouraging them to work if they have no health coverage. Fourth, the labour supply effects of health insurance on Medicaid recipients in the US are ambiguous and relatively debatable because the findings are mixed and inconsistent even within one programme. However, we have some evidence of labour supply distortion caused by CHIP and ACA. Fifth, tax subsidies seem to be a good policy tool for entrepreneurship promotion while employment-linked insurance can create 'entrepreneurship lock' in the US. General health coverage expansion which removes the link between employment and insurance seemingly boosts self-employment. Outside the US, preliminary evidence of entrepreneurship push and entrepreneurship lock is reported but more research is recommended. Sixth, universal coverage may create both an incentive and a disincentive to work depending on the design of the system. Finally, evidence on the relationship between health insurance and the level of economic formalisation in LMIC is fragmented and limited, making it difficult to draw any definite conclusion. 


\section{Annexes}

\section{Annex 2.1: Databases' coverage and their pros and cons}

This Annex provides information on coverage as well as pros and cons of three main databases used for the search, i.e. Web of Science, Google Scholar, Pubmed. This is to justify our choice of databases employed. Web of Science (WoS) has been for long considered by bibliometrics researchers as one of the main sources of science, social science, arts and humanities literature. The site is an online academic database presently owned by Thomson Reuters. On its website, Web of Science proclaims to integrate other important databases such as Elsevier's ScienceDirect, JSTOR, and MEDLINE and many other nonEnglish databases like Chinese Science Citation Database, KCI Korean Journal Database and SciELO Citation Index which covers Brazil, Spain, Portugal, the Caribbean and South Africa, and more than 12 countries in Latin America. This database, however, is limited to journal publications and hence excludes other forms of publication like working papers, books, conference papers, and so on.

As a growing alternative source to WoS, Google Scholar has become widely used as it covers various sorts of information rather than journal papers like conference proceedings, theses, reports, working papers, books and book chapters. The inclusion of Google Scholar besides WoS is to ensure that we do not miss out on non-journal studies (for example working papers, book chapters). We also include working paper sources (NBER, ECONSTOR, IDEAS, IZA, CEPR, SSRN, World Bank Working Paper Series) to ensure an extensive reach of the search.

Finally, Pubmed is a frequently used source for medical literature search. It is a service of American National Library of Medicine that provides free access to MEDLINE, the database of indexed citations and abstracts to medical, nursing, dental, veterinary, health care, and preclinical sciences journal articles. Plus, PubMed can be viewed as a parent set of MEDLINE as it also includes additional selected life sciences journals not in MEDLINE. The inclusion of PubMed in addition to Web of Science, which is comprised of MEDLINE, is to ensure that we would not miss anything on medical literature. 
Annex 2.2: Key terms used in the search

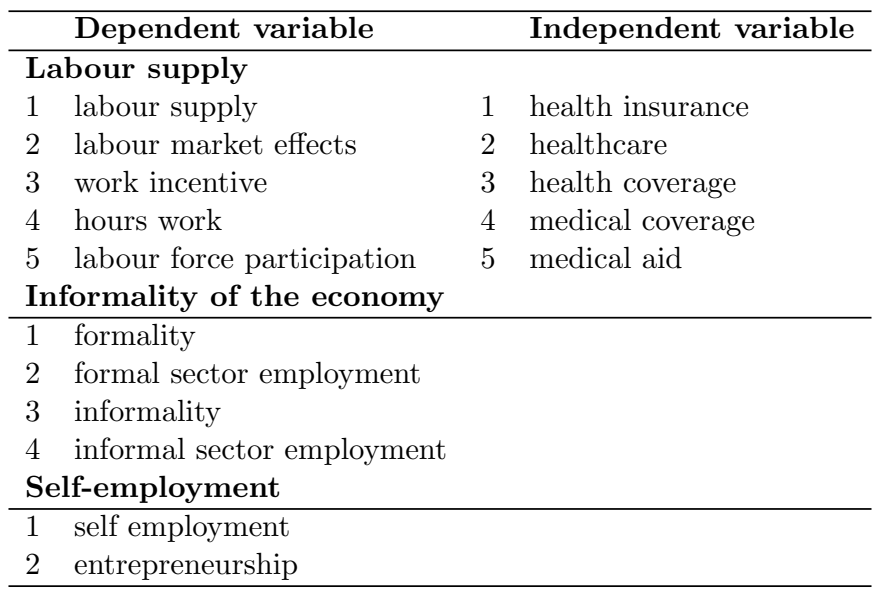



Chapter 3

\section{Effects of health insurance on labour supply in Vietnam}

\section{This chapter is based on}

Lê, N., Groot W., Tomini, S.M., and Tomini, F. (2017). Effects of health insurance on labour supply: Evidence from the health care fund for the poor in Vietnam. Applied Economics. DOI: https://doi.org/10.1080/00036846.2019.1613509 


\begin{abstract}
The expansion of health insurance in emerging countries raises concerns about the unintended negative effects of health insurance on labour supply. This chapter answers the second research question by examining the labour supply effects of the Health Care Fund for the Poor in Vietnam in terms of the number of hours worked per month and labour force participation (the probability of employment). Employing various matching methods combined with a Difference-in-Differences approach on the Vietnam Household Living Standard Surveys 2002-2006, we show that the Health Care Fund for the Poor, which aims to provide poor people and disadvantaged minority groups with free health insurance, has a negative effect on labour supply. This is manifested in both the average number of hours worked per month and the probability of employment, suggesting the income effect of the programme. Interestingly, the effects are mainly driven by the non-poor recipients living in rural areas, raising the question of the targeting strategy of the programme.
\end{abstract}




\subsection{Introduction}

The expansion of public health insurance to the poor and vulnerable has received a large amount of attention because of its potential effects on reducing catastrophic out-of-pocket spending and increasing access to health care (Lagomarsino et al., 2012). Such impacts are particularly important for the poor who normally cannot afford to pay out-of-pocket. These are hence especially desirable for many LMIC with a large proportion of poor population who normally do not have the financial resources to buy health insurance (ibid.). Many emerging economies in Asia, Latin America and Africa are making progress towards Universal Health Coverage (UHC) to reduce the financial hardship for those seeking health care (Rodin and de Ferranti, 2012; Lagomarsino et al., 2012). The momentum on achieving UHC is rather strong as many countries have increased or committed to increasing government spending on total health expenditure (Lagomarsino et al., 2012). The ambition towards UHC has also received support and active participation from important donors and international organizations (ibid.).

However, there have been concerns about the unintended labour market consequences of health insurance in general and health insurance for the low income population in particular. For instance, it has been shown that social health insurance expansion in East Europe and Central Asia during 1990-2004 has been associated with higher unemployment (Wagstaff and Moreno-Serra, 2009) and reduced aggregate employment (Wagstaff and Moreno-Serra, 2015) while increasing the aggregate share of self-employment (ibid.). Even though the authors failed to control for political changes which potentially caused unemployment, their findings provoked some debate on the potential negative impacts of health insurance on the labour market.

In the context of the UHC movement, there has been a renewed interest in the labour supply effects of health insurance. However, there is currently inadequate and inconclusive evidence on the topic. The systematic review in Chapter 2 suggests that empirical evidence on this topic in LMIC is relatively scarce and sporadic. The existing literature on the labour supply effects of pro-poor health insurance programmes is mainly represented by studies on the American healthcare system, where the evidence is mixed (Chapter 2), whereas the evidence beyond the US is very limited (ibid.). This creates a knowledge gap, especially for LMIC where health insurance coverage is expanding. Therefore, to fill this gap, it is necessary to seek for more evidence to guide policy making. For Vietnam, this is crucially relevant as health coverage is being expanded rapidly with assertive political commitment which has been translated into recent legal documents such as the Health Insurance Law versions of 2008 and 2014. In its latest strategic document, the government aims at a coverage rate of more than 90 percent by 2020 (Socialist Republic of Vietnam, $2016 b)$.

This chapter answers the second research question by investigating the effects of the Health Care Fund for the Poor (hereafter, HCFP) on the labour supply of the beneficiaries in Vietnam. Using pre-treatment matching techniques combined with a Difference-inDifferences approach on a panel of Vietnam Household Living Standards Surveys (VHLSS) during 2002-2006, we evaluate the labour supply effects of the programme in terms of 
monthly work hours and the probability of working. We separate the effects for urban and rural individuals as well as the poor and non-poor people among the treated individuals. This chapter contributes to filling the gap in our knowledge on the impact of health insurance on the labour supply and presents empirical evidence on this sporadically researched topic in the context of LMIC.

\subsection{Literature Review}

The potentially distorting effects of health insurance and welfare benefits have been discussed thoroughly in theory. The budget constraint approach argues that governmentprovided health insurance, as financed by tax, is similar to a welfare benefit and hence can be considered as a positive income shock for low income individuals and those who have high health expenses (Boyle and Lahey, 2010). Therefore, a non-contributory health scheme may reduce labour supply due to the income effect. Similarly, the static labour supply theory states that individuals make a trade-off between labour supply and leisure at a given wage level (Chou and Staiger, 2001; Rosen, 2014). Therefore, the provision of welfare benefits increases household income but also potentially reduces labour force participation (Rosen, 2014). Importantly, as argued by Chou and Staiger (2001), the income effect of non-contributory health insurance may be stronger than that of other welfare benefits as it not only increases income (in the form of the subsidy) but also reduces variation in consumption resulting from the removal of unexpected catastrophic health expenses. Therefore, compulsory health insurance which is not tied to employment may make paid work less attractive due to the consumption smoothing (Chou and Staiger, 2001). The magnitude of the income effect, however, depends on the share of health expenses in total household expenses (ibid.).

Despite being used widely, these theories implicitly use a broad definition of welfare benefits which also includes public health insurance. Therefore, the income effect of health insurance is viewed similarly to that of other social transfers which normally have a more direct income push. In the context of LMIC, this direct income effect of public health insurance is not always as obvious as in the case of cash transfers due to the negligible health premiums of many public schemes (e.g. in Vietnam the annual premium of health insurance for the poor in 2003 under HCFP was little more than 2.5 USD). Besides, the assumption of removal of catastrophic health costs is not always warranted, as this depends on the depth of the coverage (i.e. services/medicines covered and the co-payment rate for each service).

In addition, there are concerns about moral hazard arising from welfare programmes. Gruber (2010) argues that non-contributory welfare provision is negatively correlated with labour supply as it 'raises the incentive for individuals to be poor' in order to qualify for the benefits (Gruber, 2010, p.500). It is important to note that Gruber's definition refers to the American welfare system wherein welfare benefits also contain medical care (Gruber, 2010, chapter 17). Therefore, his argument is not only applicable to in-cash and in-kind transfers but also health insurance for the poor, particularly Medicaid in the US. Even though this view has been considered debatable (Banerjee et al., 2017), it seems 
consistent with theoretical predictions which suggest that increased welfare may draw more people into welfare programmes while not inducing them to leave (see the models in Ham and Shore-Sheppard, 2005; Strumpf, 2011).

These theoretical arguments indicate a negative effect of health insurance on labour supply. Nevertheless, it is important to emphasize that these models are framed in the context of Medicaid in the US and might not be applicable to LMIC. They seem to ignore the in-kind benefits of health insurance which potentially have a positive health impact on recipients. With better access to healthcare, the poor may become healthier, more productive and hence can work more to increase their income. This health fostering argument combined with a human rights based approach is widely used by UHC proponents. Nevertheless, data on health status are normally unavailable in labour market surveys to test this hypothesis (Strumpf, 2011). Additionally, the empirical evidence of the effects of health insurance on health is rather thin, especially for adults (Sommers et al., 2012). Furthermore, the health-improvement assumption does not always hold true because health insurance is not easily translated into better health (Levy and Meltzer, 2004), as this depends on the generosity of the coverage as well as the infrastructure availability.

The empirical literature on the labour supply effects of health insurance in LMIC is rather limited. According to Chapter 2, 47 out of 63 post-2000 publications reviewed are about the US. Similarly, the literature with a particular focus on low income recipients is mainly concentrated on the US, with mixed results (ibid.). Rosen (2014) shows that those without Medicaid tend to work around six hours more per week while an increase in eligibility reduces the employment likelihood by 1.7-7.2 percentage points (Dave et al., 2015). Other studies, however, find insignificant results of Medicaid introduction and expansion on labour supply in terms of work hours (Gooptu et al., 2016) and labour force participation (Strumpf, 2011; Ham and Shore-Sheppard, 2005). This inconclusive result is also confirmed by another review by Gruber and Madrian (2002) who reviewed the US literature published before 2000 .

There is no study for Vietnam on the labour supply effects of health insurance for the poor. Recent evaluations of health insurance in Vietnam have instead investigated the effects of health insurance expansion on out-of-pocket spending (Jowett et al., 2003; Wagstaff, 2010; Nguyen, 2012; Nguyen and Wang, 2013), healthcare utilization (Wagstaff, 2007, 2010; Nguyen, 2012; Nguyen and Wang, 2013; Guindon, 2014; Palmer et al., 2015) and health outcomes (Guindon, 2014). Two studies specifically assessing HCFP (Wagstaff, 2007, 2010) also fall into this category. However, results from these two studies are relatively sensitive to the methodological choices made, which make one question the robustness of the results presented. For example, Wagstaff (2007) used a single difference and Propensity Score Matching to find that HCFP substantially increased service utilization while in another study using triple differences, the author concluded that HCFP did not change service utilization albeit reducing out-of-pocket payment (Wagstaff, 2010). Thus, the evidence of the impacts of HCFP on these outcomes is limited and inconclusive, whereas the labour supply effects in particular are under-studied. 


\subsection{The Health Care Fund For The Poor}

The expansion of health coverage in Vietnam has recently accelerated owing to improvements in living standards in fast-growing regions as well as the global push for UHC. After the 1986 Reform, normally referred to as 'Doi Moi', wherein the economy was shifted from a centrally planned system to a more open and market-oriented economy, the Vietnamese government has conducted a plethora of healthcare reforms (Wagstaff, 2010) to improve healthcare access and coverage. One illustration is HCFP, which was introduced in 2003 as a subsidized health scheme for the poor and ethnic minority peoples. The aim was to tackle ever increasing out-of-pocket payments, especially for the poor and vulnerable (Wagstaff, 2010).

HCFP was founded under the Decision 139/2002/QD-TTg (Socialist Republic of Vietnam, $2002 \mathrm{~b}$ ), under which provincial governments are mandated to allocate an annual sum for the Provincial Agency of Labour, Invalids and Social Affairs - a subordinate body under Ministry of Labour, Invalids and Social affairs (MOLISA) - to buy health insurance cards and then have them delivered to the poor within the province. The budget was allocated annually based on a list of poor people proposed by the agency which gathered information from its subordinate agencies at district and commune levels via hierarchical reporting. The fund was co-financed by both the central and provincial governments and was introduced to replace a previous programme called Free Health Card (FHC) for the Poor.

According to the Decision, HCFP is to target the poor as defined by MOLISA's national poverty line issued under Decision 1143/2000/QD-LDTBXH (MOLISA, 2000). However, in practice the specification of poor households at local level was done via community meetings and consultation with local authorities who would then submit an annual list of poor people to provincial authorities. The fund targeted everyone living in the most disadvantaged communes listed under Programme 135 - one of the largest poverty reduction programmes in Vietnam under Decision 135/1998/QD-TTg (Socialist Republic of Vietnam, 1998) - or those belonging to ethnic minority groups who live in the poorest Central Highland and Northern West provinces.

HCFP pays 100 percent of the insurance premium for the poor (around 2.5 USD per person per year in 2003) to ensure that every poor person can get free access to any healthcare facility affiliated with the national social health insurance scheme. The Fund then directly pays to service providers upon utilization (according to Decision 139/2002/QD-TTg). This is to ensure that the poor, by law, do not have to pay out-of-pocket in advance. Even though the regulation requires that provincial authorities buy health insurance for the poor, during the implementation process, provincial governments can chose to either i) buy and issue free health insurance cards for the poor and hence automatically enrol them into the national social health insurance scheme, or ii) directly reimburse service providers for healthcare services delivered (Tran et al., 2011).

In practice, many provincial governments normally use both approaches: i) issuing health insurance and ii) providing free healthcare services for the poor irrespective of 
the availability of health insurance cards (Tran et al., 2011). In the latter case, poor certificates, which serve as an identification for the poor, can be used instead when seeking free treatment. Qualitative evidence also shows that some provinces tried to shift the financial burden to the social health insurance system by enrolling sick people into the national insurance scheme while providing user-fee exemption and direct reimbursement to the remaining poor (Tran et al., 2011). Therefore, some policy modifications were made in 2005 to remove direct reimbursement and ensure that the poor have health insurance (ibid.). This crucial right was then embraced in subsequent health regulations (i.e. Health Insurance Law versions of 2008 and 2014). However, the flexibility and inconsistency during the early stage of implementation as aforementioned complicates our analysis, as we cannot disentangle the effects of health insurance issued under HCFP and its precedent FHC because the health insurance card could be absent if the poor used poor certificates upon healthcare seeking. Therefore, in this analysis, we decide not to separate the two, which is consistent with previous studies like Wagstaff (2010).

\subsection{Data and Methodology}

\subsubsection{Data}

We use panel data from the Vietnam Household Living Standards Surveys (VHLSS) 20022006 (see the description of the VHLSS in Chapter 1). As this research uses information on expenditure-based poverty, we use the small samples of all surveys. The small sample sizes in 2002, 2004 and 2006 are respectively more than 30,000, 9,000 and 9,000 households. However, because VHLSS uses a sample rotating approach where only half of the total sample in a previous survey is re-sampled in the next round, this significantly reduces the sample size of the panel.

Importantly, during data crunching we find a large number of matching errors in the panel, which is consistent with what is found by McCaig (2009). The author suggested that around 10 percent of matches given by GSO's 2002-2004 official data were imprecise just simply by looking at demographic information such as gender, age and name of the individual (ibid.). The matching errors in VHLSS 2002-2004 panel led to mismatches in the longer panel 2002-2006 that is used in this chapter. The poorly matched panel creates biased estimates of many household characteristics (e.g. household size, household consumption as illustrated in McCaig, 2009) and influences estimations on many dynamic issues like labour supply, changes in health status and so on (ibid.). Therefore, in this chapter, we use the revised household and individual identifiers provided openly on the author's website (McCaig, 2017) to correct for the wrong matches.

After data verification and cleaning, we get a panel which includes 6,816 observations in 2002, 7,459 observations in 2004, and 7,441 observations in 2006. We adopt the universally accepted working age definition and only keep individuals aged between 16 
and 65 although labour regulations in Vietnam do not set the upper bound ${ }^{1}$. The age cut-offs reduce the sample size to 4,025, 4,723 and 5,095 individuals respectively. We also remove 338 observations who were covered in 2002 under the FHC scheme. The final panel is unbalanced and consists of 3,687, 4,723 and 5,095 observations in 2002, 2004 and 2006 .

One important note about the data is that the survey design in 2002 is relatively simplified compared to the other two waves. Questions on health insurance in the 2002 survey are at the household level while information in 2004 and 2006 is for each household member. We hence assume that if a household is covered with HCFP or FHC in 2002, everyone within the family is covered. This assumption is reasonable given the fact that poverty status in Vietnam is specified at household level via community meetings. Another data issue is that the 2002 survey merely asked information on HCFP and its precedent FHC while ignoring other health schemes applicable to the working-age poor (namely health insurance for students, health insurance for social assistance recipients and people of merit: the invalid, the handicapped, mothers of war martyrs). Therefore, in our definition of covered and uncovered groups in 2002, we cannot separate the effect of HCFP from other health insurance schemes for the poor (if any). This issue will be discussed further in section 3.6.

\subsubsection{Treatment definition and methods}

In our definition, covered in 2004 and 2006 is defined as being covered by either HCFP or FHC, and not covered by any other type of health insurance. Covered in 2002 is specified as being covered by either HCFP or FHC, and maybe covered by any other type of health insurance - we simply do not have any information about this. Similarly, uncovered refers to being covered by neither HCFP nor FHC. We then define treatment and control groups. In our data, the baseline year is 2002, before the introduction of HCFP in 2003. Treatment include three sub-groups: i) those covered only in 2006 (group 1), ii) those covered only in 2004 (group 2) and iii) those covered in both 2004 and 2006. We bundle these three into one treatment group. Those uncovered in all three years form a pool of potential control individuals for matching.

We combine pre-treatment matching with Difference-in-Differences (DD) to evaluate the effect. Eligibility of health insurance for the poor via HCFP or FHC schemes was not random yet mainly based on poverty status and geographic locations. We therefore use these criteria in our pre-treatment matching to determine a control group before conducting DD estimations.

In our empirical setup, certain assumptions need to be satisfied for the validity of our causal results. Most importantly, the parallel trend assumption must be satisfied. By combing matching with DD, we assume a parallel trend conditional on the matching covariates. Further diagnosis, however, is needed to confirm this parallel trend once

1 According to Vietnam's labour law in 1992 and its amendment in 2004, legal workers are those who are above fifteen. 
the matching is done. Unfortunately, we only have one pre-treatment period, making it impossible to test the trend leading to treatment. Regarding post-treatment trend, in our specification, we allow time-varying treatment effect (see the specifications below), therefore the parallel trend after treatment is relaxed. The choice of matching covariates becomes critically important. We have strong evidence to show that the covariates used for matching are relevant for determining both selection into the programme and labour supply outcomes. We use expenditure-based poverty status ${ }^{2}$, location (urban or rural), and ethnicity - determinants of HCFP eligibility - as mandated by law (Socialist Republic of Vietnam, 2002b) and hence used for the targeting of the HCFP policy. We also include healthcare utilization as a proxy for the unobserved health status considering that sick and poorer people among the poor might have been prioritised in getting covered (Tran et al., 2011). Additionally, self-reported health status is also an important variable in modelling labour supply (Parsons, 1982). Finally, we include individual and household characteristics that determine labour supply, including age, gender, literacy, marital status, work sector (farm/non-farm), household size, dependency ratio ${ }^{3}$, female headed household (dummy). These determinants of labour supply are defined based on our diagnostic Probit regressions before matching. We also base on labour supply theories (e.g. Heckman and MaCurdy (1980) and empirical evidence (Contreras and Plaza, 2010; Contreras et al., 2011; Humphries and Sarasúa, 2012) to specify these relevant characteristics.

Importantly, due to criticism of and concern about Propensity Score Matching (PSM) methods (see King and Nielsen, 2016), we deliberately choose Mahalanobis matching over the widely used PSM. However, following the advice by King and Nielsen (2016), we also conduct a number of PSM attempts (including Kernel algorithms, and nearest neighbour matching) and then compare matching results regarding efficiency, and level of bias reduction before switching to the Mahalanobis metric. T-test results are reported in the Appendices A7-A11 while Figure A illustrates the variance ratios of disturbance of all matchings (see Appendix A).

Based on the diagnostic tests (Appendices A7-A11) and disturbance illustrations (Figure A in Appendix A), we conclude that PSM in our case is not an optimal choice due to its inability to completely remove imbalances between the treated and the untreated. Consequently, PSM methods result in a very small number of off-support observations even though we know with certainty that treatment selection bias is an issue because health insurance for the poor was not randomly assigned. This is probably due to, what is explained by King and Nielsen (2016), the blindness of PSM to many imbalances as the method tries to approximate a perfect randomization. We also find that Mahalanobis matching in our case is more efficient by fully removing imbalances and bias between the two groups.

The technique, however, comes with a trade-off: after the Mahalanobis matching, we have to remove from the baseline 402 off-support treated observations which are not compatible with any observations in the potential control group. This number of trimmed observations is relatively large in the total number of 666 treated observations in 2002. Based on the T-Test results, the imbalances mostly come from two household characteristics, i.e. the

${ }^{2}$ We use poverty line (Glewwe, 2003) in 2002 to identify who were poor in the baseline year 2002.

3 This is defined as the total number of dependants aged below 16 or above 65 over the total household size. 
household size and whether the household is headed by a female. These two covariates appear to be important determinants of the treatment assignment in our diagnostic regressions. Therefore, we use Mahalanobis matching as the most stringent method. We, however, also use other matching metrics and report the results from all matching techniques.

We use two dependent variables: i) the number of hours worked per month on average (this is left-censored as only relevant for those being employed) and ii) the probability of employment as a binary choice. We employ a two-part model for analysing the former. Particularly, in the first part, a Probit regression is used to examine the determinants of being employed for all working-age individuals. The second part then uses OLS to examine the effect of the HCFP on the number of hours worked for those who are employed. Regarding labour force participation (dependent variable 2), we use the Linear Probability Model. We use individual fixed effect (the treatment level) to account for unobserved time-invariant characteristics. Because of the high level of discretion of the local authorities in implementing the HCFP (see Tran et al., 2011), as well as regional differences in terms of healthcare facilities and inputs, we also control for commune fixed effects. We use clustered standard errors by household for all regressions ${ }^{4}$. The specifications are as follows:

hour $_{i c t}=\alpha_{\text {treat }}$ ict $+\beta$ year $_{t}+\delta X_{i c t}^{\prime}+\omega_{c}+\mu_{c i}+\epsilon_{i c t}$

employ $_{i t}=$ atreat $_{i c t}+$ Byear $_{t}+\delta X_{i c t}^{\prime}+\omega_{c}+\mu_{c i}+\epsilon_{i c t}$

where:

$\mathrm{i}, \mathrm{c}$ and t respectively denote individual, commune and time subscripts.

'hour' denotes the number of hours worked per month on average in Part 2 of the two part model (this regression is only ran on employed individuals).

'employ' denotes the probability of being employed for all individuals. 'employ' equals 1 if currently employed and equals 0 otherwise.

'treat' equals 1 for treated individuals, 'treat' equals 0 for the control.

year $_{t}$ denotes year dummies, t runs from 0 to 2 that respectively denotes 2002, 2004 and 2006

$\mathrm{X}^{\prime}$ is the vector of time-variant variables that explain labour supply. $\mathrm{X}^{\prime}$ also includes the intercept.

$\omega_{c}$ is the commune fixed effects

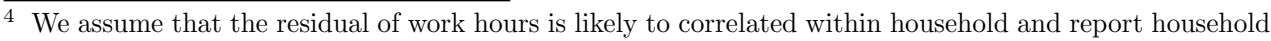
clustered standard errors in the main results. However, we also run clustered error by commune to test if the residual is correlated within local labour markets. The results are reported in Appendices A3-A6 
$\mu_{c i}$ is the individual fixed effects

$\epsilon_{i c t}$ is the idiosyncratic error term

$\alpha$ is the average treatment effect (ATT) of interest

Time-variant individual and household characteristics in vector $\mathrm{X}^{\prime}$ consist of age, age squared, literacy, marital status, household size and dependency ratio. Additionally, we proxy for health status by the number of healthcare visits per year. We also account for the effects of labour demand by specifying the geographical regions where the individuals are living using the variable 'urban' and the availability of programme 135, one of the largest and most important poverty reduction programmes targeting the poorest communes in Vietnam. We control for the farming sector, which is the most common for the Vietnamese rural poor, and type of work (wage employment in particular). Finally, because a majority of our sample work in the agriculture sector, we try to control for seasonal effects by adding interview month.

\subsection{Results}

Difference-in-Differences Matching estimates for the number of hours worked are presented in Table 3.1. Part 1 of the two part model is presented in Appendix A4.

As suggested in Table 3.1, the HCFP has a negative effect on the number of hours worked. On monthly average, those covered with free health insurance via the HCFP work around 5.2-5.8 hours less compared to those uncovered by the scheme. This finding is consistent across different matching techniques. Besides, the negative effect is more prominent in 2004 than in 2006, suggesting that the negative effect (probably due to the income effect) kicks in rather quickly.

The effects of control variables are very consistent and intuitive. Age has a concave relationship with the number of hours worked. Seeking more healthcare is associated with working less. Notably, the effect of work sector is rather large: those working in the agricultural sector, on average, work approximately 40 hours less than those working in the non-farm sector. This large effect indicates that the HCFP may have the largest effects on those working in agriculture.

Table 3.2 presents Difference-in-Differences Matching estimates of the second outcome: the probability of employment. As suggested, the HCFP has a negative effect on labour force participation. On average, those covered with free health insurance during HCFP are 2.8 percentage points less likely to participate in the labour market. This result is very consistent across different matching methods. This effect does not change over time as the effects of the time dummies are statistically insignificant.

The effects of other control variables on labour force participation are rather intuitive. Similar to the effect on the number of hours worked, age has a concave relationship with labour force participation. Interestingly, those living in a family with more dependants 
are less likely to participate in the labour market probably due to the care burden at home. Literate people are 7.5- 7.7 percentage points more likely to get employed. Those who are not married are more likely to work. Seeking more healthcare is associated with a smaller likelihood of labour force participation. Those working in agriculture are 25 percentage points more likely to participate in the labour market. Those working in a salary job (compared to self-employment) are approximately 21 percentage points more likely to work.

Table 3.1: The number of hours worked - OLS

\begin{tabular}{lrrrr}
\hline & Mahalanobis & NN matching & Kernel $(1)$ & Kernel $(2)$ \\
\hline Dependent variable: The number of hours worked & & & & \\
Treat & $-5.854^{* *}$ & $-5.271^{* *}$ & $-5.277^{* *}$ & $-5.271^{* *}$ \\
& $(2.57)$ & $(2.45)$ & $(2.45)$ & $(2.45)$ \\
Year=2004 & -3.803 & $-4.326^{*}$ & $-4.240^{*}$ & $-4.326^{*}$ \\
& $(2.35)$ & $(2.25)$ & $(2.24)$ & $(2.25)$ \\
Year=2006 & -0.712 & -1.162 & -1.071 & -1.162 \\
Age squared & $(2.23)$ & $(2.12)$ & $(2.12)$ & $(2.12)$ \\
& $-0.040^{* * *}$ & $-0.040^{* * *}$ & $-0.040^{* * *}$ & $-0.040^{* * *}$ \\
Age & $(0.01)$ & $(0.01)$ & $(0.01)$ & $(0.01)$ \\
& $2.801^{* * *}$ & $2.796^{* * *}$ & $2.772^{* * *}$ & $2.796^{* * *}$ \\
Household size & $(0.46)$ & $(0.44)$ & $(0.44)$ & $(0.44)$ \\
& -0.011 & 0.115 & 0.104 & 0.115 \\
Dependency ratio & $(0.48)$ & $(0.46)$ & $(0.46)$ & $(0.46)$ \\
Literacy (dummy) & -4.336 & -3.590 & -3.572 & -3.590 \\
Marital status (base: married individuals) & $(4.04)$ & $(3.91)$ & $(3.91)$ & $(3.91)$ \\
-Never married & -0.145 & -0.503 & -0.310 & -0.503 \\
& $(3.15)$ & $(2.88)$ & $(2.86)$ & $(2.88)$ \\
-Widowed/Divorced/Separated & $(2.55)$ & $(2.45)$ & -4.035 & $-4.063^{*}$ \\
Number of healthcare utilization p.a & -3.015 & $-5.583^{*}$ & $-5.679^{*}$ & $-5.453^{*}$ \\
Urban (dummy) & $(3.47)$ & $(3.31)$ & $(3.32)$ & $(3.31)$ \\
Belongs to P135 communes & $(1.04)$ & $(1.03)$ & $(1.03)$ & $(1.03)$ \\
Sector: agri/aquaculture (dummy) & $-41.233^{* * *}$ & $-40.682^{* * *}$ & $-40.684^{* * *}$ & $-40.682^{* * *}$ \\
Engaged in wage employment & $(2.09)$ & $(2.08)$ & $(2.08)$ & $(2.08)$ \\
Constant & 0.245 & 0.231 & 0.221 & 0.231 \\
N & $(1.73)$ & $(1.70)$ & $(1.70)$ & $(1.70)$ \\
& $161.551^{* * *}$ & $162.130^{* * *}$ & $162.292^{* * *}$ & $162.130^{* * *}$ \\
& $(12.52)$ & $(11.83)$ & $(11.78)$ & $(11.83)$ \\
\hline & 9,271 & 9,613 & 9,618 & 9,613 \\
\hline
\end{tabular}

Standard errors in parentheses. ${ }^{*} p<0.1,{ }^{* *} p<0.05,{ }^{* * *} p<0.01$. Standard errors are clustered by household. Interview month is controlled for in all regressions. Kernel (1) and (2) respectively refer to the Kernel matching methods that use the trimming and minima-maxima techniques. NN matching: Nearest neighbour matching. 
Table 3.2: Probability of being employed - Linear Probability Model

\begin{tabular}{|c|c|c|c|c|}
\hline & Mahalanobis & NN matching & Kernel (1) & Kernel (2) \\
\hline \multicolumn{5}{|c|}{ Dependent variable: currently employed (dummy) } \\
\hline \multirow[t]{2}{*}{ Treat } & $-0.028^{* *}$ & $-0.028^{* *}$ & $-0.028^{* *}$ & $-0.028^{* *}$ \\
\hline & $(0.01)$ & $(0.01)$ & $(0.01)$ & $(0.01)$ \\
\hline \multirow[t]{2}{*}{ year $=2004$} & -0.004 & -0.001 & -0.002 & -0.001 \\
\hline & $(0.01)$ & $(0.01)$ & $(0.01)$ & $(0.01)$ \\
\hline \multirow[t]{2}{*}{ year $=2006$} & 0.001 & 0.003 & 0.003 & 0.003 \\
\hline & $(0.01)$ & $(0.01)$ & $(0.01)$ & $(0.01)$ \\
\hline \multirow[t]{2}{*}{ Age squared } & $-0.001^{* * *}$ & $-0.001^{* * *}$ & $-0.001^{* * *}$ & $-0.001^{* * *}$ \\
\hline & $(0.00)$ & $(0.00)$ & $(0.00)$ & $(0.00)$ \\
\hline \multirow[t]{2}{*}{ Age } & $0.047^{* * *}$ & $0.045^{* * *}$ & $0.045^{* * *}$ & $0.045^{* * *}$ \\
\hline & $(0.00)$ & $(0.00)$ & $(0.00)$ & $(0.00)$ \\
\hline \multirow[t]{2}{*}{ Household size } & -0.002 & -0.002 & -0.002 & -0.002 \\
\hline & $(0.00)$ & $(0.00)$ & $(0.00)$ & $(0.00)$ \\
\hline \multirow[t]{2}{*}{ Dependency ratio } & $-0.034^{*}$ & $-0.037^{*}$ & $-0.036^{*}$ & $-0.037^{*}$ \\
\hline & $(0.02)$ & $(0.02)$ & $(0.02)$ & $(0.02)$ \\
\hline \multirow[t]{2}{*}{ Literacy (dummy) } & $0.077^{* * *}$ & $0.076^{* * *}$ & $0.075^{* * *}$ & $0.076^{* * *}$ \\
\hline & $(0.02)$ & $(0.02)$ & $(0.02)$ & $(0.02)$ \\
\hline \multicolumn{5}{|c|}{ Marital status (base: married individuals) } \\
\hline \multirow[t]{2}{*}{-Never married } & $-0.069^{* * *}$ & $-0.075^{* * *}$ & $-0.074^{* * *}$ & $-0.075^{* * *}$ \\
\hline & $(0.02)$ & $(0.02)$ & $(0.01)$ & $(0.02)$ \\
\hline \multirow[t]{2}{*}{-Widowed/Divorced/Separated } & $-0.056^{* * *}$ & $-0.057^{* * *}$ & $-0.057^{* * *}$ & $-0.057^{* * *}$ \\
\hline & $(0.02)$ & $(0.02)$ & $(0.02)$ & $(0.02)$ \\
\hline \multirow[t]{2}{*}{ Number of healthcare utilization p.a } & $-0.008^{*}$ & $-0.008^{*}$ & $-0.008^{*}$ & $-0.008^{*}$ \\
\hline & $(0.00)$ & $(0.00)$ & $(0.00)$ & $(0.00)$ \\
\hline \multirow[t]{2}{*}{ Urban (dummy) } & -0.005 & -0.003 & -0.002 & -0.003 \\
\hline & $(0.03)$ & $(0.03)$ & $(0.03)$ & $(0.03)$ \\
\hline \multirow[t]{2}{*}{ Belongs to P135 communes } & -0.008 & -0.003 & -0.005 & -0.003 \\
\hline & $(0.02)$ & $(0.01)$ & $(0.01)$ & $(0.01)$ \\
\hline \multirow[t]{2}{*}{ Sector: agri/aquaculture (dummy) } & $0.250^{* * *}$ & $0.257^{* * *}$ & $0.257^{* * *}$ & $0.257^{* * *}$ \\
\hline & $(0.01)$ & $(0.01)$ & $(0.01)$ & $(0.01)$ \\
\hline \multirow[t]{2}{*}{ Engaged in wage employment } & $0.213^{* * *}$ & $0.212^{* * *}$ & $0.212^{* * *}$ & $0.212^{* * *}$ \\
\hline & $(0.01)$ & $(0.01)$ & $(0.01)$ & $(0.01)$ \\
\hline \multirow[t]{2}{*}{ Constant } & $-0.197^{* * *}$ & $-0.153^{* *}$ & $-0.152^{* *}$ & $-0.153^{* *}$ \\
\hline & $(0.06)$ & $(0.06)$ & $(0.06)$ & $(0.06)$ \\
\hline $\mathrm{N}$ & 10,484 & 10,869 & 10,873 & 10,869 \\
\hline
\end{tabular}

Standard errors in parentheses. Standard errors are clustered by household. Interview month is controlled for in all regressions. Kernel (1) and (2) respectively refer to the Kernel matching methods that use the trimming and minima-maxima techniques. NN matching: Nearest neighbour matching. ${ }^{*} p<0.1,{ }^{* *} p<0.05,{ }^{* * *} p<0.01$ 
Because the employment structure and type of work are significantly different in rural and urban areas, we also break down the results by region. Additionally, as the treated individuals in our sample also include the non-poor (see Appendix A1) while the income effect might be significantly different for individuals of different levels of initial income, it is important to distinguish the effect for the poor and the non-poor to evaluate the effects on the target group of interest. These effects by region and by poverty status are presented in Tables 3.3 and 3.4. As the results are consistent across different matching methods in Tables 3.1 and 3.2, we only report the results of Mahalanobis matching in Tables 3.3 and 3.4

According to Table 3.3, the HCFP effects on the number of hours worked are more evidenced for the non-poor treated individuals while being statistically insignificant for the poor. This surprising result indicates that the income effect of HCFP is more relevant for the non-poor than the poor. On average, the treated non-poor are working 5.6 hours less than the non-poor control individuals and this effect is significant at 5 percent level. In contrast, for the poor, the effect is statistically insignificant. Table 3.3 also suggests that the negative effect of health insurance is mainly driven by rural individuals. Approximately, rural treated individuals work 8.3 hours less than rural control individual and this effect is significant at one percent level. The effect for the urban individuals is, however, statistically insignificant. 
Table 3.3: The number of hours worked per month, by poverty status and by region

\begin{tabular}{|c|c|c|c|c|}
\hline & \multicolumn{2}{|c|}{ Poverty status } & \multicolumn{2}{|c|}{ Region } \\
\hline & Non-poor & Poor & Rural & Urban \\
\hline \multicolumn{5}{|c|}{ Dependent variable: the number of hours worked } \\
\hline Treat & $\begin{array}{c}-5.644^{*} \\
(2.89)\end{array}$ & $\begin{array}{r}-9.747 \\
(7.80)\end{array}$ & $\begin{array}{c}-8.267^{* * *} \\
(2.55)\end{array}$ & $\begin{array}{l}1.883 \\
(7.13)\end{array}$ \\
\hline year $=2004$ & $\begin{array}{l}-2.172 \\
(2.59)\end{array}$ & $\begin{array}{l}-5.374 \\
(7.06)\end{array}$ & $\begin{array}{c}-5.999^{* *} \\
(2.63)\end{array}$ & $\begin{array}{l}5.960 \\
(5.55)\end{array}$ \\
\hline year $=2006$ & $\begin{array}{l}1.198 \\
(2.43)\end{array}$ & $\begin{array}{l}-8.498 \\
(9.09)\end{array}$ & $\begin{array}{l}-2.053 \\
(2.49)\end{array}$ & $\begin{array}{l}5.856 \\
(5.05)\end{array}$ \\
\hline Age squared & $\begin{array}{c}-0.043^{* * *} \\
(0.01)\end{array}$ & $\begin{array}{l}-0.018 \\
(0.01)\end{array}$ & $\begin{array}{c}-0.040^{* * *} \\
(0.01)\end{array}$ & $\begin{array}{c}-0.051^{* * *} \\
(0.01)\end{array}$ \\
\hline Age & $\begin{array}{c}2.947^{* * *} \\
(0.50)\end{array}$ & $\begin{array}{l}1.385 \\
(1.06)\end{array}$ & $\begin{array}{c}2.719^{* * * *} \\
(0.49)\end{array}$ & $\begin{array}{c}3.735^{* * *} \\
(1.19)\end{array}$ \\
\hline Household size & $\begin{array}{l}0.259 \\
(0.56)\end{array}$ & $\begin{array}{l}-0.887 \\
(1.43)\end{array}$ & $\begin{array}{l}0.027 \\
(0.54)\end{array}$ & $\begin{array}{l}0.079 \\
(1.12)\end{array}$ \\
\hline Dependency ratio & $\begin{array}{c}-7.715^{*} \\
(4.20)\end{array}$ & $\begin{array}{l}12.495 \\
(21.42)\end{array}$ & $\begin{array}{l}-4.007 \\
(4.53)\end{array}$ & $\begin{array}{l}-5.843 \\
(8.62)\end{array}$ \\
\hline Literacy (dummy) & $\begin{array}{r}-2.399 \\
(3.90)\end{array}$ & $\begin{array}{l}5.639 \\
(6.01)\end{array}$ & $\begin{array}{l}0.159 \\
(3.17)\end{array}$ & $\begin{array}{c}0.262 \\
(11.51)\end{array}$ \\
\hline Marital status (base: married individ & ials) & & & \\
\hline -Never married & $\begin{array}{r}-4.187 \\
(2.80)\end{array}$ & $\begin{array}{l}-0.767 \\
(7.40)\end{array}$ & $\begin{array}{l}-2.027 \\
(2.86)\end{array}$ & $\begin{array}{l}-7.881 \\
(5.19)\end{array}$ \\
\hline -Widowed/Divorced/Separated & $\begin{array}{r}-3.383 \\
(3.71)\end{array}$ & $\begin{array}{c}-11.024 \\
(15.71)\end{array}$ & $\begin{array}{c}-6.026 \\
(3.72)\end{array}$ & $\begin{array}{l}-1.882 \\
(8.25)\end{array}$ \\
\hline Number of healthcare utilization p.a & $\begin{array}{c}-3.653^{* * *} \\
(1.10)\end{array}$ & $\begin{array}{c}-8.970^{* * *} \\
(3.40)\end{array}$ & $\begin{array}{c}-4.763^{* * *} \\
(1.10)\end{array}$ & $\begin{array}{l}-0.753 \\
(2.52)\end{array}$ \\
\hline Urban (dummy) & $\begin{array}{l}3.545 \\
(9.07)\end{array}$ & $\begin{array}{c}0.000 \\
(0.000)\end{array}$ & & \\
\hline Belongs to P135 communes & $\begin{array}{r}-6.208 \\
(3.97)\end{array}$ & $\begin{array}{l}15.758 \\
(11.65)\end{array}$ & $\begin{array}{r}-4.211 \\
(3.81)\end{array}$ & $\begin{array}{l}16.531 \\
(13.68)\end{array}$ \\
\hline Sector: agri/aquaculture (dummy) & $\begin{array}{c}-42.824^{* * *} \\
(2.24)\end{array}$ & $\begin{array}{c}-24.328^{* * *} \\
(8.20)\end{array}$ & $\begin{array}{c}-39.664^{* * *} \\
(2.26)\end{array}$ & $\begin{array}{c}-46.872^{* * *} \\
(5.64)\end{array}$ \\
\hline Engaged in wage employment & $\begin{array}{l}0.315 \\
(1.87)\end{array}$ & $\begin{array}{l}2.811 \\
(4.81)\end{array}$ & $\begin{array}{l}2.806 \\
(1.87)\end{array}$ & $\begin{array}{c}-7.710^{*} \\
(4.11)\end{array}$ \\
\hline Constant & $\begin{array}{c}149.973^{* * *} \\
(13.76)\end{array}$ & $\begin{array}{c}184.170^{* * *} \\
(38.65)\end{array}$ & $\begin{array}{c}164.711^{* * *} \\
\quad(13.65)\end{array}$ & $\begin{array}{c}152.046^{* * *} \\
(29.42)\end{array}$ \\
\hline $\mathrm{N}$ & 8,336 & 935 & 7,201 & 2,070 \\
\hline
\end{tabular}

According to Table 3.4, there is no difference in the HCFP effect on labour force participation between the poor and the non-poor. The effect, however, is more evident for rural individuals: the HCFP make treated individuals in rural areas 3.8 percentage points less likely to get employed compared to the rural control individuals. 
Table 3.4: The probability of employment, by poverty status and by region

\begin{tabular}{|c|c|c|c|c|}
\hline & Poverty & status & Rę & ion \\
\hline & Non-poor & Poor & Rural & Urban \\
\hline Dependent variable: currently employ & ammy) & & & \\
\hline Treat & $\begin{array}{r}-0.019 \\
(0.01)\end{array}$ & $\begin{array}{r}-0.041 \\
(0.05)\end{array}$ & $\begin{array}{c}-0.038^{* *} \\
(0.01)\end{array}$ & $\begin{array}{l}0.024 \\
(0.03)\end{array}$ \\
\hline year $=2004$ & $\begin{array}{l}-0.004 \\
(0.01)\end{array}$ & $\begin{array}{c}-0.047^{*} \\
(0.03)\end{array}$ & $\begin{array}{l}0.002 \\
(0.01)\end{array}$ & $\begin{array}{l}-0.031 \\
(0.02)\end{array}$ \\
\hline year=2006 & $\begin{array}{l}0.000 \\
(0.01)\end{array}$ & $\begin{array}{c}-0.095^{* * *} \\
(0.03)\end{array}$ & $\begin{array}{l}0.005 \\
(0.01)\end{array}$ & $\begin{array}{l}-0.016 \\
(0.02)\end{array}$ \\
\hline Age squared & $\begin{array}{c}-0.001^{* * *} \\
(0.00)\end{array}$ & $\begin{array}{c}-0.000^{* * *} \\
(0.00)\end{array}$ & $\begin{array}{c}-0.000^{* * *} \\
(0.00)\end{array}$ & $\begin{array}{c}-0.001^{* * *} \\
(0.00)\end{array}$ \\
\hline Age & $\begin{array}{c}0.049^{* * *} \\
(0.00)\end{array}$ & $\begin{array}{c}0.021^{* * * *} \\
(0.01)\end{array}$ & $\begin{array}{c}0.037^{* * *} \\
(0.00)\end{array}$ & $\begin{array}{c}0.072^{* * *} \\
(0.01)\end{array}$ \\
\hline Household size & $\begin{array}{c}-0.005^{*} \\
(0.00)\end{array}$ & $\begin{array}{c}0.008 \\
(0.01)\end{array}$ & $\begin{array}{c}-0.004 \\
(0.00)\end{array}$ & $\begin{array}{l}0.001 \\
(0.01)\end{array}$ \\
\hline Dependency ratio & $\begin{array}{l}-0.030 \\
(0.02)\end{array}$ & $\begin{array}{l}-0.010 \\
(0.08)\end{array}$ & $\begin{array}{l}-0.032 \\
(0.02)\end{array}$ & $\begin{array}{l}-0.045 \\
(0.04)\end{array}$ \\
\hline Literacy (dummy) & $\begin{array}{c}0.096^{* * *} \\
(0.02)\end{array}$ & $\begin{array}{l}0.016 \\
(0.03)\end{array}$ & $\begin{array}{c}0.069^{* * *} \\
(0.02)\end{array}$ & $\begin{array}{c}0.110^{* *} \\
(0.06)\end{array}$ \\
\hline Marital status (base: married individ & & & & \\
\hline Never married & $\begin{array}{c}-0.068^{* * *} \\
(0.02)\end{array}$ & $\begin{array}{c}-0.098^{* * *} \\
(0.03)\end{array}$ & $\begin{array}{c}-0.080^{* * *} \\
(0.02)\end{array}$ & $\begin{array}{c}-0.056^{*} \\
(0.03)\end{array}$ \\
\hline Widowed/Divorced/Separated & $\begin{array}{c}-0.057^{* * *} \\
(0.02)\end{array}$ & $\begin{array}{r}-0.124^{*} \\
(0.07)\end{array}$ & $\begin{array}{c}-0.061^{* * *} \\
(0.02)\end{array}$ & $\begin{array}{l}-0.031 \\
(0.04)\end{array}$ \\
\hline Number of healthcare utilization p.a & $\begin{array}{c}-0.011^{* *} \\
(0.00)\end{array}$ & $\begin{array}{l}0.014 \\
(0.01)\end{array}$ & $\begin{array}{c}-0.003 \\
(0.00)\end{array}$ & $\begin{array}{c}-0.019^{*} \\
(0.01)\end{array}$ \\
\hline Urban (dummy) & $\begin{array}{l}0.002 \\
(0.03)\end{array}$ & $\begin{array}{c}0.000 \\
(.)\end{array}$ & & \\
\hline Belongs to P135 communes & $\begin{array}{l}-0.015 \\
(0.02)\end{array}$ & $\begin{array}{l}-0.011 \\
(0.03)\end{array}$ & $\begin{array}{l}-0.013 \\
(0.02)\end{array}$ & $\begin{array}{c}0.033 \\
(0.04)\end{array}$ \\
\hline Sector: agri/aquaculture (dummy) & $\begin{array}{c}0.247^{* * *} \\
(0.01)\end{array}$ & $\begin{array}{c}0.320^{* * * *} \\
(0.04)\end{array}$ & $\begin{array}{c}0.250^{* * *} \\
(0.01)\end{array}$ & $\begin{array}{c}0.244^{* * *} \\
(0.03)\end{array}$ \\
\hline Engaged in wage employment & $\begin{array}{c}0.223^{* * *} \\
(0.01)\end{array}$ & $\begin{array}{c}0.129^{* * *} \\
(0.02)\end{array}$ & $\begin{array}{c}0.165^{* * *} \\
(0.01)\end{array}$ & $\begin{array}{c}0.333^{* * *} \\
(0.02)\end{array}$ \\
\hline Constant & $\begin{array}{c}-0.264^{* * *} \\
(0.07) \\
\end{array}$ & $\begin{array}{c}0.383^{* *} \\
(0.15) \\
\end{array}$ & $\begin{array}{c}-0.004 \\
(0.07) \\
\end{array}$ & $\begin{array}{c}-0.739^{* * *} \\
(0.16) \\
\end{array}$ \\
\hline $\mathrm{N}$ & 9,495 & 989 & 7,918 & 2,566 \\
\hline
\end{tabular}

\subsection{Discussion}

We find evidence of negative effects of HCFP on labour supply both at the intensive and extensive margins (i.e. the number of hours worked and labour force participation). The negative effect of the HCFP found in this chapter indicates that the income effect dominates health-fostering effect in labour supply decisions. Importantly, the HCFP effect 
at the intensive margin (i.e. the number of hours worked) changes over time. Particularly, the income effect immediately kicked in after the launch of the HCFP (in 2004) while the time dummy for 2006 is statistically insignificant. This means that the negative HCFP effect on the number of hours worked is stronger for those covered in 2004 than those covered in 2006 (this group also included those covered in both years).

Our finding of the negative effects both at intensive and extensive margins of labour supply is interesting given the very small health premium subsidized (around 2.5 USD in 2003, equivalent of approximately $1 / 40$ of the annual poverty line in 2003) as well as the low cost of public healthcare services in Vietnam. One may have argued that the income increase relative to the total income of those treated non-poor individuals is not large enough to trigger the income effect from the first year of implementation. However, it is important to note out-of-pocket payments in Vietnam in 2003 were very high, at around 63 percent of total health spending (The World Bank, 2018). Therefore, the income effect in forms of reduced health expenses are large enough to trigger the negative labour supply effects.

Importantly, we find that the effect on the number of hours worked is mainly driven by the non-poor, especially those living in rural areas (see Table 3.3). These include non-poor ethnic minority peoples living in disadvantaged areas and hence qualifying the categorical targeting criteria. They can also be the near-poor who were not poor based on the World Bank expenditure based poverty line but were defined as poor by the local community. Another explanation is that they were mistakenly covered due to lots of other implementation complications - this comprises the real inclusion error of the programme. Meanwhile, in Vietnam the poor in rural regions often comprise ethnic minority individuals living in remote and disadvantaged areas where health access and health literacy are limited (Nguyen, 2010), and that it often takes some time to raise their awareness of public programmes. Therefore, during the first stage of HCFP wherein direct reimbursement was conducted in many provinces, the programme might not be able to benefit the poorest of the poor probably due to their lower take-up rate (caused by lack of knowledge and limited accessibility) and lower healthcare utilization compared to the non-poor who normally live closer to local healthcare centres. Unfortunately, information regarding distance to the nearest healthcare delivery points was not asked in all three data periods so we could not test this hypothesis. Additionally, other studies that looked at utilization and out-of-pocket payment of this specific programme (Wagstaff, 2010, 2007) only examined the average treatment effect for those covered and did not delve deeper into this poverty angle, so it is difficult to justify this extrapolation.

Most of the existing literature only evaluated the short-term effect - normally right after an intervention. In this chapter we have taken advantage of the three-wave panel and examined the effects one year and three years after the intervention. We find that the treatment effect on the number of hours worked changes over time: it kicks in quickly after the intervention but then loses its effect over time.

It is difficult to compare our results with the existing literature due to the overrepresentation of US studies as well as their inconclusive evidence (see Chapter 2). We have evidence of Medicaid, CHIP and ACA in the US but the evidence of these studies is rather mixed with different target groups of low-income beneficiaries (ibid.). Our estimates regarding the effect on the number of hours worked are smaller in size compared to an 
effect size of 6 hours per week (or on average 24 hours per month) suggested by Rosen (2014) for Medicaid recipients. This might reflect the larger generosity, and hence bigger income effect, of the Medicaid programme compared to the HCFP in Vietnam. Regarding labour force participation, the results in the literature are rather mixed. Our results are contrary to findings by Strumpf (2011) and Ham and Shore-Sheppard (2005) who suggested that the introduction and expansion of Medicaid did not affect the likelihood of labour force participation. In another randomized experiment on Medicaid by Baicker et al. (2014), the authors also found no significant effect on employment ${ }^{5}$. In contrast, our results are consistent with other studies that found that low-income childless adults reduced their employment likelihood due to the Affordable Care Act (Guy et al., 2012) and a state-level health insurance expansion in Wisconsin, the US (Dague et al., 2017).

The finding of a negative net effect of the HCFP on the number of hours worked for the non-poor raises concern in the context of moving towards UHC in Vietnam. The key question for policy makers would be how to better target the poor to ensure equity while avoiding unintended labour supply distortions.

This study comes with a data limitation caveat. Effects of health insurance subsidies other than the HCFP cannot be adequately accounted for due to data limitations in 2002. The health section of 2002's questionnaire does not include any question on health coverage. The information on HCFP and FHC is however asked at the household level in another section on public subsidies and assistance benefits. This is inconsistent with the design of the later surveys in 2004 and 2006, where different types of health insurance are specified for each household member (and hence the level of analysis is at individual level). This data limitation leads us to assume HCFP coverage for the whole family if a household answered that at least one person within the family received this health scheme in 2002. Additionally, due to not being asked, the coverage of other types of health insurance in 2002 is unknown, potentially leading to an under-or-over estimation of the effect magnitude depending how these health insurances are distributed among treatment and control groups in 2002. However, this data unavailability does not bias our estimates if we assume that conditional on the matching observables, the distribution of other types of health insurance between the treatment and control groups in 2002 are compatible. In this case, the bias caused by other types of health insurance in 2002 would be cancelled out in the pre-treatment difference (in mathematical terms, it equates treatment minus control in the baseline).

\subsection{Conclusion}

By using matching methods combined with Difference-in-Differences, we evaluated the labour supply effects of free health coverage under the HCFP for the benefit recipients in Vietnam. We examined labour supply responses at both intensive and extensive margins: the number of hours worked and employment likelihood (labour force participation). We found that the effects of free health insurance on the number of hours worked and

\footnotetext{
5 The authors used the information about whether or not an individual has an earning as a measure for
} employment 
labour force participation were both negative and statistically significant at five percent level. Importantly, the effects were mainly driven by the non-poor people living in rural areas. This raises the question of the targeting strategy of the programme, highlights the importance of infrastructure availability as well as awareness raising and improving health literacy for the poor when designing such public health schemes.

We contribute to the existing literature in several ways. First, we help fill the knowledge gap for LMIC where health insurance coverage is rapidly expanding yet unguided by empirical evidence on labour market effects. Second, we analyse the labour supply effects over a longer time span after the intervention. This allows us to capture the change over time in the income effect induced by health insurance. Third, we dig deeper into the poverty perspective to unravel the mechanisms behind labour market distortions of health insurance. 

Chapter 4

\section{Health insurance and self-employment transitions in Vietnam}

This chapter is based on

Lê, N., Groot W., Tomini, S.M., and Tomini, F. (2018). Health insurance and selfemployment transitions in Vietnam. UNU-MERIT Working Paper 2018-039. 


\begin{abstract}
Health insurance can have important effects on self-employment and self-employment transitions. However, there is a literature gap on the relationship between health insurance and self-employment in low and middle income countries, especially in the context of rapid expansion of health insurance in these countries. This chapter examines this relationship in Vietnam with a focus on the comparison between the voluntary scheme for the informal sector (mostly self-employed workers) and the compulsory insurance for the formal sector (mostly wage workers). We employ a Probit model with selection on a panel from the Vietnam Household Living Standards Surveys 2010-2014 to investigate the association between health insurance and self-employment entry and exit. We show that formal workers who are covered by compulsory health insurance in Vietnam are 10 percentage points less likely to enter self-employment compared to those having voluntary insurance (informal workers). Regarding self-employment exit, people with compulsory insurance are more likely to exit self-employment compared to those covered by voluntary insurance. However, the effect size is relatively small.
\end{abstract}




\subsection{Introduction}

There is a difference in the coverage rate of health insurance between self-employed workers and wage earners in Vietnam. This is largely a result of the gap in the coverage rate between formal and informal workers (Somanathan et al., 2014), whereby the self-employed in Vietnam are overly represented by informal workers (Cling et al., 2011) while those in the formal sector are often wage employees and public workers. In 2011, informal workers and their families represented around 50 percent of those uncovered in Vietnam while this share of formal workers was around 19 percent (Somanathan et al., 2014). The enrolment rate into health insurance of informal workers in 2011 was only 26 percent compared to 56 percent of formal ones (ibid.). Even though the current health insurance system has been pooled into a single programme called Social Health Insurance (SHI), it still inherits the targeting approach from its predecessors which depend on employment status for working-age individuals who are not assistance recipients. Therefore, different employment groups get enrolled into the SHI programme via different sub-schemes with different enforcement mechanisms. Formal workers get enrolled via the compulsory scheme while informal workers have an option to join via the voluntary scheme. As a formal worker, one would get the insurance coverage via his or her employers, in which two thirds of health insurance premiums are paid by employers out of the payroll (employees have to pay one third of the amount). On the contrary, informal workers have to pay for the premium out-of-pocket at a local insurance agency (see the description of the Vietnamese health insurance system for more details). Even though the two schemes share the same benefit package in SHI, this design has consequently led to the aforementioned discrepancy in enforcement between the formal and informal sector, possibly due to averse selection among informal workers (Somanathan et al., 2014). Notably, even in the formal sector, where health insurance coverage is compulsory by law, compliance is still an issue (ibid.), not to say anything about the voluntary scheme where there is no such enforcement mechanism. Additionally, the lack of health insurance literacy in Vietnam (Somanathan et al., 2014) may be another reason for the weaker enforcement of the voluntary insurance compared to the compulsory scheme. This leads one to argue that Vietnamese formal workers are more likely to have health insurance compared to those working in the informal sector. This enforcement issue creates a link between health insurance coverage and the institutional sector (formal/informal), which is then translated into a link between health insurance and employment category (i.e. self and wage employment) due to the structure of the Vietnamese labour market.

The relationship between health insurance and the nexus of self and wage employment (especially self-employment mobility) is an important policy issue because of its potential impact on the labour market. One of the growing concerns is about 'entrepreneurship lock' (Fairlie et al., 2011), which is believed to keep people in wage employment and hence potentially reduce job search and job matching, triggering labour market inefficiencies by impeding entrepreneurial activities if health insurance is linked to wage employment (Gumus and Regan, 2015). The term was coined by Fairlie et al. (2011) to distinguish it from 'job lock' (i.e. the effect of health insurance on job mobility in general). This perspective is influenced by the job-lock literature pioneered by Madrian et al. (1994) and Gruber and Madrian (1994) on the American labour market, which, in turn, is based on 
the idea of the job matching component of productivity by Jovanovic (1979). It is argued that the productivity of the whole economy is reduced if a better job match is impeded because someone who wants to move chooses to stay in his or her current job just because of the health benefit attached (Madrian et al., 1994). In that logic, Holtz-Eakin et al (1996) examine the effect of health insurance on entrepreneurial activity and hypothesise that employer-sponsored health insurance impedes people from leaving their wage job for self-employment. However, he finds no significant evidence to support the hypothesis (Holtz-Eakin et al., 1996). Since then, the body of literature on entrepreneurship lock has been developed further with several studies on the US. In examining labour force transition in the middle age, Zissimopoulos and Karoly (2007) study working individuals aged over 51 and suggest that having a retirement health coverage in the current job reduces the likelihood of moving into self-employment in the next period. However, Zissimopoulos and Karoly (2007) investigate the effects of many factors on the transition to self-employment rather than mainly focusing on health insurance. Fairlie et al. (2011) use a regression discontinuity approach to examine the effect of employer-provided health insurance on entrepreneurship in the elderly group at the retirement age cut-off of 65 and find an increase in the business ownership rate from just under to just above 65 years old. Outside the US, Fossen and König (2017) suggest that the public health insurance scheme in Germany, which is only mandatory for public sector workers, tends to decrease the probability of self-employment entry. They find that a cost difference in health insurance premium of 10 Euro per month can reduce the annual entry rate by 1.7 percent (Fossen and König, 2017). Contrary to the entrepreneurship lock argument, health insurance can also have an entrepreneurship promotion effect, depending on the portability of the health insurance package (i.e. whether health insurance is tied to employment or not) (see Chapter 2). Health insurance access either via the employer or a spousal package has been shown to be a significant determinant of being self-employed (Wellington, 2001; Gai and Minniti, 2015). Health insurance reforms that improve access to health insurance for the self-employed through fiscal tools (tax deductibility or tax subsidies) have been shown to increase the probability of self-employment (Heim and Lurie, 2010; Velamuri, 2012; Gumus and Regan, 2015). Similarly, state-level coverage expansion has been found to promote self-employment (Niu, 2014; DeCicca, 2007). In another study on 28 countries in Eastern Europe and Central Asia, Wagstaff and Moreno-Serra (2015) use aggregate data for the period 1990-2004 to show that social health insurance expansion seems to increase the self-employment share of total employment.

Despite its important policy implications, the effect of health insurance on self-employment and self-employment mobility in LMIC is rather under-researched (see Chapter 2). The high level of formal self-employment of the American economy is rather distinctive from the situation in low and middle income economies, which are often characterised by large proportions of informal self-employment. Importantly, the finding for Germany (Fossen and König, 2017) suggests that even in a country with universal health coverage, the health insurance differential between employment categories can negatively affect self-employment entry and hinder labour market efficiency. In other words, the entrepreneurship lock is not exclusively relevant for the American health system where health insurance is tied to employment. This raises the question of the relationship between health insurance and self-employment mobility in other health systems where health insurance schemes differ between wage and self-employment. Besides, the rapid expansion of health insurance coverage in LMIC (Rodin and de Ferranti, 2012; Lagomarsino et al., 2012) and the vital role 
of self-employment in these economies (Gindling and Newhouse, 2014) highlight the urgent need for more research on this issue. For Vietnam, given the role of the self-employment sector in the country - accounting for more than 58 percent of total employment in 2017 (The World Bank, 2018) - coupled with the aforementioned gap in health insurance coverage between self-employed workers and wage earners (Somanathan et al., 2014), it is relevant to investigate the association between insurance and self-employment.

This chapter addresses the third research question by examining the relationship between health insurance and self-employment mobility in Vietnam with a focus on the comparison between the voluntary scheme for the informal sector (mostly self-employed workers) and the compulsory scheme for the formal sector (mostly wage workers). We employ a Probit model with selection on a panel from the Vietnam Household Living Standards Surveys (VHLSS) 2010-2014 to investigate the association between health insurance coverage and self-employment entry and exit over time. To our knowledge, this study will be the first to shed some lights on this topic in Vietnam.

\subsection{The Vietnamese health insurance system}

In Vietnam, the first social health insurance was introduced as a compulsory contributionbased scheme in 1992 for the formal sector to include public servants, people working in state-owned enterprises and private companies (Palmer, 2014). Since then, different schemes have been introduced to different groups of the population. In 2008, all schemes were consolidated into one national SHI programme under the first Health Insurance Law (Socialist Republic of Vietnam, 2008). The latest policy change was the Health Insurance Law Amendment in 2014 (Socialist Republic of Vietnam, 2004) which revised some of the articles in the previous bill and explicitly endorsed universal health coverage by stating that 'health insurance is compulsory for all individuals under this law' (Article 1, Health Insurance Law, 2014). Until 2014, the last period of this study, a majority of insurance holders were part of the SHI under different categories which used to form its predecessors. These included compulsory insurance for the formal sector, free health insurance for the poor, subsidized insurance for the near-poor, free insurance for social assistance recipients (the disabled, veterans and mothers of war martyrs), free insurance for children under six, voluntary insurance for students, the informal self-employed (i.e. farmers and non-farm self-employed workers) and dependants of those in the compulsory scheme (see the history of the SHI in Section 1.1, Chapter 1). In addition to the SHI, there were also other types of private health insurance in the financial market. However, these were often more expensive and exclusively for those who could afford it. These insurances were not managed by the public system.

Despite all schemes having been pooled into one single payment programme, its management remains fragmented (Somanathan et al., 2014), with differences in enforcement mechanism, premium and co-payment rate (see Health Insurance Laws in 2008 and 2014). The current system uses a diminishing premium rate, with the premium being increasingly lower for the next family member who get enrolled into the SHI. For the compulsory and voluntary insurance schemes, different salary bases and contribution rates are used. 
Formal employees are required to contribute two percent of their salary (the remaining four percent are paid by their employers) (Socialist Republic of Vietnam, 2004). By contrast, those covered by the voluntary scheme, contribute six percent of the minimum wage of the public sector (ibid.). The diminishing premium rate then applies to the next enrollee in the family. Due to this dynamic premium formula, it is not straightforward to quantify if the formal or informal workers are paying more in insurance premium. We, however, have evidence of an enforcement gap between the two schemes (Somanathan et al., 2014).

\subsection{Data and Methodology}

We use a panel from the Vietnam Household Living Standards Surveys (VHLSS) 2010-2014 (see the description of the VHLSS in Chapter 1). As multi-purpose surveys, VHLSS do not have detailed information on job characteristics, spousal characteristics (Zissimopoulos and Karoly, 2007) or risk attitude (Van Praag and Cramer, 2001), which have been shown to significantly affect self-employment. Each survey round of the panel collects information of approximately 9,000 households in 3,000 communes in Vietnam. However, the rotating approach used in VHLSS sampling significantly reduces the sample size when the panel structure is used (see Chapter 1). After data cleaning and verification, the original panel includes approximately 1,850 households each wave. We only examine individuals aged 16-65 and individuals surveyed in all three periods. Notably, it is not possible to separate students aged above 16 in the working-age sample because the surveys in 2010 and 2012 did not ask why someone was not working over the last 12 months. Therefore, after attrition checks, we use the legal working age cut-off in Vietnam (16 years old) and the universally accepted working age (16-65) in the literature to draw a sub-sample of working-age people. The panel of working-age individuals has 4,047 observations in 2010, 4,226 observations in 2012 and 4,047 observations in 2014 .

In this chapter, we define someone as self-employed (SE) if the person reported working as a self-employed worker 'over the last 12 months' (either in agriculture or the nonfarm sector). Unlike the self-employment sector in advanced countries, which is mainly represented by formal workers and entrepreneurs, this employment category in LMIC denotes a complex taxonomy. This includes farmers, own account workers, unregistered workers working in household businesses and formal entrepreneurs. Unfortunately, the data only allow us to separate the self-employed by industry (farm and non-farm) but not by legal status (formal/informal). This data limitation implies more caution in interpreting our results because the eligibility of the two health insurance schemes of interest (voluntary and compulsory insurance) is mainly based on the legal status of the employee. Wage employment (WE) and dual employment (DE, i.e. engaged in both self-employment and wage employment simultaneously) are specified based on the self-reported work status 'over the last 12 months'.

We define SE entry and exit based on work transitions from year $t$ to year $t+1$ (i.e. transitions between 2010-2012 and 2012-2014). In particular, entry into SE is defined as a dummy variable, taking the value of 1 if a person moves from WE or DE in year $t$ to SE in year $t+1$. SE entry takes the value of 0 if the individual stayed in WE or DE for both 
periods $t$ and $t+1$. Similarly, SE exit is defined as a dummy to indicate the transition from $\mathrm{SE}$ in year $t$ to WE or DE in year $t+1$. SE exit equates 0 if the person stayed in $\mathrm{SE}$ in both years $t$ and $t+1$. After tracking the SE transitions, we only keep the observations in the baseline years (i.e. two cross-sections in 2010 and 2012).

As work transition depends on the original status (i.e. working or not working), we use a Probit model with sample selection by Van de Ven and Van Praag (1981) to account for selection into the labour market. In a nutshell, this model mimics the Heckman correction (Heckman, 1979), which is designed for explaining a non-dichotomous variable, to apply into a Probit model with a dichotomous variable. However, Van de Ven and Van Praag (1981) use both maximum likelihood and two-stage estimators for comparison to avoid the disadvantages of the Heckman's two-stage estimator. This model has two equations, a selection equation that models the selectivity into the labour market and an outcome equation for SE transitions. For identification, the model requires that the selection equation has at least one exogenous variable that is not in the outcome equation (i.e. identification variable). We use the dummy variable of employment status in 2010 (i.e. the lag value of employment status in 2012) as an identification variable. There are reasons to assume that the labour force participation in 2010 affects that of 2012 . Once a person is in the labour market, his/her employment transition in 2012 does not depend on the labour force participation in the previous time period (in 2010). This use of lag variable reduces the final sample to only include regressors from one time period (2012). The final sample for our analysis consists of 4,226 working individuals in 2012.

Because SE in Vietnam comprises both formal and informal sectors while voluntary insurance is designed for the informal self-employed, the underlying mechanism of employment mobility (or immobility) in the case of entrepreneurship lock (if any) can be varied and aligns with the process of formalisation. We expect that those with a compulsory health insurance in the formal sector (i.e. those working in the public sector or in the formal private sector) will have the tendency to stay in WE or DE, whereas those with a voluntary health insurance (farmers and the informal self-employed in the non-farm sector) are expected to be more likely to move out of SE to WE or DE with a more secured health scheme. The mechanisms are summarised in Table 4.1.

Table 4.1: Entrepreneurship lock mechanisms

\begin{tabular}{lll} 
Movement & Mechanisms & Variable \\
\hline \multirow{2}{*}{ Stay in } & -Informal WE to formal WE & \\
WE/DE & -Informal WE to DE (at least one job is formal) & \multirow{2}{*}{ Entry=0 } \\
& -DE (both are informal) to DE (at least one job is formal) & \\
SE exit & -Informal SE to DE (at least one job is formal) & Exit=1 \\
\hline SE : Self-employment only, WE : Wage employment only, DE : Dual employment &
\end{tabular}

Using lag of labour force participation as the identification variable, in the main equation, we regress SE entry and exit on health insurance coverage, individual and household characteristics, such as gender, marital status, educational attainment, the annual healthcare utilisation (proxied for health status), income per capita per month, household 
size, dependency ratio ${ }^{1}$, work industry (agriculture/non-agriculture). To account for the seasonal effect, we also control for the interview month. We only use the first type of health insurance reported for this analysis as a majority of the surveyed people only have one health insurance scheme.

\subsection{Results}

\subsubsection{Descriptive statistics}

\section{Health insurance coverage}

Table 4.2 provides information on health insurance coverage in Vietnam during 2010-2014. As suggested, health insurance was expanding rapidly during the period, from nearly 60 to 76 percent of the total population. Coverage also increased sharply for working-age people, from around 47 percent in 2010 to 58 percent in 2014. However, despite the rapid pace of coverage expansion, the results seem to be consistent with that of Somanathan et al. (2014) regarding the low enforcement of SHI, especially the contribution-based schemes (voluntary and compulsory schemes). Importantly, other types of private insurance outside the SHI programme were more popular than these contribution-based schemes, suggesting that the SHI programme might not be well received by the general public. This is explained by the observation that people do not have trust in the effectiveness of the system (Somanathan et al., 2014).

1 Dependency ratio is defined as the total number of children under 16 and elderly family members above 65 divided by the household size. 
Table 4.2: Health insurance coverage 2010-2014 (\%)

\begin{tabular}{lrrr} 
& 2010 & 2012 & 2014 \\
\hline Total population & & & \\
No insurance & 41.37 & 36.99 & 33.07 \\
Free health insurance for children under 6 & 8.23 & 5.81 & 3.22 \\
Subsidized health insurance for the poor and the near poor* & 14.07 & 16.87 & 16.07 \\
Free Health insurance for assistance recipients & 5.61 & 6.46 & 9.64 \\
Compulsory health insurance for the formal sector & 9.63 & 10.63 & 11.12 \\
Voluntary insurance & 6.78 & 7.83 & 10.75 \\
Others (private insurances) & 14.31 & 15.41 & 16.13 \\
Number of observations & 6,061 & 6,090 & 5,636 \\
\hline Working-age population & & & \\
No insurance & 52.55 & 46.90 & 41.57 \\
Subsidized health insurance for the poor and the near poor* & 14.13 & 16.06 & 14.99 \\
Free health insurance for assistance recipients & 5.07 & 5.78 & 8.80 \\
Compulsory health insurance for the formal sector & 12.81 & 13.57 & 14.17 \\
Voluntary insurance & 8.37 & 9.49 & 12.85 \\
Others (private insurance) & 7.07 & 8.21 & 7.63 \\
Number of observations & 4,047 & 4,226 & 4,047 \\
\hline
\end{tabular}

Weighted statistics. In this chapter, we only use the first type of health insurance reported.* Until 2014 , the poor were entitled to free health insurance, while the near-poor could benefit from a half-price premium reduction.

\section{The self-employed in Vietnam}

Table 4.3 shows the employment categories in Vietnam during 2010-2014 using the final panel of the working-age population. Similar to other LMIC, Vietnam is characterised by a large share of self-employment, at approximately 54 to 55 percent of total working population during 2010 and 2014. Another important feature is the role of dual employment which makes up around 22 percent of the total working population.

Table 4.3: Employment categories 2010-2014 (\%)

\begin{tabular}{llll} 
Year & $\mathbf{2 0 1 0}$ & $\mathbf{2 0 1 2}$ & $\mathbf{2 0 1 4}$ \\
\hline Total sample (working-age population) & 4,047 & 4,226 & 4,047 \\
Working population rate & 84.53 & 83.64 & 82.83 \\
\hline Total sample of the working population & 3,454 & 3,550 & 3,397 \\
WE only & 24.07 & 24.38 & 24.71 \\
DE & 22.44 & 21.22 & 22.05 \\
SE only & 53.49 & 54.41 & 53.24 \\
\hline
\end{tabular}

DE (Dual employment) denotes the combination of both WE and SE. Weighted statistics.

Table 4.4 provides information on the self-employed in Vietnam. As discussed in section 4.3, the SE sector in a developing country like Vietnam does not only include formal entrepreneurs - the concept of SE is broader and also comprises farmers, own account 
workers, and employees working for household businesses. Therefore, among those engaging in SE in Vietnam (both DE and SE only) during 2010-2014, only about 30-32 percent worked in the non-farm sector while around 68-70 percent were in agriculture. This suggests the dominance of farmers, own account workers and employees in agricultural household businesses in the self-employed population. Additionally, because a majority of agricultural household businesses in Vietnam are informal (Cling et al., 2011) while farmers and own account workers are informal by definition, the self-employed population in our data mostly represents informal workers. This is consistent with Cling et al. (2011) who suggest that the majority of the self-employed in Vietnam is in the informal sector. This is an important finding given that data limitations do not allow us to distinguish formal workers from informal ones within the self-employed. Therefore, the voluntary health insurance scheme which is designed for informal workers is actually targeted to the informal self-employed.

Table 4.4: The profile of the self-employed in Vietnam 2010-2014 (\%)

\begin{tabular}{lrrr} 
Year & $\mathbf{2 0 1 0}$ & $\mathbf{2 0 1 2}$ & $\mathbf{2 0 1 4}$ \\
\hline By sector & & & \\
SE in agriculture & 68.27 & 69.99 & 68.64 \\
SE in the non-farm sector & 31.73 & 30.01 & 31.36 \\
Total & 100 & 100 & 100 \\
\hline By sector and employment category & & & \\
- SE only in agriculture & 41.50 & 44.06 & 42.37 \\
- DE (with SE in agriculture) & 26.76 & 25.93 & 26.27 \\
- SE only in the non-farm sector & 28.95 & 27.89 & 28.34 \\
- DE (with SE in the non-farm sector) & 2.79 & 2.12 & 3.02 \\
Total & 100 & 100 & 100 \\
Total sample of those engaged in SE * & 2,697 & 2,738 & 2,632 \\
\hline
\end{tabular}

Weighted statistics. DE denotes the combination of both WE and SE. * This includes both DE and sole SE.

\section{Employment and employment mobility in Vietnam}

Table 4.5 shows the employment status by insurance scheme. As suggested, a majority of uninsured people are the self-employed (accounting for more than 58 percent of uninsured individuals in all three years), whereas around 72.8 -77.6 percent of people with compulsory insurance are people working in wage jobs. This somehow indicates that these self-employed people are working in the informal sector, and hence do not have compulsory insurance from their jobs, whereas wage earners are more likely to work in the formal sector with compulsory insurance. 
Table 4.5: Employment status by health insurance 2010-2014 (\%)

\begin{tabular}{|c|c|c|c|c|}
\hline 2010 & $\begin{array}{l}\text { WE } \\
\text { only }\end{array}$ & $\mathrm{DE}$ & $\begin{array}{c}\text { SE } \\
\text { only }\end{array}$ & Total \\
\hline No insurance & 18.81 & 22.67 & 58.51 & 100.00 \\
\hline Subsidized health insurance for the poor and the near poor* & 11.43 & 28.49 & 60.08 & 100.00 \\
\hline Free health insurance for assistance recipients & 4.67 & 27.60 & 67.73 & 100.00 \\
\hline Compulsory health insurance for the formal sector & 72.80 & 18.39 & 8.81 & 100.00 \\
\hline Voluntary insurance & 14.04 & 15.83 & 70.12 & 100.00 \\
\hline Others (private insurance) & 12.54 & 12.87 & 74.59 & 100.00 \\
\hline Total & 24.07 & 22.44 & 53.49 & 100.00 \\
\hline Number of observations & 831 & 775 & 1,848 & 3,454 \\
\hline \multicolumn{5}{|l|}{2012} \\
\hline No insurance & 17.74 & 22.26 & 59.99 & 100.00 \\
\hline Subsidized health insurance for the poor and the near poor* & 11.58 & 26.77 & 61.65 & 100.00 \\
\hline Free health insurance for assistance recipients & 2.60 & 28.59 & 68.81 & 100.00 \\
\hline Compulsory health insurance for the formal sector & 77.57 & 14.41 & 8.02 & 100.00 \\
\hline Voluntary insurance & 14.06 & 13.88 & 72.07 & 100.00 \\
\hline Others (private insurance) & 13.70 & 11.98 & 74.32 & 100.00 \\
\hline Total & 24.38 & 21.22 & 54.41 & 100.00 \\
\hline Number of observations & 865 & 753 & 1,932 & 3,550 \\
\hline \multicolumn{5}{|l|}{2014} \\
\hline No insurance & 18.90 & 21.37 & 59.73 & 100.00 \\
\hline Subsidized health insurance for the poor and the near poor* & 13.80 & 32.35 & 53.85 & 100.00 \\
\hline Free health insurance for assistance recipients & 4.35 & 26.91 & 68.74 & 100.00 \\
\hline Compulsory health insurance for the formal sector & 76.53 & 16.33 & 7.14 & 100.00 \\
\hline Voluntary insurance & 12.10 & 16.54 & 71.36 & 100.00 \\
\hline Others (private insurance) & 18.01 & 10.84 & 71.15 & 100.00 \\
\hline Total & 24.71 & 22.05 & 53.24 & 100.00 \\
\hline Number of observations & 839 & 749 & 1,809 & 3,397 \\
\hline
\end{tabular}

Weighted statistics. The number of observations is rounded up.

Table 4.6 shows the patterns of mobility in employment status in Vietnam during 2012-2014. As illustrated, the rigidity of the economy was relatively strong. After two years between 2012 and 2014, more than 85 percent of the working population stayed in the same sector, whereas as only 14 percent entered or exited SE. The rigidity is the most pronounced among the formal workers: nearly 97 percent did not enter SE. This is reasonable as SE jobs in Vietnam are mostly in the informal sector (farmers, informal household businesses), it is sensible that those with a formal jobs - which are better off with more social protection - do not want to quit for SE opportunities. 
Table 4.6: Self-employment entry and exit 2012-2014 (\%)

\begin{tabular}{lrrrrrr}
\hline & \multicolumn{3}{c}{ SE entry } & \multicolumn{3}{c}{ SE exit } \\
& $\begin{array}{l}\text { Stay in } \\
\text { DE/WE entry }\end{array}$ & Total & $\begin{array}{l}\text { Stay } \\
\text { in SE }\end{array}$ & $\begin{array}{l}\text { SE } \\
\text { exit }\end{array}$ & Total \\
& & & & & & \\
\hline No insurance & 80.48 & 19.52 & 100 & 86.64 & 13.36 & 100 \\
Insurance for the poor and the near poor & 82.67 & 17.33 & 82.78 & 100 & 17.22 & 100 \\
Insurance for assistance recipients & 72.98 & 27.02 & 86.36 & 100 & 13.64 & 100 \\
Compulsory insurance in the formal sector & 96.93 & 3.07 & 100 & 72.73 & 27.27 & 100 \\
Voluntary health insurance & 87.15 & 12.85 & 100 & 86.79 & 13.21 & 100 \\
Others (private insurance) & 88.35 & 11.65 & 100 & 79.76 & 20.24 & 100 \\
\hline Total & 85.87 & 14.13 & 100 & 85.51 & 14.49 & 100 \\
Observations & 1199 & 197 & 1,396 & 1,519 & 257 & 1,776 \\
\hline
\end{tabular}

Weighted statistics. The number of observations is rounded up. This uses the final sample of 2012 after tracking SE transitions and only includes those participating in the labour force. SE entry (or exit) is defined as moving into (or out of) SE from (or to) WE or DE.

\subsubsection{Estimation results}

Tables 4.7-4.8 show the results of SE transitions during 2012-2014 (coefficients reported). Table 4.9 reports the average marginal effects conditional on the selection into the labour market. We use maximum-likelihood estimation for asymptotic efficiency and estimate clustered standard errors on the household level.

As suggested in Tables 4.7-4.8, we reject the null hypothesis of independent equations ( $\mathrm{P}$ values of entry and exit regressions are 0.082 and 0.024 ). In other words, the selectivity is confirmed for both SE entry and exit. According to Table 4.7, conditional on the participation in the labour market, those having compulsory health insurance (the formal workers) in 2012 are significantly less likely to move into SE in 2014 compared to those with voluntary insurance (the informal workers). In particular, on average, people with compulsory insurance are 10 percentage points less likely to move into SE in the next time period (see Table 4.9). This effect is significant at five significance level. Regarding SE exit, those having compulsory insurance are more likely to exit SE compared to those covered by voluntary insurance (see Table 4.8). This effect is statistically significant at five percent significance level. However, the effect size (average marginal effect conditional on labour force participation) is relatively negligible (see Table 4.9) . 
Table 4.7: Probit Selection Model - SE entry

\begin{tabular}{|c|c|c|}
\hline Equation & Selection & Main \\
\hline Dependent variable & LFP & SE entry \\
\hline Age squared & $\begin{array}{c}-0.004^{* * *} \\
(0.00)\end{array}$ & $\begin{array}{c}0.000 \\
(0.00)\end{array}$ \\
\hline Age & $\begin{array}{c}0.264^{* * *} \\
(0.04)\end{array}$ & $\begin{array}{l}0.003 \\
(0.04)\end{array}$ \\
\hline Male & $\begin{array}{c}0.739^{* * *} \\
(0.12)\end{array}$ & $\begin{array}{c}-0.169^{*} \\
(0.10)\end{array}$ \\
\hline Household size & $\begin{array}{c}-0.095^{* *} \\
(0.04)\end{array}$ & $\begin{array}{l}-0.008 \\
(0.04)\end{array}$ \\
\hline Dependency ratio & $\begin{array}{l}0.136 \\
(0.36)\end{array}$ & $\begin{array}{l}0.155 \\
(0.29)\end{array}$ \\
\hline Marital status (base: married individuals) & & \\
\hline -Single & $\begin{array}{l}-0.179 \\
(0.20)\end{array}$ & $\begin{array}{l}-0.094 \\
(0.18)\end{array}$ \\
\hline -Widowed/ Divorced/ Separated & $\begin{array}{l}0.145 \\
(0.28)\end{array}$ & $\begin{array}{l}-0.395 \\
(0.26)\end{array}$ \\
\hline Number of health care utilization per year & $\begin{array}{l}-0.135 \\
(0.09)\end{array}$ & $\begin{array}{l}0.030 \\
(0.08)\end{array}$ \\
\hline Urban(dummy) & $\begin{array}{l}-0.119 \\
(0.13)\end{array}$ & $\begin{array}{l}-0.130 \\
(0.13)\end{array}$ \\
\hline Monthly income per capita (in millions VND) & $\begin{array}{l}-0.045 \\
(0.05)\end{array}$ & $\begin{array}{l}0.013 \\
(0.05)\end{array}$ \\
\hline Health insurance (base: voluntary insurance) & & \\
\hline -No insurance & $\begin{array}{l}0.332 \\
(0.21)\end{array}$ & $\begin{array}{l}0.287 \\
(0.21)\end{array}$ \\
\hline -Health insurance for the poor and the near poor & $\begin{array}{l}0.322 \\
(0.24)\end{array}$ & $\begin{array}{l}0.279 \\
(0.23)\end{array}$ \\
\hline -Health insurance for assistance recipients & $\begin{array}{c}0.059 \\
(0.31)\end{array}$ & $\begin{array}{c}0.364 \\
(0.28)\end{array}$ \\
\hline -Compulsory insurance in the formal sector & $\begin{array}{c}1.361^{* * *} \\
(0.24)\end{array}$ & $\begin{array}{c}-0.550^{* *} \\
(0.27)\end{array}$ \\
\hline -Others (private insurance) & $\begin{array}{c}-1.094^{* * *} \\
(0.35)\end{array}$ & $\begin{array}{r}-0.380 \\
(0.59)\end{array}$ \\
\hline Work in agri/aquaculture sector & $\begin{array}{c}7.385^{* * *} \\
(0.42)\end{array}$ & $\begin{array}{c}0.461^{* * *} \\
(0.12)\end{array}$ \\
\hline Labour force participation in 2010 (identification variable) & $1.821^{* * *}$ & \\
\hline Number of observations & 1,832 & 1,832 \\
\hline
\end{tabular}

Wald test of independent equations

$\begin{array}{ll}\rho & 0.327\end{array}$

$\mathrm{P}$ value (Probability $>\chi^{2}$ ) 0.082

LFP: Labour force participation. Standard errors in parentheses. ${ }^{*} p<0.1,{ }^{* *} p<0.05,{ }^{* * *} p<0.01$. Educational attainment and month of interview are included and statistically significant. Coefficients reported. Standard errors are clustered on the household. Maximum likelihood estimation is used. 
Table 4.8: Probit Selection Model - SE exit

\begin{tabular}{|c|c|c|}
\hline Equation & Selection & Main \\
\hline Dependent variable & LFP & SE exit \\
\hline Age squared & $\begin{array}{c}-0.003^{* * *} \\
(0.00)\end{array}$ & $\begin{array}{c}-0.001^{* *} \\
(0.00)\end{array}$ \\
\hline Age & $\begin{array}{c}0.243^{* * *} \\
(0.04)\end{array}$ & $\begin{array}{l}0.038 \\
(0.03)\end{array}$ \\
\hline Male & $\begin{array}{c}0.178 \\
(0.12)\end{array}$ & $\begin{array}{c}0.312^{* * *} \\
(0.08)\end{array}$ \\
\hline Household size & $\begin{array}{c}-0.082^{*} \\
(0.05)\end{array}$ & $\begin{array}{c}-0.068^{* *} \\
(0.03)\end{array}$ \\
\hline Dependency ratio & $\begin{array}{l}0.175 \\
(0.32)\end{array}$ & $\begin{array}{l}-0.239 \\
(0.24)\end{array}$ \\
\hline Marital status (base: married individuals) & & \\
\hline -Single & $\begin{array}{c}-0.761^{* * *} \\
(0.23)\end{array}$ & $\begin{array}{l}0.346^{*} \\
(0.19)\end{array}$ \\
\hline -Widowed/ Divorced/ Separated & $\begin{array}{c}-0.365^{*} \\
(0.22)\end{array}$ & $\begin{array}{l}0.212 \\
(0.19)\end{array}$ \\
\hline Number of health care utilization per year & $\begin{array}{c}-0.086 \\
(0.09)\end{array}$ & $\begin{array}{l}-0.007 \\
(0.06)\end{array}$ \\
\hline Urban(dummy) & $\begin{array}{l}0.006 \\
(0.13)\end{array}$ & $\begin{array}{l}-0.165 \\
(0.12)\end{array}$ \\
\hline Monthly income per capita (in millions VND) & $\begin{array}{l}0.073^{*} \\
(0.04)\end{array}$ & $\begin{array}{c}-0.057^{*} \\
(0.03)\end{array}$ \\
\hline \multicolumn{3}{|l|}{ Health insurance (base: voluntary insurance) } \\
\hline -No insurance & $\begin{array}{l}0.212 \\
(0.18)\end{array}$ & $\begin{array}{l}-0.111 \\
(0.13)\end{array}$ \\
\hline -Health insurance for the poor and the near poor & $\begin{array}{r}-0.240 \\
(0.24)\end{array}$ & $\begin{array}{l}-0.082 \\
(0.17)\end{array}$ \\
\hline -Health insurance for assistance recipients & $\begin{array}{c}-0.343 \\
(0.27)\end{array}$ & $\begin{array}{c}-0.008 \\
(0.19)\end{array}$ \\
\hline -Compulsory insurance in the formal sector & $\begin{array}{c}-0.891^{* *} \\
(0.36)\end{array}$ & $\begin{array}{c}0.712^{* *} \\
(0.33)\end{array}$ \\
\hline -Others (private insurance) & $\begin{array}{c}-0.601^{*} \\
(0.31)\end{array}$ & $\begin{array}{l}-0.121 \\
(0.28)\end{array}$ \\
\hline Work in agri/aquaculture sector & $\begin{array}{c}9.397^{* * *} \\
(0.25)\end{array}$ & $\begin{array}{l}0.171 \\
(0.11)\end{array}$ \\
\hline Labour force participation in 2010 (identification variable) & $2.130^{* * *}$ & \\
\hline Number of observations & 2,156 & 2,156 \\
\hline
\end{tabular}

Wald test of independent equations

$\begin{array}{ll}\rho & 0.397\end{array}$

$\mathrm{P}$ value (Probability $\left.>\chi^{2}\right) \quad 0.024$

LFP: Labour force participation. Standard errors in parentheses. ${ }^{*} p<0.1,{ }^{* *} p<0.05,{ }^{* * *} p<0.01$. Educational attainment and month of interview are included and statistically significant. Coefficients reported. Standard errors are clustered on the household. Maximum likelihood estimation is used. 
Table 4.9: Average marginal effect (conditional on selection into the labour market)

\begin{tabular}{lcc}
\hline & SE entry & SE exit \\
\hline Age & $0.004^{* * *}$ & -0.005 \\
Male & $(0.00)$ & $(0.05)$ \\
& $-0.056^{* *}$ & 0.069 \\
Household size & $(0.02)$ & $(0.70)$ \\
& 0.001 & -0.014 \\
Dependency ratio & $(0.01)$ & $(0.16)$ \\
Marital status (base: married individuals) & 0.030 & -0.062 \\
-Single & $(0.06)$ & $(0.48)$ \\
& & \\
-Widowed/ Divorced/ Separated & -0.016 & 0.000 \\
Number of health care utilization per year & $(0.04)$ & $(0.00)$ \\
Urban(dummy) & $-0.077^{*}$ & 0.000 \\
Monthly income per capita (in millions VND) & $(0.04)$ & $(0.00)$ \\
Health insurance (base: voluntary insurance) & 0.010 & 0.001 \\
-No insurance & $(0.02)$ & $(0.05)$ \\
& -0.025 & -0.039 \\
-Health insurance for the poor and the near poor & $(0.03)$ & $(0.36)$ \\
-Health insurance for assistance recipients & 0.004 & -0.016 \\
-Compulsory insurance in the formal sector & $(0.01)$ & $(0.12)$ \\
-Others (private insurance) & & \\
Work in agri/aquaculture sector & 0.057 & 0.000 \\
Labour force participation in 2010 (identification variable) & $(0.05)$ & $(0.00)$ \\
& 0.055 & 0.000 \\
Number of observations & $(0.05)$ & $(0.00)$ \\
Stant & 0.086 & 0.000 \\
& $(0.07)$ & $(0.00)$ \\
& $-0.102^{* *}$ & 0.000 \\
& $(0.05)$ & $(0.00)$ \\
& -0.037 & 0.000 \\
& $(0.10)$ & $(0.00)$ \\
& -0.090 & -0.240 \\
& 1,832 & 2,156 \\
\hline
\end{tabular}

Standard errors in parentheses. ${ }^{*} p<0.1,{ }^{* *} p<0.05,{ }^{* * *} p<0.01$. Educational attainment and month of interview are included and statistically significant. Standard errors are clustered on the household. Maximum likelihood estimation is used.

\subsection{Robustness checks}

\section{Endogeneity of health insurance}

One concern is the potential endogeneity of health insurance as there is adverse selection in enrolling into the SHI programme, especially for those who sign up for voluntary insurance 
(Somanathan et al., 2014). One can argue that there are idiosyncratic shocks that may affect health insurance enrolment and income, which in turn, affects employment choices. Additionally, risk-taking behaviour, which was not controlled for in the above models due to data limitation, might affect health insurance enrolment while potentially affecting self-employment choices. Therefore, we conducted different endogeneity tests to address this concern. In particular, we used Wald tests for Probit regressions and Durbin-Wu Hausman tests for OLS regressions of SE entry and exit. We concluded that endogeneity of health insurance is unproblematic in this research (see Appendices B1-B3 for more details).

\section{Dual employment and wage employment}

As DE and WE are necessarily different in essence. We also re-conducted the analysis that separate these two forms of employment (See Appendices B4 and B5). As suggested, there is no big difference between DE and WE regarding SE entry and exit. In general, all effect signs are consistent across different definitions of SE entry and exit. However, the effects are not statistically significant any more compared to the results in Tables 4.7-4.8. The loss of statistical significance is probably due to the reduction in sample size when we separate WE from DE.

\subsection{Discussion}

In this study, we have shown that health insurance has a strong association with SE entry. In particular, those insured by compulsory health insurance are less likely to enter SE compared to those having the voluntary insurance. On average, the probability of moving into SE relative to staying outside SE for those with compulsory insurance is around 10 percentage point less than that of people covered by voluntary insurance. The effect is statistically significant at five percent significance level and consistent with our hypothesis of entrepreneurship lock.

Regarding SE exit, those having compulsory insurance are more likely to exit SE compared to those covered by voluntary insurance. However, the average marginal effect is relatively negligible. We initially hypothesised that self-employed workers with voluntary insurance those in the informal sector - are more likely to exit SE to find a more secure job with a more guaranteed health insurance. What we find is consistent with this hypothesis, but the average effect size is rather negligible. This might be due to the small number of observations of these two insurance categories as our SE exit definition by default only includes self-employed workers in 2012 who were less likely to be covered by either of the schemes.

Albeit the small effect size (see Table 4.9), the significantly positive effect of compulsory insurance on SE exit suggests that self-employed workers with compulsory insurance in the formal sector are more likely to exit SE than the self-employed in the informal sector with 
voluntary insurance (farmers, own account workers, unregistered household employees). This suggests that it is easier for the formal self-employed to move out of the high risk sector and find other job opportunities in WE or DE while the informal self-employed are somehow stuck where they are. This is consistent with Gindling and Newhouse (2014) who suggest that the self-employed in developing countries are pushed into lower paid self-employment out of necessity rather than opportunity. This might be the case for Vietnam, since in our regressions we only controlled for educational attainment, excluding many other important individual characteristics that determine SE exit like experience, social network and so on due to data limitations.

Because, to our knowledge, this is the first study that looks at the relationship between health insurance and self-employment in LMIC, it is difficult to compare our results with other studies which are mainly about the US. Additionally, health regimes are very varied even within LMIC, so any attempt to compare the results should be done with caution. Wagstaff and Moreno-Serra (2015)'s study on Central Asian and Eastern European countries with very similar SHI systems examines the issue from a macro perspective and hence is not necessarily comparable to our micro analysis. The closest study is by Zissimopoulos and Karoly (2007) who use a Multinomial Logit model and track the transition into SE from one data wave to the next. They suggest a 0.7 and 0.1 percentage point decrease in transition to SE for salary men and women. Fairlie et al. (2011) report an increase of 0.013 percentage points in transition into SE for the elderly at the age cut off of 65 . These two studies seem to suggest very small effect sizes compared to our results - probably because they focus on older workers, while we examine the whole working-age population. It is intuitive that the effect size for the elderly is smaller than the general working-age population as the former are less likely to participate in the labour market in general and in self-employment in particular.

Additionally, entrepreneurship lock is more pronounced for the US (Zissimopoulos and Karoly, 2007; Fairlie et al., 2011) due to the institutional link between health insurance and employment. In Vietnam, the effect caused by health insurance might not be that strong by design, owing to the availability of the voluntary health insurance for informal workers. Therefore, our analysis might overestimate the effect size as it could not distinguish health insurance from other fringe benefits which are normally attached to formal jobs and the public sector. This is caused by data limitations, enabling us to capture only the correlation between health insurance and SE mobility rather than causality. Therefore, the interpretation of our results should emphasise that people with compulsory insurance are locked in WE and DE due to the benefits attached to the job (job security, other fringe benefits, income prospects), and that insurance coverage is just one reason among them.

The biggest limitation of this study lies in the potential omitted variable bias due to the cross-sectional nature of our analysis. Even though we have panel data, work transitions are not repeated over time for the same individual. Therefore, we took advantage of the panel structure by using the lag of employment as an identification variable in the selection equation ${ }^{2}$. However, the risk of omitted variable bias was not avoidable as we could not control for many characteristics (e.g. characteristics and employment status of the spouse, self-employment experience, risk attitude) which have been shown to impact

2 We also used the lag of health insurance to rule out the endogeneity of health insurance in the robustness checks. 
SE decisions (Gai and Minniti, 2015; Van Praag and Cramer, 2001).

Despite the limitation, we can show the correlation between health insurance and SE mobility. In Vietnam, because SE is highly overlapping with the informal sector, this suggests a relationship between health insurance and the formality of employment. In other words, the design of the SHI that separates the formal sector from the informal sector, which then has been translated into the enforcement issue and coverage gap, seems to contribute to the rigidity of the labour market. Our evidence suggests that the differential between various health insurance schemes can may be associated with self-employment mobility. The entrepreneurship lock effect is not necessarily a unique feature of the American health system where health insurance is exclusively locked to employment.

The labour market rigidity suggested leads one to discuss the potential economic inefficiency as well as the role of entrepreneurship in the Vietnamese economy. Based on the efficiency argument (Jovanovic, 1979), it is recommended to tackle the link between health insurance and employment. Even though the voluntary insurance for the informal workers is designed to remove this link, the weak enforcement of this scheme compared to the compulsory package seems to fortify this undesirable link in the labour market. Therefore, a financial incentive to encourage insurance enrolment might not be sufficient. Awareness raising, which has been shown to increase the willingness to pay for SHI premium (Nguyen and Hoang, 2017), is needed to tackle the enforcement issue. Additionally, efficiency improvement of the SHI system as well as improved quality of care is vital when people do not trust the effectiveness of SHI (Somanathan et al., 2014).

Moreover, one should be cautious in using the efficiency argument to promote selfemployment in Vietnam because better job matching and more flexibility in an economy of high concentration of the informal sector might imply moving out of the formal sector. SE in Vietnam is normally associated with the informal sector with smaller firms/economic formations and less labour protection. By contrast, the related literature, due to its focus on the US with a very high level of economic formalisation, tend to ignore labour protection while promoting entrepreneurship with the aim of improving market efficiency and flexibility. With increasing concern regarding the erosion of labour protection due to weak compliance and disguised employment in LMIC (ILO, 2015), the policy choice may be pushing for the formalisation of the informal economy, combined with entrepreneurship promotion policies for the formal self-employment sector. In the context of Vietnam, where a large proportion of workers are working in the shadow economy (Cling et al., 2011), the transition towards the formal economy might be challenging in the short term. Therefore, in the short run, the focus should be on improving the depth and breath of the SHI coverage to discourage averse selection, tackling the enforcement issue of the voluntary scheme via a compulsory mandate to reduce the rigidity and inflexibility of the economy induced by health insurance benefits. 


\subsection{Conclusion}

Even though the relationship between health insurance and self-employment mobility can have important labour market implications, we know very little about this in the context of LMIC. In this chapter, we have used a Probit model with sample selection to estimate the association between health insurance in Vietnam and the mobility in and out of SE. Even though we are not able to identify causal effects, we show that those with compulsory health insurance in Vietnam, the formal workers, are less likely to start a business compared to those having voluntary insurance. The effect is partly explained by the higher enforcement of the compulsory health insurance scheme in Vietnam which made staying out of SE (often informal SE) a preferred choice. Regarding the effect of health insurance on SE exit, we find that those with compulsory insurance are more likely to exit SE (even though is average marginal effect is relatively small in size). The rigidity of the economy is highlighted, suggesting the need to tackle the enforcement issue of the SHI programme in Vietnam in addition to other labour policies. 

Chapter 5

\section{Health insurance and patient satisfaction with medical care}

This chapter is based on

Lê, N., Groot W., Tomini, S.M., and Tomini, F. (2018). Health insurance and patient satisfaction: Evidence from the poorest regions of Vietnam. UNU-MERIT Working Paper 2018-040. 


\begin{abstract}
Even though health insurance is expanding rapidly in Vietnam, its coverage is not effective. There remain inefficiencies in the healthcare system and quality concerns, especially at primary care and in remote areas. However, very little is known about how health insurance is valued by people and whether health insurance coverage can translate into better healthcare quality. This chapter addresses the final research question by investigating the relationship between health insurance and patient satisfaction with medical care in the poorest regions of Vietnam. We use multi-level models for ordinal responses on a cross-sectional dataset of the poorest regions of Vietnam in 2012. We find that it is not health insurance per se but its financial coverage that matters to improve patient satisfaction with medical services. Patient satisfaction depends on the depth of insurance coverage (i.e. services and medicines covered, and the co-payment rate for each service) and the ability to use health insurance to reduce medical costs.
\end{abstract}




\subsection{Introduction}

Despite recent efforts towards Universal Health Coverage, the availability of health insurance has not been translated into effective coverage in Vietnam (Somanathan et al., 2014). One frequently cited reason is the chronic lack of funds and competent medical staff in primary care services, which serve as gate-keepers (Lieberman and Wagstaff, 2009; Somanathan et al., 2014). In 2013, only two-thirds of commune healthcare stations had a medical doctor (Somanathan et al., 2014). Due to inequalities in the allocation of human and financial resources between rural and urban regions, the shortage of healthcare workers and resources is even more severe in remote areas (Lieberman and Wagstaff, 2009; Somanathan et al., 2014). For example, in the North Western region, the poorest region of Vietnam, the share of commune healthcare stations with a medical doctor in 2013 was only one-third (Somanathan et al., 2014). Healthcare workers in rural and remote areas have to work under the shortage of medical equipment and continuous training (Takashima et al., 2017). People living in rural and disadvantaged regions face various socio-economic barriers to access, including long distance to healthcare facilities, poor service quality in primary care, and unaffordability (Tran et al., 2016). Whereas, they are more likely to use the lowest level of care (commune healthcare stations) which is of rather poor quality (ibid.). With limited resources in primary care (especially in rural and disadvantaged areas), combined with a lack of trust in the capability of medical staff (Thanh, 2015; Quoc, 2015), many insured patients decide to skip the referral line for tertiary care due to quality concerns (ibid.). This creates overcrowding and excessive demand for tertiary care (Somanathan et al., 2013) and negatively affects the quality of care at this level. In many central and provincial hospitals, it is rather common that two or three patients have to share one bed (Cheng, 2014). The excessive demand, in turn, triggers informal payments in the health sector (Vian et al., 2012). Finally, because not all self-referred care is covered by the Social Health Insurance programme $(\mathrm{SHI})^{1}$, the perceived poor quality of primary care leads to another issue: the non-use of health insurance among the insured who willingly skip the line and pay the total cost out-of-pocket (Thanh, 2015; Quoc, 2015).

Worryingly, another issue that weakens the effectiveness of the medical system is the discrimination against insurance holders by medical staff (see the media coverage by Dang, 2013; Kim and Vu, 2013; Duong, 2014). Among discrimination cases reported by the media, poor attitude of medical staff towards insured patients (normally in the form of a lack of friendliness and attention) is the most common (Duong, 2014). In a testimony to the National Assembly (i.e. the Parliament), the Vietnamese Minister of Health claims that the perceived discrimination is due to the huge quality gap between SHI-commissioned healthcare services (i.e. mostly public services) and premium services within the same public facilities (quoted in Duong, 2014). The premium services, which are uncovered by the SHI programme, are designed to target those who are willing to pay more to get better care. These services have been developed during the decentralisation and privatisation of healthcare services in the late 1980s and early 1990s as a departure

\footnotetext{
1 The Insurance Law in 2008 mandated a higher co-payment rate for self-referred care. In 2014, it was then revised to exclude self-referred outpatient care in SHI coverage to discourage patients from skipping the referral system.
} 
from the centrally subsidized model. Public hospitals have been encouraged to collect user-fees to offset the sharp reduction in public subsidies while private investment into public hospitals has been allowed based on a profit-sharing mechanism (Ramesh, 2013). The decentralisation policy has allowed public service providers to generate and retain revenues to deal with the chronic lack of funds and low wages for medical staff (Ramesh, 2013; Lieberman and Wagstaff, 2009). Retained profits are partly shared among medical staff as bonus (Lieberman and Wagstaff, 2009) to compensate for the low public wage. Recently, with the aim of cutting government expenditure and improving public service quality, the Government has encouraged public service providers to become financially self-sufficient (Socialist Republic of Vietnam, 2015). The Ministry of Health has further urged public hospitals to become entirely independent of public finance. The privatisation in public hospitals has been further encouraged and many public hospitals have equipment owned by private partners (Ramesh, 2013). Therefore, under Vietnam's policy of social mobilisation of financial resources ('Xa hoi hoa' in Vietnamese), the transformation of public hospitals in Vietnam, is 'merely a form of privatisation in which services remain public but users have to pay for using them' (Ramesh, 2013, p.408). The concept of 'public hospitals' in Vietnam has become very questionable as they pursue profit while competing with facilities at lower levels (Ramesh, 2013). To generate more revenue, many public hospitals currently have two types of healthcare services, one being affordable and tied to the SHI for the general public and the other providing premium services for those who can afford and willing to pay for them out-of-pocket. The two differ in terms of service fees, capitation rates, facilities and infrastructure, leading to a difference in waiting lines and waiting time (Duong, 2014). Services covered by SHI are lowly priced with price caps and a list of drugs covered while premium services are more flexible in their pricing and prescription, offering patients more luxurious and expensive services based on their willingness to pay (MOH and MOF, 2009). Uninsured people who can not afford premium services can choose the public services and pay the total amount out-of-pocket, whereas insured people who use public services can benefit from the financial benefits of health insurance in the form of co-payments. As a result, the existence of two levels of quality within the same facility may have undesirable effects for the insured who are sometimes discriminated against by medical staff (Dang, 2013; Kim and Vu, 2013; Duong, 2014). The undesirable behaviour of medical staff may be triggered by the goal of profit maximization of public hospitals in Vietnam (Ramesh, 2013), whereby they tend to favour patients who pay more for premium services.

All suggests that the Vietnamese healthcare system is having many inefficiencies and quality issues (Takashima et al., 2017), which are not necessarily resolved by the provision of health insurance. We, however, know very little about how health insurance is valued by people and whether health insurance coverage translates into quality healthcare for those in need. With quality concerns, evaluating healthcare quality in Vietnam has become more urgent than ever, especially in poor and remote regions which have far more limited healthcare resources and access (Somanathan et al., 2014; Tran et al., 2016). Among quality measures, patient satisfaction, a subjective quality measure, is an important indication of how much the current healthcare system satisfies the need of patients despite its challenges and limitations. In the context of the rapid health coverage expansion in Vietnam and the limitations in the quality of care in rural areas (Tran et al., 2016), it is important to investigate if health insurance is able to make rural people, especially the poor and the vulnerable, satisfied with the care they receive. 
This chapter addresses the final research question by investigating the association between health insurance and satisfaction with care of those who live in the remote and poor areas of Vietnam. We employ multilevel ordered logistic regression models and a dataset that covers the poorest and most disadvantaged communes in Vietnam. To our knowledge, the present chapter is the first study to investigate subjective quality evaluation of healthcare services in Vietnam. Our study contributes to the literature in several ways. First, we pioneer in researching patient satisfaction in Vietnam especially for the rural remote areas where the quality of medical services is currently of big concern due to rural-urban inequality in health resource allocation. Second, we contribute to the under-researched literature on the relationship between health insurance and patient satisfaction.

\subsection{Literature review}

This section provides a review of the concept of patient satisfaction as a measure of healthcare quality. We also summarise prior related literature on patient satisfaction to highlight the literature gap that needs to be filled.

\section{The patient satisfaction concept}

Patient satisfaction is a subjective measure of healthcare quality, which is powerful in providing information on patient preferences and expectations (Ware Jr et al., 1983). To emphasize the intrinsically subjective nature of the concept, Linder-Pelz (1982) refers to sociological and social psychological theories, such as fulfilment theory (Lawler, 1971), discrepancy theory (Lawler, 1971), social comparison theory (Kelley et al., 1966) and the theoretical distinction between attitude and perception by Fishbein and Ajzen (1975) to present a framework of determinants of patient satisfaction. In the framework, Linder-Pelz (1982, p.578) identifies five 'antecedent social psychological variables' that construct patient satisfaction, namely expectation, value evaluation, entitlement perception, occurrences and interpersonal comparisons. In other words, patient satisfaction reflects the subjective patient perception of and attitude towards the care received in the context of their pre-defined expectations and value system of what medical care should be.

Because of this subjective quality, the measurement of patient satisfaction has received a number of criticisms. It is criticised for not reflecting the objective reality nor the perceptions of healthcare providers and administrators (Ware Jr et al., 1983). Therefore, Ware Jr et al. (1983, p.247) propose to distinguish between objective evaluation ('reports about providers and care') and subjective evaluation ('satisfaction rating'). Williams (1994) challenges the validity of the patient satisfaction concept by highlighting the flaws of all assumptions widely used in conceptualizing, modelling and measuring patient satisfaction. He rejects the concept and concludes that there are important patient beliefs that 'cannot be embodied in simple expressions of satisfaction', therefore satisfaction surveys only present 'an illusion of consumerism' that does not necessarily help to improve the status quo (Williams, 1994, p.515). His criticism is in line with the concern that measurement 
surveys have been introduced before any theoretical discussion (Sitzia and Wood, 1997) in response to an increased need in healthcare quality auditing in the health sector in the West in the 1990s (Sitzia and Wood, 1997). Currently, the lack of theoretical foundation in operationalising the concept of patient satisfaction still remains and has been raised in more recent literature (e.g. Gill and White, 2009; Ng and Luk, 2018). While much effort has gone into measurement surveys and research instruments (Gill and White, 2009; Ng and Luk, 2018), there is rarely any theoretical or conceptual development of the concept (ibid.). The use of patient satisfaction concept to evaluate the perceived healthcare quality is 'seriously flawed' as the concept has 'little standardization, low reliability and uncertain validity' (Gill and White, 2009, pg.1). To fill the knowledge gap, there are a few efforts to conceptualise patient satisfaction using a concept analysis approach (e.g. Mahon, 1996; Wagner and Bear, 2009; Ng and Luk, 2018), however, this strand of literature is still in its infancy (Ng and Luk, 2018).

Despite the criticisms, it is undeniable that patient satisfaction is useful in patient evaluation of healthcare. While highlighting the distinction between subjective and objective evaluation, Ware Jr et al. (1983) argue that patient satisfaction's subjectivity is its unique advantage by bringing new insights to the satisfaction measurement. In other words, the failure to reflect the objective situation is an intrinsic feature of any subjective measure. Additionally, despite being very harsh in his criticism, Williams (1994) agrees that patient satisfaction concerns patient beliefs and feelings, which does not necessarily collide with the social psychological constructs defined by Linder-Pelz (1982). It could be argued that the weaknesses of the concept pinpointed by Williams (1994) apply to all subjective evaluations because there will always be feelings and beliefs that cannot be captured in surveys due to the complexity of human psychological processes. The lack of a standardised and universally accepted conceptual framework of patient satisfaction (Gill and White, 2009; Batbaatar et al., 2017) in its essence reflects the complexity of the concept and may not necessarily be the result of its intrinsic flaws. Therefore, the criticisms against patient satisfaction surveys should be viewed from a constructive lens, by supplementing them with objective measures and evaluations from other stakeholders (e.g. medical doctors, health auditors), rather than completely rejecting their value. The theoretical debate is useful in highlighting the multi-dimensionality and complexity of the patient satisfaction concept. Hence, one should be cautious in interpreting the results of patient satisfaction surveys.

\section{Prior literature and the literature gap}

Along with the theoretical literature, there is an abundance of empirical studies on patient satisfaction determinants, resulting in a series of reviews since the 1990s (Hall and Dornan, 1990; Sitzia and Wood, 1997; Batbaatar et al., 2017). The latest synthesis is a systematic review (Batbaatar et al., 2017) that scans all English language studies published during 1980-2014 and comes up with a collection of 109 peer-reviewed articles. They find a huge variation in results due to the lack of a globally accepted framework of defining and measuring patient satisfaction (Batbaatar et al., 2017). The review also suggests that healthcare service quality indicators (such as interpersonal care quality, technical care, accessibility, affordability, availability, the pleasantness of physical surroundings) are 
the most significant predictors of subjective patient satisfaction (ibid.). The effects of socio-demographic characteristics (i.e. age, education, marital status, race) appear to be the most heterogeneous and inconsistent across studies reviewed, implying that these are both predictors and con-founding factors of patient satisfaction (ibid.).

Despite the mounting literature on patient satisfaction determinants, little is known about the relationship between health insurance and patient satisfaction. Health insurance is sometimes examined as a control variable in a very thin literature on this topic. Additionally, this limited literature is overly represented by studies on the American system. A multivariate analysis of parents of children with special care needs in the US shows that lack of health insurance, among other determinants, is associated with patient dissatisfaction with care (Ngui and Flores, 2006). Similarly, children of all types of insurance face challenges in accessing specialty care, among which parents of children insured through Children's Health Insurance Program (CHIP) report the highest levels of frustration in getting treated (Kreider et al., 2016). Another study finds no significant difference in satisfaction with acute medical care between Medicare and private insurance holders (Clark and Gesell, 2010). In a descriptive analysis, Castillo-Laborde et al. (2017) compare the performance of the Chilean public health insurance and the private scheme regarding patient satisfaction and many other indicators. They find a larger proportion of private insurance holders being satisfied or very satisfied with the health system (CastilloLaborde et al., 2017). These studies are very few and scattered among the vast literature on patient satisfaction. Studies for the former Soviet Union countries, which are probably the most similar health systems to Vietnam's, are more about general satisfaction with healthcare (Footman et al., 2013; Luck et al., 2014) or patient and physician evaluations (Luck et al., 2014) rather than the relationship between health insurance and patient satisfaction. For Vietnam, to the best of our knowledge, no reliable evidence is available on patient satisfaction in general and its relationship with health insurance in particular. This is probably because of the heavy focus on objective measures such as accessibility (Tran et al., 2016), out-of-pocket payments (Jowett et al., 2003; Nguyen, 2012; Nguyen and Wang, 2013; Wagstaff, 2010), affordability (Tran et al., 2016) and utilisation (Wagstaff, 2010; Nguyen, 2012; Nguyen and Wang, 2013; Guindon, 2014; Palmer et al., 2015). In the context of the rapid health coverage expansion in Vietnam, it is useful to investigate how health insurance affects the level of satisfaction with medical services to unravel patients' expectations and preferences. However, as discussed above, due to its subjective nature, patient satisfaction or patient evaluations should be used together with other objective quality assessments. For Vietnam, research on patient satisfaction with medical care will compliment the current literature on objective quality measures in mapping a complete picture of healthcare quality.

\subsection{Health insurance and healthcare delivery}

In order to tackle high out-of-pocket payments in the late 1990s, the Vietnamese government has introduced a series of policies to incrementally expand health coverage (Somanathan et al., 2014). Finally, in 2008, different health insurance schemes were consolidated into a single programme called the Social Health Insurance (SHI) (see the history of the SHI in 
Section 1.1, Chapter 1). Despite the shared basket of services, the consolidated programme continues the targeting approach from its predecessors by separating different eligible groups with varied premiums and co-payment rates. Despite the impressive expansion of coverage rate, there remain gaps in financial protection for health (WHO, 2018a), with more than 5 percent of the population incurring high out-of-pocket payments ${ }^{2}$. In 2015, out-of-pocket payments accounted for more than 43 percent of the total health expenditure (The World Bank, 2018). All suggests the lack of breadth and depth of the health insurance coverage ${ }^{3}$ and the unaffordability of health services to a proportion of the population. Additionally, despite the general access is relatively high (WHO, 2018a), access to healthcare in rural and remote area is rather limited (Tran et al., 2016).

Besides budgetary increases in health spending, the government has encouraged the participation of the private sector in healthcare delivery (Ramesh, 2013), leading to the emergence of privately-run healthcare facilities, especially in urban areas. The decentralisation and privatisation have been recognised by law since the 2000s (ibid.). Consequently, healthcare in Vietnam is currently delivered by a wide range of public and private service providers. Public facilities are highly hierarchical, including commune health stations, meso-district polyclinics, district hospitals, provincial hospitals, central hospitals, specialised hospitals and other uncommon facilities such as district maternity clinics ('Nha ho sinh'), medical service centres for vaccination and simple lab tests. In remote regions where commune health stations are far away, community medical officers at the village level are the first contact points of primary care, contributing greatly to the provision of public health services and first aid for rural people (MOH, 2013). Private facilities include private hospitals, polyclinics, specialised clinics, diagnostic testing centres, and evening clinics which are often run by general practitioners or specialists of public hospitals outside office hours. Another under-studied type of care is provided by traditional herbal physicians, which is unique for Vietnam and China (Wahlberg, 2006). Interestingly, the rural population in Vietnam is very self-sufficient in the treatment of common illnesses using traditional herbal medicines, owing to a unique 'ancient history of medicine, post-colonial isolation and extensive health delivery network' (Wahlberg, 2006, p.1).

Despite the rich taxonomy, not all facilities are covered by the SHI programme. To participate in the programme, healthcare facilities need to apply and get commissioned by the VSS (MOH and MOF, 2009). Service delivery under the SHI programme is predominantly provided by public facilities, as more than 81 percent of commissioned facilities in 2016 were public (Thao, 2016). Despite accounting for 19 percent of commissioned facilities, private facilities only made up 7 percent of total healthcare use in 2016 (ibid.). Because commissioned facilities are required to meet certain quality standards, small private clinics in rural areas are less likely to be part of the SHI programme. Additionally, services provided by herbal physicians are not covered by the SHI even though herbal medicine hospitals are part of the system. Importantly, depending on the depth of the coverage, not all services at SHI commissioned facilities (hereafter, SHI facilities) are covered. The

\footnotetext{
2 This is measured by the share of population with out-of-pocket payments higher than 25 percent of total household consumption or income

3 The breadth and depth of health insurance are two dimensions of health insurance's financial protection. Coverage breadth refers to coverage rate, while coverage depth refers to services and medicines covered, the co-payment rates for services and medicines covered
} 
availability of private services within public facilities (Ramesh, 2013; Barroy et al., 2014) further emphasises this issue.

As aforementioned, the notion of 'public hospitals' in Vietnam is challenged as many of them use privately owned equipment and private resources (Ramesh, 2013; Barroy et al., 2014). They even compete with lower level facilities (ibid.), allowing patients to skip the referral line and pay out-of-pocket if they wish. As a consequence, many patients prefer tertiary care due to its higher perceived quality with better medical staff and infrastructure (Ramesh, 2013), whereas financial measures to discourage self-referral are inadequate (Barroy et al., 2014). Over time, hospitals in big cities have become increasingly more competitive compared to lower levels of care, leading to a widening gap in healthcare quality among different levels of care and between geographical regions (rural/urban). Big hospitals also have the incentive to compete with the lower level facilities due to a revenue generation goal. This cross-level competition contributes to weakening the referral system of SHI, making it less attractive. It also partly contributes to the non-use of health insurance among insured patients when seeking care at tertiary facilities (Thanh, 2015; Quoc, 2015) because self-referred out-patient care at central and provincial hospitals are not covered (Socialist Republic of Vietnam, 2014).

\subsection{Data and methodology}

We use the end-line survey of phase two of the largest poverty reduction programme in Vietnam called the National Target Programme for Poverty Reduction, often referred to as Programme 135 as it was first launched under Decision 135/1998/QD-TTg (Socialist Republic of Vietnam, 1998). The dataset is owned by UNDP Vietnam under a commission work by Nguyen et al. (2015) to evaluate the impact of the Programme-II after its closure. The surveys was conducted in 2012 and included 398 communes and 5,668 households (ibid.) (see Chapter 1 for more details).

In this study, the analysis is at the level of healthcare visit which is defined as a realised healthcare need, i.e. either seeking healthcare or self-medication without a prescription. People were asked if they were having any health issue, illness or healthcare need that led them to seek healthcare over the last 12 months. If the response was yes, questions would follow regarding the type of facility visited, type of care, how satisfied they were with the care or the contact with the contact point (in the case of self-treatment, the first contact point will be a pharmacy or a drug stand in a the local market), and how often the individual visited that specific facility over the last 12 months. A visit is identified if the person sought healthcare or realised a need (without seeing a medical staff) over the last 12 months for any reason including illness treatment, check-up, vaccination, pregnancy check, abortion and contraception intervention, self-medication (i.e. buying medicines without prescription). Each visit recorded was related to a distinctive facility. If a person visited one facility multiple times for the same need, it was recorded as one visit with a frequency of visiting that specific facility. In case the person visited different facilities for the same illness/health issue, then it was counted as different visits. The dependent variable (patient satisfaction) is presented as a Likert scale rating, taking values from 
1 to 5 for 'very unsatisfied', 'unsatisfied', 'neutral', 'satisfied' and 'very satisfied'. The independent variable of interest is health insurance coverage that denotes any health scheme of SHI. The sample includes 13,669 realised healthcare needs of 10,369 individuals from 4,556 households.

Because we are only interested in the effect of the SHI (the dominant public health programme) on patient satisfaction, we disregard any realised need that is not linked to SHI facilities. We thus exclude private clinics, pharmacies (in case of self-medication), herbal physicians and other uncommon facilities (see Table 5.3 for the taxonomy of healthcare facilities covered and uncovered). The final sample includes 10,562 healthcare visits to SHI facilities of 8,660 individuals from 4,167 households. It is important to note that even though private facilities can be commissioned by the SHI if they qualify ( $\mathrm{MOH}$ and MOF, 2009), almost all private facilities affiliated with the programme are large private hospitals and clinics in urban areas. In our sample, we categorise private facilities as ineligible for the SHI, assuming that private facilities in remote and disadvantaged areas are not large enough to be part of the programme. Similarly, services by herbal physicians are excluded because SHI only covers herbal care delivered at large herbal medicine hospitals, which are listed under the category specialised hospitals.

As the data are nested at many levels, we employ three-level mixed-effects ordered logistic regression models for ordinal responses. We follow Agresti (2010) and Rabe-Hesketh and Skrondal (2008) on applied multilevel modelling for ordinal responses. We assume that healthcare visits (level 1) are nested in households (level 2) which then cluster in communes (level 3). Based on the sampling method of the survey which sampled communes and then households, we assume no variability of individuals within the same household and ignore the individual level to enable computational feasibility. This assumption is valid as the data were collected in the presence of all household members in one setting and the household heads would often answer the questions for any absent member. However, we also conduct several four-level attempts to confirm that the individual level can be ignored (see the robustness checks and Appendix C).

The covariates include health insurance coverage (dummy), the use of health insurance and other covariates, namely age, children under five (dummy), adults above 65 (dummy), gender, literacy, ethnicity (a dummy to specify if the person belongs to the ethnic majority), income-based poverty status, health status (the annual number of illnesses/health issues reported based on the realised need), type of facility, the nature of the care (vaccination, reproductive care, illness treatment, check-ups), total out-of-pocket payment per visit, distance to and the frequency of using the facility. We combine different insurance schemes under SHI into one dummy variable because a preliminary analysis has shown that there is no sizeable difference in their effects. To account for the issue of not using insurance among the insured (Somanathan et al., 2014), we use information on the realised financial benefits of health insurance - the financial protection/ financial coverage of health insurance. If an insured patient can reduce medical costs when seeking care, that individual uses health insurance and hence benefits from its financial protection.

We use both random-intercept and random-slope models. The random-intercept model assumes the commune and household-specific effects (the random-effects specification) do not depend on any covariate. However, to investigate the issue of discrimination against 
insurance holders, we suspect that the level of discrimination varies between communes and depends on the use of insurance coverage (i.e. a dummy that specifies the ability to reduce medical costs for the care). We hence assume a slope at the commune level for health insurance usage.

\subsection{Results}

\subsubsection{Descriptive statistics}

Table 5.1 shows insurance coverage in the poorest communes in Vietnam in 2012. The coverage in the surveyed region was very high, with more than 82 percent of people being insured. This high coverage is due to the high concentration of the poor and ethnic minorities who benefited from free insurance by law ( 51.5 percent for all and 48.8 percent for those seeking care). Voluntary insurance in these regions accounted for a relatively small proportion (from 3.1 to 3.7 percent). This is consistent with the small coverage of this scheme in the general population (Somanathan et al., 2014) and may be due to a lack of awareness of insurance among ethnic minorities.

Table 5.1: Health insurance coverage (\%)

\begin{tabular}{lrrr}
\hline & All people & $\begin{array}{r}\text { Those seeking } \\
\text { any care }\end{array}$ & $\begin{array}{r}\text { Those seeking } \\
\text { care at SHI } \\
\text { facilities }\end{array}$ \\
\hline Uninsured & 17.27 & 18.04 & 12.22 \\
Insurance for the poor & 51.47 & 48.81 & 53.83 \\
Insurance for assistance recipients & 16.49 & 17.29 & 18.27 \\
Compulsory insurance & 1.83 & 2.23 & 2.26 \\
Voluntary student insurance & 3.67 & 3.15 & 2.23 \\
Free insurance for children below 6 & 1.50 & 1.89 & 2.13 \\
Voluntary insurance & 3.11 & 3.59 & 3.71 \\
Others (mostly private insurance) & 4.66 & 5.01 & 5.35 \\
Total & 100 & 100 & 100 \\
Number of observations & 22,937 & 9,986 & 8,660 \\
\hline
\end{tabular}

Weighted statistics at individual level. The number of observations is smaller due to missing values of insurance. SHI facilities exclude the use of private clinics, pharmacies for self-medication, herbal medicines and other facilities uncovered by the SHI. 
Table 5.2 describes the use of insurance upon healthcare visit. Among visits of insured people, approximately 69 percent could benefit from the financial coverage of health insurance when seeking care. Among visits to SHI facilities, the rate was over 88 percent, suggesting that more than 11 percent were not financially covered by health insurance, probably due to self-referral (i.e. people skip the referral line and hence become ineligible for insurance reimbursement), or concern about discrimination (Dang, 2013; Kim and Vu, 2013; Duong, 2014) that prevented people from reporting that they have insurance to the care facility, or the preference for premium services over public services because the former is of better quality. Another explanation might be the use of uncovered services and medicine in SHI facilities, suggesting the lack of depth of the SHI coverage.

Table 5.2: Coverage rate and the financial protection of health insurance (\%)

\begin{tabular}{lrr}
\hline Full sample & $\begin{array}{c}\text { All } \\
\text { visits }\end{array}$ & $\begin{array}{r}\text { Visits to } \\
\text { SHI facilities }\end{array}$ \\
\hline Uninsured & 17.05 & 10.59 \\
Insured, no financial protection when seeking care & 25.97 & 10.43 \\
Insured, with financial protection when seeking care & 56.98 & 78.98 \\
Total & 100 & 100 \\
Number of observations & 13,368 & 10,550 \\
\hline Among the insured & All & Visits to \\
\hline Insured, no financial protection when seeking care & visits & SHI facilities \\
Insured, with financial protection when seeking care & 31.32 & 11.67 \\
Total & 68.68 & 88.33 \\
Number of observations & 100 & 100 \\
\hline
\end{tabular}

Weighted statistics at visit level. SHI facilities exclude the use of private clinics, pharmacies for selfmedication, herbal medicines and other facilities uncovered by the SHI. The financial protection of SHI coverage in Vietnam is in the form of co-payment.

Table 5.3 reports the types of care in relation to facilities used. The most visited facility was the commune health station (over 42 percent of visits), followed by district hospitals (16.7 percent). This finding is consistent with Tran et al. (2016) who suggested that commune level facilities are mostly used by people in remote and mountainous areas in Vietnam. Notably, self-medication (i.e. purchasing medicine at a pharmacy or even in a local market without any doctor prescription) seemed very common in the surveyed regions (17.7 percent) probably due to the limited health literacy of those living in disadvantaged regions. Interestingly, pharmacies in the surveyed regions could provide many services from vaccination, check-up to medicine sale for self-treatment or contraception. Additionally, self-treatment may also relate to other alternatives besides self-medication (such as home remedies or even superstitious activities), accounting for 1.4 percent of self-treatment activities. Commune health stations seemed to be the focal point for various types of care. Village medical support by community officers, a unique service for remote areas, seem to play a positive role in vaccination in the regions. 
Table 5.3: Type of care in relation to facility categories (\%)

\begin{tabular}{lrrrrrr}
\hline & Vac. & Rep. & Check. & Ill. & Self. & Total \\
\hline SHI-commissioned facilities & & & & & & \\
Village medical support & 21.44 & 2.06 & 1.25 & 1.77 & 0.00 & 1.57 \\
Commune health station & 55.44 & 40.22 & 51.80 & 51.44 & 0.00 & 42.40 \\
Meso-district polyclinic & 0.00 & 2.08 & 0.79 & 0.95 & 0.00 & 0.78 \\
District hospital & 4.02 & 34.94 & 19.34 & 20.15 & 0.00 & 16.67 \\
Provincial hospital & 1.67 & 11.79 & 5.20 & 7.75 & 0.00 & 6.13 \\
Central hospital & 0.00 & 0.94 & 2.67 & 2.60 & 0.00 & 2.11 \\
Other types of hospital & 0.00 & 0.27 & 2.21 & 1.56 & 0.00 & 1.33 \\
\hline Non SHI-commissioned facilities & & & & & & \\
Private clinic or hospital & 13.82 & 1.63 & 10.33 & 10.29 & 0.00 & 8.40 \\
Pharmacy (self-medication) & 2.08 & 0.86 & 4.99 & 0.00 & 98.59 & 17.72 \\
Traditional herbal physician & 0.00 & 0.00 & 0.20 & 2.16 & 0.00 & 1.51 \\
Others & 1.53 & 5.22 & 1.22 & 1.32 & 1.41 & 1.39 \\
Total & 100.00 & 100.00 & 100.00 & 100.00 & 100.00 & 100.00 \\
\hline
\end{tabular}

Weighted statistics at visit level. N=13,669 visits. Vac.: Vaccination, Rep.: Reproductive care Check.: Check-up, Ill.: Illness treatment, Self.: Self treatment

Table 5.4 illustrates the frequency of different satisfaction levels. Table 5.5 presents the mean satisfaction level by insurance coverage, type of facility and type of care. Only slightly more than five percent of evaluations were unsatisfied or very unsatisfied while more than 80 percent of evaluations were satisfied or very satisfied. On average, it seems that patients in the remote and disadvantaged regions of Vietnam in 2012 positively evaluated the quality of care, with all the gradings on average being above 'neutral' (evaluation=3) and close to 'satisfied' (evaluation=4). The rating was positive across type of care and facilities used. This is surprising given the concerns about poor quality (Barroy et al., 2014; Somanathan et al., 2014) and limited access (Somanathan et al., 2014; Tran et al., 2016) of care in those regions.

Table 5.4: Patient satisfaction at SHI facilities(\%)

\begin{tabular}{lrr}
\hline Satisfaction level & Observations & Frequency \\
\hline Very unsatisfied & 48 & 0.45 \\
Unsatisfied & 545 & 5.16 \\
Neutral & 1,384 & 13.11 \\
Satisfied & 8,179 & 77.42 \\
Very satisfied & 408 & 3.86 \\
Total & 10,564 & 100.00 \\
\hline
\end{tabular}

Weighted statistics at visit level. This excludes the use of private clinics, pharmacies for self-medication, herbal medicines and other facilities uncovered by the SHI. 
Table 5.5: Patient satisfaction by health insurance, facility and type of care

\begin{tabular}{lrrr}
\hline \multicolumn{4}{c}{ Visits to SHI facilities } \\
1=Very unsatisfied, 5=Very satisfied & Obs & Mean & SD \\
\hline Health insurance coverage & 712 & 3.75 & .66 \\
Uninsured & 6,083 & 3.81 & .62 \\
Insurance for the poor & 2,002 & 3.77 & .59 \\
Insurance for assistance recipients & 153 & 3.89 & .47 \\
Compulsory insurance & 165 & 3.76 & .59 \\
Voluntary student insurance & 243 & 3.97 & .50 \\
Free insurance for children below 6 & 166 & 3.86 & .44 \\
Voluntary insurance & 626 & 3.71 & .59 \\
Others (mostly private insurance) & & & \\
\hline Facility categories & 184 & 3.72 & .63 \\
Village medical support & 6,275 & 3.78 & .63 \\
Commune health station & 120 & 3.86 & .44 \\
Meso-district polyclinic & 2,707 & 3.81 & .57 \\
District hospital & 871 & 3.85 & .50 \\
Provincial hospital & 213 & 3.62 & .83 \\
Central hospital & 192 & 3.93 & .40 \\
Other types of hospital & & & \\
\hline Type of care & 112 & 3.92 & .37 \\
Vaccination & 260 & 3.74 & .70 \\
Reproductive care & 1,166 & 3.86 & .71 \\
Check-up & 9,023 & 3.78 & .59 \\
Illness treatment & 10,564 & 3.79 & .61 \\
\hline Total & & & \\
\hline
\end{tabular}

Weighted statistics at visit level, Obs: Observations, SD: Standard deviation. This excludes the use of private clinics, pharmacies for self-medication, herbal medicines and other facilities uncovered by the SHI.

Table 5.6 provides information on the reasons for patient dissatisfaction with the medical care at SHI facilities in the surveyed regions. In general, bad attitude towards patients, ineffective treatment and lack of medicines were the most common reasons for dissatisfaction, accounting for 20.9, 19.6 and 15.3 percent of the total number of dissatisfied evaluations. Bad attitude of medical staff was common for both insured and uninsured patients. Notably, the high cost seems to affect those who did not or could not benefit from the financial coverage of health insurance the most (at 20.6 percent). This may indicate that the non-use of health insurance of insured patients was not out of choice as they had to use services uncovered by SHI. Interestingly, only 11.4 percent of uninsured patients reported high costs as the main reason for dissatisfaction, showing that insured and uninsured patients have different expectations regarding health costs when seeking healthcare at SHI facilities. 
Table 5.6: Reasons for patient dissatisfaction at SHI facilities (\%)

\begin{tabular}{lrrrr}
\hline & Uninsured & \multicolumn{2}{c}{$\begin{array}{c}\text { Insured } \\
\text { No financiaWith financial } \\
\text { protection } \\
\text { protection }\end{array}$} \\
\hline Lack of facilities & 2.31 & 2.68 & 7.07 & 5.49 \\
Lack of medicines & 2.64 & 4.50 & 21.55 & 15.33 \\
Incapable medical staff & 17.60 & 2.25 & 6.52 & 7.19 \\
Bad attitude towards patients by medical staff & 15.20 & 21.21 & 22.12 & 20.96 \\
Long waiting time & 26.15 & 14.58 & 6.10 & 10.69 \\
Very high out-of-pocket payments & 11.46 & 20.64 & 3.71 & 8.33 \\
The illness is not relieved & 8.91 & 6.07 & 26.18 & 19.56 \\
Unclean, unhygienic facilities & 0.00 & 0.71 & 0.29 & 0.34 \\
Informal payments & 9.43 & 3.53 & 2.30 & 3.56 \\
Unfair treatment by medical staff & 6.30 & 2.41 & 1.61 & 2.44 \\
Others & 0.00 & 21.43 & 2.53 & 6.11 \\
Total & 100.00 & 100.00 & 100.00 & 100.00 \\
\hline Number of observations & 91 & 135 & 421 & 647 \\
\hline Teign
\end{tabular}

Weighted statistics. The number of observations is rounded. This excludes the use of private clinics, pharmacies for self-medication, herbal medicines and other facilities uncovered by the SHI.

Table 5.7 presents the descriptive statistics of the control variables in the final sample of visits to SHI linked facilities in 2012. Among those seeking healthcare, 45 percent were men and around 72 percent were literate. The mean age was around 36, with two percent being below 5 years old and 8 percent over 65 . Only 17 percent of those seeking care in SHI facilities were Kinh people due to the high concentration of ethnic minorities in the surveyed regions. On average, the surveyed people seemed rather healthy, with a mean value of only 1.37 self-reported illnesses/health issues per year. The poverty rate was high in the sample, at 55 percent. This is expected given the high concentration of poverty among ethnic minorities in Vietnam (The World Bank and MPI, 2016), which was also the rationale for having the largest poverty reduction programme in the regions. Distance to the medical facilities varied a lot because of the varied taxonomy of facilities. Similarly, out-of-pocket payment had a wide range due to variation in type of care, facility as well as the severity of the health issue. 
Table 5.7: Descriptive statistics of control variables in the final sample

\begin{tabular}{lcrrrr}
\hline & Min & Max & Mean & Median & SD \\
\hline Individual characteristics & & & & & \\
Age & 0.00 & 110.00 & 36.36 & 36.00 & 20.25 \\
Children under 5 years old & 0.00 & 1.00 & 0.02 & 0.00 & 0.13 \\
Elderly over 65 years old & 0.00 & 1.00 & 0.08 & 0.00 & 0.28 \\
Male & 0.00 & 1.00 & 0.45 & 0.00 & 0.50 \\
Literacy (dummy) & 0.00 & 1.00 & 0.72 & 1.00 & 0.45 \\
Belongs to the ethnic majority (Kinh) & 0.00 & 1.00 & 0.17 & 0.00 & 0.38 \\
Poor & 0.00 & 1.00 & 0.55 & 1.00 & 0.50 \\
Number of illnesses/health issues p.a. (self-reported) & 1.00 & 7.00 & 1.37 & 1.00 & 0.63 \\
\hline Healthcare visit characteristics & & & & & \\
Type of healthcare facility & 1.00 & 7.00 & 2.92 & 2.00 & 1.31 \\
Type of care & 1.00 & 4.00 & 3.81 & 4.00 & 0.52 \\
Distance to the care facility (km) & 0.00 & 1500.00 & 19.22 & 5.00 & 50.57 \\
Visit frequency to that specific facility p.a. & 1.00 & 96.00 & 3.35 & 2.00 & 4.70 \\
OOP payments (in USD) & 0.00 & 9587.27 & 52.82 & 4.79 & 239.09 \\
\hline
\end{tabular}

$\mathrm{N}=10,562$ visits to SHI facilities of 8,660 individuals. SD: Standard deviation. OOP payments: Out-ofpocket payments

\subsubsection{Multilevel results}

Tables 5.8 and 5.9 present the results of random intercept and random slope models. Model 1 includes only health insurance (dummy) as the main explanatory variable, model 2 controls for the actual use of health insurance for its financial protection, and model 3 replaces the two variables with a categorical variable that separates different groups of users and non-users. As suggested in both tables, health insurance is positively related to patient satisfaction (model 1). However, when controlling for the actual use of health insurance, the positive effect actually comes from the financial protection of health insurance (model 2-3). That means the insurance itself does not lead to a higher satisfaction level, what matters is its actual financial coverage for those who use healthcare. Notably, model 3 suggests that those who were insured and used the insurance to reduce medical costs were the most satisfied. Those who were insured but did not benefit from the financial coverage of health insurance were less satisfied compared to the uninsured (even though the effect is statistically insignificant). This suggests that these insured individuals were those who had to use uncovered services and hence could not benefit from the financial coverage.

We also find intuitive and consistent results for other control variables. Literacy and social economic condition (proxied by poverty status) are not statistically significant. Those belonging to the ethnic majority (Kinh people) on average are significantly less satisfied with healthcare. Older people are less satisfied with medical services, however, those above 65 are more satisfied with medical services compared to younger ones. This might imply a U-shaped relation between age and the level of satisfaction with healthcare.

Healthcare-related variables seem to be the most significant drivers of satisfaction. Lower health status (higher number of self-reported illnesses/health issues) is associated with 
a lower level of satisfaction with medical services. However, the frequency of use of the same facility does not affect the evaluation. Those visiting higher levels of healthcare system (above district level) are more satisfied than those who choose commune health stations. Among SHI facilities, other types of hospitals rather than central and district level hospitals (specialty hospitals, military hospitals) seem to have the highest level of patient satisfaction. Regarding the type of care, it seems that vaccination in the poorest regions of Vietnam is doing better than illness treatment in making people satisfied probably because vaccination in Vietnam is mainly for children under 6 and free of charge by law. Longer distance to the facility leads to a higher level of satisfaction even after controlling for facility type. The effect of the total out-of-pocket payment is negatively significant but rather negligible in size.

According to Tables 5.8-5.9, the results are very consistent across the two sets of models. However, when switching from the random intercept model (Table 5.8) to the random slope model (Table 5.9), the effect size of the financial coverage of health insurance on satisfaction increases from 1.07 to 1.18 ordered log-odd unit (model 3). As suggested in Table 5.9, the commune effect depends on whether the patient can benefit from the financial protection of health insurance: the variance of the slope is significant at one percent level. The positively significant slope of the commune effects suggests that commune-specific effects depend on the financial benefit of using insurance, and that those using insurance to cut costs are more satisfied.

Regarding the goodness-of-fit of the two models, we perform likelihood-ratio tests which indicate that the random slope model fits better than the random intercept model ( $\mathrm{P}$ value $=0.000)$. This means that the random slope model is a better fit in terms of providing more precise estimates in size rather than in the direction of the effects. 
Table 5.8: Three-level random intercept models

\begin{tabular}{|c|c|c|c|}
\hline & $(1)$ & $(2)$ & $(3)$ \\
\hline Have health insurance & $\begin{array}{c}0.786^{* * *} \\
(0.20)\end{array}$ & $\begin{array}{r}-0.350 \\
(0.23)\end{array}$ & \\
\hline Receive financial protection when seeking care & & $\begin{array}{c}1.429^{* * *} \\
(0.17)\end{array}$ & \\
\hline Receive insurance and health insurance usage (base: no insurance) & & & \\
\hline -Have insurance, receive no financial protection when seeking care & & & $\begin{array}{c}-0.350 \\
(0.23)\end{array}$ \\
\hline -Have insurance, receive financial protection when seeking care & & & $\begin{array}{c}1.079^{* * * *} \\
(0.20)\end{array}$ \\
\hline Age & $\begin{array}{c}-0.009^{* * *} \\
(0.00)\end{array}$ & $\begin{array}{c}-0.009^{* * *} \\
(0.00)\end{array}$ & $\begin{array}{c}-0.009^{* * *} \\
(0.00)\end{array}$ \\
\hline Children under 5 & $\begin{array}{l}0.126 \\
(0.35)\end{array}$ & $\begin{array}{l}0.077 \\
(0.35)\end{array}$ & $\begin{array}{l}0.077 \\
(0.35)\end{array}$ \\
\hline Elderly over 65 & $\begin{array}{c}0.525^{* * *} \\
(0.17)\end{array}$ & $\begin{array}{c}0.512^{* * *} \\
(0.17)\end{array}$ & $\begin{array}{c}0.512^{* * *} \\
(0.17)\end{array}$ \\
\hline Male & $\begin{array}{c}-0.109^{*} \\
(0.07)\end{array}$ & $\begin{array}{r}-0.102 \\
(0.07)\end{array}$ & $\begin{array}{c}-0.102 \\
(0.07)\end{array}$ \\
\hline Literate & $\begin{array}{l}0.002 \\
(0.09)\end{array}$ & $\begin{array}{l}0.022 \\
(0.09)\end{array}$ & $\begin{array}{l}0.022 \\
(0.09)\end{array}$ \\
\hline Belongs to the ethnic majority (Kinh) & $\begin{array}{c}-0.516^{* * *} \\
(0.15)\end{array}$ & $\begin{array}{c}-0.508^{* * *} \\
(0.15)\end{array}$ & $\begin{array}{c}-0.508^{* * *} \\
(0.15)\end{array}$ \\
\hline Poor & $\begin{array}{r}-0.145 \\
(0.12)\end{array}$ & $\begin{array}{r}-0.147 \\
(0.12)\end{array}$ & $\begin{array}{r}-0.147 \\
(0.12)\end{array}$ \\
\hline Number of self-reported illnesses p.a. & $\begin{array}{c}-0.250^{* * *} \\
(0.07)\end{array}$ & $\begin{array}{c}-0.257^{* * *} \\
(0.06)\end{array}$ & $\begin{array}{c}-0.257^{* * *} \\
(0.06)\end{array}$ \\
\hline \multicolumn{4}{|l|}{ Facility type (base: commune health station) } \\
\hline -Village medical support & $\begin{array}{l}0.180 \\
(0.24)\end{array}$ & $\begin{array}{l}0.379 \\
(0.25)\end{array}$ & $\begin{array}{l}0.379 \\
(0.25)\end{array}$ \\
\hline -Meso-district polyclinic & $\begin{array}{c}0.720^{*} \\
(0.37)\end{array}$ & $\begin{array}{c}0.873^{* *} \\
(0.38)\end{array}$ & $\begin{array}{c}0.873^{* *} \\
(0.38)\end{array}$ \\
\hline -District hospital & $\begin{array}{c}0.701^{* * * *} \\
(0.12)\end{array}$ & $\begin{array}{c}0.716^{* * * *} \\
(0.12)\end{array}$ & $\begin{array}{c}0.716^{* * *} \\
(0.12)\end{array}$ \\
\hline -Provincial hospital & $\begin{array}{c}1.069^{* * *} \\
(0.19)\end{array}$ & $\begin{array}{c}1.145^{* * *} \\
(0.19)\end{array}$ & $\begin{array}{c}1.145^{* * *} \\
(0.19)\end{array}$ \\
\hline -Central hospital & $\begin{array}{c}1.246^{* * *} \\
(0.37)\end{array}$ & $\begin{array}{c}1.628^{* * *} \\
(0.36)\end{array}$ & $\begin{array}{c}1.628^{* * *} \\
(0.36)\end{array}$ \\
\hline -Other types of hospital & $\begin{array}{c}1.603^{* * *} \\
(0.38)\end{array}$ & $\begin{array}{c}2.088^{* * *} \\
(0.36)\end{array}$ & $\begin{array}{c}2.088^{* * * *} \\
(0.36)\end{array}$ \\
\hline \multicolumn{4}{|l|}{ Type of care (base: illness treatment) } \\
\hline -Vaccination & $\begin{array}{c}1.732^{* * *} \\
(0.42)\end{array}$ & $\begin{array}{c}1.876^{* * *} \\
(0.44)\end{array}$ & $\begin{array}{c}1.876^{* * *} \\
(0.44)\end{array}$ \\
\hline -Pregnancy and reproductive health care & $\begin{array}{l}0.282 \\
(0.26)\end{array}$ & $\begin{array}{l}0.381 \\
(0.27)\end{array}$ & $\begin{array}{l}0.381 \\
(0.27)\end{array}$ \\
\hline -Health check-up & $\begin{array}{r}-0.108 \\
(0.14)\end{array}$ & $\begin{array}{r}-0.106 \\
(0.14)\end{array}$ & $\begin{array}{r}-0.106 \\
(0.14)\end{array}$ \\
\hline Distance to the care facility $(\mathrm{km})$ & $\begin{array}{l}0.001 \\
(0.00)\end{array}$ & $\begin{array}{c}0.002^{* * *} \\
(0.00)\end{array}$ & $\begin{array}{c}0.002^{* *} \\
(0.00)\end{array}$ \\
\hline Visit frequency to that specific facility for the same health issue p.a. & $\begin{array}{c}-0.002 \\
(0.01)\end{array}$ & $\begin{array}{r}-0.005 \\
(0.01)\end{array}$ & $\begin{array}{c}-0.005 \\
(0.01)\end{array}$ \\
\hline OOP payments (in USD) & $\begin{array}{c}-0.000^{*} \\
(0.00)\end{array}$ & $\begin{array}{c}-0.000^{* *} \\
(0.00)\end{array}$ & $\begin{array}{c}-0.000^{* *} \\
(0.00)\end{array}$ \\
\hline Cutpoint 1 & $\begin{array}{c}-8.443^{* * *} \\
(0.39)\end{array}$ & $\begin{array}{c}-8.388^{* * *} \\
(0.40)\end{array}$ & $\begin{array}{c}-8.388^{* * *} \\
(0.40)\end{array}$ \\
\hline Cutpoint 2 & $\begin{array}{c}-4.994^{* * *} \\
(0.31)\end{array}$ & $\begin{array}{c}-4.895^{* * *} \\
(0.31)\end{array}$ & $\begin{array}{c}-4.895^{* * *} \\
(0.31)\end{array}$ \\
\hline Cutpoint 3 & $\begin{array}{c}-2.631^{* * *} \\
(0.29)\end{array}$ & $\begin{array}{c}-2.502^{* * * *} \\
(0.29)\end{array}$ & $\begin{array}{c}-2.502^{* * *} \\
(0.29)\end{array}$ \\
\hline Cutpoint 4 & $\begin{array}{c}6.317^{* * *} \\
(0.35)\end{array}$ & $\begin{array}{c}6.508^{* * *} \\
(0.36)\end{array}$ & $\begin{array}{c}6.508^{* * *} \\
(0.36)\end{array}$ \\
\hline Variance (commune intercept) & $\begin{array}{c}1.928^{* * *} \\
(0.33)\end{array}$ & $\begin{array}{c}1.898^{* * *} \\
(0.32)\end{array}$ & $\begin{array}{c}1.898^{* * *} \\
(0.32)\end{array}$ \\
\hline Variance (household intercept) & $\begin{array}{c}6.168^{* * *} \\
(0.59)\end{array}$ & $\begin{array}{c}6.121^{* * * *} \\
(0.60)\end{array}$ & $\begin{array}{c}6.121^{\text {**** }} \\
(0.60)\end{array}$ \\
\hline $\mathrm{N}$ & 10,307 & 10,307 & 10,307 \\
\hline
\end{tabular}

Standard errors in parentheses

${ }^{*} p<0.1,{ }^{* *} p<0.05,{ }^{* * *} p<0.01$ 
Table 5.9: Three-level random slope models

\begin{tabular}{|c|c|c|c|}
\hline & (1) & $(2)$ & (3) \\
\hline Have health insurance & $\begin{array}{c}0.691^{* * *} \\
(0.20)\end{array}$ & $\begin{array}{l}-0.357 \\
(0.23)\end{array}$ & \\
\hline Receive financial protection when seeking care & & $\begin{array}{c}1.538^{* * * *} \\
(0.17)\end{array}$ & \\
\hline \multicolumn{4}{|l|}{ Health insurance and health insurance usage (base: no insurance) } \\
\hline -Have insurance, receive no financial protection when seeking care & & & $\begin{array}{c}-0.357 \\
(0.23)\end{array}$ \\
\hline -Have insurance, receive financial protection when seeking care & & & $\begin{array}{c}1.180^{* * * *} \\
(0.21)\end{array}$ \\
\hline Age & $\begin{array}{c}-0.009^{* * *} \\
(0.00)\end{array}$ & $\begin{array}{c}-0.009^{* * *} \\
(0.00)\end{array}$ & $\begin{array}{c}-0.009^{* * * *} \\
(0.00)\end{array}$ \\
\hline Children under 5 & $\begin{array}{l}0.123 \\
(0.35)\end{array}$ & $\begin{array}{l}0.092 \\
(0.36)\end{array}$ & $\begin{array}{l}0.092 \\
(0.36)\end{array}$ \\
\hline Elderly over 65 & $\begin{array}{c}0.531^{* * * *} \\
(0.18)\end{array}$ & $\begin{array}{c}0.519^{* * * *} \\
(0.18)\end{array}$ & $\begin{array}{c}0.519^{* * * *} \\
(0.18)\end{array}$ \\
\hline Male & $\begin{array}{r}-0.110 \\
(0.07)\end{array}$ & $\begin{array}{c}-0.105 \\
(0.07)\end{array}$ & $\begin{array}{r}-0.105 \\
(0.07)\end{array}$ \\
\hline Literate & $\begin{array}{l}0.005 \\
(0.09)\end{array}$ & $\begin{array}{l}0.032 \\
(0.09)\end{array}$ & $\begin{array}{l}0.032 \\
(0.09)\end{array}$ \\
\hline Belongs to the ethnic majority (Kinh) & $\begin{array}{c}-0.469^{* * *} \\
(0.15)\end{array}$ & $\begin{array}{c}-0.441^{* * *} \\
(0.15)\end{array}$ & $\begin{array}{c}-0.441^{* * *} \\
(0.15)\end{array}$ \\
\hline Poor & $\begin{array}{c}-0.144 \\
(0.12)\end{array}$ & $\begin{array}{c}-0.149 \\
(0.12)\end{array}$ & $\begin{array}{r}-0.149 \\
(0.12)\end{array}$ \\
\hline Number of self-reported illnesses p.a. & $\begin{array}{c}-0.243^{* * *} \\
(0.07)\end{array}$ & $\begin{array}{c}-0.248^{* * *} \\
(0.07)\end{array}$ & $\begin{array}{c}-0.248^{* * *} \\
(0.07)\end{array}$ \\
\hline \multicolumn{4}{|l|}{ Facility type (base: commune health station) } \\
\hline -Village medical support & $\begin{array}{l}0.143 \\
(0.24)\end{array}$ & $\begin{array}{l}0.332 \\
(0.25)\end{array}$ & $\begin{array}{l}0.332 \\
(0.25)\end{array}$ \\
\hline -Meso-district polyclinic & $\begin{array}{c}0.705^{*} \\
(0.37)\end{array}$ & $\begin{array}{c}0.831^{* *} \\
(0.37)\end{array}$ & $\begin{array}{c}0.831^{* *} \\
(0.37)\end{array}$ \\
\hline -District hospital & $\begin{array}{c}0.694^{* * * *} \\
(0.12)\end{array}$ & $\begin{array}{c}0.709^{* * *} \\
(0.12)\end{array}$ & $\begin{array}{c}0.709^{* * *} \\
(0.12)\end{array}$ \\
\hline -Provincial hospital & $\begin{array}{c}1.080^{* * * *} \\
(0.19)\end{array}$ & $\begin{array}{c}1.142^{* * *} \\
(0.19)\end{array}$ & $\begin{array}{c}1.142^{* * *} \\
(0.19)\end{array}$ \\
\hline -Central hospital & $\begin{array}{c}1.273^{* * * *} \\
(0.38)\end{array}$ & $\begin{array}{c}1.603^{* * * *} \\
(0.37)\end{array}$ & $\begin{array}{c}1.603^{* * *} \\
(0.37)\end{array}$ \\
\hline -Other types of hospital & $\begin{array}{c}1.671^{* * * *} \\
(0.37)\end{array}$ & $\begin{array}{c}2.073^{* * *} \\
(0.36)\end{array}$ & $\begin{array}{c}2.073^{* * *} \\
(0.36)\end{array}$ \\
\hline \multicolumn{4}{|l|}{ Type of care (base: illness treatment) } \\
\hline & $(0.42)$ & $(0.44)$ & $(0.44)$ \\
\hline -Pregnancy and reproductive health care & $\begin{array}{l}0.309 \\
(0.27)\end{array}$ & $\begin{array}{c}0.398 \\
(0.27)\end{array}$ & $\begin{array}{c}0.398 \\
(0.27)\end{array}$ \\
\hline -Health check-up & $\begin{array}{r}-0.097 \\
(0.14)\end{array}$ & $\begin{array}{l}-0.090 \\
(0.14)\end{array}$ & $\begin{array}{l}-0.090 \\
(0.14)\end{array}$ \\
\hline Distance to the care facility $(\mathrm{km})$ & $\begin{array}{l}0.002^{*} \\
(0.00)\end{array}$ & $\begin{array}{c}0.002^{* *} \\
(0.00)\end{array}$ & $\begin{array}{c}0.002^{* *} \\
(0.00)\end{array}$ \\
\hline Visit frequency to that specific facility for the same health issue p.a. & $\begin{array}{l}-0.003 \\
(0.01)\end{array}$ & $\begin{array}{l}-0.005 \\
(0.01)\end{array}$ & $\begin{array}{l}-0.005 \\
(0.01)\end{array}$ \\
\hline OOP payments (in USD) & $\begin{array}{c}-0.000^{*} \\
(0.00) \\
\end{array}$ & $\begin{array}{c}-0.000^{*} \\
(0.00)\end{array}$ & $\begin{array}{c}-0.000^{*} \\
(0.00) \\
\end{array}$ \\
\hline Cutpoint 1 & $\begin{array}{c}-8.479^{* * *} \\
(0.40)\end{array}$ & $\begin{array}{c}-8.375^{* * *} \\
(0.40)\end{array}$ & $\begin{array}{c}-8.375^{* * *} \\
(0.40)\end{array}$ \\
\hline Cutpoint 2 & $\begin{array}{c}-4.982^{* * * *} \\
(0.32)\end{array}$ & $\begin{array}{c}-4.852^{* * *} \\
(0.32)\end{array}$ & $\begin{array}{c}-4.852^{* * *} \\
(0.32)\end{array}$ \\
\hline Cutpoint 3 & $\begin{array}{c}-2.580^{* * *} \\
(0.30)\end{array}$ & $\begin{array}{c}-2.432^{* * *} \\
(0.30)\end{array}$ & $\begin{array}{c}-2.432^{* * *} \\
(0.30)\end{array}$ \\
\hline Cutpoint 4 & $\begin{array}{c}6.560^{* * * *} \\
(0.37)\end{array}$ & $\begin{array}{c}6.718^{* * *} \\
(0.38)\end{array}$ & $\begin{array}{c}6.718^{* * * *} \\
(0.38)\end{array}$ \\
\hline Variance (commune slope) & $\begin{array}{c}1.284^{* * * *} \\
(0.33)\end{array}$ & $\begin{array}{c}1.062^{* * *} \\
(0.31)\end{array}$ & $\begin{array}{c}1.062^{* * * *} \\
(0.31)\end{array}$ \\
\hline Variance (commune intercept) & $\begin{array}{c}1.573^{* * *} \\
(0.32)\end{array}$ & $\begin{array}{c}1.356^{* * *} \\
(0.29)\end{array}$ & $\begin{array}{c}1.356^{* * * *} \\
(0.29)\end{array}$ \\
\hline Variance (household intercept) & $\begin{array}{c}6.311^{* * *} \\
(0.62)\end{array}$ & $\begin{array}{c}6.240^{* * * *} \\
(0.62)\end{array}$ & $\begin{array}{c}6.240^{* * *} \\
(0.62)\end{array}$ \\
\hline $\mathrm{N}$ & 10,307 & 10,307 & 10,307 \\
\hline
\end{tabular}


Because Kinh people (those belonging to the ethnic majority) are less likely to be satisfied with medical services (see Tables 5.8-5.9), we run separate regressions for Kinh and nonKinh ethnic groups in Table 5.10. We find that even though the effect of health insurance 's financial coverage is positively significant for both groups, it is more pronounced for non-Kinh peoples with a larger effect size.

Importantly, the effects of all other regressors seem to depend on ethnicity. The U-shaped relationship between age and satisfaction level is only found in non-Kinh peoples. Kinh men are less likely to be satisfied with medical services than Kinh women while the effect of gender is insignificant within non-Kinh groups. Distance to a healthcare facility is positively related to the satisfaction level of Kinh people (at 10 percent significance level) but not significant for the non-Kinh. The effects of type of facility and type of care between the two groups differ in magnitude rather than in the effect sign. The results seem to suggest that there are significant cultural differences that affect the ethnic differences in satisfaction level with medical care. Alternatively, this ethnicity-based discrepancy might be due to the difference in social referencing group between Kinh people and the non-Kinh, because ethnic minority peoples frequently tend to be poorer and left behind in various social development dimensions (The World Bank and MPI, 2016). 
Table 5.10: Three-level intercept and random slope models by ethnicity

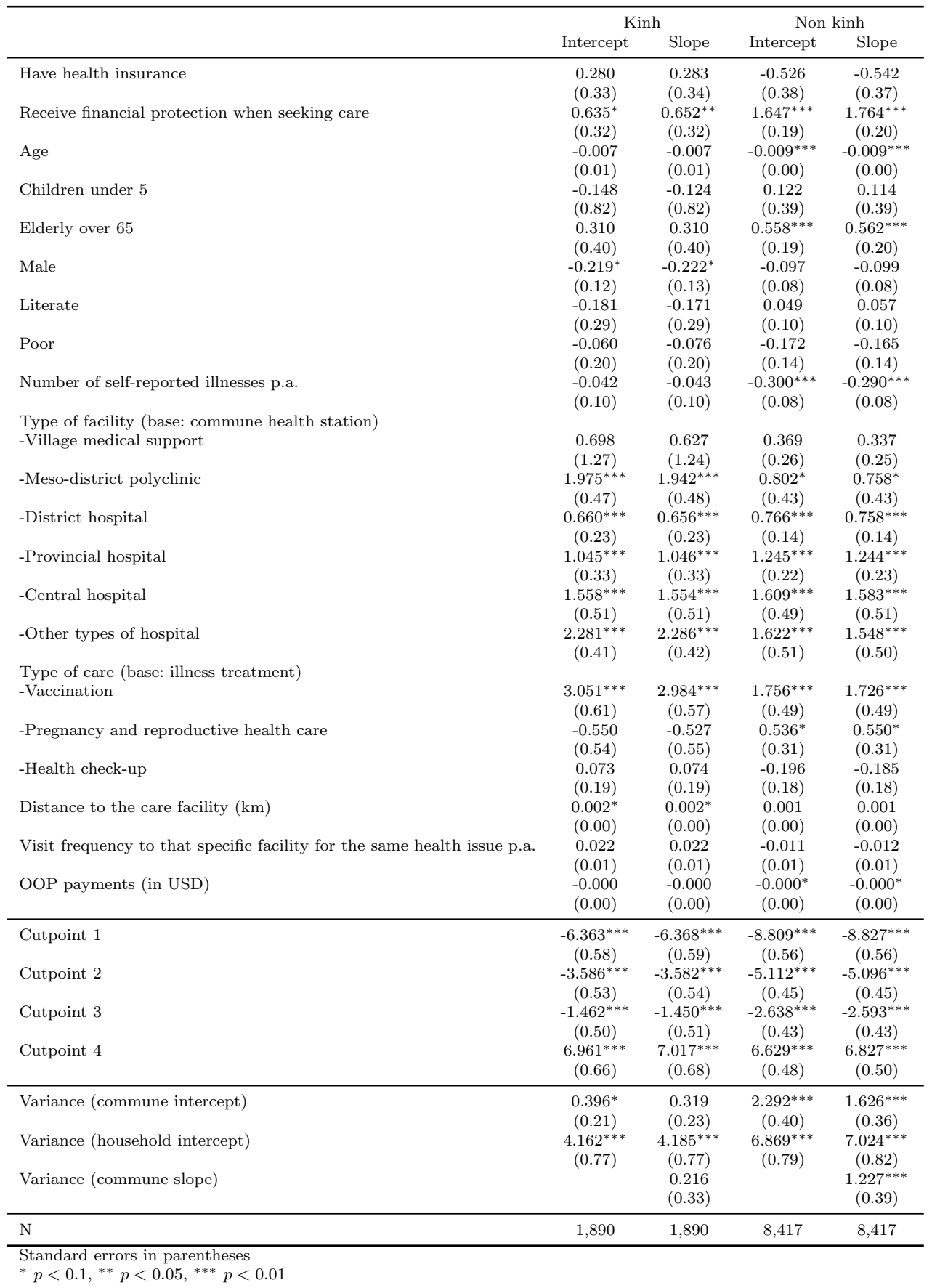


Table 5.11 presents the intra-class correlation coefficients (ICC) for the random intercept and random slope models in Tables 5.8 and 5.9. ICC in this case is the ICC of the underlying linear model while the variances reported are of the cumulative probability model (see the methodology). The ICC are very high in all models, indicating that the within-household and within-commune correlation are significantly larger than zero. That means the random effects models are necessary to capture the heterogeneity within the study population. Importantly, in all models, nearly two-thirds of the variation is due to within-household correlation, suggesting that household-specific effects can explain most of the unobserved heterogeneity. If we allow commune-specific effects to depend on the realised financial protection of health insurance, the variation from the intercept is larger than that from the slope. Finally, it seems that the random effects are consistent across Models 1-3 of both random intercept and slope models, suggesting that the fixed-effects specifications within random effects models are very robust.

Table 5.11: Variance and intra-class correlation coefficients (ICC)

\begin{tabular}{lccccccccccc}
\hline & \multicolumn{3}{c}{ Random intercept models } & \multicolumn{5}{c}{ Random slope models } \\
& \multicolumn{2}{c}{$\begin{array}{c}\text { Commune } \\
\text { Variance ICC }\end{array}$} & $\begin{array}{c}\text { Household } \\
\text { Variance ICC }\end{array}$ & \multicolumn{2}{c}{ Commune(s) } & \multicolumn{2}{c}{ Commune (i) } & Voriance ICC & Variance ICC & Variance ICC \\
\hline Model 1 & 1.928 & 0.369 & 6.168 & 0.652 & 1.284 & 0.281 & 1.573 & 0.323 & 6.311 & 0.657 \\
Model 2 & 1.898 & 0.366 & 6.121 & 0.650 & 1.062 & 0.244 & 1.356 & 0.292 & 6.240 & 0.655 \\
Model 3 & 1.898 & 0.366 & 6.121 & 0.650 & 1.062 & 0.244 & 1.356 & 0.292 & 6.240 & 0.655 \\
\hline
\end{tabular}

Commune(s) and commune (i) denote the statistics for commune-specific slopes and intercepts

\subsection{Robustness checks}

One can argue that sample selection bias can be problematic in our models if those who were not satisfied with healthcare or lived so far away from the nearest primary facilities would have abstained from seeking healthcare when needed. Consequently, we only observed the satisfaction level of those who sought healthcare in 2012. However, in this dataset, we used information on 'realised care needs' based on self-reported illnesses/health issues, and hence observed any action taken to get treated including self-medication, professional herbal therapies, home remedies and so on. Therefore, for a robustness analysis, we re-ran the models with the full sample to include these types of visits to reduce the risk of selection bias due to the unmet need (see Appendices C3-C4). As expected, the results of the full sample regressions are consistent with Tables 5.8-5.9, which makes the sample selection issue less likely. Additionally, we argue that healthcare is a special need that cannot be easily forgone. If sick, someone must take some action to feel better regardless of the involvement of professional care. Therefore, our broad definition of visit as 'realised care need' seems to be a good strategy to deal with the issue of sample selection. Even if we missed a small number of those forgoing medical treatment due to recall bias, our analysis remains valid and informative about the satisfaction level of those who were sick and managed to seek some care.

The issue of endogeneity of health insurance might be more problematic because health 
insurance was not randomly assigned. One could argue that those who were not satisfied with medical services for many unobserved reasons could have opted out in the voluntary scheme. However, the high coverage rate (over 82 percent), combined with the relatively small voluntary insurance coverage (more than 3 percent) compared to free and compulsory insurance schemes in the surveyed regions helps to minimise that risk. Additionally, the issue of adverse selection in the voluntary scheme (Somanathan et al., 2014) seems to suggest that voluntary health coverage in Vietnam is mainly driven by need and health status, which was controlled for in our regressions (we used the number of self-reported illnesses/health issues per year as a proxy for health status), rather than by satisfaction level.

For robustness checks, we also ran regressions controlling for household size, employment status and income but these were removed from parsimonious models after Wald tests. We replaced the health insurance dummy with different health schemes (Appendix C2). Finally, we accounted for the variability of individuals within households and tried a four-level model. As suggested in Appendix C1, the variance of the individual level is not statistically significant, confirming that our assumption to ignore the individual level is valid.

\subsection{Discussion and conclusion}

We find that it is not health insurance per se but the financial coverage when seeking healthcare that matters to improve patient satisfaction. In other words, patient satisfaction is positively associated with the depth of coverage and the ability to use health insurance to reduce medical costs when seeking care.

Importantly, our results suggest that the claim of discrimination against SHI insurance holders is unsupported at least in the poorest regions of Vietnam: those who used health insurance upon utilisation to reduce medical costs were the most satisfied. They were more satisfied than those who did not have health insurance and those who were insured but did not benefit from the financial protection of health insurance (probably because they could not). The consistency in statistical significance of the slope as well as its positive signs across random slope models help rule out the claim of discrimination against the insured at least in our sample. This is positive news for the government in providing free health insurance and affordable healthcare for the poor and disadvantaged ethnic minority groups in the surveyed regions. Probably the discrimination phenomenon reported by the media (Dang, 2013; Kim and Vu, 2013; Duong, 2014) is due to media exaggeration of negative news. Another explanation might be that this issue is more rampant in central hospitals in big cities (see Dang (2013); Kim and Vu (2013); Duong (2014)) where patients are over-stressed with the chronic overcrowding and observe the visible difference between public services and premium services within the same facility. This comparison and sense of relative inequality was described in a testimony by the Minister of Health in 2014 (Duong, 2014). As discussed earlier in the literature, patient satisfaction is a subjective measure which depends on patient expectations, beliefs and feelings (Linder-Pelz, 1982; Williams, 1994). Having two lines of services within the same health centre may raise 
expectations, induce comparison and trigger the sense of unfairness and inequality among patients who are struggling to navigate in an overcrowded surrounding. Literature on happiness economics seems to suggest this explanation by highlighting something called 'jealousy effects' (Van Praag, 2011, p.124) via the inclusion of a social referencing process in measuring subjective inequality and happiness. Perhaps Vietnamese patients who use public services tend to feel discriminated if they compare themselves with those using premium services because comparison negatively affects subjective feelings, subjective well-being as well as subjective inequality (Van Praag, 2011). However, it is notable that our data only represents the poorest regions of Vietnam, so the above explanations are mainly theory-based. In the future, it would be interesting to do the same research for empirical evidence if data are available for the whole of Vietnam.

The fact that those who were insured but did not benefit from the financial coverage of health insurance were less satisfied compared to the uninsured (even though the effect is statistically insignificant) seemingly indicates that the former had to use uncovered services and hence could not benefit from the insurance. In this case, the unmet expectation of a financial coverage made them feel less satisfied than the uninsured. Therefore, the non-use of health insurance in this case was not a choice. This is consistent with the finding in Table 5.6 that one of the main reasons for patient dissatisfaction of those insured but not receiving any financial protection was the high costs. These individuals were even more dissatisfied than the uninsured (Table 5.8-5.9). This is intuitive as insured people often expect some financial protection before seeking care and hence become easily dissatisfied when not covered while the uninsured visit healthcare without expecting any financial coverage. Therefore, the phenomenon of self-referral or deliberately not using health insurance is not an issue in the surveyed regions, probably because of the limited willingness to pay.

The finding that many insured people did not receive the financial protection of health insurance highlights the lack of depth of the SHI coverage, which supports the argument by Somanathan et al. (2014) that SHI coverage in Vietnam does not lead to an effective coverage. This is also the reason for high out-of-pocket payments in Vietnam (ibid.). In the context of moving towards UHC, this finding becomes highly policy relevant, as it challenges the effectiveness of the well-intentioned SHI programme.

Even though the random slope model is a better fit than the random intercept model, it is only slightly more precise in predicting the effect sizes. Generally, both models suggest a positive relationship between the ability to use health insurance to cut medical costs (i.e. the financial protection of health insurance) and patient satisfaction. The positively significant commune-specific slope in Table 5.9 confirms our assumption that the commune effects depend on the ability to use insurance for financial protection. It highlights the variation in how the insured and uninsured are treated among different communes. In general, the commune effects are larger for those who are financially covered by health insurance when seeking SHI-commissioned care (positive slope of insurance usage implies that the commune effects are higher for insured people than the uninsured within the same commune). This might be a good area for future research in investigating within-commune variation in healthcare quality and patient satisfaction.

Because of the vast heterogeneity of the effects of social demographic variables on patient 
satisfaction (Batbaatar et al., 2017), it is difficult to compare it with other studies. Besides, our study only looks at the poorest regions in Vietnam, while previous studies including those for former Soviet Union countries with relatively similar health systems (Footman et al., 2013; Luck et al., 2014) normally use a sample of the general population. Therefore, comparing our results with the literature should be done with caution. Our results seem to be inconsistent with the literature that finds higher levels of satisfaction for older people (Butler et al., 1996; Jackson et al., 2001; Kersnik, 2001; Atkinson and Haran, 2005; Bleich et al., 2009; Hekkert et al., 2009; Schoenfelder et al., 2011). We find a U-shaped relationship between age and satisfaction with healthcare by adding dummies that specify the most illness-susceptible groups (aged under 5 or above 65). Income-based poverty status is not significant, which is inconsistent with the positive effect found in a majority of other studies (Gulliford et al., 2006; Xiao and Barber, 2008; Footman et al., 2013). The reason is probably the extremely high prevalence of poverty in our surveyed areas while the other papers (Footman et al., 2013) investigate the general population. Another explanation might be the relatively low income inequality in the poorest areas of Vietnam because income inequality is more pronounced between rural and urban areas rather than within rural areas (The World Bank and MPI, 2016). Interestingly, we find no general gender-based difference in patient satisfaction (the effect of gender is only slightly significant in one intercept model) while the literature finds significant effects (Batbaatar et al., 2017). However, when separating the sample by ethnicity, Kinh men are less satisfied with medical care than Kinh women. Another important finding is the difference in satisfaction level between Kinh people (the ethnic majority) and the others, suggesting that Kinh people (often the better-off) are less satisfied with medical services in general even after accounting for other social economic indicators (income and literacy). This suggests that Kinh people are more demanding with medical care received, signalling a cultural difference in perceiving and expecting the quality of public services of Kinh people and the others. Alternatively, this may also suggest the difference in the frame of reference and expectations for healthcare between Kinh and non-Kinh people.

The results of other variables related to care, health status and the facility used are very intuitive. People are more satisfied with higher levels of care which are further from home, however, this is only true for Kinh people. Interestingly, after controlling for facility type, distance to the facility is positively related to patient satisfaction. This indicates that Kinh people tend to prefer quality to accessibility and they are willing to travel farther to get better care. Another explanation is that Kinh people are more likely to live in commune and district centres whereas ethnic minority groups often live very remotely. The higher number of self-reported illnesses/health issues per year is related to a lower level of patient satisfaction, whereas the frequency of going to the same health facility is not significant. This is consistent with a series of studies (Jackson et al., 2001; Danielsen et al., 2007; Hekkert et al., 2009; Rahmqvist and Bara, 2010; Schoenfelder et al., 2011; Footman et al., 2013) and the literature synthesis (Batbaatar et al., 2017) that suggests a negative relationship between health status and patient satisfaction. We find a negative relationship between total out-of-pocket payments and patient satisfaction but the effect size is negligible. This is probably due to the low capitation rate in those areas as well as the high rate of insurance usage among the insured (see descriptive statistics).

Some descriptive results are worth discussing. In general, the surveyed people, with or without insurance, are relatively satisfied with healthcare: the evaluation mean is close to 
'satisfied'. This is interesting given the concern over limited healthcare quality in rural areas due to inequalities in resource allocation (Somanathan et al., 2013) and limited accessibility (Tran et al., 2016). This probably can be explained by the fact that ethnic minority groups are less demanding regarding healthcare compared to the ethnic majority, whereas 79 percent of the evaluations are from the ethnic minority people.

In general, bad attitude towards patients, ineffective treatment and lack of medicines are the most common reasons for dissatisfaction in the surveyed areas. The rate of self-medication in the surveyed regions is relatively high, at more than 17 percent of visits. Those who use self-medication seem as satisfied as those using professional care even in comparison with the district hospitals. This is probably because of the simplicity of the illness involved, as seeking self-medication can help to cure it. Another explanation might be the easy access to (or even the lack of control in selling) antibiotics and specialty medicines in Vietnam (Duong et al., 1997; Larsson, 2003) which might lead to long-term negative effects. Traditional herbal therapies with professional physicians are also an important source of care in the rural poor areas in Vietnam and people seem to be satisfied with them.

We find that commune health stations can provide various types of care and are the most popular facility among people living in the poorest regions of Vietnam, which is similar to what is suggested by Tran et al. (2016), who study several rural and remote communes. Notably, the rate of self-medication is relatively high (17.7 percent) despite the high insurance coverage (more than 80 percent), suggesting a necessity to improve health literacy, raise the awareness of people, as well as to improve accessibility in the surveyed regions.

It is important to emphasise that the results only reflect correlations not causality. Additionally, the biggest limitation of this study is the potential of omitted variable bias as a myriad of service-related characteristics are not controlled for. The latest systematic review on determinants of patient satisfaction (Batbaatar et al., 2017) summarises more than 30 confounding factors to be investigated. Unfortunately, as a general survey, our dataset does not have that luxury. However, we managed to cover many objective quality aspects (the type of care, facility type, accessibility) and affordability (proxied by out-ofpocket payments) which are found to be the strongest determinants of patient satisfaction (Batbaatar et al., 2017). 


Chapter 6

\section{Conclusion}

\subsection{Background}

This dissertation has examined the effects of health insurance on labour supply and patient satisfaction with medical care in Vietnam. The research focuses are important and relevant as Vietnam is moving towards UHC with strong political commitment (Somanathan et al., 2014). Recent studies (Chou and Staiger, 2001; Kan and Lin, 2009; Wagstaff and MorenoSerra, 2009, 2015) and theoretical discussions (Strumpf, 2011; Gruber, 2010) have shown that health insurance potentially has undesirable impacts on labour supply. However, little is known about the labour market effects of health insurance for LMIC in general and for Vietnam in particular (see Chapter 2). Additionally, recent studies have shown that health insurance coverage in Vietnam is not effective (Somanathan et al., 2013), with quality concerns at all care levels. Therefore, the provision of health insurance may not necessarily lead to better quality of care. Nevertheless, knowledge gaps remain regarding how health insurance is valued by patients and whether health insurance can make patients more satisfied with the care they receive. Therefore, this dissertation aims at filling the aforementioned knowledge gaps.

In order to investigate the labour supply effects of health insurance, Chapter 2 systematically reviews all available evidence on labour supply effects of health insurance. Relevant outcomes reviewed include labour force participation (i.e. labour supply at extensive mar- 
gin), the number of hours worked (i.e. labour supply at intensive margin), self-employment decision, and the formalisation of the economy. The systematic review shows that the current literature on the effects of health insurance on labour supply is overly represented by studies on the American healthcare system. Non-US studies are very scattered and sporadic. Despite limited non-US evidence, the chapter shows that the relationship between health insurance and employment is a strong driver of self-employment decisions. Universal coverage may create either an incentive or a disincentive to work depending on the design of the system (Chapter 2). Evidence on the relationship between health insurance and the level of economic formalisation in developing countries is fragmented and inconclusive (ibid.). Regarding evidence on the American system, spousal coverage in the US is associated with reduced labour supply of secondary earners (ibid.). The effect of Medicaid in the US on labour supply of its recipients is ambiguous (ibid.). However, there is some evidence of labour supply distortion caused by CHIP, ACA and other public health insurance expansions (ibid.). Another tentative result is that dependent young adults in the US who can access health insurance via their parents' employer have lower labour supply through fewer hours worked while keeping the same employment probability. Chapter 2 also shows that the health insurance-employment link in the US is an important determinant of labour supply of people with health problems.

The dominance of US literature revealed in Chapter 2 highlights the need to have more research on the topic for LMIC in the global wave of moving towards UHC. Following the findings in Chapter 2, we examine the effects of health insurance on the number of hours worked, the probability of employment, and self-employment in Chapter 3 and 4. Vietnam is selected and researched as an example for the global trend of UHC. Chapter 3 investigates the effects of the HCFP on the number of hours worked and the probability of employment in Vietnam. Launched in 2003, the HCFP is a health policy that provides free health insurance for the poor and disadvantaged ethnic minority peoples in Vietnam. The results in Chapter 3 suggest that the HCFP has a negative labour supply effect due to the income effect. Chapter 4 examines the relationship between health insurance and self-employment transitions in Vietnam over time. It finds that, in Vietnam, people who are insured by the compulsory health insurance (the formal workers) are less likely to enter self-employment compared to those having voluntary insurance. The effect is partly explained by the better enforcement of the compulsory health insurance scheme in Vietnam, making staying out of self-employment (often informal self-employment) a preferred choice.

To answer the question if health insurance can make patients more satisfied with medical care, Chapter 5 examines the relationship between health insurance and patient satisfaction in the most poorly-resourced regions of Vietnam. Chapter 5 finds that it is not the availability of health insurance but the financial protection of health insurance that is linked to more patient satisfaction with medical services. Patient satisfaction depends on the depth of insurance coverage (i.e. services and medicines covered, co-payment rate for each service) and the ability to use health insurance to reduce medical costs via the co-payment mechanism. In particular, insured patients who can receive financial protection from their health insurance when seeking care are the most satisfied.

In this final chapter, the main findings and statements of the dissertation will be discussed. These findings are presented as concise statements to serve as key take-away messages for 
the reader, especially those advocating for UHC in LMIC in general and in Vietnam in particular.

\subsection{Discussion of statements}

\section{Statement 1: The American literature on the labour supply ef- fects of health insurance is rather informative for LMIC in their path towards UHC.}

Chapter 2 suggests that the current literature on the labour supply effects of health insurance is rather thin and sporadic for LMIC whilst being overly represented by studies on the US. The scope of our review in Chapter 2 is larger than that of previous reviews (Gruber and Madrian, 2002; Madrian, 2006) which merely focus on the US. However, despite the thorough scope and more updated studies reviewed, Chapter 2 still shows the American dominance in the existing literature. This over-representation of American studies in the literature may be attributable to the decades-long debate on the trade-off between equity and efficiency in the US. The institutional link between health insurance and employment in the country might be another reason why the topic is more studied.

This literature bias combined with the US's unique employment-based health insurance system raises the concern about the limited generalisability of the existing literature to LMIC. It then motivates to seek more evidence for LMIC in general and Vietnam in particular in the context of the UHC movement.

However, Chapter 3 and 4 of this dissertation lead to the conclusion that the American literature is still valid and informative for LMIC. From the theoretical aspect, the American literature lays an important theoretical ground for the topic. Discussions of the income effect of health insurance (e.g. Chou and Staiger, 2001), the static labour supply theory (Chou and Staiger, 2001; Rosen, 2014), together with theoretical analyses of moral hazard of welfare (Gruber, 2010; Ham and Shore-Sheppard, 2005; Strumpf, 2011) ${ }^{1}$, help to explain the channel through which health insurance may negatively affect labour supply (See Chapter 3 for the in-depth discussion of these theoretical underpinnings). Empirically, US-based studies provide useful insights, which can be used in studies for LMIC. The labour supply effects of health insurance is not only relevant for such an employment-based health insurance system as that of the US. For instance, Chapter 3 suggests that providing free health insurance for the poor has a negative effect on labour supply at both intensive and extensive margins. This is consistent with studies by Rosen (2014) for Medicaid recipients and Guy et al. (2012) for low-income childless adults who get insured under the Affordable Care Act. Despite the mixed effects found in the US literature regarding the effects of health insurance on assistance recipients and low-income people (see Chapter 2), comparing the results of Chapter 3 with US studies helps to

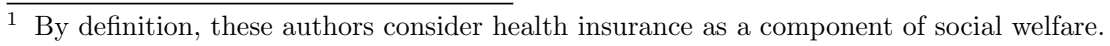


reveal why low-income people react differently to the provision and expansion of health insurance. Similarly, the entrepreneurship lock (found in Zissimopoulos and Karoly, 2007; Fairlie et al., 2011), which is often thought to be relevant for the US only due to the aforementioned employment-insurance tie, is also relevant for Vietnam. Particularly, Chapter 4 finds an association between different health schemes and self-employment transitions in Vietnam.

Therefore, with the current shortage of evidence for LMIC, the merit of the American literature should be acknowledged. The perception that the negative labour supply effect of health insurance is only relevant for the US is not necessarily correct and empirically unsupported.

\section{Policy implications}

Ideally, country-specific and policy-specific evidence for LMIC is recommended to account for the heterogeneity of health systems and health interventions among these countries. However, results from Chapters 3 and 4 of this dissertation show that evidence for Vietnam is relatively aligned with what is found for the US. This helps to address concern about the generalisability of the US literature to LMIC. As doing research will require time and financial resources, using what we have learned from the American literature to inform policy making in LMIC may be the most realistic and cost-saving choice.

\section{Statement 2: Within the SHI programme, free health insurance for the poor in Vietnam is found to have a negative effect on labour supply, manifested in both the number of hours worked and labour force participation.}

As shown in Chapter 3, the provision of free health insurance for the poor via the HCFP has a negative effect on labour supply at both intensive and extensive margins of the treated individuals (i.e. the number of hours worked and labour force participation). This finding is consistent with the prediction of an income effect, which is based on the traditional budget constraint approach and the static labour supply theory (see Chou and Staiger, 2001; Rosen, 2014).

Even though the premium subsidy under the HCFP is relatively small (around 2.5 USD in 2003, equivalent to approximately $1 / 40^{\text {th }}$ of the annual poverty line in 2003), it is still enough to trigger the income effect (see Chapter 3). This can be explained by the reduced out-of-pocket health expenses which were very high in Vietnam, at more than 39.5 percent of total health spending (The World Bank, 2018). Therefore, despite the small subsidized premium, its income effect can be sizeable via reducing health costs. This is another channel which contributes to increasing the income effect of non-contributory health insurance compared to other welfare benefits (Chou and Staiger, 2001).

Interestingly, Chapter 3 also demonstrates the inclusion error in the first years of the 
HCFP where many non-poor beneficiaries can benefit from the policy, and that the labour supply effects of health insurance for this group are more pronounced than for the poor. Even though this inclusion error is partly caused by the varied definitions of poverty in Vietnam (see Chapter 3 for more details) as well as the complex targeting strategy of the policy $^{2}$, this finding implies that the labour supply responses (both at the intensive and extensive margins) to the launch of the HCFP of the non-poor are stronger than those of the poor. The distinctive behavioural responses between the poor and the non-poor might be due to the lower take-up rate and lower healthcare utilization of the poor, who are more likely to belong to ethnic minority groups and hence live further away from local healthcare centres (Nguyen, 2010).

\section{Policy implications and suggestions for future research}

Given its political imperative as well as progress made in many LMIC (Rodin and de Ferranti, 2012; Lagomarsino et al., 2012), UHC may not be a distant future. Therefore, the undesirable effects of health insurance on labour supply should be viewed as a challenge rather than a roadblock on the path towards UHC. Importantly, there seems to be an assumption in the labour supply literature that working more is better while working conditions are often ignored. Even though increasing aggregate labour supply is good for economic growth, there is increasing concern about the rise of precarious and non-standard employment which is often associated with less labour protection and negative health outcomes (Quinlan et al., 2015). Therefore, the working-more-is-better assumption should be carefully contextualised to avoid unintended social impacts on workers. In this light, the income effect of health insurance is not necessarily bad from the perspective of the beneficiaries if, for example, they can improve their productivity and hence do not need to work as hard as before.

As shown in Chapter 2, the existing literature on the labour supply effects of health insurance for low-income people are overly concentrated on the American system with the Medicaid, Medicare and CHIP. Our study in Chapter 3 is among the very rare studies on this matter for LMIC. Therefore, more research for LMIC on the labour supply effects of health interventions for the poor and low-income people is needed.

In Chapter 3, even though theoretical models suggest two conflicting channels under which health insurance may have an effect on labour supply (see the literature review in Chapter 3 ), its results posit that the net effect is dominated by the income effect (negative). Even though the health-improvement effect of health insurance is intended in policy design, in Chapter 3 we cannot directly measure it because data on health status are not available. This data limitation is also discussed by Strumpf (2011) who posits that health status is normally unavailable in labour market surveys to test the health-fostering hypothesis. Besides, it is important to emphasise that even when the health improvement hypothesis holds true, whether people will work more or less will depend on how they view work relative to leisure given a budget constraint and how the improved health status will affect productivity. Therefore, quantifying the positive effect of health insurance on labour supply requires the examination of many other aspects beyond health status. As health, productivity and labour supply are interlinked, it is recommended that labour surveys in

2 The HCFP combined means-testing (i.e. poverty targeting) and categorical targeting. It not only included the poor but also some specific ethnic minority groups living in several selected provinces. 
the future should incorporate health information to unravel the mechanisms behind these intertwined components of well-being.

\section{Statement 3: To improve the efficiency of the SHI in Viet- nam and overcome the undesirable link between employment and health insurance coverage, the boundaries between different health schemes need to be removed.}

Chapter 4 shows that even though the SHI is a single payer system, its management is fragmented with different sub-schemes due to its historical context. Sub-schemes differ in enforcement mechanism, premium and co-payment rate (see descriptive results and description of the health insurance system in Vietnam in Chapter 4). This is consistent with Somanathan et al. (2014) who highlight the gaps in enforcement and financing mechanisms of different insurance sub-schemes within the SHI. Even though all of the SHI's predecessors have been consolidated into one system, the funds are not pooled (ibid.). The fragmentation is both vertical and horizontal: each of 63 provinces has a fund managed by provincial Vietnam Social Securities (VSS) agencies, in which a provincial fund is divided into smaller sub-funds for various health insurance schemes (ibid.). The vertical fragmentation is probably a result of administrative decentralisation in Vietnam where public funding is allocated to and managed by provincial governments. Meanwhile, horizontal fragmentation (the existence of multiple sub-scheme funds within the SHI) is the remnant of its predecessors. This demonstrates that the consolidation of the social health insurance system in Vietnam in 2008 was more of 'a new bottle for old wines' as the fragmentation remains, limiting the risk pooling intended for social health insurance as well as negatively affecting the efficiency of the SHI (ibid.).

More importantly, the existence of separate health insurance schemes in Vietnam may have undesirable effects by impeding self-employment entry, dampening job mobility and reducing labour market flexibility (Chapter 4). Chapter 4 shows that in Vietnam, the boundary between the compulsory health insurance and voluntary insurance is associated with self-employment entry. In particular, those covered by compulsory insurance are less likely to move into self-employment compared to those covered by voluntary insurance. One explanation is that people are more likely to stay in wage employment (more likely the formal sector) to enjoy the benefits of the compulsory health insurance combined with other fringe benefits. This finding is consistent with the literature of health insurance-induced entrepreneurship lock. ${ }^{3}$

To summarise, the boundaries between different health insurance schemes in Vietnam negatively affect the efficiency of SHI management on the one hand while limiting the labour market efficiency on the other hand. Therefore, removing the within-SHI heterogeneity is needed.

\footnotetext{
3 This phenomenon refers to the fact that wage earners prefer staying in wage employment for the health
} benefits attached to the job. 


\section{Policy implications and suggestions for future research}

The negative relationship between having compulsory health insurance and self-employment entry suggests the need to address the enforcement issue of the SHI programme in Vietnam. This can done via tackling the fragmentation of the SHI. All sub-scheme funds and provincial funds should be pooled. With the boom of ICT in Vietnam (Quynh, 2018), the application of e-governance of the SHI should be considered to improve the efficiency while facilitating the enrolment process.

Besides the SHI consolidation, other labour policies are recommended. The efficiency argument to promote self-employment in Vietnam should be considered carefully because better job matching and more flexibility in an economy of high concentration of the informal sector like Vietnam may imply the support for economic informalisation. With the erosion of labour protection due to weak compliance and disguised employment in LMIC (ILO, 2015), the policy choice may be pushing for the formalisation process, accompanied by entrepreneurship promotion policies for the formal self-employment sector.

Due to the scant literature on entrepreneurship lock (see Chapter 2), future research should focus on this topic for LMIC. Besides, the effects of health insurance on the economic formalisation process in LMIC should also be studied more (see Chapter 2), as this aspect should be examined in parallel with the efficiency argument.

\section{Statement 4: Health insurance can make insured patients more satisfied with medical care if they can benefit from its financial coverage.}

It is suggested in Chapter 5 that in the poorest regions of Vietnam, people with SHI are more satisfied with medical care if they are financially covered when seeking care. Due to the lack of coverage depth as well as quality concerns in primary care that cause people to skip the referral line, not all insured people can benefit from the financial protection of health insurance. In Chapter 5, we find that SHI-insured individuals who can benefit from its financial coverage are the most satisfied with medical care, compared to those who are insured but cannot benefit from the financial protection of health insurance and those who are uninsured. This suggests a significant relationship between patient satisfaction with medical care and the financial protection of the SHI despite its shallow coverage depth (Chapter 5). The positive relationship between SHI's financial coverage and patient satisfaction to some extend highlights the burden of out-of-pocket payments in Vietnam, which accounted for more than 39.5 percent of total health expenditure in 2012 (the study period in Chapter 5) (The World Bank, 2018). This also explains why one of the main reasons for patient dissatisfaction is the high out-of-pocket payments (see Chapter 5). As suggested in Chapter 5, more than 20 percent of those who are insured by SHI but cannot receive any financial benefits from the insurance scheme report that they are unsatisfied because of the high out-of-pocket costs. 
Even though this result cannot be generalized for the whole of Vietnam due to the limited scope of the data used, it shows that the limited coverage of health insurance can still help those living in the most disadvantaged areas (about half of whom are currently poor). Particularly, benefiting from the financial protection of health insurance is associated with higher patient satisfaction with medical care. In other words, for the beneficiaries, just a bit of financial protection is still better than nothing.

Surprisingly, we find that patients living in the most disadvantaged regions of Vietnam are relatively happy with the medical care they receive despite quality concerns (Tran et al., 2016) and the lack of resources (Takashima et al., 2017; Lieberman and Wagstaff, 2009; Somanathan et al., 2014). This shows the subjective nature of patient satisfaction that reflects patients' preferences, perceptions and relative referencing (Chapter 5). The high level of satisfaction measured in chapter 5 is due to the narrow frame of reference of those living in the poorest areas. Therefore, this finding should be interpreted with the cognizance of the subjective nature of patient satisfaction. As Chapter 5 is the very first investigation into the relationship between health insurance and patient satisfaction with medical care for LMIC in general and for Vietnam in particular, it is difficult to compare our findings with other similar studies. However, it is a useful reminder about the importance of patients' feelings and emotions in addition to other technical and physical considerations.

\section{Policy implications and suggestions for future research}

The findings in Chapter 5 imply that future expansion of the SHI in its depth (the expansion in services and medicines covered and the reduction in co-payment rate for each service) will contribute positively to patient satisfaction. Future health interventions to improve patient satisfaction with healthcare should be focused on expanding the depth of the SHI. Importantly, it is emphasized that patient satisfaction is a subjective measure which has its limitations. Therefore, objective quality measures should complement subjective quality assessments to have a complete view. The fact that most people in our study are satisfied with medical care should not be a reason for being over-optimistic.

Our finding in Chapter 5 opens new research opportunities on the relationship between health insurance and patient satisfaction. It also pinpoints the need for future research on this topic for LMIC in the context of moving towards UHC (Rodin and de Ferranti, 2012; Lagomarsino et al., 2012) and quality concerns of medical care in these countries. The narrow scope of the data used in Chapter 5 is a limitation. Even though it is very relevant to evaluate patient satisfaction in the most disadvantaged areas with limited health resources, it would be, however, more interesting if the same analysis can be done for the whole of Vietnam once the data are available. 


\section{Statement 5: Currently, health insurance coverage in Vietnam is rather limited and ineffective, which negatively affects patient satisfaction of those who are insured but cannot benefit from its financial coverage.}

Despite its rapid expansion, the SHI coverage is rather ineffective with many inefficiencies on the supply side. The shallow coverage has been shown in Chapter 5 wherein many insured patients could not take advantage of its financial coverage. This is one of the reasons for the very high out-of-pocket payments in Vietnam (Somanathan et al., 2014; The World Bank, 2018) despite the extensive expansion of SHI coverage rate. Also in Chapter 5, insured patients who did not get any financial protection from the health insurance were less satisfied compared to uninsured people.

One explanation for the non-use of health insurance of insured patients is that these patients may have used services or medicines uncovered by the SHI. This, in turn, can be caused by moral hazard on the supply side where hospitals have the incentive to conduct balance billing and 'charge patients high prices for 'better quality' services, pharmaceuticals, and supplies that are not part of the SHI coverage' (Somanathan et al., 2014, p.43). Balance billing is rampant in Vietnamese hospitals (ibid.) and is just one manifestation of profit maximization of 'public' hospitals in Vietnam (see the discussion of Vietnamese public hospitals in Chapter 5 and Ramesh, 2013; Lieberman and Wagstaff, 2009) as well as forms of corruption in the Vietnamese healthcare sector (Vian et al., 2012). Another explanation may be that they have skipped the referral line due to quality concerns and hence became ineligible for SHI benefits (Somanathan et al., 2014). It is also possible that they were not aware of the entitlements of SHI due to their lack of information (ibid.). Consequently, many patients are 'not enrolling in SHI, not using the card even when they are enrolled, or paying more in co-payments than they should' (Somanathan et al., 2014, p.43). The vested interest between pharmaceutical companies and prescribers (Nguyen et al., 2018) may be another reason why many insured patients may not receive SHI-covered services and medicines.

Complementing our research in Chapter 5, Somanathan et al. (2014) illustrate the paradox that the SHI coverage is both irrationally generous and shallow at the same time (Somanathan et al., 2014). Even though the SHI covers quite an extensive drug list (ibid.), they are not preferably prescribed by medical physicians due to balance billing (ibid.) and corruption in the drug prescription (Nguyen et al., 2018). SHI coverage is shallow and limited also because SHI reimbursement rates are not updated according to the rise in prices of medical services and drugs (Somanathan et al., 2014).

\section{Policy implications and suggestions for future research}

To improve the financial protection of the SHI, future health policies should focus on expanding not only the breadth of the SHI (increase in coverage rate) but also its depth (expansion in the list of services and medicines covered and reduction in co-payment rate). Supply side inefficiencies and corruption practices should be prevented to minimise the 
information asymmetry issue and moral hazard in the health sector. To reduce self-referrals (i.e. patients skip the referral line to use hospital care with better services and medical staff), the focus should also be placed on improving accessibility in the rural areas and the quality of care. The Ministry of Health has been making lots of effort to bridge the quality gap between rural and urban regions. The rate of increase in human resources for rural healthcare facilities has been recently faster than that in cities (Somanathan et al., 2014). However, more action is needed to reduce the gap, ensuring equality of access for all while having a functional referral system. Increasing the capability of medical staff in rural areas via continuous training combined with increased healthcare inputs are urgently needed. Raising awareness of SHI entitlements via education and communication campaigns is also vitally important.

The expansion of the SHI coverage at both breadth and depth is easier said than done because it requires an intensive increase in healthcare funding to ensure its financial sustainability. Therefore, in addition to expanding fiscal space for healthcare, increasing efficiency of the SHI is a more realistic choice. Cost reduction strategies may include, but are not limit to, tackling the abuse of Vietnam's Social Security Fund caused by the oversupply of services and many other supply side distortions (Somanathan et al., 2014), and fixing the fragmentation of the system (see Statement 3) to cut administrative costs.

Future research should be focused on unravelling the supply side distortions in the Vietnamese healthcare delivery. Somanathan et al. (2014) only pinpoint the general problems of the system, more in-depth investigations are needed to examine behaviours, incentives of physicians as well as other stakeholders (hospital managers, pharmaceutical firms, and so on) to come up with specific solutions.

In summary, more action needs to be taken to expand the shallow coverage of the SHI as well as to improve its efficiency. What is needed the most, perhaps, is the political will to create changes in a healthcare system with rampant challenges.

\subsection{Concluding remarks}

Health insurance might have important implications for the labour market as well as patient satisfaction with medical care. These implications are highly relevant for Vietnam in particular and LMIC in general in the context of moving towards UHC.

This dissertation has demonstrated that the literature on the labour supply effects of health insurance is overly represented by US studies while studies for LMIC are sporadic and limited. This dissertation has also suggested that the American literature on the topic can nevertheless be utilised for policy making in LMIC. This is thanks to its profound theoretical foundation as well as the similarity between American evidence and what is found for Vietnam in this dissertation. Free health insurance for the poor in Vietnam has been found to have a negative effect on labour supply at both intensive and extensive margins (i.e. the number of hours worked and labour force participation). This highlights the income effect of health insurance which policy makers should be well aware of. It also 
emphasises the need to examine the nexus between health, productivity and labour supply in future research to minimise the undesirable effects of health insurance. This dissertation has also found that the link between employment and health insurance coverage in Vietnam may become a barrier to self-employment. In particular, individuals covered by compulsory insurance are less likely to move into self-employment in comparison with those covered by voluntary insurance. Therefore, to overcome the undesirable employment-insurance link, the boundaries between different health insurance schemes need to be removed. Finally, health insurance can make insured patients more satisfied with medical care if they can benefit from its financial coverage. Currently, the lack of depth of the SHI coverage has been shown to negatively affect the evaluation of insured patients who cannot benefit from its financial coverage. Therefore, in addition to expanding SHI coverage rate (i.e. the breadth of its coverage), it is recommended to expand the depth of its coverage in the future to improve patient satisfaction as well as to tackle the issue of high out-of-pocket payments in Vietnam.

Moving towards UHC is not only about rolling out the SHI programme because health insurance is merely an instrument to achieve quality and affordable care for all. What is more central is the quality of care as well as a patient-centred approach in healthcare delivery to ensure that everyone will get access to quality healthcare without any financial hardship. As the right to health is a basic human right, moving towards UHC is undoubtedly a must. Therefore, the undesirable effects of health insurance on labour supply should be viewed as a challenge rather than a roadblock on the way to UHC. 



\section{Dissertation summary}

The main aim of this dissertation is to investigate the effects of health insurance on the labour market and on patient satisfaction with medical care. These focuses are relevant in the context of moving toward Universal Health Coverage (UHC) in low and middle income countries (Rodin and de Ferranti, 2012; Lagomarsino et al., 2012; Cotlear et al., 2015). This dissertation focuses on Vietnam as an example for this global trend as the country is fervently taking the path toward UHC despite many inefficiencies in its healthcare delivery as well as in the Social Health Insurance (SHI) programme (Somanathan et al., 2014; Takashima et al., 2017). This dissertation is motivated by the concern that rapid insurance coverage expansion in Vietnam may not necessarily translate into quality healthcare for all. Another concern is centred around the potential undesirable effects of health insurance on the labour market.

\section{Chapter 1}

In this chapter, policy problems, the motivation and relevance of the topics are discussed. The chapter starts with the policy context of Vietnam in which its government is showing unprecedented political commitment to moving toward Universal Health Coverage. However, challenges remain. Chronic problems of the Vietnamese healthcare system (i.e. limited resources at primary care and in rural areas, overcrowding and informal payments in hospital care) are discussed. Inefficiencies of the health insurance programme (the $\mathrm{SHI}$ ), especially the fragmentation in its management, are analysed. The inefficiencies of the SHI, combined with the issues of the healthcare system as a whole, potentially weaken the desirable impacts of health insurance and raise scepticism about whether providing universal health insurance is a good way to achieve affordable and quality care for all. This puts quality of care and patient satisfaction with medical care at the core of moving toward UHC in Vietnam. Meanwhile, the expansion of health insurance may 
have important implications for the labour market, which, in turn, may negatively affect economic achievements that Vietnam has been gaining.

Therefore, this dissertation asks two central questions:

- Question 1. What are the labour market effects of health insurance in Vietnam?

- Question 2. What are the implications of health insurance for patient satisfaction with medical care in Vietnam?

Specific research questions of the dissertation are as follows:

- Sub-question 1. What can we learn from the existing literature on the labour supply effects of health insurance?

- Sub-question 2. In Vietnam, what are the effects of health insurance on the number of hours worked and labour force participation?

- Sub-question 3. In Vietnam, what are the effects of health insurance on self employment?

- Sub-question 4. With the health insurance coverage expansion in Vietnam, how do patients evaluate the quality of healthcare?

The chapter also highlights knowledge gaps and pinpoints specific areas of focus for the dissertation. Data and methodologies used across the dissertation are summarised.

\section{Chapter 2}

Chapter 2 presents a systematic review of the existing literature on the effects of health insurance on labour supply. The review is conducted in a systematic way, covering all English language studies published after the year 2000 in many related disciplines, such as health economics, labour economics, public economics, public policy, health and medical studies. The databases used included Web of Science, Google Scholar, Pubmed, NBER, ECONSTOR, IDEAS, IZA, CEPR, SSRN, World Bank Working Paper Series. The final collection of studies reviewed includes 63 articles.

One of the key findings is that the current literature is vastly concentrated on the US whilst the literature for LMIC is very scant and sporadic. We show that spousal coverage in the US is associated with reduced labour supply of secondary earners. The effect of Medicaid in the US on labour supply of its recipients is ambiguous. However there is evidence of labour supply distortion caused by the Children's Health Insurance Program, the Affordable Care Act and other health insurance expansions. A tentative result is that dependent young adults in the US who can access health insurance via their parents' employer have lower labour supply through fewer hours worked while keeping the same employment probability. The employment-coverage link is an important determinant of the labour supply of people with health problems. The link between health insurance and employment 
is also related to self-employment decisions, manifested in the entrepreneurship $\operatorname{lock}^{4}$ or the entrepreneurship promotion effect of health insurance.

Despite the under-representation of LMIC-relevant studies, we found some important and suggestive evidence. Universal coverage may create either an incentive or a disincentive to work depending on the design of the system as shown in studies for Thailand (Wagstaff and Manachotphong, 2012) and Taiwan (Chou and Staiger, 2001; Chou et al., 2002; Liao, 2011). Evidence of the relationship between health insurance and the level of economic formalisation in developing countries is fragmented and limited.

\section{Chapter 3}

Chapter 3 delves into the effects of health insurance on labour supply. This chapter is motivated by the potential negative effects of health insurance on labour supply, which is discussed in public economics (e.g. Gruber, 2010) and labour economics (Chou et al., 2006; Rosen, 2014). The policy under investigation is the Health Care Fund for the Poor (HCFP) launched in 2003 in Vietnam. Using different matching techniques combined with a Difference-in-Differences model on panel data from the Vietnam Household Living Standard Surveys 2002-2006 (VHLSS 2002-2006), this chapter explores how labour supply of those covered with free health insurance under the HCFP changed over time.

We show that the HCFP has a negative effect on labour supply of those covered with free insurance under this scheme. The negative effect is manifested at both intensive (i.e. the number of hours worked) and extensive margins (i.e. labour force participation) of labour supply. This negative effects indicates that the income effects of health insurance tends to outweigh health-fostering effect of health insurance.

Interestingly, the negative effect of health insurance is mainly driven by the non-poor recipients living in rural areas. This raises the question of the targeting strategy of the programme which seems to trigger more labour responses from the non-poor than from the poor. It also highlights the need to discuss the labour supply effects of health insurance in Vietnam to avoid unintended labour supply distortions.

\section{Chapter 4}

Chapter 4 explores the relationship between health insurance and self-employment transitions in Vietnam by comparing the voluntary scheme for the informal sector (mostly self-employed workers) and the compulsory insurance for the formal sector (mostly wage workers). This chapter is motivated by the issue of 'entrepreneurship lock' (Fairlie et al., 2011) which refers to the insurance-induced rigidity of the labour market when people prefer staying in wage employment for the health insurance benefits attached to the job.

We employ a Probit model with selection (Van de Ven and Van Praag, 1981) on panel data from the Vietnamese Household Living Standards Surveys 2010-2014 (VHLSS 2010-2014) to investigate the association between health insurance and self-employment entry and exit

\footnotetext{
4 Entrepreneurship lock of health insurance is a phenomenon where a wage employee does not want to move to self-employment because he/she is locked in his/her salary job with its health insurance benefits.
} 
over time. We find that those with compulsory health insurance in Vietnam, the formal workers, are 10 percentage points less likely to enter self-employment compared to those having voluntary insurance. The effect is partly explained by the better enforcement of the compulsory health insurance scheme in Vietnam, making staying out of self-employment (often informal self-employment) a preferred choice. With respect to the effect of health insurance on self-employment exit, we find that those covered by compulsory insurance are more likely to exit self-employment. However, the effect size is relatively small. This chapter also highlights the rigidity of the Vietnamese economy, suggesting the need to tackle the enforcement issue of the SHI programme in Vietnam.

\section{Chapter 5}

Chapter 5 examines the relationship between health insurance and patient satisfaction with medical care in Vietnam. This chapter is motivated by quality concerns in healthcare delivery in Vietnam, especially at primary care and in remote areas (Somanathan et al., 2013, 2014; Tran et al., 2016). Primary care in the country, especially in disadvantaged and remote regions, is chronically in need of financial and human resources as well as other medical inputs (Lieberman and Wagstaff, 2009; Somanathan et al., 2014). This creates patient's lack of trust in the quality of care at primary care facilities and in rural areas. Many patients, therefore, decide to skip the referral line and seek care at higher level facilities, resulting in excessive demand and overcrowding in hospitals.

This chapter investigates the relationship in the context of the poorest regions of Vietnam, which are suffering from far more severe shortage of resources, inputs and medical personnel (Tran et al., 2016; Takashima et al., 2017). This chapter employs multi-level models for ordinal responses on a cross-sectional dataset of the poorest regions of Vietnam in 2012. We find that it is not health insurance coverage per se but the financial coverage when seeking healthcare that matters to improve patient satisfaction. Patient satisfaction depends on the depth of insurance coverage (i.e. services and medicines covered and the co-payment rate for each service) and the ability to use health insurance to reduce medical costs via the co-payment mechanism. The chapter also highlights the limited financial coverage of the SHI programme as many insured patients cannot get the cost-sharing benefits of the insurance coverage. As a surprising result, this chapter also finds that most people living in these disadvantaged regions of Vietnam are relatively satisfied with medical care. This is explained by the low terms of reference of those living in remote and poor regions of Vietnam. It also highlights the need to complement patient satisfaction analyses with other objective measures of healthcare quality.

\section{Chapter 6}

This Chapter summarises and discusses the main findings of the dissertation across Chapters 2-5. They are presented in concise policy statements, which can be used as takeaway policy messages for the reader. For each statement, policy and research implications are provided to help inform future health policy reforms in Vietnam. These statements include:

Statement 1: The American literature on the labour supply effects of health insurance is rather informative for LMIC in their path toward UHC. 
The US literature has laid a firm theoretical foundation for the limited literature beyond the US. The main findings across Chapter 3-5 suggest that the labour supply effects of health insurance are not only relevant for an employment-tied insurance system such as that of the US. Therefore, with the current shortage of LMIC literature, US studies are useful to shed some lights on the topic of the labour supply effects of health insurance.

Statement 2: Within the SHI programme, free health insurance for the poor in Vietnam is found to have a negative effect on labour supply, manifested in both the number of hours worked and labour force participation.

This statement is based on Chapter 3 which examines the effects of the HCFP on labour supply in Vietnam. Even though health insurance may theoretically have both positive and negative effects on labour supply (i.e. via the health-fostering effect and the income effect), it seems that the latter will dominate if the insurance coverage is not enough to generate any sizable health effect.

Statement 3: To improve the efficiency of the SHI in Vietnam and overcome the undesirable link between employment and health insurance coverage, the boundaries between different health schemes need to be removed.

This statement is based on the finding that the SHI in Vietnam is fragmented both vertically and horizontally. There remain gaps in enforcement among different health insurance sub-schemes, especially between the voluntary and compulsory schemes. The gap then leads to the undesirable entrepreneurship lock when people with compulsory insurance are less likely to enter self-employment compared to those covered by voluntary insurance.

Statement 4: Health insurance can make insured patients more satisfied with medical care if they can benefit from its financial coverage.

Health insurance can make patients who are living in the poorest regions of Vietnam more satisfied with medical care thanks to its financial coverage. This statement suggests that future interventions to improve patient satisfaction in Vietnam should focus on expanding the financial coverage of the SHI programme.

Statement 5: Currently, health insurance coverage in Vietnam is rather limited and ineffective, which negatively affects patient satisfaction of those who are insured but cannot benefit from its financial coverage.

Statement 5 highlights that despite the fast expansion of coverage rate, SHI coverage in Vietnam is very shallow as a large proportions of insured patients cannot benefit from its financial coverage when seeking care. This once again suggests the urgent need to increase the depth of the SHI coverage.

In Chapter 6, policy implications are also provided regarding health and labour policy making. Areas for further research are also pinpointed. It is recommended that policy making in Vietnam and other LMIC should pay attention to the design, management and monitoring of the health insurance system to improve the efficiency and effectiveness of 
the insurance coverage. To improve efficiency in managing the SHI whilst improving the equity and equality in SHI enrolment compliance, it is important to focus on tackling its fragmentation. Besides, objective quality measures should complement subjective quality assessments to have a complete view. The fact that most people living in disadvantaged regions of Vietnam are rather satisfied with medical care (Chapter 5), despite the severe lack of resources and medical staff in those regions, is a strong indication of the subjective nature of patient satisfaction. Therefore, this finding should not be a reason for being over-optimistic.

In addition to empirical analyses, Chapters 2-5 also highlight the knowledge gaps to be filled. LMIC-relevant areas for further research include the effects of health insurance on labour supply (the number of hours worked and labour force participation), self-employment and economic formalisation. More research on the labour supply effects of health interventions for the poor and low-income people are needed to guide policy making in LMIC. Future research should also focus on the health effects of health insurance for adults due to the lack of evidence of positive insurance-induced health effect (Sommers et al., 2012). Finally, more research for LMIC on the relationship between health insurance and self-employment is also recommended. 


\section{Bibliography}

Agresti, A. (2010). Analysis of ordinal categorical data, volume 656. John Wiley \& Sons.

Ahearn, M. C., El-Osta, H., Mishra, A. K., et al. (2013). Considerations in work choices of US farm households: The role of health insurance. Journal of Agricultural and Resource Economics, 38(1):19-33.

Antwi, Y. A., Moriya, A. S., and Simon, K. (2013). Effects of federal policy to insure young adults: evidence from the 2010 Affordable Care Act's dependent-coverage mandate. American Economic Journal: Economic Policy, 5(4):1-28.

Aterido, R., Hallward-Driemeier, M., et al. (2011). Does expanding health insurance beyond formal-sector workers encourage informality? measuring the impact of Mexico's Seguro Popular. World Bank Policy Research Working Paper No. 5785, The World Bank.

Atkinson, S. and Haran, D. (2005). Individual and district scale determinants of users' satisfaction with primary health care in developing countries. Social Science 8 Sedicine, 60(3):501-513.

Azuara, O. and Marinescu, I. (2013). Informality and the expansion of social protection programs: Evidence from Mexico. Journal of health economics, 32(5):938-950.

Baicker, K. and Chandra, A. (2005). The consequences of the growth of health insurance premiums. American Economic Review, 95(2):214-218.

Baicker, K. and Chandra, A. (2006). The labor market effects of rising health insurance premiums. Journal of Labor Economics, 24(3):609-634. 
Baicker, K., Finkelstein, A., Song, J., and Taubman, S. (2014). The impact of Medicaid on labor market activity and program participation: evidence from the Oregon Health Insurance Experiment. American Economic Review, 104(5):322-28.

Bailey, J. B. (2013). Health insurance and the supply of entrepreneurs: new evidence from the Affordable Care Act's dependent coverage mandate. Social Science Research Network. Available at https: //ssrn.com/abstract $=2230099$.

Banerjee, A. V., Hanna, R., Kreindler, G., and Olken, B. A. (2015). Debunking the stereotype of the lazy welfare recipient: Evidence from cash transfer programs worldwide. Harvard Kennedy School Working Paper No. 076. Available at https : //ssrn.com/abstract $=2703447$.

Banerjee, A. V., Hanna, R., Kreindler, G. E., and Olken, B. A. (2017). Debunking the stereotype of the lazy welfare recipient: Evidence from cash transfer programs. The World Bank Research Observer, 32(2):155-184.

Barroy, H., Jarawan, E., and Bales, S. (2014). Vietnam: Learning from Smart Reforms on the Road to Universal Health Coverage. The World Bank, Washington, DC.

Batbaatar, E., Dorjdagva, J., Luvsannyam, A., Savino, M. M., and Amenta, P. (2017). Determinants of patient satisfaction: a systematic review. Perspectives in public health, 137(2):89-101.

Becker, T. and Tuzemen, D. (2014). Self-employment and health care reform: Evidence from massachusetts. Federal Reserve Bank of Kansas City Working Paper No. 14-16. Retrieved on 5 Nov 2015 from https ://ssrn.com/abstract $=2531068$.

Bergolo, M. and Cruces, G. (2014). Work and tax evasion incentive effects of social insurance programs: Evidence from an employment-based benefit extension. Journal of Public Economics, 117:211-228.

Bleich, S. N., Özaltin, E., and Murray, C. J. (2009). How does satisfaction with the healthcare system relate to patient experience? Bulletin of the World Health Organization, 87(4):271-278.

Boerma, T., Eozenou, P., Evans, D., Evans, T., Kieny, M.-P., and Wagstaff, A. (2014). Monitoring progress towards universal health coverage at country and global levels. PLoS medicine, 11(9):e1001731.

Bosch, M. and Campos-Vazquez, R. M. (2014). The trade-offs of welfare policies in labor markets with informal jobs: the case of the Seguro Popular program in Mexico. American Economic Journal: Economic Policy, 6(4):71-99.

Boyle, M. A. and Lahey, J. N. (2010). Health insurance and the labor supply decisions of older workers: Evidence from a US Department of Veterans Affairs expansion. Journal of public economics, 94(7):467-478.

Boyle, M. A. and Lahey, J. N. (2016). Spousal labor market effects from government health insurance: Evidence from a veterans affairs expansion. Journal of health economics, 45:63-76. 
Bradley, C. J., Neumark, D., and Motika, M. (2012). The effects of health shocks on employment and health insurance: the role of employer-provided health insurance. International journal of health care finance and economics, 12(4):253-267.

Buchmueller, T. C. and Valletta, R. G. (1999). The effect of health insurance on married female labor supply. Journal of Human Resources, 34(1):42-70.

Butler, D., Oswald, S. L., and Turner, D. E. (1996). The effects of demographics on determinants of perceived health-care service quality: the case of users and observers. Journal of Management in Medicine, 10(5):8-20.

Camacho, A., Conover, E., and Hoyos, A. (2014). Effects of Colombia's social protection system on workers' choice between formal and informal employment. The World Bank Economic Review, 28(3):446-466.

Campos-Vazquez, R. M. and Knox, M. A. (2013). Social Protection Programs and Employment The Case of Mexico's Seguro Popular Program. Economía Mexicana. Nueva Época, 22(2):403-448.

Castillo-Laborde, C., Aguilera-Sanhueza, X., Hirmas-Adauy, M., Matute, I., DelgadoBecerra, I., Ferrari, M. N.-D., Olea-Normandin, A., and González-Wiedmaier, C. (2017). Health insurance scheme performance and effects on health and health inequalities in Chile. MEDICC Review, 19:57-64.

Cebi, M. and Wang, C. (2013). Employer-provided health insurance and labor supply of married women. Eastern Economic Journal, 39(4):493-510.

Cheng, T.-M. (2014). Vietnam's health care system emphasizes prevention and pursues universal coverage. Health Affairs, 33(11):2057-2063.

Cho, Y., Margolis, D., Newhouse, D., and Robalino, D. (2012). Labor markets in low and middle income countries: trends and implications for social protection and labor policies. World Bank Social Protection ELabor Discussion Paper No.1207, The World Bank, 67613.

Chou, S.-Y., Liu, J.-T., and Hammitt, J. K. (2002). Health insurance and households' precautionary behaviors-an unusual natural experiment. NBER Working Paper No. 9394.

Chou, S.-Y., Liu, J.-T., and Hammitt, J. K. (2006). Households' precautionary behaviorsthe effects of the introduction of National Health Insurance in Taiwan. Review of Economics of the Household, 4(4):395-421.

Chou, Y.-J. and Staiger, D. (2001). Health insurance and female labor supply in Taiwan. Journal of Health Economics, 20(2):187-211.

Clark, P. A. and Gesell, S. B. (2010). Using patient evaluations to empirically assess medicaid programs for social justice. Social work in public health, 25(5):486-510.

Cling, J.-P., Razafindrakoto, M., and Roubaud, F. (2011). The informal economy in Viet Nam. The Ministry of Labour, Invalids and Social Affairs, Vietnam. 
Contreras, D., De Mello, L., and Puentes, E. (2011). The determinants of labour force participation and employment in Chile. Applied Economics, 43(21):2765-2776.

Contreras, D. and Plaza, G. (2010). Cultural factors in women's labor force participation in Chile. Feminist Economics, 16(2):27-46.

Cotlear, D., Nagpal, S., Smith, O., Tandon, A., and Cortez, R. (2015). Going universal: how 24 developing countries are implementing universal health coverage from the bottom up. The World Bank, Washington, DC.

Currie, J. and Gruber, J. (1996). Health insurance eligibility, utilization of medical care, and child health. The Quarterly Journal of Economics, 111(2):431-466.

Currie, J. and Madrian, B. C. (1999). Health, health insurance and the labor market, volume 3, chapter 50, pages 3309-3416. Elsevier, first edition.

Dague, L., DeLeire, T., and Leininger, L. (2017). The effect of public insurance coverage for childless adults on labor supply. American Economic Journal: Economic Policy, $9(2): 124-54$.

Dahlen, H. M. (2015). "aging out" of dependent coverage and the effects on US labor market and health insurance choices. American journal of public health, 105(S5):S640 S650.

Dang, M. (09 Nov 2013). [Vietnamese] Dai bieu quoc hoi ke chuyen bi 'lam kho' khi kham bao hiem y te, [English] A congress man tells a story of him being discriminated when seeking healthcare with health insurance. CAND online. Retrieved on 23 Feb 2018 from http ://cand.com.vn/Xa - hoi/Dai - bieu - Quoc - hoi - ke - chuyen bi - lam - kho - khi - kham - bao - hiem - y-te-243030/.

Danielsen, K., Garratt, A. M., Bjertnæs, Ø. A., and Pettersen, K. I. (2007). Patient experiences in relation to respondent and health service delivery characteristics: a survey of 26,938 patients attending 62 hospitals throughout norway. Scandinavian Journal of Social Medicine, 35(1):70-77.

Dave, D., Decker, S. L., Kaestner, R., and Simon, K. I. (2015). The effect of Medicaid expansions in the late 1980s and early 1990s on the labor supply of pregnant women. American Journal of Health Economics, 1(2):165-193.

DeCicca, P. (2007). Health insurance availability and entrepreneurship: evidence from New Jersey. Social Science Research Network. Available at https : //ssrn.com/abstract = 1003309 .

Depew, B. (2015). The effect of state dependent mandate laws on the labor supply decisions of young adults. Journal of health economics, 39:123-134.

Duong, D. V., Binns, C. W., and Le, T. V. (1997). Availability of antibiotics as over-thecounter drugs in pharmacies: a threat to public health in Vietnam. Tropical medicine \& international health, 2(12):1133-1139. 
Duong, T. (02 April 2014). [Vietnamese] BT Tien: Benh nhan co bao hiem y te bi phan biet doi xu, [English] The Health Minister: Insured patients face discrimination. 24h news. Retrieved on 23 Feb 2018 from http: //us.24h.com.vn/tin - tuc - trongngay/bt-tien-benh-nhan-co-bhxh-bi-phan-biet-doi-xu-c46a620445.htmll.

Erosa, A., Fuster, L., and Kambourov, G. (2012). Labor supply and government programs: A cross-country analysis. Journal of Monetary Economics, 59(1):84-107.

Escobar, M.-L., Griffin, C. C., and Shaw, R. P. (2011). The impact of health insurance in low-and middle-income countries. Brookings Institution Press.

Fairlie, R. W., Kapur, K., and Gates, S. (2011). Is employer-based health insurance a barrier to entrepreneurship? Journal of Health Economics, 30(1):146-162.

Fishbein, M. and Ajzen, I. (1975). Belief, attitude, intention and behavior: An introduction to theory and research. Addison-Wesley publishing Company.

Footman, K., Roberts, B., Mills, A., Richardson, E., and McKee, M. (2013). Public satisfaction as a measure of health system performance: a study of nine countries in the former soviet union. Health Policy, 112(1):62-69.

Fossen, F. M. and König, J. (2017). Public health insurance, individual health, and entry into self-employment. Small Business Economics, 49(3):647-669.

Gai, Y. and Minniti, M. (2015). Health insurance, job lock, and the supply of selfemployment. Journal of Small Business Management, 53(2):558-580.

Garthwaite, C., Gross, T., and Notowidigdo, M. J. (2014). Public health insurance, labor supply, and employment lock. The Quarterly Journal of Economics, 129(2):653-696.

Gill, L. and White, L. (2009). A critical review of patient satisfaction. Leadership in Health Services, 22(1):8-19.

Gindling, T. and Newhouse, D. (2014). Self-employment in the developing world. World Development, 56:313-331.

Glewwe, P. (2003). Procedure for calculating nominal and real expenditures, and poverty indicators, for the 2002 VHLSS. The World Bank. Available at http : //microdata.worldbank.org/index.php/catalog/2306/download/34491.

Gooptu, A., Moriya, A. S., Simon, K. I., and Sommers, B. D. (2016). Medicaid expansion did not result in significant employment changes or job reductions in 2014. Health affairs, 35(1):111-118.

Gruber, J. (2000). Health insurance and the labor market, volume 1, pages 645-706. Elsevier.

Gruber, J. (2010). Public finance and public policy. Worth Publishers, third edition.

Gruber, J. and Madrian, B. C. (1994). Health insurance and job mobility: The effects of public policy on job-lock. ILR Review, 48(1):86-102. 
Gruber, J. and Madrian, B. C. (2002). Health insurance, labor supply, and job mobility: a critical review of the literature. NBER Working Paper No. 881\%. Available at http : //www.nber.org/papers/w8817.

Guindon, G. E. (2014). The impact of health insurance on health services utilization and health outcomes in Vietnam. Health Economics, Policy and Law, 9(04):359-382.

Gulliford, M., Naithani, S., and Morgan, M. (2006). What is 'continuity of care'? Journal of Health Services Research \& Policy, 11(4):248-250.

Gumus, G. and Regan, T. L. (2015). Self-employment and the role of health insurance in the US. Journal of Business Venturing, 30(3):357-374.

Gurley-Calvez, T. (2011). Will tax-based health insurance reforms help the self-employed stay in business? Contemporary Economic Policy, 29(3):441-460.

Guy, G. P., Atherly, A., and Adams, E. K. (2012). Public health insurance eligibility and labor force participation of low-income childless adults. Medical Care research and review, 69(6):645-662.

Hahn, Y. and Yang, H.-S. (2016). Do work decisions among young adults respond to extended dependent coverage? ILR Review, 69(3):737-771.

Hall, J. A. and Dornan, M. C. (1990). Patient sociodemographic characteristics as predictors of satisfaction with medical care: a meta-analysis. Social science $\mathscr{E}$ medicine, 30(7):811-818.

Ham, J. C. and Shore-Sheppard, L. D. (2005). Did expanding Medicaid affect welfare participation? ILR Review, 58(3):452-470.

Heckman, J. J. (1979). Sample selection bias as a specification error. Econometrica: Journal of the econometric society, 47(1):153-161.

Heckman, J. J. and MaCurdy, T. E. (1980). A life cycle model of female labour supply. The Review of Economic Studies, 47(1):47-74.

Heim, B. T. and Lurie, I. Z. (2010). The effect of self-employed health insurance subsidies on self-employment. Journal of Public Economics, 94(11):995-1007.

Hekkert, K. D., Cihangir, S., Kleefstra, S. M., van den Berg, B., and Kool, R. B. (2009). Patient satisfaction revisited: a multilevel approach. Social science $\&$ medicine, 69(1):6875 .

Holtz-Eakin, D., Penrod, J. R., and Rosen, H. S. (1996). Health insurance and the supply of entrepreneurs. Journal of Public Economics, 62(1):209-235.

Howell, E., Decker, S., Hogan, S., Yemane, A., and Foster, J. (2010). Declining child mortality and continuing racial disparities in the era of the medicaid and schip insurance coverage expansions. American journal of public health, 100(12):2500-2506.

Humphries, J. and Sarasúa, C. (2012). Off the record: Reconstructing women's labor force participation in the European past. Feminist Economics, 18(4):39-67. 
ILO (2015). Labour protection in a transforming world of work. A recurrent discussion on the strategic objective of social protection (labour protection). International Labour Organisation, Geneve.

Jackson, J. L., Chamberlin, J., and Kroenke, K. (2001). Predictors of patient satisfaction. Social science $\&$ medicine, 52(4):609-620.

Jia, Y. G. (2014). Health insurance coverage and self-employment among young US adults. Social Science Research Network. Available at https : //ssrn.com/abstract $=2533648$.

Jovanovic, B. (1979). Job matching and the theory of turnover. Journal of political economy, 87(5, Part 1):972-990.

Jowett, M., Contoyannis, P., and Vinh, N. D. (2003). The impact of public voluntary health insurance on private health expenditures in Vietnam. Social Science 85 Medicine, $56(2): 333-342$.

Kan, K. and Lin, Y.-L. (2009). The labor market effects of national health insurance: evidence from Taiwan. Journal of Population Economics, 22(2):311-350.

Kapinos, K. A. (2009). Changes in spousal health insurance coverage and female labor supply decisions, volume 12, pages 1-24. Walter de Gruyter GmbH \& Co. KG.

Kelley, H. H. et al. (1966). The social psychology of groups. Transaction Publishers.

Kersnik, J. (2001). Determinants of customer satisfaction with the health care system, with the possibility to choose a personal physician and with a family doctor in a transition country. Health policy, 57(2):155-164.

Kim, Q. and Vu, H. (09 Nov 2013). [Vietnamese] Nhieu nguoi ne bao hiem y te vi bi phan biet doi xu, [English] Many avoid using health insurance due to discrimination. CAND online. Retrieved on 23 Feb 2018 from http : //cand.com.vn/thoi - su/Nhieunguoi - ne - bao - hiem - y-te - vi - bi - phan - biet - doi - xu - 243048/.

King, G. and Nielsen, R. (2016). Why propensity scores should not be used for matching. Available at $h t t p: / / j . m p / 2 o v Y G s W$.

Kreider, A. R., French, B., Aysola, J., Saloner, B., Noonan, K. G., and Rubin, D. M. (2016). Quality of health insurance coverage and access to care for children in low-income families. JAMA pediatrics, 170(1):43-51.

Lagomarsino, G., Garabrant, A., Adyas, A., Muga, R., and Otoo, N. (2012). Moving towards universal health coverage: health insurance reforms in nine developing countries in Africa and Asia. The Lancet, 380(9845):933-943.

Larsson, M. (2003). Antibiotic use and resistance: Assessing and improving utilisation and provision of antibiotics and other drugs in Vietnam. Institutionen för folkhälsovetenskap/Department of Public Health Sciences, Karolinska Institute, Sweden.

Lawler, E. (1971). Pay and organization effectiveness: A psychological view. McGraw Hill. 
Lê, N., Groot, W., Tomini, S. M., and Tomini, F. (2019). Effects of health insurance on labour supply: A systematic review. International Journal of Manpower.

Lee, H. J. and Tomohara, A. (2008). Public health insurance expansions and labour supply of married women: the state children's health insurance programme. Applied Economics, 40(7):863-874.

Levy, H. and Meltzer, D. (2001). What do we really know about whether health insurance affects health. Economic Research Initiative on the Uninsured (ERIU), the University of Michigan. Retrieved on 11 Oct 2017 from http : //www.rwjf eriu.org/pdf/levy.meltzer - final.pdf.

Levy, H. and Meltzer, D. (2004). What do we really know about whether health insurance affects health. Urban Institute Press: Washington, DC.

Levy, S. (2010). Good intentions, bad outcomes: Social policy, informality, and economic growth in Mexico. Brookings Institution Press. Washington, DC.

Liao, P.-A. (2011). Heterogeneous impact of Taiwan's National Health Insurance on labor force participation of married women by income and family structures. Health care for women international, 32(2):154-173.

Liao, P.-A. and Taylor, J. E. (2010). Health care reform and farm women's off-farm labor force participation: Evidence from Taiwan. Journal of Agricultural and Resource Economics, 35(2):281-298.

Liberati, A., Altman, D. G., Tetzlaff, J., Mulrow, C., GÃ,tzsche, P. C., Ioannidis, J. P. A., Clarke, M., Devereaux, P. J., Kleijnen, J., and Moher, D. (2009). The PRISMA Statement for Reporting Systematic Reviews and Meta-Analyses of Studies That Evaluate Health Care Interventions: Explanation and Elaboration. PLoS Med, $6(7)$.

Lieberman, S. S. and Wagstaff, A. (2009). Health financing and delivery in Vietnam: looking forward. The World Bank, Washington, DC.

Linder-Pelz, S. (1982). Toward a theory of patient satisfaction. Social science 83 medicine, 16(5):577-582.

Luck, J., Peabody, J., DeMaria, L., Alvarado, C., and Menon, R. (2014). Patient and provider perspectives on quality and health system effectiveness in a transition economy: evidence from Ukraine. Social Science \& Medicine, 114:57-65.

Madrian, B. (2006). The US health care system and labor markets. NBER Working Paper No.11980. Available at http://www.nber.org/papers/w11980.

Madrian, B. C., Burtless, G., and Gruber, J. (1994). The effect of health insurance on retirement. Brookings Papers on Economic Activity, 1994(1):181-252.

Mahon, P. Y. (1996). An analysis of the concept 'patient satisfaction' as it relates to contemporary nursing care. Journal of advanced nursing, 24(6):1241-1248.

Matsushima, M. and Yamada, H. (2016). Impacts of bribery in healthcare in vietnam. The Journal of Development Studies, 52(10):1479-1498. 
McCaig, B. (2009). The reliability of matches in the 2002-2004 Vietnam Household Living Standards Survey Panel. Discussion paper. Centre for Economic Policy Research, Australian National University. Available at https : //www.rse.anu.edu.au/media/604599/dp622.pdf.

McCaig, B. (2017). Note on VHLSS. Data retrieved on 30 Jan 2017 from Brian McCaig's website, https ://sites.google.com/site/briandmccaig/home/notes - on - vhlsss.

Mills, A. (2014). Health care systems in low-and middle-income countries. New England Journal of Medicine, 370(6):552-557.

MOH (2013). Circular 07/2013/TT-BYT on capability standard, role and responsibility of community medical officers at the village level. Ministry of Health, Hanoi, Vietnam.

MOH and MOF (2009). Circular 09/2009/TTLT-BYT-BTC on guidance on health insurance law. Ministry of Health and Ministry of Finance, Hanoi, Vietnam.

Moher, D., Liberati, A., Tetzlaff, J., and Altman, D. G. (2009). Preferred reporting items for systematic reviews and meta-analyses: the PRISMA statement. PLoS Med, 6(7).

MOLISA (2000). Decision 1143/2000/QD-LDTBXH on poverty line during 2001-2005. MOLISA, Hanoi, Vietnam.

Montgomery, E. and Navin, J. C. (2000). Cross-state variation in medicaid programs and female labor supply. Economic Inquiry, 38(3):402-418.

Murasko, J. E. (2008). Married women's labor supply and spousal health insurance coverage in the United States: Results from panel data. Journal of Family and Economic Issues, 29(3):391-406.

Netzer, N. and Scheuer, F. (2007). Taxation, insurance, and precautionary labor. Journal of Public Economics, 91(7-8):1519-1531.

Ng, J. H. and Luk, B. H. (2018). Patient satisfaction: Concept analysis in the healthcare context. Patient education and counseling.

Ngan, A. (25 Dec 2017). [Vietnamese] Ty le bao phu bao hiem y te da dat hon $86 \%$. [English] Health insurance coverage reaches more than $86 \%$. Nhandan news online. Retrieved on 16 Feb 2018 from http : //www.nhandan.com.vn/xahoi/item/35104002ty - le - bao - phu - bao-hiem -y-te-da-dat - hon-86.html.

Ngui, E. M. and Flores, G. (2006). Satisfaction with care and ease of using health care services among parents of children with special health care needs: the roles of race/ethnicity, insurance, language, and adequacy of family-centered care. Pediatrics, 117(4):1184-1196.

Nguyen, C., Phung, T., Phung, T., Vu, N., and Westbrook, D. (2013). The impact of a national poverty reduction program on ethnic minorities in Vietnam: the lens of baseline and endline surveys. Munich personal RePEc Archive No.44017.

Nguyen, C. V. (2012). The impact of voluntary health insurance on health care utilization and out-of-pocket payments: New evidence for Vietnam. Health economics, 21(8):946966. 
Nguyen, C. V., Phung, T. D., and Westbrook, D. (2015). Do the poorest ethnic minorities benefit from a large-scale poverty reduction program? evidence from Vietnam. The Quarterly Review of Economics and Finance, 56:3-14.

Nguyen, H. and Wang, W. (2013). The effects of free government health insurance among small children. evidence from the free care for children under six policy in Vietnam. The International journal of health planning and management, 28(1):3-15.

Nguyen, L. H. and Hoang, A. T. D. (2017). Willingness to pay for social health insurance in Central Vietnam. Frontiers in public health, 5:89.

Nguyen, T. A., Knight, R., Mant, A., Razee, H., Brooks, G., Dang, T. H., and Roughead, E. E. (2018). Corruption practices in drug prescribing in vietnam-an analysis based on qualitative interviews. BMC health services research, 18(1):587.

Nguyen, V. (2010). Public health services and health care utilization in Vietnam. Munich Personal RePEc Archive 33610. Available at https : //mpra.ub.uni muenchen.de/33610.

Niu, X. (2014). Health insurance and self-employment: Evidence from massachusetts. ILR Review, 67(4):1235-1273.

OECD (2019). Economic outlook for Southeast Asia, China and India 2019. Towards smart urban transportation. Organisation for Economic Co-operation and Development,Paris. Retrieved on 16 Apr 2019 from https : //www.oecd.org/development/asia pacific $/ 01_{S}$ AEO2019 overview $_{W}$ EB.pdf.

Okun, A. M. (1975). Equality and Efficiency: The Big Tradeoff. Brookings Institution, Washington, DC.

Olson, C. A. (1998). A comparison of parametric and semiparametric estimates of the effect of spousal health insurance coverage on weekly hours worked by wives. Journal of Applied Econometrics, 13(5):543-565.

Olson, C. A. (2002). Do workers accept lower wages in exchange for health benefits? Journal of Labor Economics, 20(S2):S91-S114.

Page, T. F. (2011). Labor supply responses to government subsidized health insurance: evidence from kidney transplant patients. International journal of health care finance and economics, 11(2):133.

Palmer, M., Mitra, S., Mont, D., and Groce, N. (2015). The impact of health insurance for children under age 6 in Vietnam: a regression discontinuity approach. Social Science E Medicine, 145:217-226.

Palmer, M. G. (2014). Inequalities in universal health coverage: evidence from Vietnam. World Development, 64:384-394.

Parsons, D. O. (1982). The male labour force participation decision: health, reported health, and economic incentives. Economica, 49(193):81-91.

Quinlan, M. et al. (2015). The effects of non-standard forms of employment on worker health and safety. International Labour Organization, Geneva, Switzerland. 
Quoc, N. (22 Jan 2015). [Vietnamese] Benh nhan bo bao hiem y te, vuot tuyen, [English] Insured patients do not use health insurance, skipping the referral line. Tienphong news online. Retrieved on 23 Feb 2018 from https ://www.tienphong.vn/xa - hoi/benhnhan - bo - bao-hiem-y-te-vuot - tuyen - 813484.tpo.

Quynh, N. (07 Nov 2018). IT industry in vietnam enjoying boom. Vietnam Economic News. Retrieved on 10 Nov 2018 from http : //ven.vn/it - industry - in - vietnamenjoying - boom - 35716.html.

Rabe-Hesketh, S. and Skrondal, A. (2008). Multilevel and longitudinal modeling using Stata. Stata press.

Rahmqvist, M. and Bara, A.-C. (2010). Patient characteristics and quality dimensions related to patient satisfaction. International Journal for Quality in Health Care, 22(2):8692 .

Ramesh, M. (2013). Health care reform in vietnam: Chasing shadows. Journal of Contemporary Asia, 43(3):399-412.

Rockers, P. C., Feigl, A. B., Røttingen, J.-A., Fretheim, A., de Ferranti, D., Lavis, J. N., Melberg, H. O., and Bärnighausen, T. (2012). Study-design selection criteria in systematic reviews of effectiveness of health systems interventions and reforms: A meta-review. Health Policy, 104(3):206-214.

Rodin, J. and de Ferranti, D. (2012). Universal health coverage: the third global health transition? The Lancet, 380(9845):861.

Rosen, G. (2014). Determinants of employment: Impact of Medicaid and CHIP among unmarried female heads of household with young children. Social work in public health, 29(5):491-502.

Royalty, A. B. and Abraham, J. M. (2006). Health insurance and labor market outcomes: Joint decision-making within households. Journal of Public Economics, 90(8):1561-1577.

Saez, E. (2002). Optimal income transfer programs: intensive versus extensive labor supply responses. The Quarterly Journal of Economics, 117(3):1039-1073.

Schoenfelder, T., Klewer, J., and Kugler, J. (2011). Determinants of patient satisfaction: a study among 39 hospitals in an in-patient setting in germany. International journal for quality in health care, 23(5):503-509.

Sitzia, J. and Wood, N. (1997). Patient satisfaction: a review of issues and concepts. Social science \& medicine, 45(12):1829-1843.

Socialist Republic of Vietnam (1998). Decision 135/1998/QD-TTg on socio-economic development plan for the most difficulty communes in mountainous areas and isolated regions. The Vietnamese Government Office, Hanoi, Vietnam.

Socialist Republic of Vietnam (2002a). Decision 139/2002/QD-TTg on healthcare for the poor. The Vietnamese Government Office, Hanoi, Vietnam.

Socialist Republic of Vietnam (2002b). Decision 139/2002/QD-TTg on healthcare for the poor. The Vietnamese Government Office, Hanoi, Vietnam. 
Socialist Republic of Vietnam (2004). Law on child protection, care and education. The Vietnamese National Assembly, Hanoi, Vietnam.

Socialist Republic of Vietnam (2008). Health Insurance Law 2008, No. 25/2008/QH12. The Vietnamese National Assembly, Hanoi, Vietnam.

Socialist Republic of Vietnam (2014). Health insurance law 2014, No. 46/2014/QH13. The Vietnamese National Assembly, Hanoi, Vietnam.

Socialist Republic of Vietnam (2015). Decree No. 16/2015/ND-CP on independent finance for public service institutions. The Vietnamese Government Office, Hanoi, Vietnam.

Socialist Republic of Vietnam (2016a). Decision 1167/QD-TTg on adjustment in the target of universal health coverage during 2016-2020. The Vietnamese Government Office, Hanoi, Vietnam.

Socialist Republic of Vietnam (2016b). Decision 1167/QD-TTg on target adjustments for expanding health insurance coverage in Vietnam during 2016-2020. The Vietnamese Government Office, Hanoi, Vietnam.

Somanathan, A., Dao, H. L., and Tien, T. V. (2013). Integrating the poor into universal health coverage in Vietnam. The World Bank, Washington, DC.

Somanathan, A., Tandon, A., Dao, H. L., Hurt, K. L., and Fuenzalida-Puelma, H. L. (2014). Moving toward universal coverage of social health insurance in Vietnam: assessment and options. The World Bank, Washington, DC.

Sommers, B. D., Baicker, K., and Epstein, A. M. (2012). Mortality and access to care among adults after state Medicaid expansions. New England Journal of Medicine, 367(11):1025-1034.

Strumpf, E. (2011). Medicaid's effect on single women's labor supply: Evidence from the introduction of Medicaid. Journal of Health Economics, 30(3):531-548.

Takashima, K., Wada, K., Tra, T. T., and Smith, D. R. (2017). A review of vietnam's healthcare reform through the direction of healthcare activities (DOHA). Environmental health and preventive medicine, 22(1):74.

Thanh, Q. (12 Feb 2015). [Vietnamese] Nguoi benh van vuot tuyen du khong duoc chi tra bao hiem y te, [English] Patients still skip the referral line even though the care is not covered by health insurance. Nhandan news online. Retrieved on 23 Feb 2018 from http : //www.nhandan.com.vn/suckhoe/tin - tuc/item/25595902 - nguoi - benh van - vuot - tuyen - du-khong - duoc-bao-hiem-y-te-chi-tra.html.

Thao, M. (12 Mar 2016). [Vietnamese] Kham chua benh BHYT: Benh vien tu gap kho vi su phan biet cong tu? , [English] Healthcare under SHI programme: private hospitals face public-private discrimination? Financial Times Vietnam online. Retrieved on 23 Feb 2018 from http : //thoibaotaichinhvietnam.vn/pages/tien-te-bao-hiem/2016$03-11 /$ kham - chua - benh - bhyt - benh - vien - tu - gap - kho - vi - su - phanbiet - cong - tu - 29518.aspx.

The World Bank (2018). Country data of Vietnam. The World Bank. Retrieved on 5 Sep 2018 from https://data.worldbank.org/country/vietnam. 
The World Bank and MPI (2016). Vietnam 2035 : Toward Prosperity, Creativity, Equity, and Democracy. The World Bank, Washington, DC.

Tomohara, A. and Lee, H. (2007). Did state children's health insurance program affect married women's labor supply? Journal of Family and Economic Issues, 28(4):668-683.

Tran, B. X., Nguyen, L. H., Nong, V. M., and Nguyen, C. T. (2016). Health status and health service utilization in remote and mountainous areas in vietnam. Health and quality of life outcomes, 14(1):85.

Tran, V. T., Hoang, T. P., Mathauer, I., and Nguyen, T. (2011). Health financing review of Vietnam with a focus on social health insurance: Bottlenecks in institutional design and organizational practice of health financing and options to accelerate progress towards universal coverage. World Health Organisation, Geneva, Switzerland.

Tunceli, K., Short, P. F., Moran, J. R., and Tunceli, O. (2009). Cancer survivorship, health insurance, and employment transitions among older workers. INQUIRY: The Journal of Health Care Organization, Provision, and Financing, 46(1):17-32.

Van de Ven, W. P. and Van Praag, B. M. (1981). The demand for deductibles in private health insurance: A probit model with sample selection. Journal of econometrics, $17(2): 229-252$.

Van Praag, B. (2011). Well-being inequality and reference groups: an agenda for new research. The Journal of Economic Inequality, 9(1):111-127.

Van Praag, C. M. and Cramer, J. S. (2001). The roots of entrepreneurship and labour demand: Individual ability and low risk aversion. Economica, 68(269):45-62.

Velamuri, M. (2012). Taxes, health insurance, and women's self-employment. Contemporary Economic Policy, 30(2):162-177.

Vian, T., Brinkerhoff, D. W., Feeley, F. G., Salomon, M., and Vien, N. T. K. (2012). Confronting corruption in the health sector in vietnam: patterns and prospects. Public Administration and Development, 32(1):49-63.

Wagner, D. and Bear, M. (2009). Patient satisfaction with nursing care: a concept analysis within a nursing framework. Journal of advanced nursing, 65(3):692-701.

Wagstaff, A. (2007). Health insurance for the poor: initial impacts of Vietnam's health care fund for the poor. World Bank Policy Research Working Paper No. 4134, The World Bank.

Wagstaff, A. (2010). Estimating health insurance impacts under unobserved heterogeneity: the case of Vietnam's health care fund for the poor. Health economics, 19(2):189-208.

Wagstaff, A. and Manachotphong, W. (2012). Universal health care and informal labor markets: the case of Thailand. World Bank Policy Research Working Paper No. 6116, The World Bank.

Wagstaff, A. and Moreno-Serra, R. (2007). Europe and Central Asia's great postcommunist social health insurance experiment: impacts on health sector and labor market outcomes. World Bank Policy Research Working Paper No.4371, The World Bank. 
Wagstaff, A. and Moreno-Serra, R. (2009). Europe and central Asia's great postcommunist social health insurance experiment: impacts on health sector and labour market outcomes. Policy Research Working Paper No. WPS4371, The World Bank.

Wagstaff, A. and Moreno-Serra, R. (2015). Social health insurance and labor market outcomes: Evidence from Central and Eastern Europe, and Central Asia, volume 21, pages 83-106. Emerald Group Publishing Limited.

Wahlberg, A. (2006). Bio-politics and the promotion of traditional herbal medicine in vietnam. Health:, 10(2):123-147.

Ware Jr, J. E., Snyder, M. K., Wright, W. R., and Davies, A. R. (1983). Defining and measuring patient satisfaction with medical care. Evaluation and program planning, 6(3-4):247-263.

Wellington, A. J. (2001). Health insurance coverage and entrepreneurship. Contemporary Economic Policy, 19(4):465-478.

Wellington, A. J. and Cobb-Clark, D. A. (2000). The labor supply effects of universal health coverage: What can we learn from individuals with spousal coverage?, volume 19, pages 315-344. Emerald Group Publishing Limited.

Wenger, J. B. and Reynolds, J. (2009). Older married workers and non-standard jobs: The effects of health and health insurance. Industrial Relations: A Journal of Economy and Society, 48(3):411-431.

WHO (2010). The World Health Report: Health Systems Financing: The path to universal coverage. World Health Organization.

WHO (2013). The World Health Report 2013: Research for Universal Health Coverage. World Health Organization. Retrieved on 9 April 2018 from http : //www.who.int/whr/2013/report/en/.

WHO (2018a). UHC and SDG country profile 2018, Vietnam. World Health Organisation, Geneva, Switzerland. Retrieved on 5 Sep 2018 from http : //www.wpro.who.int/vietnam/mediacentre/releases/2018/viet-nam-uhc-sdgcountry - profiles - 2018 - eng.pdf.

WHO (25 May 2005). World Health Assembly concludes: adopts key resolutions affecting global public health. World Health Organisation, Geneva, Switzerland. Retrieved on 9 April 2018 from http : //www.who.int/mediacentre/news/releases/2005/pr $r_{w}$ ha06/en.

WHO (7 Apr 2018b). WHO calls for action to achieve health for all in Vietnam. World Health Organisation. Retrieved on 16 Apr 2019 from http : //www.wpro.who.int/vietnam/mediacentre/releases/2018/WorldHealthDay2018/en/.

WHO and The World Bank (2015). Tracking universal health coverage: first global monitoring report. World Health Organization, Geneva, Switzerland.

WHO and The World Bank (2017). Tracking universal health coverage: 2017 global monitoring report. World Health Organization, Geneva, Switzerland. 
WHO and the World Bank (2014). Monitoring progress towards universal health coverage at country and global levels: framework, measures and targets. Technical report, World Health Organization and the World Bank.

Williams, B. (1994). Patient satisfaction: a valid concept? Social science 8 medicine, 38(4):509-516.

Xiao, H. and Barber, J. P. (2008). The effect of perceived health status on patient satisfaction. Value in Health, 11(4):719-725.

Yelowitz, A. (2003). Medicaid and work decisions of married women. Economic Research Initiative on the Uninsured Working Paper No.21, The University of Michigan. Retrieved on 6 March 2017 from http://www.umich.edu/ eriu/pdf/wp21.pdf.

Zimmer, D. M. (2010). The role of health insurance in labor supply decisions of divorced females. The Quarterly Review of Economics and Finance, 50(2):121-131.

Zissimopoulos, J. M. and Karoly, L. A. (2007). Transitions to self-employment at older ages: The role of wealth, health, health insurance and other factors. Labour Economics, 14(2):269-295. 



\section{Appendices}

\section{Appendix A: Descriptive analysis for Chapter 3}

Coverage of HCFP or its precedent during 2002-2006 is presented in Appendix A1. As suggested, coverage increased over time during 2002-2006. Those who were covered in 2002 were the beneficiaries of FHC policy which was then replaced by HCFP in late 2002 and 2003. The introduction of HCFP indeed has contributed to raising the coverage for eligible people, from nearly 17 percent in 2002 to around 34 and 50 percent in 2004 and 2006 respectively.

Inclusion error was another issue as more than 11 per cent of those ineligible in 2006 got coverage. Moreover, exclusion error was high, probably due to budget constraints as in 2006 only half of the eligible poor population were covered. Our findings of inclusion and exclusion errors are consistent with other estimates of HCFP coverage and leakage (see Wagstaff, 2010). 
Table A1: HCFP and FHC coverage (\%)

Whole population

\begin{tabular}{lrrrrrrrrr}
\hline & & \multicolumn{3}{c}{2002} & & & 2004 & & \\
Eligibility & No & Yes & Total & No & Yes & Total & No & Yes & Total \\
\hline Uncovered & 96.76 & 83.21 & 92.22 & 94.26 & 66.34 & 87.48 & 88.64 & 50.01 & 81.70 \\
Covered & 3.24 & 16.79 & 7.78 & 5.74 & 33.66 & 12.52 & 11.36 & 49.99 & 18.30 \\
Working-age population & & & & & & & \\
\hline Uncovered & 97.04 & 84.07 & 93.16 & 94.39 & 65.86 & 88.28 & 91.48 & 50.87 & 84.84 \\
Covered & 2.96 & 15.93 & 6.84 & 5.61 & 34.14 & 11.72 & 8.52 & 49.13 & 15.16 \\
\hline
\end{tabular}

Eligibility is based on Decision 139/2002/QD-TTg. This coverage is sampling weighted.

Table A2: Employment status and hours worked, 2002-2006

\begin{tabular}{lrrr} 
Employment status (\%) & 2002 & 2004 & 2006 \\
\hline Not working & 12.97 & 15.07 & 17.79 \\
Working & 87.03 & 84.93 & 82.21 \\
Total & 100.00 & 100.00 & 100.00 \\
Number of observations & 3,687 & 4,723 & 5,095 \\
Number of hours worked per month (hours/month) & 2002 & 2004 & 2006 \\
\hline Mean & 161.19 & 156.36 & 160.17 \\
Standard Deviation & 58.21 & 64.92 & 65.03 \\
Min & 2 & 8 & 8 \\
Max & 364 & 450 & 400 \\
Number of observations (working individuals only) & 3,209 & 4,047 & 4,207 \\
\hline
\end{tabular}

Weighted statistics. This sample only includes working-age people (aged 16-65) before matching.

Table A3: Employment status and hours worked by poverty status, 2002-2006

\begin{tabular}{lrrrrrr}
\hline & \multicolumn{3}{c}{ Poor individuals } & \multicolumn{4}{c}{ Non-poor individuals } \\
& 2002 & 2004 & 2006 & 2002 & 2004 & 2006 \\
Employment status (\%) & & & & & & \\
\hline Not working & 6.94 & 7.42 & 12.03 & 14.37 & 16.15 & 18.06 \\
Working & 93.06 & 92.58 & 87.97 & 85.63 & 83.85 & 81.94 \\
Total & 100.00 & 100.00 & 100.00 & 100.00 & 100.00 & 100.00 \\
Number of observations & 722 & 678 & 263 & 2,965 & 4,045 & 4,832 \\
Number of hours worked per month (hours/month) & & & & & & \\
\hline Mean & 158.98 & 143.56 & 139.36 & 161.75 & 158.35 & 161.19 \\
Standard Deviation & 48.53 & 54.21 & 51.34 & 60.39 & 66.22 & 65.46 \\
Min & 4 & 8 & 12 & 2 & 8 & 8 \\
Max & 308 & 300 & 300 & 364 & 450 & 400 \\
Number of observations (working individuals only) & 677 & 633 & 230 & 2,532 & 3,414 & 3,977 \\
\hline
\end{tabular}

Weighted statistics. This sample only includes working-age people (aged 16-65) before matching. 
Table A4: Part 1 - Probit model - Probability of being employed (all individuals)

\begin{tabular}{|c|c|c|c|c|}
\hline & Mahalanobis & NN matching & Kernel (1) & Kernel (2) \\
\hline \multicolumn{5}{|l|}{ Employed=1: currently employed } \\
\hline Age & $\begin{array}{c}0.243^{* * *} \\
(0.01)\end{array}$ & $\begin{array}{c}0.233^{* * *} \\
(0.01)\end{array}$ & $\begin{array}{c}0.234^{* * *} \\
(0.01)\end{array}$ & $\begin{array}{c}0.233^{* * *} \\
(0.01)\end{array}$ \\
\hline Age squared & $\begin{array}{c}-0.003^{* * *} \\
(0.00)\end{array}$ & $\begin{array}{c}-0.003^{* * *} \\
(0.00)\end{array}$ & $\begin{array}{c}-0.003^{* * *} \\
(0.00)\end{array}$ & $\begin{array}{c}-0.003^{* * *} \\
(0.00)\end{array}$ \\
\hline Household size & $\begin{array}{r}-0.005 \\
(0.01)\end{array}$ & $\begin{array}{r}-0.001 \\
(0.01)\end{array}$ & $\begin{array}{r}-0.001 \\
(0.01)\end{array}$ & $\begin{array}{r}-0.001 \\
(0.01)\end{array}$ \\
\hline Dependency ratio & $\begin{array}{c}0.257^{* *} \\
(0.11)\end{array}$ & $\begin{array}{c}0.264^{* *} \\
(0.11)\end{array}$ & $\begin{array}{c}0.271^{* *} \\
(0.11)\end{array}$ & $\begin{array}{c}0.264^{* *} \\
(0.11)\end{array}$ \\
\hline Literacy (dummy) & $\begin{array}{c}0.306^{* * *} \\
(0.08)\end{array}$ & $\begin{array}{c}0.308^{* * *} \\
(0.08)\end{array}$ & $\begin{array}{c}0.299^{* * *} \\
(0.08)\end{array}$ & $\begin{array}{c}0.308^{* * *} \\
(0.08)\end{array}$ \\
\hline \multicolumn{5}{|l|}{ Marital status (base: married individuals) } \\
\hline -Never married & $\begin{array}{c}-0.607^{* * *} \\
(0.08)\end{array}$ & $\begin{array}{c}-0.637^{* * *} \\
(0.07)\end{array}$ & $\begin{array}{c}-0.629^{* * *} \\
(0.07)\end{array}$ & $\begin{array}{c}-0.637^{* * *} \\
(0.07)\end{array}$ \\
\hline -Widowed/Divorced/Separated & $\begin{array}{c}-0.501^{* * *} \\
(0.09)\end{array}$ & $\begin{array}{c}-0.493^{* * *} \\
(0.09)\end{array}$ & $\begin{array}{c}-0.496^{* * *} \\
(0.09)\end{array}$ & $\begin{array}{c}-0.493^{* * *} \\
(0.09)\end{array}$ \\
\hline \multicolumn{5}{|l|}{ Relation to the household head (base: head) } \\
\hline -spouse & $\begin{array}{c}-0.342^{* * *} \\
(0.06)\end{array}$ & $\begin{array}{c}-0.344^{* * *} \\
(0.06)\end{array}$ & $\begin{array}{c}-0.344^{* * *} \\
(0.06)\end{array}$ & $\begin{array}{c}-0.344^{* * *} \\
(0.06)\end{array}$ \\
\hline -child & $\begin{array}{r}-0.089 \\
(0.09)\end{array}$ & $\begin{array}{r}-0.122 \\
(0.09)\end{array}$ & $\begin{array}{r}-0.123 \\
(0.09)\end{array}$ & $\begin{array}{c}-0.122 \\
(0.09)\end{array}$ \\
\hline -others & $\begin{array}{c}-0.603^{* * *} \\
(0.11)\end{array}$ & $\begin{array}{c}-0.675^{* * *} \\
(0.10)\end{array}$ & $\begin{array}{c}-0.666^{* * *} \\
(0.10)\end{array}$ & $\begin{array}{c}-0.675^{* * *} \\
(0.10)\end{array}$ \\
\hline Number of healthcare utilization per year & $\begin{array}{c}-0.083^{* * *} \\
(0.03)\end{array}$ & $\begin{array}{c}-0.082^{* * *} \\
(0.03)\end{array}$ & $\begin{array}{c}-0.081^{* * *} \\
(0.03)\end{array}$ & $\begin{array}{c}-0.082^{* * *} \\
(0.03)\end{array}$ \\
\hline Urban (dummy) & $\begin{array}{c}-0.493^{* * *} \\
(0.04)\end{array}$ & $\begin{array}{c}-0.482^{* * *} \\
(0.04)\end{array}$ & $\begin{array}{c}-0.482^{* * *} \\
(0.04)\end{array}$ & $\begin{array}{c}-0.482^{* * *} \\
(0.04)\end{array}$ \\
\hline Belongs to P135 communes & $\begin{array}{c}0.262^{* * *} \\
(0.07)\end{array}$ & $\begin{array}{c}0.289^{* * *} \\
(0.07)\end{array}$ & $\begin{array}{c}0.297^{* * *} \\
(0.07)\end{array}$ & $\begin{array}{c}0.289^{* * *} \\
(0.07)\end{array}$ \\
\hline Constant & $\begin{array}{c}-2.578^{* * *} \\
(0.32)\end{array}$ & $\begin{array}{c}-2.361^{* * *} \\
(0.30)\end{array}$ & $\begin{array}{c}-2.378^{* * *} \\
(0.30)\end{array}$ & $\begin{array}{c}-2.361^{* * *} \\
(0.30)\end{array}$ \\
\hline $\mathrm{N}$ & 10,482 & 10,867 & 10,871 & 10,867 \\
\hline
\end{tabular}


Table A5: Part 2 - The number of hours worked - OLS

(with commune clustered standard errors)

\begin{tabular}{|c|c|c|c|c|}
\hline & Mahalanobis & NN matching & Kernel (1) & Kernel (2) \\
\hline \multirow[t]{2}{*}{ Treat } & $-5.854^{*}$ & $-5.271^{*}$ & $-5.277^{*}$ & $-5.271^{*}$ \\
\hline & $(3.13)$ & $(3.05)$ & $(3.05)$ & $(3.05)$ \\
\hline \multirow[t]{2}{*}{ year $=2004$} & -3.803 & -4.326 & -4.240 & -4.326 \\
\hline & $(2.78)$ & $(2.66)$ & $(2.66)$ & $(2.66)$ \\
\hline \multirow[t]{2}{*}{ year $=2006$} & -0.712 & -1.162 & -1.071 & -1.162 \\
\hline & $(2.67)$ & $(2.55)$ & $(2.55)$ & $(2.55)$ \\
\hline \multirow[t]{2}{*}{ Age squared } & $-0.040^{* * *}$ & $-0.040^{* * *}$ & $-0.040^{* * *}$ & $-0.040^{* * *}$ \\
\hline & $(0.01)$ & $(0.01)$ & $(0.01)$ & $(0.01)$ \\
\hline \multirow[t]{2}{*}{ Age } & $2.801^{* * *}$ & $2.796^{* * *}$ & $2.772^{* * *}$ & $2.796^{* * *}$ \\
\hline & $(0.50)$ & $(0.48)$ & $(0.48)$ & $(0.48)$ \\
\hline \multirow[t]{2}{*}{ Household size } & -0.011 & 0.115 & 0.104 & 0.115 \\
\hline & $(0.57)$ & $(0.55)$ & $(0.54)$ & $(0.55)$ \\
\hline \multirow[t]{2}{*}{ Dependency ratio } & -4.336 & -3.590 & -3.572 & -3.590 \\
\hline & $(4.73)$ & $(4.58)$ & $(4.58)$ & $(4.58)$ \\
\hline \multirow[t]{2}{*}{ Literacy (dummy) } & -0.145 & -0.503 & -0.310 & -0.503 \\
\hline & $(3.62)$ & $(3.26)$ & $(3.24)$ & $(3.26)$ \\
\hline \multicolumn{5}{|l|}{ Marital status (base: married individuals) } \\
\hline \multirow[t]{2}{*}{ Never married } & -4.046 & -4.063 & -4.035 & -4.063 \\
\hline & $(2.79)$ & $(2.68)$ & $(2.67)$ & $(2.68)$ \\
\hline \multirow[t]{2}{*}{ Widowed/Divorced/Separated } & -5.015 & -5.583 & -5.679 & -5.583 \\
\hline & $(3.82)$ & $(3.65)$ & $(3.66)$ & $(3.65)$ \\
\hline \multirow[t]{2}{*}{ Number of healthcare utilization per year } & $-3.981^{* * *}$ & $-4.204^{* * *}$ & $-4.221^{* * *}$ & $-4.204^{* * *}$ \\
\hline & $(1.11)$ & $(1.09)$ & $(1.09)$ & $(1.09)$ \\
\hline \multirow[t]{2}{*}{ Urban (dummy) } & 2.158 & 2.995 & 2.954 & 2.995 \\
\hline & $(9.83)$ & $(9.66)$ & $(9.66)$ & $(9.66)$ \\
\hline \multirow[t]{2}{*}{ Belongs to P135 communes } & -2.905 & -5.312 & -5.168 & -5.312 \\
\hline & $(4.43)$ & $(4.56)$ & $(4.64)$ & $(4.56)$ \\
\hline \multirow[t]{2}{*}{ Sector: agri/aquaculture (dummy) } & $-41.233^{* * *}$ & $-40.682^{* * *}$ & $-40.684^{* * *}$ & $-40.682^{* * *}$ \\
\hline & $(2.42)$ & $(2.42)$ & $(2.42)$ & $(2.42)$ \\
\hline \multirow[t]{2}{*}{ Engaged in wage employment } & 0.245 & 0.231 & 0.221 & 0.231 \\
\hline & (1.98) & (1.96) & $(1.95)$ & (1.96) \\
\hline \multirow[t]{2}{*}{ Constant } & $161.551^{* * *}$ & $162.130^{* * *}$ & $162.292^{* * *}$ & $162.130^{* * *}$ \\
\hline & (14.19) & $(13.26)$ & (13.23) & (13.26) \\
\hline $\mathrm{N}$ & 9,271 & 9,613 & 9,618 & 9,613 \\
\hline
\end{tabular}

Standard errors in parentheses. Standard errors are clustered by commune.

Kernel (1) and (2) refer to Kernel matching methods using the trimming and minima-maxima techniques.

Interview month is controlled for in all regressions.

NN matching: Nearest neighbour matching. ${ }^{*} p<0.1,{ }^{* *} p<0.05,{ }^{* * *} p<0.01$ 
Table A6: Probability of being employed - Linear Probability Model (with commune clustered standard errors)

\begin{tabular}{|c|c|c|c|c|}
\hline Employed=1: currently employed & Mahalanobis & NN matching & Kernel (1) & Kernel (2) \\
\hline Treat & $\begin{array}{c}-0.028^{*} \\
(0.02)\end{array}$ & $\begin{array}{c}-0.028^{*} \\
(0.02)\end{array}$ & $\begin{array}{c}-0.028^{*} \\
(0.02)\end{array}$ & $\begin{array}{c}-0.028^{*} \\
(0.02)\end{array}$ \\
\hline year $=2004$ & $\begin{array}{l}-0.004 \\
(0.01)\end{array}$ & $\begin{array}{l}-0.001 \\
(0.01)\end{array}$ & $\begin{array}{l}-0.002 \\
(0.01)\end{array}$ & $\begin{array}{l}-0.001 \\
(0.01)\end{array}$ \\
\hline year $=2006$ & $\begin{array}{l}0.001 \\
(0.01)\end{array}$ & $\begin{array}{l}0.003 \\
(0.01)\end{array}$ & $\begin{array}{l}0.003 \\
(0.01)\end{array}$ & $\begin{array}{l}0.003 \\
(0.01)\end{array}$ \\
\hline Age squared & $\begin{array}{c}-0.001^{* * *} \\
(0.00)\end{array}$ & $\begin{array}{c}-0.001^{* * *} \\
(0.00)\end{array}$ & $\begin{array}{c}-0.001^{* * *} \\
(0.00)\end{array}$ & $\begin{array}{c}-0.001^{* * *} \\
(0.00)\end{array}$ \\
\hline Age & $\begin{array}{c}0.047^{* * *} \\
(0.00)\end{array}$ & $\begin{array}{c}0.045^{* * *} \\
(0.00)\end{array}$ & $\begin{array}{c}0.045^{* * *} \\
(0.00)\end{array}$ & $\begin{array}{c}0.045^{* * *} \\
(0.00)\end{array}$ \\
\hline Household size & $\begin{array}{r}-0.002 \\
(0.00)\end{array}$ & $\begin{array}{r}-0.002 \\
(0.00)\end{array}$ & $\begin{array}{c}-0.002 \\
(0.00)\end{array}$ & $\begin{array}{c}-0.002 \\
(0.00)\end{array}$ \\
\hline Dependency ratio & $\begin{array}{l}-0.034 \\
(0.02)\end{array}$ & $\begin{array}{r}-0.037 \\
(0.02)\end{array}$ & $\begin{array}{c}-0.036 \\
(0.02)\end{array}$ & $\begin{array}{l}-0.037 \\
(0.02)\end{array}$ \\
\hline Literacy (dummy) & $\begin{array}{c}0.077^{* * *} \\
(0.02)\end{array}$ & $\begin{array}{c}0.076^{* * *} \\
(0.02)\end{array}$ & $\begin{array}{c}0.075^{* * *} \\
(0.02)\end{array}$ & $\begin{array}{c}0.076^{* * *} \\
(0.02)\end{array}$ \\
\hline Marital status (base: married individuals) & & & & \\
\hline -Never married & $\begin{array}{c}-0.069^{* * *} \\
(0.02)\end{array}$ & $\begin{array}{c}-0.075^{* * *} \\
(0.02)\end{array}$ & $\begin{array}{c}-0.074^{* * *} \\
(0.02)\end{array}$ & $\begin{array}{c}-0.075^{* * *} \\
(0.02)\end{array}$ \\
\hline -Widowed/Divorced/Separated & $\begin{array}{c}-0.056^{* * *} \\
(0.02)\end{array}$ & $\begin{array}{c}-0.057^{* * *} \\
(0.02)\end{array}$ & $\begin{array}{c}-0.057^{* * *} \\
(0.02)\end{array}$ & $\begin{array}{c}-0.057^{* * *} \\
(0.02)\end{array}$ \\
\hline Number of healthcare utilization per year & $\begin{array}{c}-0.008^{*} \\
(0.00)\end{array}$ & $\begin{array}{c}-0.008^{*} \\
(0.00)\end{array}$ & $\begin{array}{c}-0.008^{*} \\
(0.00)\end{array}$ & $\begin{array}{c}-0.008^{*} \\
(0.00)\end{array}$ \\
\hline Urban (dummy) & $\begin{array}{l}-0.005 \\
(0.03)\end{array}$ & $\begin{array}{l}-0.003 \\
(0.03)\end{array}$ & $\begin{array}{l}-0.002 \\
(0.03)\end{array}$ & $\begin{array}{l}-0.003 \\
(0.03)\end{array}$ \\
\hline Belongs to P135 communes & $\begin{array}{l}-0.008 \\
(0.02)\end{array}$ & $\begin{array}{r}-0.003 \\
(0.01)\end{array}$ & $\begin{array}{r}-0.005 \\
(0.01)\end{array}$ & $\begin{array}{l}-0.003 \\
(0.01)\end{array}$ \\
\hline Sector: agri/aquaculture (dummy) & $\begin{array}{c}0.250^{* * *} \\
(0.01)\end{array}$ & $\begin{array}{c}0.257^{* * *} \\
(0.01)\end{array}$ & $\begin{array}{c}0.257^{* * *} \\
(0.01)\end{array}$ & $\begin{array}{c}0.257^{* * *} \\
(0.01)\end{array}$ \\
\hline Engaged in wage employment & $\begin{array}{c}0.213^{* * *} \\
(0.01)\end{array}$ & $\begin{array}{c}0.212^{* * *} \\
(0.01)\end{array}$ & $\begin{array}{c}0.212^{* * *} \\
(0.01)\end{array}$ & $\begin{array}{c}0.212^{* * *} \\
(0.01)\end{array}$ \\
\hline Constant & $\begin{array}{c}-0.197^{* * *} \\
(0.07)\end{array}$ & $\begin{array}{c}-0.153^{* *} \\
(0.07)\end{array}$ & $\begin{array}{c}-0.152^{* *} \\
(0.07)\end{array}$ & $\begin{array}{c}-0.153^{* *} \\
(0.07)\end{array}$ \\
\hline $\mathrm{N}$ & 10,484 & 10,869 & 10,873 & 10,869 \\
\hline
\end{tabular}

Standard errors in parentheses. Standard errors are clustered by commune.

Kernel (1) and (2) refer to Kernel matching methods using the trimming and minima-maxima techniques.

Interview month is controlled for in all regressions.

NN matching: Nearest neighbour matching. ${ }^{*} p<0.1,{ }^{* *} p<0.05,{ }^{* * *} p<0.01$ 
Table A7: The number of hours worked per month, by poverty status and by region (with commune clustered standard errors)

\begin{tabular}{|c|c|c|c|c|}
\hline & \multicolumn{2}{|c|}{ Poverty status } & \multicolumn{2}{|c|}{ Region } \\
\hline & Non-poor & Poor & Rural & Urban \\
\hline \multirow[t]{2}{*}{ Treat } & -5.644 & -9.747 & $-8.267^{* * *}$ & 1.883 \\
\hline & $(3.49)$ & $(9.51)$ & $(3.16)$ & $(8.44)$ \\
\hline \multirow[t]{2}{*}{ year $=2004$} & -2.172 & -5.374 & $-5.999^{*}$ & 5.960 \\
\hline & $(3.01)$ & $(7.82)$ & $(3.18)$ & $(6.21)$ \\
\hline \multirow[t]{2}{*}{ year $=2006$} & 1.198 & -8.498 & -2.053 & 5.856 \\
\hline & $(2.90)$ & $(9.60)$ & $(3.01)$ & $(5.91)$ \\
\hline \multirow[t]{2}{*}{ Age squared } & $-0.043^{* * *}$ & -0.018 & $-0.040^{* * *}$ & $-0.051^{* * *}$ \\
\hline & $(0.01)$ & $(0.01)$ & $(0.01)$ & $(0.01)$ \\
\hline \multirow[t]{2}{*}{ Age } & $2.947^{* * *}$ & 1.385 & $2.719^{* * *}$ & $3.735^{* * *}$ \\
\hline & $(0.55)$ & $(1.05)$ & $(0.55)$ & $(1.18)$ \\
\hline \multirow[t]{2}{*}{ Household size } & 0.259 & -0.887 & 0.027 & 0.079 \\
\hline & $(0.68)$ & $(1.81)$ & $(0.65)$ & $(1.29)$ \\
\hline \multirow[t]{2}{*}{ Dependency ratio } & -7.715 & 12.495 & -4.007 & -5.843 \\
\hline & $(4.87)$ & $(25.60)$ & $(5.25)$ & (10.08) \\
\hline \multirow[t]{2}{*}{ Literacy (dummy) } & -2.399 & 5.639 & 0.159 & 0.262 \\
\hline & $(4.55)$ & $(6.58)$ & $(3.53)$ & $(14.27)$ \\
\hline \multicolumn{5}{|l|}{ Marital status (base: married individuals) } \\
\hline \multirow[t]{2}{*}{-Never married } & -4.187 & -0.767 & -2.027 & -7.881 \\
\hline & $(3.12)$ & $(7.67)$ & $(3.16)$ & $(5.53)$ \\
\hline \multirow[t]{2}{*}{-Widowed/Divorced/Separated } & -3.383 & -11.024 & -6.026 & -1.882 \\
\hline & $(4.11)$ & $(17.07)$ & $(3.96)$ & $(9.29)$ \\
\hline \multirow[t]{2}{*}{ Number of healthcare utilization per year } & $-3.653^{* * *}$ & $-8.970^{* *}$ & $-4.763^{* * *}$ & -0.753 \\
\hline & $(1.16)$ & $(3.60)$ & $(1.13)$ & $(2.84)$ \\
\hline \multirow[t]{2}{*}{ Urban (dummy) } & 3.545 & 0.000 & & \\
\hline & $(10.09)$ & $()$. & & \\
\hline \multirow[t]{2}{*}{ Belongs to P135 communes } & -6.208 & 15.758 & -4.211 & 16.531 \\
\hline & $(4.46)$ & $(12.95)$ & $(4.52)$ & $(12.53)$ \\
\hline \multirow[t]{2}{*}{ Sector: agri/aquaculture (dummy) } & $-42.824^{* * *}$ & $-24.328^{* * *}$ & $-39.664^{* * *}$ & $-46.872^{* * *}$ \\
\hline & $(2.57)$ & $(9.06)$ & $(2.64)$ & $(6.27)$ \\
\hline \multirow[t]{2}{*}{ Engaged in wage employment } & 0.315 & 2.811 & 2.806 & -7.710 \\
\hline & $(2.15)$ & $(4.76)$ & $(2.14)$ & $(4.82)$ \\
\hline \multirow[t]{2}{*}{ Constant } & $149.973^{* * *}$ & $184.170^{* * *}$ & $164.711^{* * *}$ & $152.046^{* * *}$ \\
\hline & $(15.74)$ & $(39.77)$ & $(15.51)$ & $(32.87)$ \\
\hline $\mathrm{N}$ & 8,336 & 935 & 7,201 & 2,070 \\
\hline
\end{tabular}

Standard errors in parentheses. Standard errors are clustered by commune.

Interview month is included to control for the seasonal effect. ${ }^{*} p<0.1,{ }^{* *} p<0.05,{ }^{* * *} p<0.01$ 
Table A8: The probability of employment, by poverty status and by region (with commune clustered standard errors)

\begin{tabular}{|c|c|c|c|c|}
\hline & \multicolumn{2}{|c|}{ Poverty status } & \multicolumn{2}{|c|}{ Region } \\
\hline & Non-poor & Poor & Rural & Urban \\
\hline \multirow[t]{2}{*}{ Treat } & -0.019 & -0.041 & $-0.038^{* *}$ & 0.024 \\
\hline & $(0.02)$ & $(0.05)$ & $(0.02)$ & $(0.04)$ \\
\hline \multirow{2}{*}{ year $=2004$} & -0.004 & -0.047 & 0.002 & -0.031 \\
\hline & $(0.01)$ & $(0.03)$ & $(0.01)$ & $(0.02)$ \\
\hline \multirow[t]{2}{*}{ year $=2006$} & 0.000 & $-0.095^{* * *}$ & 0.005 & -0.016 \\
\hline & $(0.01)$ & $(0.03)$ & $(0.01)$ & $(0.02)$ \\
\hline \multirow[t]{2}{*}{ Age squared } & $-0.001^{* * *}$ & $-0.000^{* * *}$ & $-0.000^{* * *}$ & $-0.001^{* * *}$ \\
\hline & $(0.00)$ & $(0.00)$ & $(0.00)$ & $(0.00)$ \\
\hline \multirow[t]{2}{*}{ Age } & $0.049^{* * *}$ & $0.021^{* * *}$ & $0.037^{* * *}$ & $0.072^{* * *}$ \\
\hline & $(0.00)$ & $(0.01)$ & $(0.00)$ & $(0.01)$ \\
\hline \multirow[t]{2}{*}{ Household size } & -0.005 & 0.008 & -0.004 & 0.001 \\
\hline & $(0.00)$ & $(0.01)$ & $(0.00)$ & $(0.01)$ \\
\hline \multirow[t]{2}{*}{ Dependency ratio } & -0.030 & -0.010 & -0.032 & -0.045 \\
\hline & $(0.02)$ & $(0.10)$ & $(0.02)$ & $(0.05)$ \\
\hline \multirow[t]{2}{*}{ Literacy (dummy) } & $0.096^{* * *}$ & 0.016 & $0.069^{* * *}$ & $0.110^{* *}$ \\
\hline & $(0.02)$ & $(0.03)$ & $(0.02)$ & $(0.05)$ \\
\hline \multicolumn{5}{|l|}{ Marital status (base: married individuals) } \\
\hline \multirow[t]{2}{*}{-Never married } & $-0.068^{* * *}$ & $-0.098^{* * *}$ & $-0.080^{* * *}$ & -0.056 \\
\hline & $(0.02)$ & $(0.04)$ & $(0.02)$ & $(0.04)$ \\
\hline \multirow[t]{2}{*}{-Widowed/Divorced/Separated } & $-0.057^{* * *}$ & $-0.124^{*}$ & $-0.061^{* * *}$ & -0.031 \\
\hline & $(0.02)$ & $(0.07)$ & $(0.02)$ & $(0.04)$ \\
\hline \multirow[t]{2}{*}{ Number of healthcare utilization per year } & $-0.011^{* *}$ & 0.014 & -0.003 & $-0.019^{*}$ \\
\hline & $(0.01)$ & $(0.01)$ & $(0.00)$ & $(0.01)$ \\
\hline \multirow[t]{2}{*}{ Urban (dummy) } & 0.002 & 0.000 & & \\
\hline & $(0.03)$ & $()$. & & \\
\hline \multirow[t]{2}{*}{ Belongs to P135 communes } & -0.015 & -0.011 & -0.013 & 0.033 \\
\hline & $(0.02)$ & $(0.04)$ & $(0.02)$ & $(0.03)$ \\
\hline \multirow[t]{2}{*}{ Sector: agri/aquaculture (dummy) } & $0.247^{* * *}$ & $0.320^{* * *}$ & $0.250^{* * *}$ & $0.244^{* * *}$ \\
\hline & $(0.01)$ & $(0.05)$ & $(0.01)$ & $(0.03)$ \\
\hline \multirow[t]{2}{*}{ Engaged in wage employment } & $0.223^{* * *}$ & $0.129^{* * *}$ & $0.165^{* * *}$ & $0.333^{* * *}$ \\
\hline & $(0.01)$ & $(0.02)$ & $(0.01)$ & $(0.02)$ \\
\hline \multirow[t]{2}{*}{ Constant } & $-0.264^{* * *}$ & $0.383^{* * *}$ & -0.004 & $-0.739^{* * *}$ \\
\hline & $(0.07)$ & $(0.15)$ & $(0.07)$ & $(0.17)$ \\
\hline $\mathrm{N}$ & 9,495 & 989 & 7,918 & 2,566 \\
\hline
\end{tabular}

Standard errors in parentheses. Standard errors are clustered by commune.

Interview month is included to control for the seasonal effect. ${ }^{*} p<0.1,{ }^{* *} p<0.05,{ }^{* * *} p<0.01$ 
Table A9: Matching results

\begin{tabular}{|c|c|c|c|}
\hline Sample & Mean Bias & Median Bias & Variance Ratio \\
\hline \multicolumn{4}{|l|}{ Mahalanobis matching } \\
\hline Unmatched & 35.4 & 37.6 & 25 \\
\hline Matched & 0.0 & 0.0 & 0 \\
\hline Number of off-support observations & & & 402 \\
\hline \multicolumn{4}{|c|}{ PSM-Kernel algorithm, minima-maxima common support } \\
\hline Unmatched & 35.4 & 37.6 & 25 \\
\hline Matched & 3.5 & 3.2 & 50 \\
\hline Number of off-support observations & & & 17 \\
\hline \multicolumn{4}{|c|}{ PSM - Kernel algorithm, trimming at 2 percent for common support } \\
\hline Unmatched & 35.4 & 37.6 & 25 \\
\hline Matched & 3.7 & 3.1 & 50 \\
\hline Number of off-support observations & & & 13 \\
\hline \multicolumn{4}{|c|}{ PSM - Nearest neighbour matching algorithm } \\
\hline Unmatched & 35.4 & 37.6 & 25 \\
\hline Matched & 3.7 & 3.8 & 50 \\
\hline Number of off-support observations & & & 17 \\
\hline
\end{tabular}

Table A10: Post-matching TTest results - Mahalanobis Matching

\begin{tabular}{|c|c|c|c|c|c|}
\hline \multirow[t]{2}{*}{ Variable } & \multicolumn{2}{|c|}{ Mean } & \multicolumn{3}{|c|}{ TTest } \\
\hline & Treated & Control & $\mathrm{T}$ statistic & $\mathrm{P}$ value & Variance ratio \\
\hline Age & 35.909 & 35.879 & 0.03 & 0.975 & 1.00 \\
\hline Male(dummy) & .50758 & .50758 & -0.00 & 1.000 & 1.00 \\
\hline Household size & 4.5909 & 4.5909 & 0.00 & 1.000 & 1.00 \\
\hline Dependency ratio & .37334 & .37334 & -0.00 & 1.000 & 1.00 \\
\hline Literacy (dummy) & 1 & 1 & . & . & . \\
\hline Marital status & 1.8864 & 1.8864 & -0.00 & 1.000 & 1.00 \\
\hline Female headed household & .03788 & .03788 & 0.00 & 1.000 & 1.00 \\
\hline Poverty status & .22348 & .22348 & -0.00 & 1.000 & 1.00 \\
\hline Belongs to P135 communes & .14394 & .14394 & -0.00 & 1.000 & 1.00 \\
\hline Belongs to P168 regions & 0 & 0 & . & . & . \\
\hline Belongs to P186 regions & .01894 & .01894 & 0.00 & 1.000 & 1.00 \\
\hline Work sector: agriculture (dummy) & .66288 & .66288 & -0.00 & 1.000 & 1.00 \\
\hline
\end{tabular}

* denotes 'of concern', i.e. variance ratio in [0.5, 0.8) or $(1.25,2]$

Variance ratio is bad if below 0.5 or above 2 
Table A11: Post-matching TTest results - Nearest Neighbour Matching

\begin{tabular}{|c|c|c|c|c|c|}
\hline \multirow[t]{2}{*}{ Variable } & \multicolumn{2}{|c|}{ Mean } & \multicolumn{3}{|c|}{ TTest } \\
\hline & Treated & Control & $\mathrm{T}$ statistic & $P$ value & Variance ratio \\
\hline Age & 35.82 & 36.237 & -0.61 & 0.545 & 0.97 \\
\hline Male (dummy) & .48844 & .48998 & -0.06 & 0.956 & 1.00 \\
\hline Household size & 5.4206 & 5.3032 & 1.02 & 0.307 & $1.41^{*}$ \\
\hline Dependency ratio & .37816 & .38207 & -0.35 & 0.729 & 1.00 \\
\hline Literacy (dummy) & .88906 & .8775 & 0.65 & 0.517 & 1.02 \\
\hline Marital status & 1.8521 & 1.8544 & -0.09 & 0.930 & 1.18 \\
\hline Female headed HH (dummy) & .0678 & .05316 & 1.11 & 0.269 & $1.30^{*}$ \\
\hline Poverty status & .42835 & .44992 & -0.78 & 0.434 & 1.11 \\
\hline Belongs to P135 communes & .36055 & .3879 & -1.02 & 0.309 & 1.00 \\
\hline Belongs to P168 regions & .08629 & .08128 & 0.33 & 0.745 & 0.99 \\
\hline Belongs to P186 regions & .21109 & .20609 & 0.22 & 0.824 & 1.00 \\
\hline Work sector: agriculture & .72111 & .69145 & 1.17 & 0.241 & 1.02 \\
\hline
\end{tabular}

* denotes 'of concern', i.e. variance ratio in $[0.5,0.8)$ or $(1.25,2]$

Variance ratio is bad if below 0.5 or above 2

Table A12: Post-matching TTest results - Kernel Matching (minima maxima algorithm)

\begin{tabular}{|c|c|c|c|c|c|}
\hline \multirow[t]{2}{*}{ Variable } & \multicolumn{2}{|c|}{ Mean } & \multicolumn{3}{|c|}{ TTest } \\
\hline & Treated & Control & $\mathrm{T}$ statistic & $\mathrm{P}$ value & Variance ratio \\
\hline Age & 35.82 & 36.62 & -1.16 & 0.247 & 0.98 \\
\hline Male (dummy) & .48844 & .49268 & -0.15 & 0.879 & 1.00 \\
\hline Household size & 5.4206 & 5.2884 & 1.16 & 0.245 & $1.54^{*}$ \\
\hline Dependency ratio & .37816 & .3754 & 0.24 & 0.808 & 0.95 \\
\hline Literacy (dummy) & .88906 & .8804 & 0.49 & 0.625 & 0.99 \\
\hline Marital status & 1.8521 & 1.8526 & -0.02 & 0.984 & 1.22 \\
\hline Female headed HH (dummy) & .0678 & .05222 & 1.18 & 0.238 & $1.29^{*}$ \\
\hline Poverty status & .42835 & .44216 & -0.50 & 0.616 & 1.05 \\
\hline Belongs to P135 communes & .36055 & .37573 & -0.57 & 0.571 & 0.99 \\
\hline Belongs to P168 regions & .08629 & .08062 & 0.37 & 0.712 & 1.00 \\
\hline Belongs to P186 regions & .21109 & .21161 & -0.02 & 0.982 & 1.00 \\
\hline Work sector: agriculture & .72111 & .68208 & 1.54 & 0.125 & 0.97 \\
\hline
\end{tabular}

* denotes 'of concern', i.e. variance ratio in $[0.5,0.8)$ or $(1.25,2]$

Variance ratio is bad if below 0.5 or above 2 
Table A13: Post-matching TTest results - Kernel Matching (trimming at 2 percent)

\begin{tabular}{|c|c|c|c|c|c|}
\hline \multirow[t]{2}{*}{ Variable } & \multicolumn{2}{|c|}{ Mean } & \multicolumn{3}{|c|}{ TTest } \\
\hline & Treated & Control & $\mathrm{T}$ statistic & $P$ value & Variance ratio \\
\hline Age & 35.778 & 36.486 & -1.03 & 0.303 & 0.95 \\
\hline Male (dummy) & .48698 & .49181 & -0.17 & 0.862 & 1.00 \\
\hline Household size & 5.4686 & 5.2881 & 1.58 & 0.114 & $1.46^{*}$ \\
\hline Dependency ratio & .38109 & .37569 & 0.48 & 0.633 & 0.95 \\
\hline Literacy (dummy) & .88668 & .8787 & 0.45 & 0.654 & 0.99 \\
\hline Marital status & 1.8499 & 1.8498 & 0.01 & 0.996 & 1.20 \\
\hline Female headed HH (dummy) & .06585 & .0519 & 1.07 & 0.285 & $1.28^{*}$ \\
\hline Poverty & .43798 & .4517 & -0.50 & 0.618 & 1.05 \\
\hline Belongs to P135 communes & .36753 & .38322 & -0.59 & 0.559 & 1.00 \\
\hline Belongs to P168 regions & .09954 & .09539 & 0.25 & 0.800 & 1.00 \\
\hline Belongs to P186 regions & .20368 & .20143 & 0.10 & 0.920 & 1.00 \\
\hline Work sector: agriculture & .72435 & .68478 & 1.57 & 0.117 & 0.99 \\
\hline
\end{tabular}

* denotes 'of concern', i.e. variance ratio in $[0.5,0.8)$ or $(1.25,2]$

Variance ratio is bad if below 0.5 or above 2 

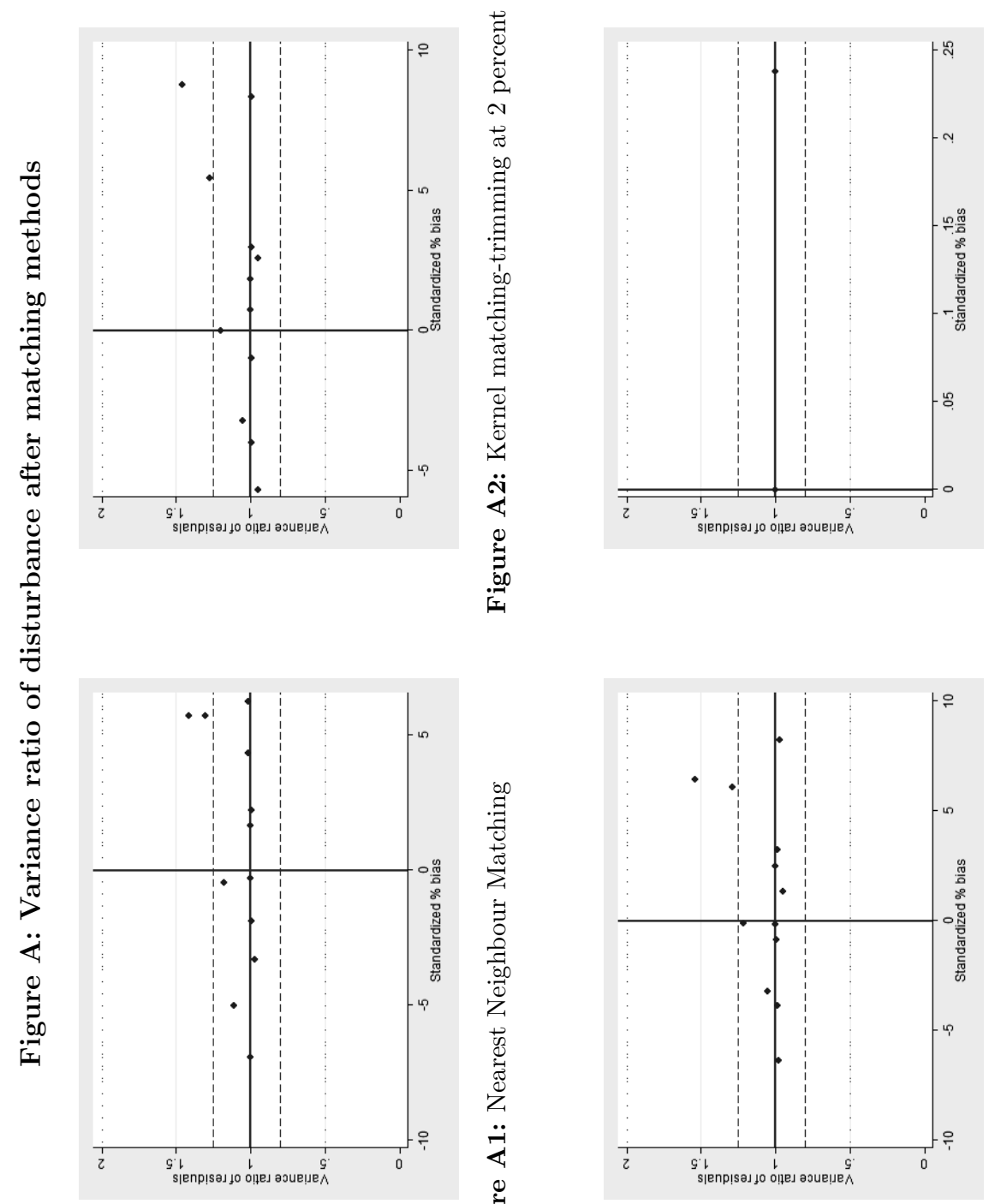

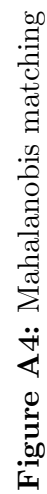

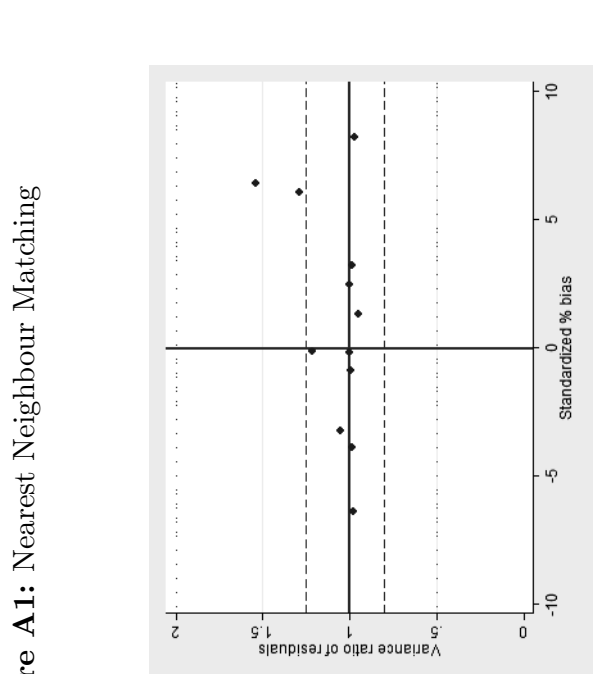

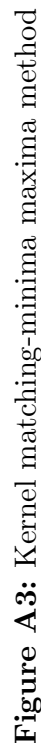




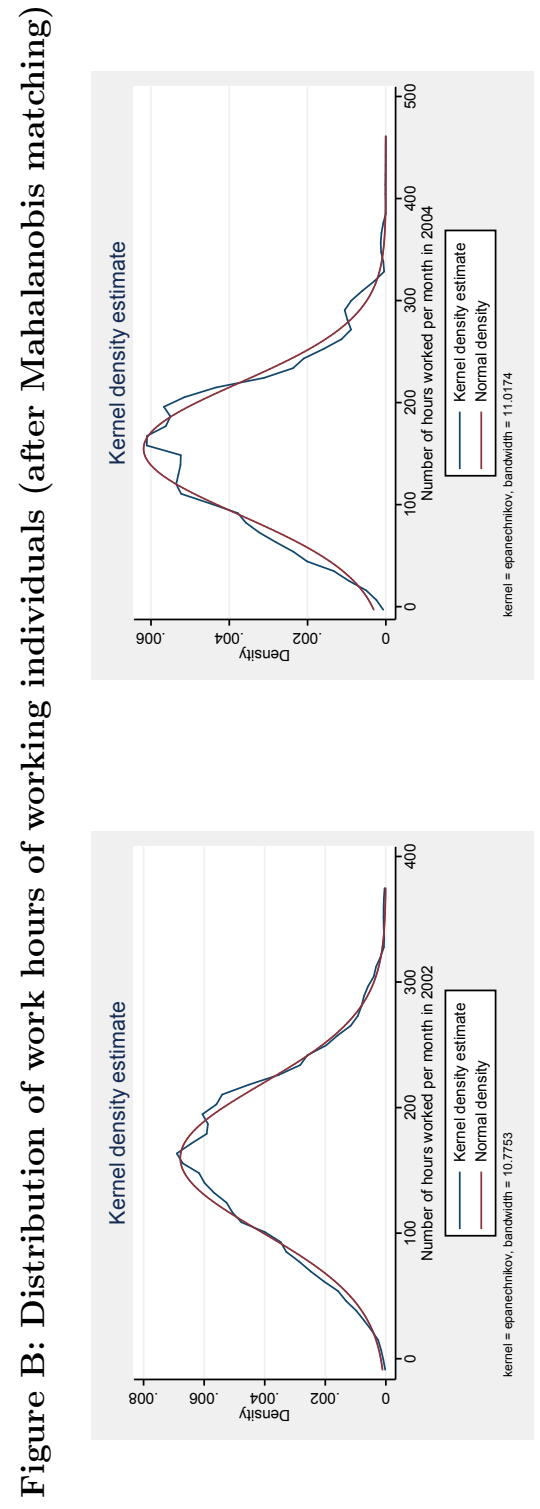

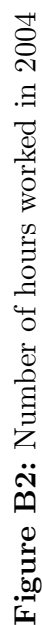

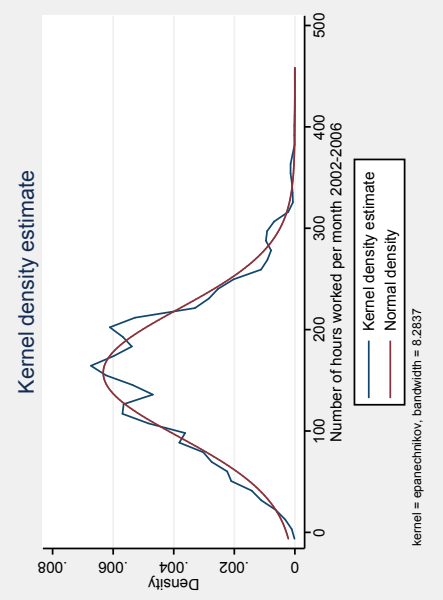

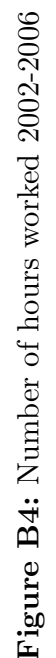

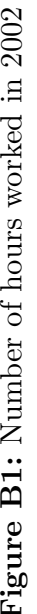

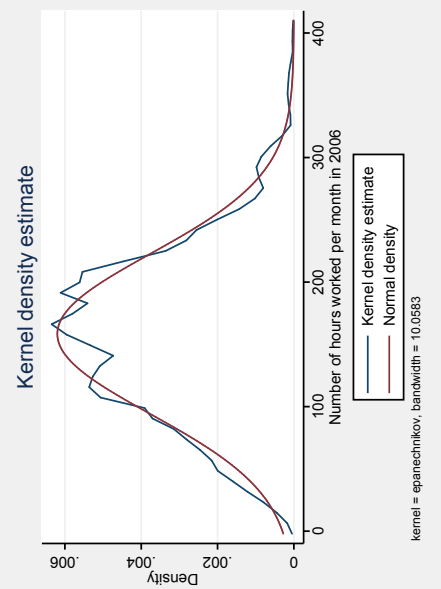

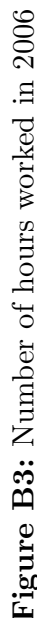



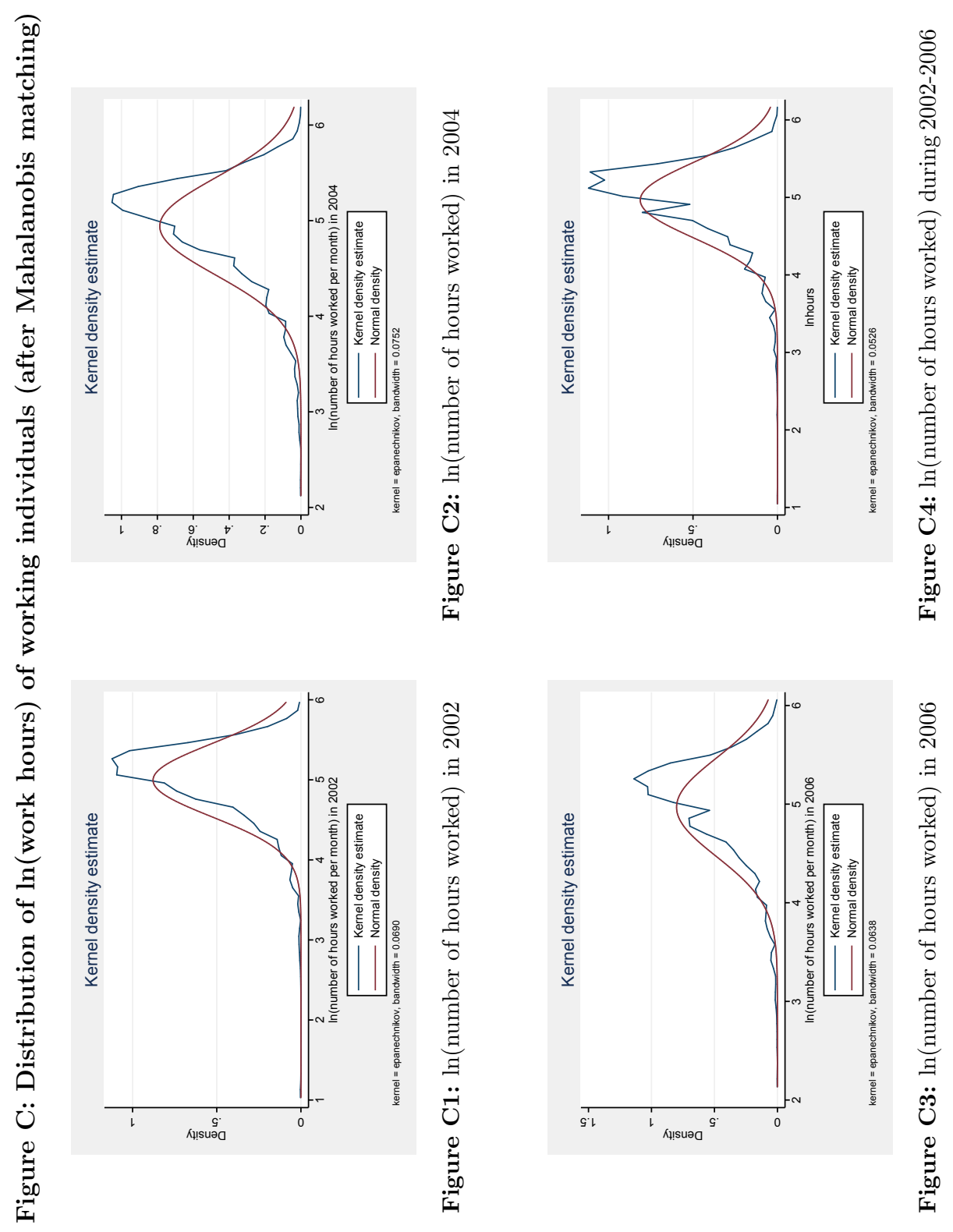

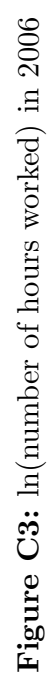



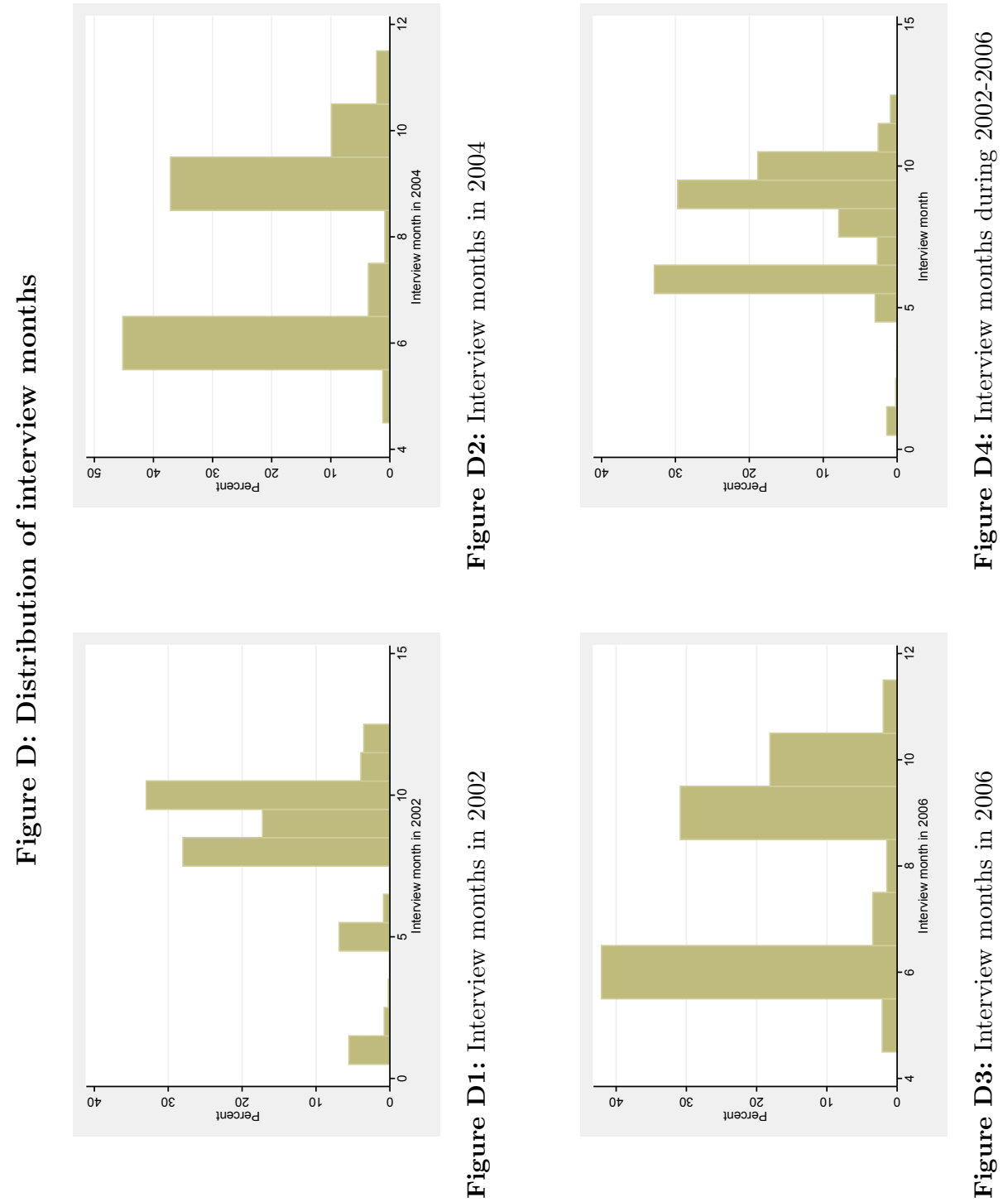


\section{Appendix B: Robustness checks for Chapter 4}

\section{Wald Test of endogeneity (probit) and Durbin-Wu Hausman test of endogene- ity (OLS)}

We use the health insurance coverage in 2010 as an instrument variable for health insurance coverage in 2012 to test for the endogeneity issue. We assume that health insurance in the previous year (2010) is a strong determinant of whether the person will continue signing up for the health scheme in 2012 while it is not related to SE transitions. Variable 'health insurance' (categorical) is transformed into a dummy variable, which takes the value of 1 for compulsory insurance and 0 for voluntary insurance, other health schemes are removed. As suggested in the Wald test results (see Table B1), we can not reject the null hypothesis of exogeneity of health insurance. In other words, the endogeneity of health insurance is not an issue and therefore a regular probit regression would be appropriate.

Similarly, the result of the Durbin-Wu Hausman test for the OLS model in Table B3 is consistent with the Wald test. 
Table B1: Probit with endogenous health insurance - First equation

\begin{tabular}{lcc}
\hline & SE entry & SE exit \\
\hline Instrumented: compulsory insurance (dummy) & & \\
Instrument: Insurance status in 2010 & $0.048^{* * *}$ & -0.004 \\
& $(0.01)$ & $(0.01)$ \\
Age squared & -0.000 & $0.000^{* *}$ \\
& $(0.00)$ & $(0.00)$ \\
Age & 0.007 & $-0.031^{*}$ \\
& $(0.02)$ & $(0.02)$ \\
Male & $-0.111^{* * *}$ & -0.007 \\
& $(0.04)$ & $(0.04)$ \\
Household size & $0.047^{* * *}$ & -0.012 \\
& $(0.02)$ & $(0.02)$ \\
Dependency ratio & -0.058 & 0.009 \\
& $(0.11)$ & $(0.12)$ \\
Marital status (base: married individuals) & & \\
-Single & -0.106 & -0.056 \\
& $(0.07)$ & $(0.12)$ \\
-Widowed/ Divorced/ Separated & -0.101 & 0.036 \\
Number of health care utilization per year & $(0.10)$ & $(0.09)$ \\
& -0.020 & $-0.060^{* *}$ \\
Urban(dummy) & $(0.03)$ & $(0.03)$ \\
& -0.008 & 0.037 \\
Monthly income per capita (in millions VND) & $(0.04)$ & $(0.05)$ \\
Work in agri/aquaculture sector & $\left(0.047^{* * *}\right.$ & $-0.001)$ \\
& $-0.332^{* * *}$ & $(0.01)$ \\
Number of observations & $(0.06)$ & $(0.04)$ \\
\hline
\end{tabular}

Standard errors in parentheses. ${ }^{*} p<0.1,{ }^{* *} p<0.05,{ }^{* * *} p<0.01$. Educational attainment and interview month are included. Variable 'health insurance' (categorical) is transformed into a dummy variable, which takes the value of 1 for compulsory insurance and 0 for voluntary insurance, other health schemes are removed. Coefficients reported. 
Table B2: Probit with endogenous health insurance - Main equation

\begin{tabular}{lcc}
\hline & SE entry & SE exit \\
\hline Dependent variable: SE entry (SE exit) & & \\
Compulsory insurance (dummy) & 0.904 & $3.753^{* * *}$ \\
Age squared & $(1.22)$ & $(0.37)$ \\
& 0.001 & -0.002 \\
Age & $(0.00)$ & $(0.00)$ \\
Male & -0.080 & 0.094 \\
& $(0.12)$ & $(0.09)$ \\
Household size & $0.842^{* *}$ & 0.130 \\
& $(0.33)$ & $(0.25)$ \\
Dependency ratio & -0.071 & 0.005 \\
& $(0.12)$ & $(0.10)$ \\
Marital status (base: married individuals) & -0.089 & -0.004 \\
-Single & $(0.70)$ & $(0.47)$ \\
& & \\
-Widowed/ Divorced/ Separated & 0.246 & 0.113 \\
& $(0.55)$ & $(0.54)$ \\
Number of health care utilization per year & 0.215 & -0.044 \\
& $(0.71)$ & $(0.41)$ \\
Urban(dummy) & 0.219 & $0.238^{* *}$ \\
Monthly income per capita (in millions VND) & $(0.17)$ & $(0.10)$ \\
Work in agri/aquaculture sector & -0.205 & -0.096 \\
& $(0.31)$ & $(0.22)$ \\
Number of observations & $(0.13)$ & -0.008 \\
Wat & $1.359^{* * *}$ & $-0.04)$ \\
& $(0.44)$ & $(0.33)$ \\
\hline & 327 & 228 \\
\hline
\end{tabular}

Wald test, null hypothesis: exogeneity of compulsory insurance $\mathrm{P}$ value (Probability $>\chi^{2}$ ) $0.4017 \quad 0.3603$

Standard errors in parentheses. ${ }^{*} p<0.1,{ }^{* *} p<0.05,{ }^{* * *} p<0.01$. Educational attainment and interview month are included. Variable 'health insurance' (categorical) is transformed into a dummy variable, which takes the value of 1 for compulsory insurance and 0 for voluntary insurance. Coefficients reported. 
Table B3: Self-employment entry and exit - OLS with endogenous health insurance

\begin{tabular}{lcc}
\hline & SE entry & SE exit \\
\hline Dependent variable: SE entry (SE exit) & & \\
Endogenous variable: Compulsory insurance (dummy) & 0.078 & 2.012 \\
& $(0.15)$ & $(4.45)$ \\
Age squared & 0.000 & -0.001 \\
& $(0.00)$ & $(0.00)$ \\
Age & -0.010 & 0.040 \\
& $(0.01)$ & $(0.14)$ \\
Male & $0.050^{* *}$ & 0.076 \\
& $(0.02)$ & $(0.10)$ \\
Household size & -0.002 & 0.006 \\
& $(0.01)$ & $(0.08)$ \\
Dependency ratio & 0.002 & -0.006 \\
& $(0.06)$ & $(0.25)$ \\
Marital status (base: married individuals) & & \\
-Single & 0.017 & -0.046 \\
-Widowed/ Divorced/ Separated & $(0.04)$ & $(0.26)$ \\
& -0.008 & -0.003 \\
Number of health care utilization per year & $(0.07)$ & $(0.24)$ \\
Urban(dummy) & 0.019 & 0.151 \\
Monthly income per capita (in millions VND) & $(0.01)$ & $(0.31)$ \\
Work in agri/aquaculture sector & -0.012 & -0.091 \\
& $(0.02)$ & $(0.28)$ \\
Number of observations & -0.009 & -0.007 \\
Tests of endogeneity, null hypothesis: compulsory insurance is exogenous & $(0.01)$ & $(0.02)$ \\
Durbin : $\chi^{2}(1)$ & 0.726041 & 0.552309 \\
Palue & $(0.3942)$ & $(0.4574)$ \\
Stausman : F(1,216) & 0.686156 & 0.496152 \\
& $(0.4079)$ & $(0.4820)$ \\
\hline
\end{tabular}

Standard errors in parentheses. ${ }^{*} p<0.1,{ }^{* *} p<0.05,{ }^{* * *} p<0.01$. Educational attainment and interview month are included. Variable 'health insurance' (categorical) is transformed into a dummy variable, which takes the value of 1 for compulsory insurance and 0 for voluntary insurance. 
Table B4: Probit Selection Model - Selection equation Separating WE from DE

\begin{tabular}{|c|c|c|c|c|}
\hline & \multicolumn{2}{|c|}{ Wage Employment } & \multicolumn{2}{|c|}{ Dual Employment } \\
\hline & SE entry & SE exit & SE entry & SE exit \\
\hline \multicolumn{5}{|l|}{ Currently employed (dummy) } \\
\hline Age squared & $\begin{array}{r}-0.003^{* * *} \\
(0.00)\end{array}$ & $\begin{array}{r}-0.003^{* * *} \\
(0.00)\end{array}$ & $\begin{array}{r}-0.005^{* * *} \\
(0.00)\end{array}$ & $\begin{array}{r}-0.003^{* * *} \\
(0.00)\end{array}$ \\
\hline Age & $\begin{array}{r}0.233^{* * *} \\
(0.04)\end{array}$ & $\begin{array}{r}0.225^{* * *} \\
(0.04)\end{array}$ & $\begin{array}{r}0.394^{* * *} \\
(0.07)\end{array}$ & $\begin{array}{r}0.252^{* * *} \\
(0.04)\end{array}$ \\
\hline Male & $\begin{array}{r}0.645^{* * *} \\
(0.13)\end{array}$ & $\begin{array}{c}0.144 \\
(0.12)\end{array}$ & $\begin{array}{r}0.734^{* * *} \\
(0.20)\end{array}$ & $\begin{array}{r}0.062 \\
(0.12)\end{array}$ \\
\hline Household size & $\begin{array}{r}-0.062 \\
(0.05)\end{array}$ & $\begin{array}{r}-0.094^{*} \\
(0.05)\end{array}$ & $\begin{array}{r}-0.306^{* * *} \\
(0.07)\end{array}$ & $\begin{array}{r}-0.096^{* *} \\
(0.05)\end{array}$ \\
\hline Dependency ratio & $\begin{array}{c}0.103 \\
(0.40)\end{array}$ & $\begin{array}{r}0.212 \\
(0.33)\end{array}$ & $\begin{array}{r}0.221 \\
(0.50)\end{array}$ & $\begin{array}{r}0.141 \\
(0.34)\end{array}$ \\
\hline Marital status (base: married individuals) & & & & \\
\hline -Single & $\begin{array}{r}-0.316 \\
(0.23)\end{array}$ & $\begin{array}{r}-0.845^{* * *} \\
(0.25)\end{array}$ & $\begin{array}{r}-0.672^{* *} \\
(0.32)\end{array}$ & $\begin{array}{r}-0.873^{* * *} \\
(0.25)\end{array}$ \\
\hline -Widowed/ Divorced/ Separated & $\begin{array}{l}-0.017 \\
(0.37)\end{array}$ & $\begin{array}{r}-0.464^{*} \\
(0.24)\end{array}$ & $\begin{array}{r}-0.339 \\
(0.37)\end{array}$ & $\begin{array}{r}-0.485^{* *} \\
(0.24)\end{array}$ \\
\hline Number of health care utilization per year & $\begin{array}{l}-0.139 \\
(0.11)\end{array}$ & $\begin{array}{l}-0.093 \\
(0.08)\end{array}$ & $\begin{array}{r}-0.154 \\
(0.12)\end{array}$ & $\begin{array}{r}-0.111 \\
(0.08)\end{array}$ \\
\hline Urban(dummy) & $\begin{array}{c}0.058 \\
(0.13)\end{array}$ & $\begin{array}{r}0.127 \\
(0.13)\end{array}$ & $\begin{array}{r}-0.596^{* * *} \\
(0.20)\end{array}$ & $\begin{array}{c}0.064 \\
(0.13)\end{array}$ \\
\hline Monthly income per capita (in millions VND) & $\begin{array}{c}0.024 \\
(0.05)\end{array}$ & $\begin{array}{r}0.079^{* *} \\
(0.04)\end{array}$ & $\begin{array}{r}-0.172^{* *} \\
(0.08)\end{array}$ & $\begin{array}{r}0.086^{* *} \\
(0.04)\end{array}$ \\
\hline Health insurance (base: voluntary insurance) & & & & \\
\hline -No insurance & $\begin{array}{c}0.492^{*} \\
(0.25)\end{array}$ & $\begin{array}{r}0.180 \\
(0.20)\end{array}$ & $\begin{array}{r}0.225 \\
(0.37)\end{array}$ & $\begin{array}{r}0.179 \\
(0.20)\end{array}$ \\
\hline -Health insurance for the poor and the near poor & $\begin{array}{r}0.181 \\
(0.33)\end{array}$ & $\begin{array}{r}-0.141 \\
(0.27)\end{array}$ & $\begin{array}{r}0.489 \\
(0.44)\end{array}$ & $\begin{array}{r}-0.102 \\
(0.27)\end{array}$ \\
\hline -Health insurance for assistance recipients & $\begin{array}{r}0.587 \\
(0.48)\end{array}$ & $\begin{array}{r}0.090 \\
(0.32)\end{array}$ & $\begin{array}{l}-0.077 \\
(0.53)\end{array}$ & $\begin{array}{r}0.273 \\
(0.37)\end{array}$ \\
\hline -Compulsory insurance in the formal sector & $\begin{array}{r}0.587^{* *} \\
(0.27)\end{array}$ & $\begin{array}{r}-1.293^{* * *} \\
(0.36)\end{array}$ & $\begin{array}{l}-0.125 \\
(0.39)\end{array}$ & $\begin{array}{r}-1.480^{* * *} \\
(0.36)\end{array}$ \\
\hline -Others & $\begin{array}{r}-0.239 \\
(0.29)\end{array}$ & $\begin{array}{r}-0.477 \\
(0.37)\end{array}$ & $\begin{array}{r}-0.540 \\
(0.60)\end{array}$ & $\begin{array}{r}-0.457 \\
(0.39)\end{array}$ \\
\hline Work in agri/aquaculture sector & $\begin{array}{r}8.037^{* * *} \\
(0.48)\end{array}$ & $\begin{array}{r}8.803^{* * *} \\
(0.27)\end{array}$ & $\begin{array}{r}9.492^{* * *} \\
(0.69)\end{array}$ & $\begin{array}{r}8.679^{* * *} \\
(0.28)\end{array}$ \\
\hline Employment status in 2010 (identification variable) & $\begin{array}{r}1.563^{* * *} \\
(0.14)\end{array}$ & $\begin{array}{r}2.226^{* * *} \\
(0.18)\end{array}$ & $\begin{array}{r}2.884^{* * *} \\
(0.30)\end{array}$ & $\begin{array}{r}2.242^{* * *} \\
(0.18)\end{array}$ \\
\hline Number of observations & 1,080 & 1,965 & 1,098 & 2,107 \\
\hline
\end{tabular}

Standard errors in parentheses. ${ }^{*} p<0.1,{ }^{* *} p<0.05,{ }^{* * *} p<0.01$. Educational attainment and interview month are included. Coefficients reported. Standard errors are clustered on the household. Maximum likelihood estimation is used 
Table B5: Probit Selection Model - Main equation Separating WE from DE

\begin{tabular}{|c|c|c|c|c|}
\hline & \multicolumn{2}{|c|}{ Wage Employment } & \multicolumn{2}{|c|}{ Dual Employment } \\
\hline & SE entry & SE exit & SE entry & SE exit \\
\hline \multirow[t]{2}{*}{ Age squared } & -0.002 & 0.000 & 0.001 & $-0.001^{* *}$ \\
\hline & $(0.00)$ & $(0.00)$ & $(0.00)$ & $(0.00)$ \\
\hline \multirow[t]{2}{*}{ Age } & 0.158 & -0.023 & -0.043 & $0.067^{*}$ \\
\hline & $(0.11)$ & $(0.04)$ & $(0.05)$ & $(0.03)$ \\
\hline \multirow[t]{2}{*}{ Male } & 0.221 & $0.481^{* * *}$ & $-0.315^{* *}$ & $0.242^{* * *}$ \\
\hline & $(0.20)$ & $(0.14)$ & $(0.13)$ & $(0.09)$ \\
\hline \multirow[t]{2}{*}{ Household size } & -0.094 & $-0.103^{* *}$ & 0.019 & $-0.064^{*}$ \\
\hline & $(0.07)$ & $(0.05)$ & $(0.05)$ & $(0.04)$ \\
\hline \multirow[t]{2}{*}{ Dependency ratio } & -0.519 & 0.016 & 0.382 & -0.295 \\
\hline & $(0.58)$ & $(0.38)$ & $(0.38)$ & $(0.26)$ \\
\hline \multicolumn{5}{|l|}{ Marital status (base: married individuals) } \\
\hline \multirow[t]{2}{*}{-Single } & -0.065 & $0.627^{* * *}$ & 0.042 & 0.207 \\
\hline & $(0.24)$ & $(0.21)$ & $(0.29)$ & $(0.25)$ \\
\hline \multirow[t]{2}{*}{-Widowed/ Divorced/ Separated } & -0.072 & -0.004 & $-0.572^{*}$ & 0.222 \\
\hline & $(0.55)$ & $(0.37)$ & $(0.32)$ & $(0.21)$ \\
\hline \multirow[t]{2}{*}{ Number of health care utilization per year } & -0.017 & 0.058 & 0.001 & 0.000 \\
\hline & $(0.15)$ & $(0.10)$ & $(0.09)$ & $(0.07)$ \\
\hline \multirow[t]{2}{*}{ Urban(dummy) } & -0.125 & 0.210 & 0.011 & $-0.377^{* *}$ \\
\hline & $(0.19)$ & $(0.17)$ & $(0.23)$ & $(0.16)$ \\
\hline \multirow[t]{2}{*}{ Monthly income per capita (in millions VND) } & -0.096 & 0.027 & 0.086 & $-0.076^{*}$ \\
\hline & $(0.08)$ & $(0.03)$ & $(0.08)$ & $(0.04)$ \\
\hline \multicolumn{5}{|l|}{ Health insurance (base: volutary insurance) } \\
\hline \multirow[t]{2}{*}{-No insurance } & 0.363 & 0.327 & 0.055 & -0.015 \\
\hline & $(0.40)$ & $(0.26)$ & $(0.30)$ & $(0.16)$ \\
\hline \multirow[t]{2}{*}{-Health insurance for the poor and the near poor } & -0.129 & 0.234 & 0.138 & 0.221 \\
\hline & $(0.53)$ & $(0.33)$ & $(0.33)$ & $(0.19)$ \\
\hline \multirow[t]{2}{*}{-Health insurance for assistance recipients } & 0.927 & -0.383 & -0.108 & -0.089 \\
\hline & $(0.75)$ & $(0.44)$ & $(0.40)$ & $(0.30)$ \\
\hline \multirow[t]{2}{*}{-Compulsory insurance in the formal sector } & -0.360 & $1.330^{* * *}$ & -0.405 & 0.325 \\
\hline & $(0.45)$ & $(0.37)$ & $(0.41)$ & $(0.38)$ \\
\hline \multirow[t]{2}{*}{-Others } & -0.005 & $0.631^{*}$ & $-5.811^{* * *}$ & 0.385 \\
\hline & $(0.64)$ & $(0.37)$ & $(0.41)$ & $(0.30)$ \\
\hline \multirow[t]{2}{*}{ Work in agri/aquaculture sector } & 0.460 & -0.140 & $0.329^{* *}$ & 0.202 \\
\hline & $(0.29)$ & $(0.17)$ & $(0.16)$ & $(0.14)$ \\
\hline Number of observations & 1,080 & 1,965 & 1,098 & 2,107 \\
\hline \multicolumn{5}{|l|}{ Wald tests of independence } \\
\hline$\rho$ & 0.634 & 0.519 & 0.340 & 0.190 \\
\hline $\mathrm{P}$ value (Probability $>\chi^{2}$ ) & 0.271 & 0.148 & 0.283 & 0.481 \\
\hline
\end{tabular}

Standard errors in parentheses. ${ }^{*} p<0.1,{ }^{* *} p<0.05,{ }^{* * *} p<0.01$. Educational attainment and interview month are included. Coefficients reported. Standard errors are clustered on the household. Maximum likelihood estimation is used 


\section{Appendix C: Robustness checks of Chapter 5}

Table C1: Three-level and four-level intercept models

\begin{tabular}{|c|c|c|}
\hline & Three level & Four level \\
\hline Receive financial protection when seeking care & $\begin{array}{c}1.315^{* * *} \\
(0.14)\end{array}$ & $\begin{array}{c}1.315^{* * *} \\
(0.14)\end{array}$ \\
\hline Age & $\begin{array}{c}-0.009^{* * *} \\
(0.00)\end{array}$ & $\begin{array}{c}-0.009^{* * * *} \\
(0.00)\end{array}$ \\
\hline Children under 5 & $\begin{array}{l}0.106 \\
(0.35)\end{array}$ & $\begin{array}{l}0.106 \\
(0.35)\end{array}$ \\
\hline Elderly over 65 & $\begin{array}{c}0.501^{* * *} \\
(0.18)\end{array}$ & $\begin{array}{c}0.501^{* * *} \\
(0.18)\end{array}$ \\
\hline Belongs to majority racial group (Kinh) & $\begin{array}{c}-0.464^{* * *} \\
(0.15)\end{array}$ & $\begin{array}{c}-0.464^{* * *} \\
(0.15)\end{array}$ \\
\hline Poor & $\begin{array}{c}-0.146 \\
(0.12)\end{array}$ & $\begin{array}{c}-0.146 \\
(0.12)\end{array}$ \\
\hline Number of self-reported health issues p.a. & $\begin{array}{c}-0.260^{* * *} \\
(0.06)\end{array}$ & $\begin{array}{c}-0.260^{* * *} \\
(0.06)\end{array}$ \\
\hline \multicolumn{3}{|l|}{ Facility type (base:commune health station) } \\
\hline -Village medical support & $\begin{array}{l}0.368 \\
(0.25)\end{array}$ & $\begin{array}{l}0.368 \\
(0.25)\end{array}$ \\
\hline -Meso-district polyclinic & $\begin{array}{c}0.856^{* *} \\
(0.38)\end{array}$ & $\begin{array}{c}0.856^{* *} \\
(0.38)\end{array}$ \\
\hline -District hospital & $\begin{array}{c}0.722^{* * *} \\
(0.12)\end{array}$ & $\begin{array}{c}0.722^{* * *} \\
(0.12)\end{array}$ \\
\hline -Provincial hospital & $\begin{array}{c}1.149^{* * *} \\
(0.19)\end{array}$ & $\begin{array}{c}1.149^{* * *} \\
(0.19)\end{array}$ \\
\hline -Central hospital & $\begin{array}{c}1.619^{* * *} \\
(0.36)\end{array}$ & $\begin{array}{c}1.619^{* * *} \\
(0.36)\end{array}$ \\
\hline -Other types of hospital & $\begin{array}{c}2.099^{* * * *} \\
(0.37)\end{array}$ & $\begin{array}{c}2.099^{* * * *} \\
(0.37)\end{array}$ \\
\hline \multicolumn{3}{|l|}{ Type of care (base: illness treatment) } \\
\hline -Vaccination & $\begin{array}{c}1.879^{* * *} \\
(0.44)\end{array}$ & $\begin{array}{c}1.879^{* * *} \\
(0.44)\end{array}$ \\
\hline -Pregnancy and reproductive health care & $\begin{array}{l}0.383 \\
(0.27)\end{array}$ & $\begin{array}{l}0.383 \\
(0.27)\end{array}$ \\
\hline -Health check-up & $\begin{array}{l}-0.102 \\
(0.14)\end{array}$ & $\begin{array}{l}-0.102 \\
(0.14)\end{array}$ \\
\hline Distance to the care facility $(\mathrm{km})$ & $\begin{array}{c}0.002^{* *} \\
(0.00)\end{array}$ & $\begin{array}{c}0.002^{* *} \\
(0.00)\end{array}$ \\
\hline Visit frequency to that specific facility for the same health issue p.a. & $\begin{array}{l}-0.005 \\
(0.01)\end{array}$ & $\begin{array}{l}-0.005 \\
(0.01)\end{array}$ \\
\hline OOP payments (in USD) & $\begin{array}{c}-0.000^{*} \\
(0.00) \\
\end{array}$ & $\begin{array}{c}-0.000^{*} \\
(0.00)\end{array}$ \\
\hline Cutpoint 1 & $\begin{array}{c}-8.149^{* * * *} \\
(0.36)\end{array}$ & $\begin{array}{c}-8.149^{* * *} \\
(0.36)\end{array}$ \\
\hline Cutpoint 2 & $\begin{array}{c}-4.652^{* * *} \\
(0.27)\end{array}$ & $\begin{array}{c}-4.652^{* * *} \\
(0.27)\end{array}$ \\
\hline Cutpoint 3 & $\begin{array}{c}-2.258^{* * *} \\
(0.24)\end{array}$ & $\begin{array}{c}-2.258^{* * *} \\
(0.24)\end{array}$ \\
\hline Cutpoint 4 & $\begin{array}{c}6.761^{* * *} \\
(0.34)\end{array}$ & $\begin{array}{c}6.761^{* * * *} \\
(0.34)\end{array}$ \\
\hline Variance(commune intercept) & $\begin{array}{c}1.909^{* * *} \\
(0.32)\end{array}$ & $\begin{array}{c}1.909^{* * *} \\
(0.32)\end{array}$ \\
\hline Variance(household intercept) & $\begin{array}{c}6.144^{* * *} \\
(0.60)\end{array}$ & $\begin{array}{c}6.144^{* * * *} \\
(0.60)\end{array}$ \\
\hline Variance(individual intercept) & & $\begin{array}{c}0.000^{* * * *} \\
(0.00)\end{array}$ \\
\hline $\mathrm{N}$ & 10,318 & 10,318 \\
\hline
\end{tabular}

Standard errors in parentheses. This only includes visits to SHI facilities. ${ }^{*} p<0.1,{ }^{* *} p<0.05,{ }^{* * *} p<0.01$. Gender and literacy are included but insignificant 
Table C2: Three-level models, separating different types of insurance

\begin{tabular}{|c|c|c|}
\hline & Random intercept & Random slope \\
\hline \multicolumn{3}{|l|}{ Health insurance (base: no insurance) } \\
\hline -Insurance for the poor & $\begin{array}{l}-0.017 \\
(0.22)\end{array}$ & $\begin{array}{c}-0.025 \\
(0.22)\end{array}$ \\
\hline -Insurance for assistance recipients & $\begin{array}{l}-0.257 \\
(0.24)\end{array}$ & $\begin{array}{l}-0.270 \\
(0.24)\end{array}$ \\
\hline -Compulsory insurance & $\begin{array}{l}0.139 \\
(0.31)\end{array}$ & $\begin{array}{l}0.157 \\
(0.31)\end{array}$ \\
\hline -Voluntary student insurance & $\begin{array}{l}-0.290 \\
(0.34)\end{array}$ & $\begin{array}{l}-0.280 \\
(0.35)\end{array}$ \\
\hline -Free insurance for children below 6 & $\begin{array}{l}0.071 \\
(0.36)\end{array}$ & $\begin{array}{l}0.103 \\
(0.37)\end{array}$ \\
\hline -Voluntary insurance & $\begin{array}{c}-0.663^{*} \\
(0.36)\end{array}$ & $\begin{array}{c}-0.644^{*} \\
(0.37)\end{array}$ \\
\hline -Others & $\begin{array}{c}-0.566^{*} \\
(0.31)\end{array}$ & $\begin{array}{c}-0.535^{*} \\
(0.31)\end{array}$ \\
\hline Receive financial protection when seeking care & $\begin{array}{c}1.338^{* * *} \\
(0.16)\end{array}$ & $\begin{array}{c}1.425^{* * *} \\
(0.17)\end{array}$ \\
\hline Age & $\begin{array}{c}-0.009^{* * *} \\
(0.00)\end{array}$ & $\begin{array}{c}-0.009^{* * *} \\
(0.00)\end{array}$ \\
\hline Children under 5 & $\begin{array}{l}0.025 \\
(0.38)\end{array}$ & $\begin{array}{l}0.022 \\
(0.38)\end{array}$ \\
\hline Elderly over 65 & $\begin{array}{c}0.600^{* * *} \\
(0.18)\end{array}$ & $\begin{array}{c}0.603^{* * *} \\
(0.18)\end{array}$ \\
\hline Belongs to majority racial group (Kinh) & $\begin{array}{c}-0.444^{* * *} \\
(0.15)\end{array}$ & $\begin{array}{c}-0.389^{* *} \\
(0.15)\end{array}$ \\
\hline Poor & $\begin{array}{c}-0.199^{*} \\
(0.12)\end{array}$ & $\begin{array}{c}-0.198^{*} \\
(0.12)\end{array}$ \\
\hline Number of self-reported health issues p.a. & $\begin{array}{c}-0.255^{* * *} \\
(0.07)\end{array}$ & $\begin{array}{c}-0.248^{* * *} \\
(0.07)\end{array}$ \\
\hline \multicolumn{3}{|l|}{ Type of facility (base: commune health station) } \\
\hline -Village medical support & $\begin{array}{l}0.423 \\
(0.27)\end{array}$ & $\begin{array}{l}0.379 \\
(0.26)\end{array}$ \\
\hline -Meso-district polyclinic & $\begin{array}{c}0.793^{* *} \\
(0.38)\end{array}$ & $\begin{array}{c}0.768^{* *} \\
(0.37)\end{array}$ \\
\hline -District hospital & $\begin{array}{c}0.714^{* * *} \\
(0.12)\end{array}$ & $\begin{array}{c}0.709^{* * * *} \\
(0.12)\end{array}$ \\
\hline -Provincial hospital & $\begin{array}{c}1.137^{* * *} \\
(0.19)\end{array}$ & $\begin{array}{c}1.133^{* * *} \\
(0.19)\end{array}$ \\
\hline -Central hospital & $\begin{array}{c}1.622^{* * *} \\
(0.36)\end{array}$ & $\begin{array}{c}1.610^{* * * *} \\
(0.37)\end{array}$ \\
\hline -Other types of hospital & $\begin{array}{c}2.066^{* * * *} \\
(0.37)\end{array}$ & $\begin{array}{c}2.051^{* * * *} \\
(0.37)\end{array}$ \\
\hline \multicolumn{3}{|l|}{ Type of care (base: illness treatment) } \\
\hline -Vaccination & $\begin{array}{c}1.690^{* * *} \\
(0.42)\end{array}$ & $\begin{array}{c}1.647^{* * * *} \\
(0.41)\end{array}$ \\
\hline -Pregnancy and reproductive health care & $\begin{array}{l}0.382 \\
(0.27)\end{array}$ & $\begin{array}{l}0.402 \\
(0.27)\end{array}$ \\
\hline -Health check-up & $\begin{array}{l}-0.107 \\
(0.14)\end{array}$ & $\begin{array}{l}-0.090 \\
(0.14)\end{array}$ \\
\hline Distance to the care facility $(\mathrm{km})$ & $\begin{array}{l}0.001^{*} \\
(0.00)\end{array}$ & $\begin{array}{l}0.002^{*} \\
(0.00)\end{array}$ \\
\hline Visit frequency to that specific facility for the same health issue p.a. & $\begin{array}{r}-0.002 \\
(0.01)\end{array}$ & $\begin{array}{l}-0.002 \\
(0.01)\end{array}$ \\
\hline OOP payments (in USD) & $\begin{array}{c}-0.000^{*} \\
(0.00)\end{array}$ & $\begin{array}{c}-0.000^{*} \\
(0.00)\end{array}$ \\
\hline Cutpoint 1 & $\begin{array}{c}-8.125^{* * *} \\
(0.40)\end{array}$ & $\begin{array}{c}-8.119^{* * *} \\
(0.40)\end{array}$ \\
\hline Cutpoint 2 & $\begin{array}{c}-4.696^{* * *} \\
(0.30)\end{array}$ & $\begin{array}{c}-4.663^{* * *} \\
(0.31)\end{array}$ \\
\hline Cutpoint 3 & $\begin{array}{c}-2.330^{* * *} \\
(0.28)\end{array}$ & $\begin{array}{c}-2.272^{* * *} \\
(0.29)\end{array}$ \\
\hline Cutpoint 4 & $\begin{array}{c}6.579^{* * *} \\
(0.35)\end{array}$ & $\begin{array}{c}6.765^{* * * *} \\
(0.37)\end{array}$ \\
\hline Variance(commune intercept) & $\begin{array}{c}1.864^{* * *} \\
(0.31)\end{array}$ & $\begin{array}{c}1.407^{* * *} \\
(0.29)\end{array}$ \\
\hline Variance(household intercept) & $\begin{array}{c}5.744^{* * *} \\
(0.58)\end{array}$ & $\begin{array}{c}5.865^{* * *} \\
(0.60)\end{array}$ \\
\hline Variance(commune slope) & & $\begin{array}{c}0.908^{* * * *} \\
(0.29)\end{array}$ \\
\hline $\mathrm{N}$ & 9,916 & 9,916 \\
\hline
\end{tabular}

Standard errors in parentheses. This only includes visits to SHI facilities. ${ }^{*} p<0.1,{ }^{* *} p<0.05,{ }^{* * *} p<0.01$. Gender and literacy are included but insignificant 
Table C3: Three-level random intercept models (full sample)

\begin{tabular}{|c|c|c|c|}
\hline & (1) & (2) & (3) \\
\hline Have health insurance & $\begin{array}{c}0.493^{* * *} \\
(0.13)\end{array}$ & $\begin{array}{c}-0.017 \\
(0.15)\end{array}$ & \\
\hline Receive financial protection when seeking care & & $\begin{array}{c}1.087^{* * *} \\
(0.14)\end{array}$ & \\
\hline \multicolumn{4}{|l|}{ Health insurance and its use (base: no insurance) } \\
\hline -Have insurance, receive no financial protection when seeking care & & & $\begin{array}{c}-0.017 \\
(0.15)\end{array}$ \\
\hline -Have insurance, receive financial protection when seeking care & & & $\begin{array}{c}1.071^{* * *} \\
(0.15)\end{array}$ \\
\hline Age & $\begin{array}{c}-0.007^{* * *} \\
(0.00)\end{array}$ & $\begin{array}{c}-0.008^{* * *} \\
(0.00)\end{array}$ & $\begin{array}{c}-0.008^{* * * *} \\
(0.00)\end{array}$ \\
\hline Children under 5 & $\begin{array}{l}0.125 \\
(0.28)\end{array}$ & $\begin{array}{l}0.134 \\
(0.29)\end{array}$ & $\begin{array}{l}0.134 \\
(0.29)\end{array}$ \\
\hline Elderly over 65 & $\begin{array}{c}0.321^{* *} \\
(0.14)\end{array}$ & $\begin{array}{c}0.320^{* *} \\
(0.14)\end{array}$ & $\begin{array}{c}0.320^{* *} \\
(0.14)\end{array}$ \\
\hline Belongs to the ethnic majority (Kinh) & $\begin{array}{c}-0.317^{* *} \\
(0.13)\end{array}$ & $\begin{array}{c}-0.317^{* *} \\
(0.13)\end{array}$ & $\begin{array}{c}-0.317^{* *} \\
(0.13)\end{array}$ \\
\hline Poor & $\begin{array}{r}-0.140 \\
(0.10)\end{array}$ & $\begin{array}{r}-0.139 \\
(0.10)\end{array}$ & $\begin{array}{r}-0.139 \\
(0.10)\end{array}$ \\
\hline Number of self-reported health issues p.a. & $\begin{array}{c}-0.170^{* * *} \\
(0.05)\end{array}$ & $\begin{array}{c}-0.171^{* * *} \\
(0.05)\end{array}$ & $\begin{array}{c}-0.171^{* * * *} \\
(0.05)\end{array}$ \\
\hline \multicolumn{4}{|l|}{ Healthcare facility (base: commune health station) } \\
\hline -Village medical support & $\begin{array}{l}0.121 \\
(0.23)\end{array}$ & $\begin{array}{l}0.301 \\
(0.24)\end{array}$ & $\begin{array}{l}0.301 \\
(0.24)\end{array}$ \\
\hline -Meso-district polyclinic & $\begin{array}{l}0.518 \\
(0.40)\end{array}$ & $\begin{array}{l}0.617 \\
(0.41)\end{array}$ & $\begin{array}{l}0.617 \\
(0.41)\end{array}$ \\
\hline -District hospital & $\begin{array}{c}0.621^{* * * *} \\
(0.11)\end{array}$ & $\begin{array}{c}0.661^{* * * *} \\
(0.11)\end{array}$ & $\begin{array}{c}0.661^{* * *} \\
(0.11)\end{array}$ \\
\hline -Provincial hospital & $\begin{array}{c}0.960^{* * * *} \\
(0.17)\end{array}$ & $\begin{array}{c}1.056^{* * * *} \\
(0.17)\end{array}$ & $\begin{array}{c}1.056^{* * * *} \\
(0.17)\end{array}$ \\
\hline -Central hospital & $\begin{array}{c}0.917^{* * *} \\
(0.33)\end{array}$ & $\begin{array}{c}1.303^{* * *} \\
(0.32)\end{array}$ & $\begin{array}{c}1.303^{* * *} \\
(0.32)\end{array}$ \\
\hline -Other types of hospital & $\begin{array}{c}1.348^{* * *} \\
(0.33)\end{array}$ & $\begin{array}{c}1.816^{* * *} \\
(0.33)\end{array}$ & $\begin{array}{c}1.816^{* * *} \\
(0.33)\end{array}$ \\
\hline -Private clinics & $\begin{array}{c}1.159^{* * * *} \\
(0.20)\end{array}$ & $\begin{array}{c}1.981^{* * *} \\
(0.22)\end{array}$ & $\begin{array}{c}1.981^{* * *} \\
(0.22)\end{array}$ \\
\hline -Pharmacies (without prescription) & $\begin{array}{c}1.198^{* *} \\
(0.53)\end{array}$ & $\begin{array}{c}1.865^{* * *} \\
(0.52)\end{array}$ & $\begin{array}{c}1.865^{* * *} \\
(0.52)\end{array}$ \\
\hline -Traditional herbal medicines & $\begin{array}{c}0.621^{* *} \\
(0.27)\end{array}$ & $\begin{array}{c}1.478^{* * *} \\
(0.31)\end{array}$ & $\begin{array}{c}1.478^{* * *} \\
(0.31)\end{array}$ \\
\hline -Others & $\begin{array}{c}0.575^{*} \\
(0.34)\end{array}$ & $\begin{array}{c}1.048^{* * * *} \\
(0.33)\end{array}$ & $\begin{array}{c}1.048^{* * *} \\
(0.33)\end{array}$ \\
\hline \multicolumn{4}{|l|}{ Type of care (base: self-treatment) } \\
\hline -Vaccination & $\begin{array}{c}2.178^{* * * *} \\
(0.64)\end{array}$ & $\begin{array}{c}2.102^{* * *} \\
(0.62)\end{array}$ & $\begin{array}{c}2.102^{* * *} \\
(0.62)\end{array}$ \\
\hline -Pregnancy and reproductive health care & $\begin{array}{c}1.165^{* *} \\
(0.57)\end{array}$ & $\begin{array}{c}1.066^{*} \\
(0.55)\end{array}$ & $\begin{array}{l}1.066^{*} \\
(0.55)\end{array}$ \\
\hline -Health check-up & $\begin{array}{l}0.506 \\
(0.53)\end{array}$ & $\begin{array}{l}0.346 \\
(0.50)\end{array}$ & $\begin{array}{l}0.346 \\
(0.50)\end{array}$ \\
\hline -Illness treatment & $\begin{array}{l}0.626 \\
(0.53)\end{array}$ & $\begin{array}{l}0.448 \\
(0.50)\end{array}$ & $\begin{array}{l}0.448 \\
(0.50)\end{array}$ \\
\hline Distance to the care facility $(\mathrm{km})$ & $\begin{array}{c}0.002^{* * * *} \\
(0.00)\end{array}$ & $\begin{array}{c}0.002^{* * * *} \\
(0.00)\end{array}$ & $\begin{array}{c}0.002^{* * * *} \\
(0.00)\end{array}$ \\
\hline Visit frequency to that specific facility for the same health issue p.a. & $\begin{array}{l}0.001 \\
(0.01)\end{array}$ & $\begin{array}{r}-0.001 \\
(0.01)\end{array}$ & $\begin{array}{r}-0.001 \\
(0.01)\end{array}$ \\
\hline OOP payments (in USD) & $\begin{array}{c}-0.000^{*} \\
(0.00)\end{array}$ & $\begin{array}{c}-0.000^{*} \\
(0.00)\end{array}$ & $\begin{array}{c}-0.000^{*} \\
(0.00)\end{array}$ \\
\hline Cut-point 1 & $\begin{array}{c}-7.544^{* * *} \\
(0.64)\end{array}$ & $\begin{array}{c}-7.324^{* * *} \\
(0.61)\end{array}$ & $\begin{array}{c}-7.324^{* * *} \\
(0.61)\end{array}$ \\
\hline Cut-point 2 & $\begin{array}{c}-4.309^{* * *} \\
(0.59)\end{array}$ & $\begin{array}{c}-4.053^{* * *} \\
(0.56)\end{array}$ & $\begin{array}{c}-4.053^{* * *} \\
(0.56)\end{array}$ \\
\hline Cut-point 3 & $\begin{array}{c}-1.835^{* * *} \\
(0.59)\end{array}$ & $\begin{array}{c}-1.557^{* * *} \\
(0.56)\end{array}$ & $\begin{array}{c}-1.557^{* * *} \\
(0.56)\end{array}$ \\
\hline Cut-point 4 & $\begin{array}{c}6.512^{* * * *} \\
(0.61)\end{array}$ & $\begin{array}{c}6.836^{* * * *} \\
(0.59)\end{array}$ & $\begin{array}{c}6.836^{* * *} \\
(0.59)\end{array}$ \\
\hline Variance (commune intercept) & $\begin{array}{c}1.494^{* * *} \\
(0.22)\end{array}$ & $\begin{array}{c}1.469^{* * *} \\
(0.21)\end{array}$ & $\begin{array}{c}1.469^{* * *} \\
(0.21)\end{array}$ \\
\hline Variance (household intercept) & $\begin{array}{c}4.979^{* * *} \\
(0.45)\end{array}$ & $\begin{array}{c}4.964^{* * *} \\
(0.46)\end{array}$ & $\begin{array}{c}4.964^{* * * *} \\
(0.46)\end{array}$ \\
\hline $\mathrm{N}$ & 13,358 & 13,357 & 13,357 \\
\hline
\end{tabular}

Standard errors in parentheses, coefficients reported. ${ }^{*} p<0.1,{ }^{* *} p<0.05,{ }^{* * *} p<0.01$.

Gender and literacy are included but insignificant 
Table C4: Three-level random slope models (full sample)

\begin{tabular}{|c|c|c|c|}
\hline & $(1)$ & $(2)$ & $(3)$ \\
\hline Have health insurance & $\begin{array}{c}0.560^{* * *} \\
(0.15)\end{array}$ & $\begin{array}{c}0.021 \\
(0.16)\end{array}$ & \\
\hline Receive financial protection when seeking care & & $\begin{array}{c}1.100^{* * *} \\
(0.14)\end{array}$ & \\
\hline \multicolumn{4}{|l|}{ Health insurance and its usage (base: no health insurance) } \\
\hline -Have insurance, receive no financial protection when seeking care & & & $\begin{array}{c}0.021 \\
(0.16)\end{array}$ \\
\hline -Have insurance, receive financial protection when seeking care & & & $\begin{array}{c}1.121^{* * *} \\
(0.16)\end{array}$ \\
\hline Age & $\begin{array}{c}-0.007^{* * *} \\
(0.00)\end{array}$ & $\begin{array}{c}-0.007^{* * *} \\
(0.00)\end{array}$ & $\begin{array}{c}-0.007^{* * *} \\
(0.00)\end{array}$ \\
\hline Children under 5 years old & $\begin{array}{l}0.134 \\
(0.28)\end{array}$ & $\begin{array}{l}0.141 \\
(0.28)\end{array}$ & $\begin{array}{l}0.141 \\
(0.28)\end{array}$ \\
\hline Elderly over 65 years old & $\begin{array}{c}0.333^{* *} \\
(0.14)\end{array}$ & $\begin{array}{c}0.323^{* *} \\
(0.14)\end{array}$ & $\begin{array}{c}0.323^{* *} \\
(0.14)\end{array}$ \\
\hline Belongs to the ethnic majority group (Kinh) & $\begin{array}{c}-0.286^{* *} \\
(0.13)\end{array}$ & $\begin{array}{c}-0.300^{* *} \\
(0.13)\end{array}$ & $\begin{array}{c}-0.300^{* *} \\
(0.13)\end{array}$ \\
\hline Poor & $\begin{array}{r}-0.136 \\
(0.10)\end{array}$ & $\begin{array}{r}-0.133 \\
(0.10)\end{array}$ & $\begin{array}{c}-0.133 \\
(0.10)\end{array}$ \\
\hline Number of self-reported health issues p.a. & $\begin{array}{c}-0.165^{* * *} \\
(0.05)\end{array}$ & $\begin{array}{c}-0.166^{* * *} \\
(0.05)\end{array}$ & $\begin{array}{c}-0.166^{* * *} \\
(0.05)\end{array}$ \\
\hline \multicolumn{4}{|l|}{ Type of facility (base: commune health station) } \\
\hline -Village medical support & $\begin{array}{l}0.157 \\
(0.23)\end{array}$ & $\begin{array}{l}0.342 \\
(0.24)\end{array}$ & $\begin{array}{l}0.342 \\
(0.24)\end{array}$ \\
\hline -Meso-district polyclinic & $\begin{array}{l}0.502 \\
(0.40)\end{array}$ & $\begin{array}{l}0.608 \\
(0.41)\end{array}$ & $\begin{array}{l}0.608 \\
(0.41)\end{array}$ \\
\hline -District hospital & $\begin{array}{c}0.619^{* * *} \\
(0.11)\end{array}$ & $\begin{array}{c}0.662^{* * *} \\
(0.11)\end{array}$ & $\begin{array}{c}0.662^{* * *} \\
(0.11)\end{array}$ \\
\hline -Provincial hospital & $\begin{array}{c}0.921^{* * *} \\
(0.18)\end{array}$ & $\begin{array}{c}1.022^{* * *} \\
(0.18)\end{array}$ & $\begin{array}{c}1.022^{* * *} \\
(0.18)\end{array}$ \\
\hline -Central hospital & $\begin{array}{c}0.876^{* * *} \\
(0.33)\end{array}$ & $\begin{array}{c}1.271^{* * *} \\
(0.32)\end{array}$ & $\begin{array}{c}1.271^{* * *} \\
(0.32)\end{array}$ \\
\hline -Other types of hospital & $\begin{array}{c}1.366^{* * *} \\
(0.33)\end{array}$ & $\begin{array}{c}1.843^{* * *} \\
(0.32)\end{array}$ & $\begin{array}{c}1.843^{* * *} \\
(0.32)\end{array}$ \\
\hline -Private clinics & $\begin{array}{c}1.172^{* * *} \\
(0.20)\end{array}$ & $\begin{array}{c}2.000^{* * *} \\
(0.22)\end{array}$ & $\begin{array}{c}2.000^{* * *} \\
(0.22)\end{array}$ \\
\hline -Pharmacies (without prescription) & $\begin{array}{c}0.693^{* * *} \\
(0.16)\end{array}$ & $\begin{array}{c}1.547^{* * *} \\
(0.19)\end{array}$ & $\begin{array}{c}1.547^{* * *} \\
(0.19)\end{array}$ \\
\hline -Traditional herbal medicines & $\begin{array}{c}0.578^{* *} \\
(0.27)\end{array}$ & $\begin{array}{c}1.446^{* * *} \\
(0.31)\end{array}$ & $\begin{array}{c}1.446^{* * *} \\
(0.31)\end{array}$ \\
\hline -Others & $\begin{array}{l}0.507 \\
(0.36)\end{array}$ & $\begin{array}{c}1.031^{* * *} \\
(0.34)\end{array}$ & $\begin{array}{c}1.031^{* * *} \\
(0.34)\end{array}$ \\
\hline \multicolumn{4}{|l|}{ Type of care (base: self-treatment) } \\
\hline -Vaccination & $\begin{array}{c}1.769^{* * *} \\
(0.41)\end{array}$ & $\begin{array}{c}1.885^{* * *} \\
(0.42)\end{array}$ & $\begin{array}{c}1.885^{* * *} \\
(0.42)\end{array}$ \\
\hline -Pregnancy and reproductive health care & $\begin{array}{c}0.746^{* *} \\
(0.29)\end{array}$ & $\begin{array}{c}0.844^{* * *} \\
(0.29)\end{array}$ & $\begin{array}{c}0.844^{* * *} \\
(0.29)\end{array}$ \\
\hline -Health check-up & $\begin{array}{l}0.103 \\
(0.22)\end{array}$ & $\begin{array}{l}0.136 \\
(0.22)\end{array}$ & $\begin{array}{l}0.136 \\
(0.22)\end{array}$ \\
\hline -Illness treatment & $\begin{array}{l}0.202 \\
(0.18)\end{array}$ & $\begin{array}{l}0.224 \\
(0.18)\end{array}$ & $\begin{array}{l}0.224 \\
(0.18)\end{array}$ \\
\hline Distance to the care facility $(\mathrm{km})$ & $\begin{array}{c}0.002^{* * *} \\
(0.00)\end{array}$ & $\begin{array}{c}0.002^{* * *} \\
(0.00)\end{array}$ & $\begin{array}{c}0.002^{\text {*** }} \\
(0.00)\end{array}$ \\
\hline Visit frequency to that specific facility for the same health issue p.a. & $\begin{array}{r}-0.001 \\
(0.01)\end{array}$ & $\begin{array}{r}-0.002 \\
(0.01)\end{array}$ & $\begin{array}{r}-0.002 \\
(0.01)\end{array}$ \\
\hline OOP payments in USD & $\begin{array}{r}-0.000 \\
(0.00)\end{array}$ & $\begin{array}{r}-0.000 \\
(0.00)\end{array}$ & $\begin{array}{r}-0.000 \\
(0.00)\end{array}$ \\
\hline Cut-point 1 & $\begin{array}{c}-7.911^{* * *} \\
(0.39)\end{array}$ & $\begin{array}{c}-7.512^{* * *} \\
(0.39)\end{array}$ & $\begin{array}{c}-7.511^{* * *} \\
(0.39)\end{array}$ \\
\hline Cut-point 2 & $\begin{array}{c}-4.668^{* * *} \\
(0.31)\end{array}$ & $\begin{array}{c}-4.233^{* * *} \\
(0.31)\end{array}$ & $\begin{array}{c}-4.233^{* * *} \\
(0.31)\end{array}$ \\
\hline Cut-point 3 & $\begin{array}{c}-2.178^{* * *} \\
(0.30)\end{array}$ & $\begin{array}{c}-1.721^{* * *} \\
(0.29)\end{array}$ & $\begin{array}{c}-1.721^{* * *} \\
(0.29)\end{array}$ \\
\hline Cut-point 4 & $\begin{array}{c}6.173^{* * *} \\
(0.34)\end{array}$ & $\begin{array}{c}6.675^{* * *} \\
(0.36)\end{array}$ & $\begin{array}{c}6.675^{* * *} \\
(0.36)\end{array}$ \\
\hline Variance(commune slope) & $\begin{array}{c}0.588^{*} \\
(0.35)\end{array}$ & $\begin{array}{l}0.440 \\
(0.34)\end{array}$ & $\begin{array}{c}0.441 \\
(0.34)\end{array}$ \\
\hline Variance(commune intercept) & $\begin{array}{c}0.961^{* * *} \\
(0.33)\end{array}$ & $\begin{array}{c}1.074^{* * *} \\
(0.32)\end{array}$ & $\begin{array}{c}1.073^{* * *} \\
(0.32)\end{array}$ \\
\hline Variance(household intercept) & $\begin{array}{c}4.969^{* * *} \\
(0.45)\end{array}$ & $\begin{array}{c}4.950^{* * *} \\
(0.45)\end{array}$ & $\begin{array}{c}4.950^{* * *} \\
(0.45)\end{array}$ \\
\hline $\mathrm{N}$ & 13,408 & 13,407 & 13,407 \\
\hline
\end{tabular}

Standard errors in parentheses. ${ }^{*} p<0.1,{ }^{* *} p<0.05,{ }^{* * *} p<0.01$. Gender and literacy are included but insignificant 


\title{
Valorisation Addendum
}

\author{
Economic and social relevance
}

This $\mathrm{PhD}$ dissertation focuses on the implications of health insurance for the labour market and how health insurance affects patient satisfaction with medical care in Vietnam. It is contextualised in the movement toward Universal Health Coverage (UHC) in Vietnam where health insurance coverage is rapidly expanding. In 2004, Social Health Insurance (SHI) in Vietnam only covered 20 percent of the population (Somanathan et al., 2013), it then exponentially increased to more than 86 percent in 2017 (Ngan, 2017). However, despite the rapid expansion of health insurance coverage, the SHI is inefficient and ineffective with lots of inefficiencies in its management (Somanathan et al., 2014) as well as in the healthcare system (Takashima et al., 2017). Therefore, the impressive expansion of health insurance coverage does not necessarily translate into quality medical care, raising the concern of healthcare quality and patient satisfaction. From the labour market perspective, the expansion of health insurance may have important implications for the Vietnamese labour market. Evidence from post-Soviet countries of reduced employment due to social health insurance (see Wagstaff and Moreno-Serra, 2009) as well as the theoretical prediction of reduced labour supply induced by social welfare (Gruber, 2010) raise concern about potential disincentive to work induced by social health insurance. This disincentive to work, if empirically evidenced, will potentially undermine the economic achievements that have been gained so far in Vietnam. This threat is very relevant given that the country maintains its strong ambition and commitment to economic growth and accelerating the catching-up with advanced economies (The World Bank and MPI, 2016). With the healthcare quality concern, combined with potential labour market distortions, the effects of health insurance on patient satisfaction and on the labour supply should be discussed seriously. This dissertation aims to provide more empirical evidence on the matters to inform policy making in Vietnam. Additionally, as the wave of global UHC is gaining more and more momentum in many other low and middle income countries (LMIC), this dissertation is relevant not only for Vietnam but also for these countries.

\section{Target audience outside academia}

This dissertation helps to inform policy making in Vietnam in particular and in other LMIC in general in the global wave of moving toward UHC (Lagomarsino et al., 2012). 
In addition to filling the literature gaps for LMIC on effects of health insurance on labour supply (see Lê et al., 2019) and on patient satisfaction (see Chapter 1), this dissertation provides important policy implications for both the labour and health sectors. In this $\mathrm{PhD}$ project, findings about Vietnam have shown that health insurance indeed has a negative effect on labour supply both in terms of labour force participation and the number of hours worked (Chapter 3). Besides, boundaries among different health insurance schemes in Vietnam seem to create a barrier to self-employment entry. In particular, people covered by compulsory insurance (the formal workers) are less likely to enter self-employment compared to those having voluntary insurance (Chapter 4). These two findings are important and relevant for both labour and health ministries, suggesting that the coordination between the Ministry of Health and Ministry of Labour, Invalids and Social Affairs is needed in designing health insurance policies. Additionally, the finding that health insurance can make people more satisfied with medical care via its cost-sharing benefit (Chapter 5) contributes to the understanding of patient satisfaction. Future efforts by the Ministry of Health in raising patient satisfaction can use this evidence as a guideline for action. Equally, this $\mathrm{PhD}$ dissertation is and should be of interest to policy makers in other LMIC which are also taking the path of UHC.

\section{Products of this $\mathrm{PhD}$ research and future plans}

All empirical chapters of this dissertation have been published or submitted to academic journals. At the time of writing this addendum, Chapter 2 has been published in the International Journal of Manpower, Chapter 3 has been published in Applied Economics while the rest (Chapters 4-5) have been submitted to academic journals. Within one year after the defence, the author hopes to revise and publish Chapters 4-5. Additionally, given the policy relevance of this dissertation to LMIC, in the future, the author hopes to be involved in policy discussions of UHC to help provide some insights. Blog posts can also be used as a means of disseminating the knowledge gained from this project. 


\section{Curriculum Vitae}

Nga Lê (Nga Leopold) is a PhD fellow at Maastricht Graduate School of Governance/UNUMERIT, Maastricht University. While in Maastricht, she has been involved in several projects commissioned and funded by UNICEF Vietnam on the social assistance system for Vietnamese children. She used to work as a researcher at Indochina Research and Consulting in Vietnam where she engaged in a wide range of consulting projects commissioned by the World Bank, Action Aid, Oxfam GB, IFAD, AusAID, Overseas Development Institute (UK), Global Development Solutions LLC (Virginia, USA), General Inspectorate of Vietnam, Vietnamese Ministry of Education and Training, Belgian Development Agency (BTC) and Action Aid. Besides the PhD fellowship, Nga is presently also a part-time correspondent of Tiasang magazine in Vietnam (the magazine for the Vietnamese academic community) and covers many policy issues.

She holds a Master's degree in Public Policy and Human Development from Maastricht Graduate School of Governance/UNU-MERIT(Maastricht University), with a specialisation in Social Protection Financing and Design. She was awarded a High Potential Scholarship for talented non-EU students for her Master's study, and a UNU-MERIT Fellowship for the Doctoral study at Maastricht University.

Her areas of interest include labour economics, health economics, health policy, social protection and poverty reduction.

\section{Publications and working papers}

- Le, N., Groot, W., Tomini, S. M., \& Tomini, F. (2019), Effects of health insurance on labour supply: Evidence from the Health Care Fund for the Poor in Vietnam. Applied Economics. DOI: https://doi.org/10.1080/00036846.2019.1613509

- Le, N., Groot, W., Tomini, S. M., \& Tomini, F. (2019), Effects of health insurance on labour supply: A systematic review. International Journal of Manpower. DOI: https://doi.org/10.1108/IJM-02-2018-0038

- Le, N., Groot, W., Tomini, S. M., \& Tomini, F. (2019), Health insurance and self-employment transitions in Vietnam, UNU-MERIT Working Paper 2019-008

- Le, N., Groot, W., Tomini, S. M., \& Tomini, F. (2018), Health insurance and patient satisfaction: Evidence from the poorest regions of Vietnam, UNU-MERIT Working Paper 2018-040 
- Le, N., Groot, W., Tomini, S. M., \& Tomini, F. (2017), Effects of health insurance on labour supply: Evidence from the health care fund for the poor in Viet Nam, UNU-MERIT Working Paper 2017-050

- Le, N., Groot, W., Tomini, S. M., \& Tomini, F. (2017), Effects of health insurance on labour supply: A systematic review, UNU-MERIT Working Paper 2017-017

- Moldalieva, J., Muttaqien A., Muzyamba, C., Osei, D., Stoykova, E., \& Le, N. (2016), Millennium Development Goals (MDGs): Did they change social reality?, UNU-MERIT Working Paper 2016-035

\section{Recent policy articles and reports}

- Vanore, M., Franziska G., Tran N.T., Pham T.M., Le, N. \& Timar, E. (2017), Study on Improving the Effectiveness and Coverage of Social Assistance for Children with Focus on Consolidation Policy (Family/Child Benefit Package), Report commissioned by UNICEF

- Le N., [Vietnamese] Song chung voi duong ong vo, [English] Living with a broken water supply system, Vnexpress (the largest online newspaper in Vietnam), Available at https://vnexpress.net/tin-tuc/goc-nhin/song-chung-voi-duong-ong-vo3272168.html

- Le, N., [Vietnamese] Goc nhin moi ve binh dang gioi,[English] A new perspective on gender equality, Dantri news, Available at https://duhoc.dantri.com.vn/duhoc/goc-nhin-moi-ve-binh-dang-gioi-cua-nghien-cuu-sinh-tien-si-viet-tai-ha-lan20160309151423898.htm

- Le, N., [Vietnamese], Nen kinh te khong su dung tien mat: Co hoi va thach thuc cua nen tang thanh toan di dong, [English] A cashless society: opportunities and challenges of mobile payment platforms, TiaSang online and TiaSang magazine (the magazine for the Vietnamese academic community), Available at http://tiasang.com.vn/-quan-ly-khoa-hoc/Nen-kinh-te-khong-su-dung-tien-matCo-hoi-va-thach-thuc-cua-nen-tang-thanh-toan-di-dong-11274

- Le, N., [Vietnamese], Viet Nam xep hang 56 the gioi ve R\&D va doi moi sang tao, [English] Vietnam ranks the 56th in R\&D and innovation, TiaSang online and TiaSang magazine, Available at http://tiasang.com.vn/-doi-moi-sang-tao/Viet-Namxep-hang-56-the-gioi-ve-RD-va-doi-moi-sang-tao-11059 


\section{UNU-MERIT/MGSoG Dissertation Series}

2019

\section{Nga Le}

The implications of health insurance for the labour market and patient satisfaction with medical care in Vietnam

UNU-MERIT/MGSoG Dissertation Series № 230

\section{Jinhyuck Park}

Intellectual Property right protection and cross-border RED investments by multinational enterprises

UNU-MERIT/MGSoG Dissertation

Series № 229

\section{Richard de Groot}

Show me the Money:

Essays on the Impact of Cash Transfers on Child Nutrition and the Role of

Intra-Household Dynamics

UNU-MERIT/MGSoG Dissertation

Series № 228

\section{Catie Lott}

Diamonds are a Women's Best Friend

Broadening Measures of Women's Access to Formal Political DecisionMaking UNU-MERIT/MGSoG Dissertation Series № 227

\author{
Ana Cristina Calderon Ramirez \\ Public Management Reforms \\ Three stories about public procurement \\ agencification in Latin America \\ UNU-MERIT/MGSoG Dissertation \\ Series № 226
}

\section{Camilo Nicanor Carrillo Purin}

Teachers' in-service training and student achievement:

The effect of in-service training of Peruvian teachers on student achievement UNU-MERIT/MGSoG Dissertation Series № 225

\section{Hugo Confraria}

Developing scientific capacity in the

Global South

UNU-MERIT/MGSoG Dissertation Series № 224

\section{Alison Cathles}

Educational Pathways and Skills:

Past, Present, and Future

UNU-MERIT/MGSoG Dissertation

Series № 223

\section{Ibrahima Sory Kaba}

Aggregate Fluctuations and

Development: Essays on

Macroeconomic Volatility and

Economic Growth

UNU-MERIT/MGSoG Dissertation

Series № 222 


\section{Charlotte Keijser}

Firm Participation, Learning and

Innovation in Heterogenous Value

Chains of IT-enabled Services

UNU-MERIT/MGSoG Dissertation

Series № 221

\section{Salih Çevikarslan}

Innovation Strategies and Their

Implications for Technological Change

and Market Outcomes:

An Evolutionary Multi-Agent Based

Modelling Approach

UNU-MERIT/MGSoG Dissertation

Series № 220

\section{Wondimagegn Mesfin Tesfaye}

Essays on the Impacts of Climate-

Smart Agricultural Innovations on

Household Welfare

UNU-MERIT/MGSoG Dissertation

Series № 219

\section{Tatevik Poghosyan}

How Board Networks Affect Firm

Performance and Innovation Incentives

in Transition Economies: The Case of

Armenia

UNU-MERIT/MGSoG Dissertation

Series № 218

\section{Arip Muttaqien}

Essays on Inequality and Polirization:

Empirical Studies in Developing Asia

UNU-MERIT/MGSoG Dissertation

Series № 217

2018

\section{Katrin Marchand}

Essays on Forced Migration and

Labour Market Participation in

Developing Countries

UNU-MERIT/MGSoG Dissertation

Series № 216

\section{Ortrun Merkle}

The Myth of Gender Neutral Power:

Corruption and Gender Norms

UNU-MERIT/MGSoG Dissertation

Series № 215

\section{Biljana Meshkovska}

Life after Trafficking:

(re)integration processes of women that have been trafficked for the purpose of sexual exploitation in Europe

UNU-MERIT/MGSoG Dissertation

Series № 214

\section{Vincenzo Vinci}

The Relevance of Institutions and

People's Preferences for Social

Protection

UNU-MERIT/MGSoG Dissertation

Series № 213

\section{Silke Heuser}

The Effectiveness of Environmental Policies on Reducing Deforestation in the Brazilian Amazon

UNU-MERIT/MGSoG Dissertation

Series № 212

\section{Jennifer Waidler}

Social Assistance and Remittances and

Their Role in the Fight Against

Poverty

UNU-MERIT/MGSoG Dissertation

Series № 211 


\section{Choolwe Muzyamba}

The role of community mobilization in the promotion of maternal health of women living with HIV in Zambia UNU-MERIT/MGSoG Dissertation Series № 210

\section{Juan Carlos A. Castillo Sánchez}

Assessing the Role of the Export Sector in Mexican Economic

Development,1965-2014

UNU-MERIT/MGSoG Dissertation

Series № 209

\section{Tareq Abuelhaj}

Food Security Policy Impact Analysis:

The Econometrics of Cash and Food

Assistance Cost Effectiveness

UNU-MERIT/MGSoG Dissertation

Series № 208

Marta Férnandez de Arroyabe Arranz

Essays on MEAS and Innovation

UNU-MERIT/MGSoG Dissertation

Series № 207

\section{Clotilde Mahé}

Essays on Migration and Occupational Choice

UNU-MERIT/MGSoG Dissertation

Series № 206

\section{Simone Sasso}

Talent on the move. Essays on Human

Capital, Graduate Mobility and

Economic Development

UNU-MERIT/MGSoG Dissertation

Series № 205
Khaled Walid Rajab

Strategic Planning under Fragility

UNU-MERIT/MGSoG Dissertation

Series № 204

Mutinta Hambayi Nseluke

A Tall Order: Improving Child Linear Growth

UNU-MERIT/MGSoG Dissertation Series № 203

\section{Elvis Korku Avenyo}

Innovations and Firm Performance

in sub-Saharan Africa: Empirical

Analyses

UNU-MERIT/MGSoG Dissertation

Series № 202

\section{Ni Zhen}

Employment Dynamics, Firm

Performance and Innovation

Persistence in the Context of

Differentiated Innovation Types:

Evidence from Luxembourg

UNU-MERIT/MGSoG Dissertation

Series № 201

\section{Caroline Wehner}

Too Scared to Achieve: The Relation

Between Neuroticism,

Conscientiousness

and Socioeconomic Outcomes

UNU-MERIT/MGSoG Dissertation

Series № 200

\section{Stefania Innocenti}

On Institutional Persistence

UNU-MERIT/MGSoG Dissertation Series № 199 


\section{Hassen Abda Wako}

Economic Globalization, Institutions and Development: Essays on Aid, Foreign Direct Investment and Trade UNU-MERIT/MGSoG Dissertation Series № 198

2017

\section{Hans-Erik Edsand}

Winds of Change

UNU-MERIT/MGSoG Dissertation Series № 197

\section{Ana Patricia Silva Vara}

Redressing the Gender Gap UNU-MERIT/MGSoG Dissertation Series № 196

\section{Andrés Iván Mideros Mora}

Essays on the Economic Effects of Noncontributory Social Protection UNU-MERIT/MGSoG Dissertation Series № 195

\section{Tobias Broich}

New Actors in the Global Economy UNU-MERIT/MGSoG Dissertation Series № 194

\section{Bernard Nikaj}

From No-government to E-government UNU-MERIT/MGSoG Dissertation Series № 193

\section{Ali Safarnejad}

Prioritizing the HIV Response UNU-MERIT/MGSoG Dissertation Series № 192

\section{Clovis Freire}

Diversification and Structural

Economic Dynamics

UNU-MERIT/MGSoG Dissertation

Series № 191

\section{Michael Verba}

Innovation and Knowledge Dynamics:

Essays on the Knowledge Economy

UNU-MERIT/MGSoG Dissertation

Series № 190

\section{Pui Hang Wong}

The Hearts and Minds in Conflict and Peace: The Economics of

Counterinsurgency and the Psychology of Reconstruction

UNU-MERIT/MGSoG Dissertation

Series № 189

\section{Brenda Yamba}

Schooling Despite All Odds: Evidence from Lesotho on Female Child Carers who Stayed in School UNU-MERIT/MGSoG Dissertation Series № 188

\section{Sheng Zhong}

Moving towards An Energy Efficient Future: Essays on Energy Efficiency, Technology and Development UNU-MERIT/MGSoG Dissertation Series № 187 


\section{Julieta Marotta}

Access to Justice and Legal

Empowerment of Victims of Domestic

Violence through Legal Organizations in the City of Buenos Aires: A

Qualitative Empirical Legal Study

UNU-MERIT/MGSoG Dissertation

Series, № 186

\section{Andrea Franco-Correa}

On the Measurement of

Multidimensional Poverty as a Policy

Tool: Empirical Applications to Chile,

Colombia, Ecuador and Peru

UNU-MERIT/MGSoG Dissertation

Series, № 185

2016

Yesuf Awel

Insurance for Growth: Empirical

Essays on Insurance Demand and

Impacts in Africa

UNU-MERIT Dissertation Series,

№ 108

\section{Tigist Mekonnen Melesse}

Grow More Food using Fewer

Resources: Agricultural Technology

Adoption and Innovation Practices for

Inclusive and Sustainable

Development

UNU-MERIT Dissertation Series, № 107

\section{Eleni Yitbarek}

Getting Ahead or left Behind? Essays

on Poverty Dynamics and Social

Mobility in Africa

UNU-MERIT Dissertation Series,

№ 106

\section{Thuy Dieu Nguyen}

Firm-Level Theory and Evidence of

Corruption

UNU-MERIT Dissertation Series,

№ 105

\section{Raquel Tsukada Lehman}

Essays on Household Production with

Labor-Saving Technology

UNU-MERIT Dissertation Series,

№ 104

\section{Eva Barteková}

Multi-Problem Challenges for a

Renewable Future: Empirical Studies

on Competitive Disadvantages from

Electricity Price Differentials and

Mineral Supply Risk in an Open

Economy

UNU-MERIT Dissertation Series,

№ 103

\section{Jocelyn Olivari}

Entrepreneurial Traits and Innovation:

Evidence from Chile

UNU-MERIT Dissertation Series,

№ 102

\section{Muhammad Shafique}

Essays on the role of knowledge, RED, and Technology-based Firms in the Evolution of Socio-techno-economic System

UNU-MERIT Dissertation Series, № 101 


\section{Serdar Türkeli}

Governance of Innovation Policy:

Empirical Studies on Applied Political

Economy by Multi-Methods Analysis

UNU-MERIT Dissertation Series,

№ 100

\section{Ayokunu Adedokun}

Pathways to Sustainable Peace

building in Divided Societies: Lessons

and Experiences from Mozambique

MGSoG Dissertation Series, № 75

\section{Luiz Rothier Bautzer}

Organizing Concurrent Engineering

through ICT Platforms

Blueprinting Product Lifecycle

Management Platforms across

Disciplinary Agencies

MGSoG Dissertation Series, № 74

\section{Natalia Popova}

Migration in the Periphery of the

European Union:

Determinants of Successful and

Sustainable Labour Market Integration

of Return Migrants in Albania, Egypt, Moldova and Tunisia

MGSoG Dissertations Series, № 73

\section{Richard A. Martina}

Uncertainty and Resource Constraint in the Small Island Developing States: Essays in Entrepreneurial Cognition MGSoG Dissertations Series, № 72

\section{Cécile Cherrier}

The Expansion of Basic Social

Protection in Low-income Countries:

An Analysis of Foreign Aid Actors'

Role in the Emergence of Social

Transfers in Sub-Saharan Africa

MGSoG Dissertations series, № 71

\section{Paul Caldron}

The Tacit Bargain in Short-Term

Medical Missions: Why U.S.

physicians go and what it costs

MGSoG Dissertation Series, № 70

\section{Mahmut Kobal}

Customs \& Excellence: A Comparative Approach on Administrative and Regulatory Compliance Perspectives of the EU-Turkey Customs Union

MGSoG Dissertation Series, № 69

\section{Craig Loschmann}

Essays on Conflict-related Migration and Development in the Case of Afghanistan

MGSoG Dissertations Series, № 68

\section{Andrea Milan}

Rural Livelihoods, Location and Vulnerable Environments: Approaches to Migration in Mountain areas of

Latin America

MGSoG Dissertation Series, № 67

\section{Farida Lada}

On Guarding the Welfare of Clinical

Trial Subjects While Promoting Novel

Drug Innovation

A Game Theoretical Approach

MGSoG Dissertation Series, № 66 


\section{Francesca Guadagno}

Hibret Belete Maemir

Dissecting Aggregate Productivity:

International Integration and Growth

with Heterogeneous Firms

UNU-MERIT Dissertation Series,

№ 96

\section{Giorgio Triulzi}

Looking for the Right Path: Technology

Dynamics, Inventive Strategies and

Catching-up in the Semiconductor

Industry

UNU-MERIT Dissertation Series, № 95

\section{Abdul Baseer Qazi}

Knowledge flows and networks in the

ICT sector: The case of Pakistan

UNU-MERIT Dissertation Series, № 94

\section{Ajay Thutupalli}

Technology Paradigm Shifts in

Agriculture: Drivers of Sustainability

and Catch up

UNU-MERIT Dissertation Series, № 93

\section{Eduardo Urias}

Improving access to HIV/AIDS

treatment in Brazil: When are

Compulsory Licenses effective in Price

Negotiations?

UNU-MERIT Dissertation Series, № 92
Why have so few Countries

Industrialised?

UNU-MERIT Dissertation Series, № 91

\section{Daniel Opolot}

The Evolution of Beliefs and Strategic

Behaviour

UNU-MERIT Dissertation Series,

№ 90

\author{
Alejandro Lavopa \\ Structural Transformation and \\ Economic Development: Can \\ Development Traps be Avoided \\ UNU-MERIT Dissertation Series, \\ № 89
}

\section{Jinjin Zhao}

Urban water management reform: The

Case of China

UNU-MERIT Dissertation Series,

№ 88

\section{Simona Vezzoli}

Borders, Independence and Postcolonial Ties: the Role of the State in Caribbean Migration

MGSoG Dissertation Series, № 65

\section{Silvia Consuelo Gómez Soler}

Civil Conflict and Education: How

Does Exposure to Civil Conflict Affect

Human Capital Accumulation?

Evidence from Standardized Exit

Exams in Colombia

MGSoG Dissertation Series, № 64 


\section{Paula Nagler}

Occupational Choice in the Developing

World

MGSoG Dissertation Series, № 63

\section{Jasmin Kientzel}

Determinants of Professional

Commitment to Environmental

Sustainability

MGSoG Dissertation Series, № 62

\section{Mehmet Güney Celbiş}

Regional Policies: Convergence, Trade, and the Allocation of Public Capital

MGSoG Dissertation Series, № 61

\section{Florian Henning}

Living Up to Standard:

Interoperability Governance and

Standards Adoption in Government

Information Networks

MGSoG Dissertation Series, № 60

\section{Niels P. Groen}

The Never-Ending Project

Understanding E-Government Project

Escalation

MGSoG Dissertation Series, № 59

\section{Derek Copp}

Teacher-Based Reactivity to Provincial

Large-scale Assessment in Canada

MGSoG Dissertation Series, № 58

\section{Michaella Vanore}

Family-Member Migration and the Psychosocial Health Outcomes of Children in Moldova and Georgia MGSoG Dissertation Series, № 57

\section{Sonja Fransen}

The Economic and Social Effects of

Remittances and Return Migration in

Conflict-Affected Areas: The Case of

Burundi

MGSoG Dissertation Series, № 56

\section{Ibrahim Khalil Conteh}

The Impact of Floods on Primary

School Education in Zambia

MGSoG Dissertation Series, № 55

\section{Richard Bluhm}

Growth Dynamics and Development Essays in Applied Econometrics and Political Economy

MGSoG Dissertation Series, № 54

\section{Nevena P. Zhelyazkova}

Work-Family Reconciliation and Use of Parental Leave in Luxembourg:

Empirical Analysis of Administrative Records

MGSoG Dissertation Series, № 53

\section{4}

\section{Dirk Crass}

The Impact of Brands on Innovation and Firm Performance: Empirical Evidence from Germany UNU-MERIT Dissertation Series, № 87

\section{Samyukta Bhupatiraju}

The Geographic Dimensions of Growth and Development

UNU-MERIT Dissertation Series, № 86 


\section{François Lafond}

TheEvolution of Knowledge Systems

UNU-MERIT Dissertation Series, № 85

\section{Annalisa Primi}

Promoting Innovation in Latin

America: What Countries Have

Learned (and What They Have Not) in

Designing and Implementing

Innovation and Intellectual Property

Policies

UNU-MERIT Dissertation Series, № 84

\section{Fatoumata Lamarana Diallo}

Evaluation of Meal and Deworming Programs for Primary Schools in Rural Senegal

UNU-MERIT Dissertation Series, № 83

\section{Sachin Kumar Badkas}

Metachoice and Metadata: Innovating with Environmental Policy Analysis in Europe

MGSoG Dissertation Series, № 52

\section{Irina S. Burlacu}

An Evaluation of Tax-Benefit Systems Impact on the Welfare of Frontier Worker:

The Case of Luxembourg and Belgium MGSoG Dissertation Series, № 51

\section{Özge Bilgili}

Simultaneity in Transnational

Migration Research: Links Between

Migrants' Host and Home Country

Orientation

MGSoG Dissertation Series, № 50

\section{Yulia Privalova Krieger}

Reshaping the Big Agenda:

Transnational Politics and Domestic ResistanceFinancial crisis and social protection reform in Bosnia and Herzegovina

MGSoG Dissertation Series, № 49

\section{Marieke van Houte}

Moving Back or Moving Forward?

Return migration after Conflict

MGSoG Dissertation Series, № 48

\section{Oxana Slobozhan}

Global Governance in the Management of Natural Resources: The Case of the Extractive Industries Transparency Initiative (EITI)

MGSoG Dissertation Series, № 47

\section{Luis Bernardo Mejia Guinand}

The Changing Role of the Central

Planning Offices in Latin America: A

Comparative Historical Analysis

Perspective (1950-2013)

MGSoG Dissertation Series, № 46

\section{Cheng Boon Ong}

Ethnic Segregation in Housing,

Schools and Neighbourhoods in the

Netherlands

MGSoG Dissertation Series, № 45

\section{Luciana V. Cingolani}

Bureaucracies for Development:

Oxymoron or Reality? Studies on State

Capacity in Challenging Governance

Contexts

MGSoG Dissertation Series, № 44 


\section{Carlos Cadena Gaitán}

Green Politics in Latin American

Cities - Sustainable Transport Agendas

MGSoG Dissertation Series, № 43

\section{Katie Kuschminder}

Female Return Migration and

Reintegration Strategies in Ethiopia

MGSoG Dissertation Series, № 42

\section{Metka Hercog}

Highly-Skilled Migration and New

Destination Countries

MGSoG Dissertation Series, № 41

\section{Margaret Agaba Rugadya}

Can Remittances Influence the Tenure and Quality of Housing in Uganda?

MGSoG Dissertation Series, № 40

\section{Ilire Agimi}

New Governance Under Limited

Statehood: The Case of Local

Government Reform in Kosovo

MGSoG Dissertation Series, № 39

2013

\section{Anant Kamath}

Information Sharing through Informal

Interaction in Low-Tech Clusters

UNU-MERIT Dissertation Series, № 82

\section{Flavia Pereira de Carvalho}

What we talk about when we talk about Brazilian Multinationals: An Investigation on Brazilian FDI, Economic Structure, Innovation and the Relationship between them UNU-MERIT Dissertation Series, № 81

\section{Jun Hou}

Complementarity in Innovation and Development: A Cross-country

Comparison

UNU-MERIT Dissertation Series, № 80

\section{Rufin Baghana}

Impacts of Government Incentives to $R \mathcal{E D}$, Innovation and Productivity: A Microeconometric Analysis of the Québec Case

UNU-MERIT Dissertation Series, № 79

\section{Lilia I. Stubrin}

High-Tech Activities in Emerging Countries: A Network perspective on the Argentinean Biotech Activity UNU-MERIT/MGSoG Dissertation Series, № 78

\section{Kristine Farla}

Empirical Studies on Institutions, Policies and Economic Development MGSoG Dissertation Series, № 38 
Marina Petrovic

Social Assistance and Activation in the Pursuit of Happiness: Shedding New

Light on Old Policy Solutions to Social Exclusion

MGSoG Dissertation Series, № 37

\section{Laura Torvinen}

Assessing Governance Assessments:

The Case of Mozambique: Governance

Assessments in the Context of Aid

Effectiveness Discourse

MGSoG Dissertation Series, № 36

\section{Biniam Egu Bedasso}

Institutional Change in the Long

Shadow of Elite: Essays on

Institutions, Human Capital and

Ethnicity in Developing Countries

MGSoG Dissertation Series, № 35

\section{Sepideh Yousefzadeh Faal}

Deghati

Childhoods Embargoed: Constructing

and Reconstructing Multidimensional

Child Poverty in Iran 1984-2009

MGSoG Dissertation Series, № 34

\section{Robert Bauchmüller}

Investing in Early Childhood Care and Education: The Impact of Quality on Inequality

MGSoG Dissertation Series, № 33

\section{Martin Rehm}

Unified Yet Separated: Empirical

Study on the Impact of Hierarchical

Positions within Communities of

Learning

MGSoG Dissertation Series, № 32
2012

\author{
Abdul Waheed \\ Innovation Determinants and \\ Innovation as a Determinant: Evidence \\ from Developing Countries \\ UNU-MERIT Dissertation Series, \\ № 77
}

\section{Bilal Mirza}

Energy Poverty and Rural Energy

Markets in Pakistan

UNU-MERIT Dissertation Series, № 76

\section{Benjamin Engelstätter}

Enterprise Software and Video Games:

An Empirical Analysis

UNU-MERIT Dissertation Series,

№ 75

\section{Fulvia Farinelli}

Natural Resources, Innovation and Export Growth: The Wine Industry in Chili and Argentina

UNU-MERIT Dissertation Series

\section{Rodolfo Lauterbach}

Innovation in Manufacturing: From

Product Variety and Labor

Productivity Growth to Economic

Development in Chile

UNU-MERIT Dissertation Series

\section{Kirsten Wiebe}

Quantitative Assessment of

Sustainable Development and Growth in Sub-Saharan Africa

UNU-MERIT Dissertation Series, № 74 


\section{Julio Miguel Rosa}

Organizational Strategies, Firms'

Performance and Spatial Spillovers:

The Canadian Case in Research and

Development.

UNU-MERIT Dissertation Series,

№ 73

Johannes Wilhelmus Marie Boels

Joseph Schumpeter, Honderd Jaar

Economische Ontwikkeling: Een

Historisch-theoretische Beschouwing.

UNU-MERIT Dissertation Series

\section{Dorcas Mbuvi}

Utility Reforms and Performance of the

Urban Water Sector in Africa

MGSoG Dissertation Series, № 31

\section{Lina Salanauskaite}

Distributional Impacts of Public

Policies: Essays in Ex-Ante and Ex-

Post Evaluation

MGSoG Dissertation Series, № 30

\section{Esther Schüring}

To Condition or not - is that the

Question?

An Analysis of the Effectiveness of ExAnte and Ex-Post Conditionality in

Social Cash Transfer Programs

MGSoG Dissertation Series, № 29

\section{Joe Abah}

Strong Organisations in Weak States:

Atypical Public Sector Performance in

Dysfunctional Environments

MGSoG Dissertation Series, № 28

\section{Zina Samih Nimeh}

Social Citizenship Rights: Inequality

and Exclusion

MGSoG Dissertation Series, № 27

2011

\section{Daniel Vertesy}

Interrupted Innovation: Emerging

Economies in the Structure of the

Global Aerospace Industry

UNU-MERIT Dissertation Series,

№ 72

\section{Tina Saebi}

Successfully Managing Alliance

Portfolios: AnAlliance Capability View

UNU-MERIT Dissertation Series,

№ 71

\section{Nora Engel}

Tuberculosis in India: A Case of

Innovation and Control

UNU-MERIT/MGSoG Dissertation

Series, № 70

\section{Evans Mupela}

Connectivity and growth in Sub-

Saharan Africa: The Role of

Communication Satellites

UNU-MERIT Dissertation Series, № 69

\section{Nantawan Kwanjai}

Cross Cultural Intelligence amid

Intricate Cultural Webs: A Tale of the

UnDutchables in the Land of 1002

Smiles

UNU-MERIT Dissertation Series, № 68 


\section{Lina Sonne}

Innovation in Finance to Finance Innovation: Supporting Pro-poor Entrepreneur-based Innovation UNU-MERIT Dissertation Series, № 67

\section{Lenka Eisenhamerová}

Legitimacy of 'Humanitarian Military

Intervention'

MGSoG Dissertation Series, № 26

\section{Sonila Tomini}

Informal Payments for Health Care

Services in Albania

MGSoG Dissertation Series, № 25

\section{Jinjing Li}

Dynamic Microsimulation in Public

Policy Evaluation

MGSoG Dissertation Series, № 24

\section{Aziz Atamanov}

Rural Nonfarm Employment and International Migration as

Alternatives to Agricultural

Employment: The Case of Kyrgyzstan

MGSoG Dissertation Series, № 23

\section{Frieda Vandeninden}

Poverty Alleviation: Aid and Social

Pensions

MGSoG Dissertation Series, № 22

\section{Juliana Nyasha Tirivayi}

The Welfare Effects of Integrating AIDS Treatment with Food Transfers:

Evidence from Zambia

MGSoG Dissertation Series, № 21

\section{Agnieska Ewa Sowa}

Who's Left Behind? Social Dimensions of Health Transition and Utilization of Medical Care in Poland

MGSoG Dissertation Series, № 20

\section{Emmanaouil Sfakianakis}

The Role of Private Actors in the

Provision of Public Goods with

Applications to Infrastructure and

Financial Stability

MGSoG Dissertation Series, № 19

\section{Siu Hing Lo}

White Collars Green Sleeves: An Interorganizational Comparison of Determinants of Energy-Related Behaviors among Office Workers MGSoG Dissertation Series, № 18

\section{Treena Wu}

Constraints to Human Capital Investment in Developing Countries: Using the Asian Financial Crisis in Indonesia as a Natural Experiment MGSoG Dissertation Series, № 17

\section{Henry Espinoza Peña}

Impact Evaluation of a Job-Training

Programme for Disadvantaged Youths:

The Case of Projoven

MGSoG Dissertation Series, № 16 
Fernando Santiago

Human Resources Management

Practices and Learning for Innovation in Developing Countries:

Pharmaceutical Firms in Mexico

UNU-MERIT Dissertation Series, № 66

\section{Zakaria Babutsidze}

Essays on Economies with

Heterogeneous Interacting Consumers

UNU-MERIT Dissertation Series, № 65

\section{Bertha Vallejo}

Learning and Innovation Under

Changing Market Conditions: The

Auto Parts Industry in Mexico

UNU-MERIT Dissertation Series,

№ 64

\section{Donatus Ayitey}

Technical Change, Competitiveness and Poverty Reduction: A Study of the Ghanaian Apparel Industry

UNU-MERIT Dissertation Series, № 63

\section{Sergey Filippov}

Multinational Subsidiary Evolution:

Corporate Change in New EU Member States

UNU-MERIT Dissertation Series, № 62

\section{Asel Doranova}

Technology Transfer and Learning under the Kyoto Regime: Exploring the Technological Impact of CDM Projects in Developing Countries

UNU-MERIT Dissertation Series, № 61

\section{Florian Tomini}

Between Family and Friend:

Understanding the Interdependency of Private Transfers

MGSoG Dissertation Series, № 15

\section{Michał Polalowski}

The Institutional Transformation of Social Policy in East Central Europe: Poland and Hungary in Comparative and Historical Perspective

MGSoG Dissertation Series, № 14

\section{Maha Ahmed}

Defining, Measuring and Addressing

Vulnerability: The Case of Post

Conflict Environments

MGSoG Dissertation Series, № 13

\section{Pascal Beckers}

Local Space and Economic Success:

The Role of Spatial Segregation of

Migrants in the Netherlands

MGSoG Dissertation Series, № 12

\section{Victor Cebotari}

Conflicting Demands in Ethnically

Diverse Societies: Ethno political

Contention and Identity Values in

Europe

MGSoG Dissertation Series, № 11 
Dennis Gyllensporre

Competing and Complementary

Perspectives on the EU as a Crisis

Management Actor:

An Examination of the Common

Security and Defence Policy through

the Lenses of Idealism and Realism

MGSoG Dissertation Series, № 10

\section{Judit Vall Castello}

Business Cycle and Policy Effects on Labour Market Transitions of Older and Disabled Workers in Spain

MGSoG Dissertation Series, № 9

\section{Keetie Roelen}

False Positives or Hidden Dimensions:

The Definition and Measurement of

Child Poverty

MGSoG Dissertation Series, № 8

\section{Denisa Maria Sologon}

Earning Dynamics in Europe

MGSoG Dissertation Series, № 7

\section{Melissa Siegel}

Money and Mobility: Migration and

Remittances

MGSoG Dissertation Series, № 6

\section{Jessica S. Hagen-Zanker}

Modest Expectations: Causes and

Effects of Migration on Migrant

Households inSource Countries

MGSoG Dissertation Series, № 5
2009
Alexis Habiyaremye
From Primary Commodity Dependence
to Diversification and Growth:
Absorptive Capacity and Technological
Catch Up in Botswana and Mauritius.
UNU-MERIT Dissertation Series,
№ 60

\section{Yoseph Getachew}

The Role of Public Capital in Economic

Development

UNU-MERIT Dissertation Series, № 59

\section{Sandra Leitner}

Embodied Technological Change and

Patterns of Investment in Austrian

Manufacturing

UNU-MERIT Dissertation Series,

№ 58

\section{Semih Akçomak}

The Impact of Social Capital on

Economic and Social Outcomes

UNU-MERIT Dissertation Series, № 57

\section{Abraham Garcia \\ The Role of Demand in Technical \\ Change \\ UNU-MERIT Dissertation Series, № 56}

\section{Saurabh Arora}

Coherence in Socio-technical Systems:

A Network Perspective on the Innovation Process

UNU-MERIT Dissertation Series, № 55 


\section{Mirtha R. Muniz Castillo}

Human Development and Autonomy in Project Aid: Experiences from four bilateral projects in Nicaragua and El Salvador

MGSoG Dissertation Series, № 4

\section{Christiane Arndt}

Governance Indicators

MGSoG Dissertation Series, № 3

\section{Britta Augsburg}

Microfinance: Greater Good or Lesser

Evil?

MGSoG Dissertation Series, № 2

2008

\section{Rutger Daems}

Medicines for the Developing World UNU-MERIT Dissertation Series, № 54

\section{Johannes Hanel}

Assessing Induced Technology:

Sombart's Understanding of Technical Change in the History of Economics UNU-MERIT Dissertation Series, № 53

\section{Rifka Weehuizen}

Mental Capital: the Economic Significance of Mental Health UNU-MERIT Dissertation Series, № 52

\section{Danielle Cloodt}

The Relationship between RED

Partnership Formation, Social

Embeddedness and Innovative

Performance

UNU-MERIT Dissertation Series, № 51

\section{Sabine Fuss}

Sustainable Energy Development under Uncertainty

UNU-MERIT Dissertation Series,

№ 50

\section{Geranda Notten}

Measuring and Managing Poverty

Risks

MGSoG Dissertation Series, № 1

2007

\section{Tobias Kronenberg}

Reconciling Environmental

Conservation with Economic

Prosperity: The Feasibility of Double

Dividends in the Short and Long Run UNU-MERIT Dissertation Series, № 49

\section{Viktoria Kravtsova}

Assessing the Impact of Foreign Direct Investment in Transition Economies UNU-MERIT Dissertation Series, № 48 


\section{Suhail Sultan}

The Competitive Advantage of Small and Medium Sized Enterprises: The Case of Jordan's Natural Stone Industry

UNU-MERIT Dissertation Series, № 47

2006

\section{Bulat Sanditov}

Essays on Social Learning and Imitation

UNU-MERIT Dissertation Series, № 46

\section{Mamata Parhi}

Dynamics of New Technology

Diffusion: A Study of the Indian

Automotive Industry

UNU-MERIT Dissertation Series, № 45

\section{Andreas Reinstaller}

Social Structures and the Innovation Process: Their Role in the Demand of Firms and Consumers

UNU-MERIT Dissertation Series, № 44

\section{Rose Kiggundu}

Innovation systems and Development:

The Journey of a Beleaguered Nile

Perch Fishery in Uganda

UNU-MERIT Dissertation Series, № 43

\section{Thomas Pogue}

The Evolution of Research

Collaboration in South African Gold Mining: 1886-1933

UNU-MERIT Dissertation Series, № 42

\section{Geoffrey Gachino}

Foreign Direct Investment, Spillovers and Innovation: The Case of Kenyan Manufacturing Industry

UNU-MERIT Dissertation Series, № 41

\section{Önder Nomaler}

Technological Change, International Trade and Growth: An Evolutionary, Multi-Agents-Based Modeling

Approach

UNU-MERIT Dissertation Series, № 40

2005

\section{Samia Satti Osman Mohamed-}

Nour

Change and Skill Development in the Arab Gulf Countries

UNU-MERIT Dissertation Series, № 39

\section{Elad Harison}

Intellectual Property Rights:

Economics and Policy Analysis

UNU-MERIT Dissertation Series, № 38 


\section{Daniel Dalohoun}

Learning to innovate: agricultural innovation and entrepreneurship: the case of Songhaï farmers in Benin UNU-MERIT Dissertation Series, № 37

\section{Müge Ozman}

Networks, Organizations and

Knowledge

UNU-MERIT Dissertation Series, № 36

\section{Bas Straathof}

Product Variety and Economic

Growth: The Counteracting Effects of Scale and Idiosyncrasy

UNU-MERIT Dissertation Series, № 35

\section{Wilfred Schoenmakers}

Knowledge Flows between

Multinational Companies: A Patent

Data Analysis

UNU-MERIT Dissertation Series, № 34

\section{Myriam Cloodt}

Mergers and Acquisitions ( $M$ and As) in High-Tech Industries: Measuring the Post-M and A Innovative

Performance of Companies

UNU-MERIT Dissertation Series, № 33
2004

\section{Paola Criscuolo}

$R \mathcal{E D}$ Internationalisation and

Knowledge Transfer: Impact on MNEs and their Home Countries

UNU-MERIT Dissertation Series, № 32

\section{Maarten Verkerk}

Trust and Power on the Shop Floor UNU-MERIT Dissertation Series, № 31

\section{Gottfried Leibbrandt}

Adoption, Harmonization and Succession of Network Technologies across Countries

UNU-MERIT Dissertation Series, № 30

\section{Mark Sanders}

Skill Biased Technical change: Its Origins, the Interaction with the Labour Market and Policy Implications UNU-MERIT Dissertation Series, № 29

2003

\section{Nadine Roijakkers}

Inter-firm Cooperation in High-tech Industries: a Study of R\&D

Partnerships in Pharmaceutical

Biotechnology

UNU-MERIT Dissertation Series, № 28 
Viki Sonntag

Speed, Scale and Sustainability

UNU-MERIT Dissertation Series, № 27

\section{Masaru Yarime}

From End-of-Pipe Technology to Clean Technology

UNU-MERIT Dissertation Series, № 26

\section{Stéphane Malo}

The Combinatorial Chemistry Revolution: Sustaining a Superior

Performance Position through

Technological Learning

UNU-MERIT Dissertation Series,

№ 25

\section{2}

\section{Annelies Hogenbirk}

Determinants of Inward Foreign

Direct Investment: the Case of the

Netherlands

UNU-MERIT Dissertation Series, № 24

\section{Bastiaan Johan terWeel}

The Computerization of the Labour Market

UNU-MERIT Dissertation Series
2001

\section{John Adeoti}

Technology Investment in Pollution Control in Sub-Saharan Africa: The Case of the Nigerian Manufacturing Industry

UNU-MERIT Dissertation Series, № 23

\section{Edward Huizenga}

Innovation Management: How

Frontrunners Stay Ahead: An

Empirical Study on Key Success

Factors in the ICT sector

UNU-MERIT Dissertation Series, № 22

2000

\section{Machiel van Dijk}

Technological Change and the

Dynamics of Industries: Theoretical Issues and Empirical evidence from Dutch Manufacturing UNU-MERIT Dissertation Series, № 21

\section{9}

\section{Jan Cobbenhagen}

Managing Innovation at the Company Level: A Study on Non-Sector-Specific Success Factors

UNU-MERIT Dissertation Series, № 20 
Marjolein Caniëls

Regional Growth Differentials: The

Impact of Locally Bounded Knowledge

Spillovers

UNU-MERIT Dissertation Series, № 19

1998

\section{Aldo Geuna}

Resource Allocation and Knowledge production: Studies in the Economics of University Research

UNU-MERIT Dissertation Series, № 18

1996

\section{Reinoud Joosten}

Dynamics, Equilibria, and Values

UNU-MERIT Dissertation Series,

№ 17

\section{Hugo Kruiniger}

Investment, $R \mathcal{E} D$, and the Financing

Decisions of the Firm

UNU-MERIT Dissertation Series, № 16

\section{5}

\section{Hans van Meijl}

Endogenous Technological Change:

The Case of Information Technology,

Theoretical Considerations and

Empirical Results

UNU-MERIT Dissertation Series, № 15

\section{René Kemp}

Environmental Policy and Technical

Change: A Comparison of the

Technological Impact of Policy

Instruments

UNU-MERIT Dissertation Series,

№ 14

\section{Rohini Acharya}

The Impact of New Technologies on

Economic Growth and Trade: A Case

Study of Biotechnology

UNU-MERIT Dissertation Series,

№ 13

\section{Geert Duysters}

The Evolution of Complex Industrial Systems: The Dynamics of Major IT Sectors

UNU-MERIT Dissertation Series, № 12

\section{Marjan Groen}

Technology, Work and Organisation: A Study of the Nursing Process in Intensive Care Units

UNU-MERIT Dissertation Series, № 11

\section{4}

\section{Huub Meijers}

On the Diffusion of Technologies in a Vintage Framework: Theoretical Considerations and Empirical Results UNU-MERIT Dissertation Series, № 10 
Theon van Dijk

The Limits of Patent Protection: Essays on the Economics of Intellectual

Property Rights

UNU-MERIT Dissertation Series, № 9

\section{Hans Voordijk}

Naar Integrale Logistiek in

Bedrijfsketens: Ontwikkelingen in de Bouw

UNU-MERIT Dissertation Series, № 8

1993

\section{Paul Diederen}

Technological Progress in Enterprises and Diffusion of Innovation:

Theoretical Reflections and Empirical

Evidence

UNU-MERIT Dissertation Series, № 7

\section{Ben Dankbaar}

Economic Crisis and Institutional

Change: The Crisis of Fordism from the Perspective of the Automobile Industry UNU-MERIT Dissertation Series, № 6

\section{Hanno Roberts}

Accountability and Responsibility: The Influence of Organisation Design on Management Accounting UNU-MERIT Dissertation Series, № 5
1992

\section{Bart Verspagen}

Uneven Growth between

Interdependent Economies: An

Evolutionary View on Technology

Gaps, Trade and Growth

UNU-MERIT Dissertation Series,

№ 4

\section{Sjoerd Romme}

A Self-organization Perspective on

Strategy Formation

UNU-MERIT Dissertation Series, № 3

\section{9}

\section{John Spangenberg}

Economies of Scale, and Atmosphere in Research Organisations

UNU-MERIT Dissertation Series, № 2

1988

\section{John Hagedoorn}

Evolutionary and Heterodox

Innovation Analysis: A Study of

Industrial and Technological

Development in Process Control and Information Technology

UNU-MERIT Dissertation Series, № 1 



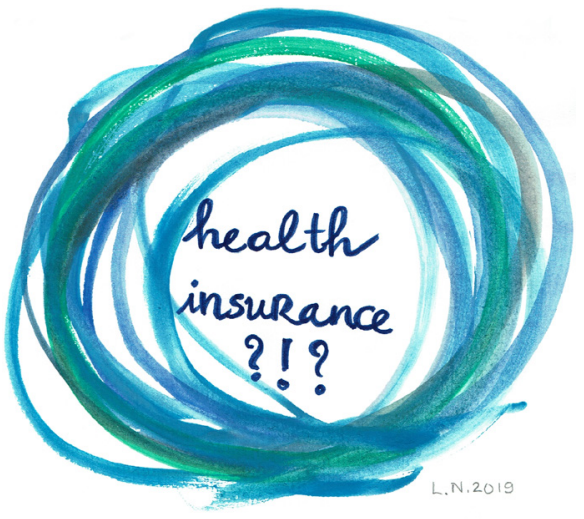

